\title{
The pricing and production of audit services
}

Citation for published version (APA):

Schelleman, C. C. M. (2003). The pricing and production of audit services. [Doctoral Thesis, Maastricht University]. Universiteit Maastricht. https://doi.org/10.26481/dis.20030611cs

Document status and date:

Published: 01/01/2003

DOI:

$10.26481 /$ dis.20030611cs

Document Version:

Publisher's PDF, also known as Version of record

\section{Please check the document version of this publication:}

- A submitted manuscript is the version of the article upon submission and before peer-review. There can be important differences between the submitted version and the official published version of record.

People interested in the research are advised to contact the author for the final version of the publication, or visit the DOI to the publisher's website.

- The final author version and the galley proof are versions of the publication after peer review.

- The final published version features the final layout of the paper including the volume, issue and page numbers.

Link to publication

\footnotetext{
General rights rights.

- You may freely distribute the URL identifying the publication in the public portal. please follow below link for the End User Agreement:

www.umlib.nl/taverne-license

Take down policy

If you believe that this document breaches copyright please contact us at:

repository@maastrichtuniversity.nl

providing details and we will investigate your claim.
}

Copyright and moral rights for the publications made accessible in the public portal are retained by the authors and/or other copyright owners and it is a condition of accessing publications that users recognise and abide by the legal requirements associated with these

- Users may download and print one copy of any publication from the public portal for the purpose of private study or research.

- You may not further distribute the material or use it for any profit-making activity or commercial gain

If the publication is distributed under the terms of Article $25 \mathrm{fa}$ of the Dutch Copyright Act, indicated by the "Taverne" license above, 


\section{THE PRICING AND PRODUCTION OF AUDIT SERVICES}


The pricing and production of audit services

(c) C.C.M. Schelleman, Maastricht 2003

ISBN 9090167943

Cover design and layout: Ramon Schelleman, www.daradàr.com Printer: Datawyse Maastricht 


\title{
THE PRICING AND PRODUCTION OF AUDIT SERVICES
}

\author{
PROEFSCHRIFT
}

ter verkrijging van de graad van doctor aan de Universiteit Maastricht, op gezag van de Rector Magnificus, Prof. dr A.C. Nieuwenhuijzen Kruseman, volgens het besluit van het College van Decanen, in het openbaar te verdedigen op woensdag 11 juni 2003 om 14.00 uur

door

Carmen Charlotte Maria Schelleman 


\section{Promotores:}

Prof. dr S.J. Maijoor

Prof. dr R.J.M. Dassen RA

Beoordelingscommissie:

Prof. dr R.H.G. Meuwissen RA (voorzitter)

Dr M.A. Carree

Prof. dr W.R. Knechel (University of Florida) 


\section{ACKNOWLEDGEMENTS}

So it's true what they say: the last mile is the longest one. Clichés are clichés for a reason... However, the trip was worth the effort, since you are now holding the result in your hands. Fortunately I did not have to travel alone - I could not have managed without the help and support of many others and I would like to take this opportunity to thank them.

First of all my supervisors Steven Maijoor and Roger Dassen, who hired me as a Ph.D. student and thus gave me the opportunity to write this dissertation. Each has contributed to this project in his own way. Steven Maijoor was instrumental in collecting the dataset and in the practical supervision of the project. His conscientious criticisms and comments have helped shape the manuscript. Being an audit researcher but first and foremost an audit practitioner, Roger Dassen provided the necessary check on audit reality, especially in the last stages of the process. Thank you both for your support.

Empirical research is not possible without a dataset. Therefore, I would like to thank the technical department and the audit practitioners of the audit firm for supplying the dataset used in this dissertation. I also thank Martin Carree, Robert Knechel, and Roger Meuwissen for evaluating the final manuscript and for providing useful comments - special thanks to Martin Carree for his help on econometric issues. A special thank-you to Willem. Buijink for his useful suggestions at important moments in the process.

I thank my colleagues for their support, encouragement, and distraction, and for simply providing a pleasant working environment. I would especially like to thank the members of the "Botte Bijl", Laury Bollen, Rogier Deumes, Roger Meuwissen, Thomas Thijssens, and Mark Vluggen, for many a profound discussion on the more important things in music; Alexander Brüggen, Bas Geus, Roel Ronken, RobbertPaul Roomberg, Miriam Scheepers, Yvonne Schols, Leon Timmermans, and Rita Walczuch for our culinary meals in the mensa and our "occasional" drinks in de Klok; Rick Cuijpers, Frank Moers, Erik Peek, Ann Vanstraelen, and Phillip 
Vergauwen for trivial and not-so-trivial discussions on many subjects; and my neighbor Eddy Vaassen for being an ever-present sounding board.

I also thank my family and friends who, in some way or another motivated and inspired me while I was working on my "booklet", particularly my brother Ramon for the cover design and layout of this dissertation, and Ghislaine Gillessen, Annelies Hogenbirk, Hans van Kranenburg, Gunter Lemmen, Marike Mostard, and Frédérique Wendeborn for providing highly appreciated moral support.

But above all, I thank my dear parents for their unconditional support and for being there whenever I need them. No matter how hard it was from time to time, knowing how proud you would be of me today kept me going. Mamma en Pappa: this one's for you!

Caren Schelleman

Maastricht, March 2003 
Voor Mamma en Pappa 



\section{CONTENTS}

Acknowledgements

Contents

1 Introduction

1.1 The pricing and production of audit services

1.2 Positioning the topics of this dissertation

1.2.1 Approaches to and taxonomies of audit research

1.2.2 Prior research: some key references

1.3 Outline of this dissertation

Notes

2 Prior audit pricing and production research and data collection 9

2.1 Introduction 9

2.2 Prior research on audit pricing and audit production 9

2.2 .1 General review 10

2.2.2 The audit production problem 11

2.2 .3 Effect of litigation risk 13

2.2.4 Effect of market structure 14

2.3 Data collection $\quad 15$

2.4 Conclusion $\quad 16$

$\begin{array}{lr}\text { Notes } & 17\end{array}$

3 Benchmarking the production of audit services: An efficiency frontier approach

$\begin{array}{lll}3.1 & \text { Introduction } & 19\end{array}$

3.2 Prior research on the fficiency of audit services 21

3.3 Variables and model $\quad 22$

3.4 Efficiency frontier techniques and stochastic frontier analysis 25 
$\begin{array}{lll}3.5 & \text { Data and results } & 28\end{array}$

3.5.1 Data and descriptives $\quad 28$

3.5 .2 OLS regression results 28

3.5.3 SFA results and tests 32

3.6 Conclusions, limitations, and suggestions for future research $\quad 37$

$\begin{array}{lll}\text { Appendix 3A Stochastic frontier analysis } & 39\end{array}$

3A.1 Introduction $\quad 39$

3A.2 Stochastic frontier analysis $\quad 39$

3A.3 Mean efficiency 40

3A.4 Efficiency per observation $\quad 40$

3A.5 Tests of hypotheses 41

Notes $\quad 42$

4 The impact of potential earnings management on the pricing and production of audit services $\quad 49$

4.1 Introduction $\quad 49$

4.2 Prior research $\quad 50$

4.2.1 Issue more conservative audit reports 51

4.2.2 Screen out high-risk clients 53

4.2 .3 Increase audit effort 54

4.2.4 Charge a fee premium 55

4.2.5 Negotiate adjustments $\quad 56$

4.3 Variables and model 57

4.3.1 Dependent variables 57

4.3.2 Independent variables from prior audit fee and production studies 59

4.3.3 A measure for potential earnings management 61

4.3.4 Recapitulation 64

4.4 Data and results 66

4.4.1 Data and descriptives 66

4.4.2 Models excluding measures of potentiall earnings management 66

$\begin{array}{lll}\text { 4.4.3 Models including measures of potential earnings management } & 72\end{array}$

4.5 Conclusions, limitations, and suggestions for future research 79

Notes $\quad 85$

5 Determinants of the profitability of audit engagements 91

$\begin{array}{ll}5.1 \text { Introduction } & 91\end{array}$

5.2 Prior research $\quad 92$

5.2.1 Prior research on audit engagement profitability 93

5.2.2 Prior industrial organization research 93

5.2.3 Local/regional versus national audit markets 95 
5.3 Variables and model 97

5.3.1 Measurement bias and market definition 97

5.3.2 Dependent variable: a measure for profitability 98

5.3.3 Independent variables from prior audit fee and production $\begin{array}{ll}\text { studies } & 99\end{array}$

5.3.4 Independent variables from prior industrial organization $\begin{array}{ll}\text { research } & 100\end{array}$

$\begin{array}{ll}5.3 .5 & \text { Local audit market definition } \\ 5.3 .6 & 102\end{array}$

5.3.6 Recapitulation 103

$\begin{array}{ll}5.4 \text { Data collection } & 103\end{array}$

5.5 Analyses and results $\quad 105$

5.5.1 Descriptives 105

5.5.2 Profitability model excluding market concentration and/or $\begin{array}{ll}\text { market share variables } & 107\end{array}$

5.5.3 Profitability model including market concentration and/or $\begin{array}{ll}\text { market share variables } & 110\end{array}$

5.6 Conclusions, limitations, and suggestions for future research $\quad 113$

$\begin{array}{ll}\text { Notes } & 117\end{array}$

6 Summary and discussion $\quad 125$

$\begin{array}{lll}6.1 \text { Introduction } & 125\end{array}$

$\begin{array}{lll}6.2 & \text { Summary } & 125\end{array}$

6.2.1 Benchmarking the production of audit services: An efficiency $\begin{array}{ll}\text { frontier approach } & 126\end{array}$

6.2.2 The impact of potential earnings management on the pricing $\begin{array}{ll}\text { and production of audit services } & 127\end{array}$

6.2.3 Determinants of the profitability of audit engagements $\quad 128$

6.3 Limitations and suggestions for future research 129

6.4 Policy implications $\quad 132$

6.4.1 Implications for audit firms and the audit profession 133

6.4.2 Implications for audit clients 135

6.4.3 Implications for regulators $\quad 136$

6.4.4 Conclusion 137

$\begin{array}{ll}\text { Notes } & 138\end{array}$

$\begin{array}{ll}\text { References } & 141\end{array}$

Summary in Dutch (Nederlandse samenvatting)

$\begin{array}{ll}\text { Curriculum vitae } & 163\end{array}$ 



\section{CHAPTER 1 INTRODUCTION}

\subsection{The pricing and production of audit services}

Currently, the audit industry is the center of much attention. This dissertation studies the pricing and production of services in the audit industry. More specifically, it examines efficiency in the production of andit services, the effect of potential earnings management on audit pricing and audit production, and the profitability of audit services. Although there is ample research on the pricing of audit services, and to a lesser extent the production of audit services, research in all three specific areas mentioned above is rather scarce. This is mainly due to the proprietary nature of the data necessary to conduct these types of stidies. The dataset used in this dissertation contains detailed information on client and engagement characteristics for a sample of audit engagements conducted by one of the (then) Big Six audit firms, thus providing the opportunity to extend current research and contribute to these important but as yet poorly investigated areas of research.

Efficiency in the production of audit services is the first topic studied in this dissertation. Research on this issue is relevant for audit firms to compete effectively in the audit market. If an audit firm wants to offer services at competitive prices, it needs information on the costs that it spends during the performance of audit engagements. To be more specific, the firm needs information on the minimum amount of costs necessary to conduct an audit engagement. Since the majority of the costs in service organizations consist of costs related to the use of labor hours, the firm also needs information on the minimum amount of labor hours that are needed to perform an audit. Thus, research on the cost and labor efficiency of audit services can provide important insights for audit firms when competing on the audit services market in general and on the dimension of pricing in particular.

The second issue investigated in this dissertation concerns the effect of potentiall earnings management on the pricing and production of audit services. The recent 
developments involving companies such as Enron, WorldCom, and Ahold stress the importance and timeliness of studying this issue, as not only the companies accused of earnings manipulation are scrutinized, but their audlitors as well, culminating in the recent disintegration of Andersen. Auditors can deal with the risk associated with companies' potential earnings management in a number of ways. This dissertation studies two of these: increasing audit effort and charging a fee premium. The dataset offers the unique possibility to study the effect of potential earnings management on both audit effort and audit fees, as well as the interaction between the two. For instance, when potential earnings management results in a higher audit fee, it is possible to examine whether this higher fee follows from more effort ${ }_{s}$ a fee premium, or both.

The third and last issue studied in this dissertation is the profitability of audit engagements. Like research on the efficiency of audit production, research on the profitability of audit engagements can be considered relevant for audit firm policymaking. For instance, if research shows that some types of clients are more and others less profitable to the audit firm, the firm can take this kind of information into account in its client-acceptance and/or pricing policies.

On a more conceptual level, the motivation for studying the profitability of audit engagements is the frequently expressed concern regarding the extent, or even lack, of competition on the audit market. The general argument here is that market power allows audit firms to raise price above cost as a consequence of collusion and monopoly behavior. The dataset used in this dissertation allows to test directly how market structure (and other factors) affects the relationship between price and cost (i.e., profitability).

In sum, using a unique dataset, this dissertation studies audit pricing and production issues that are interesting and relevant for both audit practice and audit research.

The purpose of the remainder of this introductory chapter is twofold. First, the topics of this dissertation are put into their proper context. To that end, Section 1.2 briefly discusses different approaches to and taxonomies of audit research and provides a characterization of the subjects studied in this dissertation by positioning these subjects within these approaches and taxonomies. In addition, it also briefly outlines prior research on audit pricing and audit production to indicate some key references in this field. ${ }^{2}$

Second, a concise overview of the dissertation is presented by providing an outline of the remainder of the dissertation in Section 1.3. 


\subsection{Positioning the topics of this dissertation}

\subsubsection{Approaches to and taxonomies of audit research}

Based on the distinguishing characteristic that is chosen for classification, audit research can be categorized in several ways. A very broad classification, based on the predominant research perspective that is used, distinguishes behavioral audit research on the one hand and economics-based audit research on the other (see Meuwissen 1999, 12). Behavioral audit research studies auditor judgment and decision making in the broadest sense of the word, and derives its theoretical framework mainly from psychology and the cognitive sciences. ${ }^{3}$ Obviously, economics-based audit research draws upon (micro)economic theory to explain audit practice, assuming that rational individuals act so as to maximize their own welfare (see Watts and Zimmerman 1986, 6-7). This dissertation uses an economics framework in studying issues related to audit pricing and audit production.

To further characterize economics-based audit research, Meuwissen $(1999,12)$ distinguishes between the audit product market and the audit factor market. In the audit product market the demand for audit services from clients interacts with the supply of audit services by audit firms. In the audit factor market audit firms' demand for human capital interacts with the supply of these inputs by individual auditors.

The pricing and production issues that are studied in this dissertation all pertain to the audit product market, where the demand for and supply of audit services meet.4

Another convenient taxonomy of audit research is provided by Smith and Krogstad $(1984,1988,1991)$ and further adapted by Maijoor, Meuwissen and Quadackers (2000). This taxonomy categorizes audit research along two dimensions: research topic and research method. Nine main categories of research topics are distinguished. These main categories and their subcategories are presented in Table 1.1 below. 5

The audit pricing and production issues studied in this dissertation fall in the category Audit markets. More specifically, the subjects can be characterized as a combination of the subcategories Market structure and Pricing. ${ }^{6}$ The study on the efficiency of the production of audit services and the study on the effect of potential earnings management on audit pricing and audit production both come under the subcategory Pricing, and the study on the profitability of audit engagements can be described as a mixture of the subcategories Market structure and Pricing. ${ }^{7}$

Smith and Krogstad $(1984,109 ; 1988,109 ; 1991,85-88)$ distinguish six categories of research methods. These categories as well as a short description of each are provided in Table 1.2 below.

The research method used in this dissertation can be characterized as a mixture of three categories of research methods. As will be discussed in Chapter 2, the data 
Table 1.1

Categories of audit research topics

\begin{tabular}{|c|c|c|}
\hline Professtonal issues & Audit technology & Reporting \\
\hline Policy & Firm approaches & Audit/disclosure issues \\
\hline Independence: & Sampling & Other attest/limited assurance \\
\hline Legal environment & $\mathrm{EDP}^{2}$ & \\
\hline $\begin{array}{l}\text { Description of gemeral atidit } \\
\text { environment }\end{array}$ & Expert systems & $\begin{array}{l}\text { Internal/operational auditing } \\
\text { Reliance by external auditors }\end{array}$ \\
\hline Pim administration & Andil process & Personnel considerations \\
\hline Personnel considerations & Auditor behavior & Technology \\
\hline Engagement letters & Error characteristics & Scheduling \\
\hline Quality assurance & $\begin{array}{l}\text { Plamning } \\
\text { Risk }\end{array}$ & Auditee behavior \\
\hline Awdit markets & Materiality & Other \\
\hline Market structure & Internal control & Literature analysis \\
\hline Pricing & Anallytical procedures & \\
\hline Audit commiltees & Tests of details/balances & \\
\hline Expectation gap/liability & $\begin{array}{l}\text { Workpaper review } \\
\text { Going-concern decisions }\end{array}$ & \\
\hline $\begin{array}{l}\text { Audit education } \\
\text { Curriculnm issues } \\
\text { Othen }\end{array}$ & & \\
\hline
\end{tabular}

Source: adapted from Smith and Krogstad $(1988,1991)$ and Maijoor et al. (2000).

used in this dissertation were collected by means of a questionnaire sent to partners of one of the (then) Big Six audit firms, requesting information from the firm's internal billing and time registration system, the (electronic) audit workpapers, and clients' financial statements. In each of the three studies, these data were subsequently analyzed by means of a number of statistical techniques. This method can be typified as a combination of the Survey method, the Review/Historical method, and the Empirical method.

\subsubsection{Prior research: some key references}

As indicated in the introduction to this chapter, this dissertation studies issues related to the pricing and production of audit services. There is an extensive body of research in these areas, which has essentially started with the seminal study by Simunic (1980). To examine the competitiveness of the audit market, he constructed a model of the determinants of audit fees, which include a number of auditor and auditee characteristics. Simunic's work has served as a major stimulus for further research in this field, and most subsequent research is based on elements of his 
Table 1.2

Categories of audit research methods:

Suroey

Reoiew/Historical

Normalive/Prescriptive

Modeling

Experimental

Empirical2
A questionnaire is used to obtain data on practices, attitudes and perceptions.

Use of archival methods and/or review of the development of practice and literature.

Employ deduction or theory to develop logical explanations, conclusions, opinions, or predictions.

Development of analytic, economic, or statistical models and simulations.

Use of students or professional subjects in a laboratory setting, or use of actual or simulated scenarios to draw decisions, judgments and reactions.

Use of inductive methods to collect and analyze data on the actual functioning of firms, markets, and systems.

I Smith and Krogstad $(1988,109 ; 1991,85)$ indicate that these categories are not mutually exclusive, and that there might be some overlap between them.

${ }^{2}$ Maijoor et al. $(2000,586)$ note that this category is broadly defined, and includes both capital market studies on auditing and archival studies that use audit firm documentation.

Source: adapted from Smith and Krogstad $(1988,1991)$ and Maijoor et all. (2000).

framework. Apart from competition on the audit market, these replications and extensions have investigated many different audit market issues, such as reputation effects, the provision of nonaudit services, off-peak pricing, learning over time, price cutting, and client participation. In all these different applications the atidit fee model as initially constructed by Simunic (1980) has shown to be convincingly robust across time periods (1970s, 1980s, 1990s), countries (US, UK, Australia, New Zealand, Canada, the Netherlands, Hong Kong, Singapore, Malaysia, India, South Africa) and sample composition (listed or unlisted clients, small or large clients).

Most audit pricing studies have used data that were publicly available, and/or collected from among auditees. However, in addition to public data, data on audit production also requires privale data from auditors. Due to the proprietary nature of these data, the number of audit production studies is relatively low compared to that of pricing studies. Audit production models are based on the models used in prior audit pricing research. While the earliest studies have used total audit hours (see Palmrose 1989; Davis, Ricchiute, and Trompeter 1993), the more recent ones have used audit hours disaggregated by staff level (e.g. OKeefe, Simunic and Stein 1994), and by staff level and audit activity (Hackenbrack and Knechel 1997). Research on 
audit production confirms the robustness of the models used in audit pricing studies, since factors that are important determinants of audit fees are shown to be important determinants of audit effort as well. A more detailed review of prior audit fee and production research is provided in Chapter 2.

\subsection{Outline of this dissertation}

Besides this introductory chapter, this dissertation consists of a descriptive chapter (Chapter 2), three empirical chapters (Chapters 3,4, and 5), and a concluding chapter (Chapter 6).

Chapter 2 discusses prior research on audit pricing and audit production as well as the method of data collection. Although each of the three empirical chapters investigates separate pricing and production issues, the three studies are related in that they all build on the same audit pricing and production literature and use one and the same dataset. Therefore, prior audit pricing and production research and the method of data collection are discussed in a separate chapter rather than in each of the three empirical chapters.

Chapter 3 is the first empirical chapter of this dissertation. Using models from the audit pricing and production literature and applying an efficiency frontier technique, this chapter evaluates the cost and labor efficiency of audit services production. Estimating the efficiency of audit engagements is a form of benchmarking, of which economics oriented research has seen many applications. The application to auditing, however, is relatively new.

Chapter 4 is the second empirical chapter. This chapter investigates how the risk associated with companies' potential earnings management affects the pricing and production of audit services. Based on previous audit pricing and production research and prior literature on earnings management, the chapter constructs and empirically tests a model relating a proxy for potential earnings management to audit fees, audit effort, and the relationship between the two.

Chapter 5 is the third and last empirical chapter of this dissertation. The chapter studies the determinants of the profitability of audit engagements, with a specific focus on the effect of market structure. The empirical model constructed and tested in this chapter combines insights from prior audit pricing and production research, the economics of industrial organization, and the relatively recent studies on local (rather than national) audit markets.

As indicated, Chapters 3,4 and 5 are related in that they all study audit pricing and production issues and thus all build upon the same literature. Together, they add to this literature by investigating topics that heretofore have not been studied extensively. However, each empirical chapter deals with a specific subject, has its 
own additional background literature besides the common literature on audit pricing and audit production, ${ }^{8}$ and can therefore be seen as a separate study.

Finally, Chapter 6 concludes by summarizing the dissertation, discussing its limitations, offering suggestions for future research, and providing some policy implications. 


\section{Notes}

${ }^{1}$ Audit firms are 3 uffering from a dramatic decline in public confidence in the audit profession due to recent international dewelopments. For example, in the US companies such as Enron and WorldCom are accused of misrepresentations in their financial statements; in the Netherlands, a governmental fact-finding committee has investigated accusations of anti-trust violations and fraud against a number of construction companies such as Heijmans, Boskalis, and Ballast Nedam; and very recently, Ahold has announced major profit restatements following accounting irregularities and fraud at one of its US subsidiaries. In these cases, not only the responsibilities of the companies involved but also those of their auditors are subject to careful scrutiny. A prominent and immediate result is the recent downfall of Andersen, which reduced the Big Five audit firms to the "Final Four". In addition, these developments have sparked intensive debates on the role and responsibilities of the auditor. Although the exact effects of all these events are difficult to assess, it is clear that the consequences for the audit industry will be severe.

2. Note: a more detailed review of prior research in this area is provided in Chapter 2, Section 2.2.

${ }^{3}$ For an excellent overwiew of judgment and decision making research in auditing, see Solomon and Shields (1995).

"However, by studying a number of production issues, in a way this dissertation also provides indirect insight into the demand for certain production factors, thus (indirectly) adding to research on the audit factor market as well.

5 Originally, Smith and Krogstad $(1984,109 ; 1988,110-111 ; 1991,86-87)$ identified seven main cattegories of topics. Maijoor, Meuwissen and Quadackers (2000,575-576) added the categories Audit markets and Audit education, removed the subcategory Market structure/pricing from the main category Firm administration, and added the two subcategories Market structure and Pricing to the main category Audit markets. In addition, compared to Smith and Krogstad (1984, 1988, 1991), Maijoor et al. (2000, 575-576) added the subcategory Description of general andit environment to the main category Professional issues, and added the subcategories Auditor behawior and Going-concern dedisions to the main category Audit process.

- Note that there is no separate subcategory for audit production topics in this taxonomy. Since the theoretical framework and models used in audit production studies are similar to those used in audit pricing studies (set Chapter 2), the subcategory Audit pricing is considered to cover both audit pricing and audit production research issues.

? Indirectly and partially, the study on the efficiency of audit services production also inwolves Personnel considerations (in the main category Firm administration). Likewise, the study on the effect of potential earnings management on the pricing and production of audit services also indirectly and partially concerns Audit/disclosure issues (in the main category Reporting).

As can be inferred from the discussion above, for Chapter 3 this is the literature on efficiency frontier techniques, for Chapter 4 the literature on earnings management, and for Chapter 5 industrial organization research and literature on local audit markets. 


\section{CHAPTER 2}

PRIOR AUDIT PRICING AND PRODUCTION RESEARCH AND DATA COLLECTION

\subsection{Introduction}

This chapter discusses prior research on audit pricing and audit production and the method of data collection. As indicated in Chapter 1 , the three empirical chapters of this dissertation have a common basis since they all build on the same prior literature and use the same dataset. Therefore, both this literature and the dataset are discussed here in a separate chapter.

The chapter is structured as follows: Section 2.2 reviews prior audit pricing and production research, Section 2.3 discusses the data collection, and Section 2.4 concludes.

\subsection{Prior research on audit pricing and audit production}

Although each of the studies in the empirical chapters is based on the same prior audit pricing and production research, ${ }^{1}$ each study has drawn from this research with a particular, slightly different focus, depending on the study's topic. Obviously, since Chapter 3 investigates the efficiency of audit services production, this study has focused particularly on prior research on audit production. Chapter 4 investigates the effect of potential earnings management on audit pricing and audit production. Since the risk associated with potential earnings management is believed to increase auditor litigation risk, this study has concentrated specifically on the effect of litigation risk on audit pricing and audit production. Finally, since Chapter 5 specifically focuses on the effect of market structure on audit engagement profitability, it has paid specific attention to the effect of market structure in studying the prior audit pricing and production literature. 
Therefore, besides a brief general account, the review of previous audit pricing and production research will also have three more specific foci: (1) audit production, more particularly, the audit production problem; (2) the effect of litigation risk on audit pricing and production; and (3) the effect of market structure on audit pricing and production.

\subsubsection{General review}

As already indicated in Chapter 1 (Section 1.2.2), Simunic (1980) was the first to develop an extensive model of audit fees. In examining the competitiveness of the audit market, he hypothesized and found factors relating to auditee size, auditee complexity, auditee asset composition, auditee industry, auditee risk and financial distress, auditor tenure and auditor type (Big Eight/Six/Five/Four vs. non-Big Eight/Six/Five/Four) to be associated with audit fees. Simunic's study has initiated a large stream of research replicating and extending his work. Besides assessing the competitiveness of the audit market (see e.g. Francis 1984) these studies have investigated a multitude of issues, such as reputation effects (e.g. Craswell, Francis, and Taylor 1995), the provision of nonaudit services (e.g. Palmrose 1986b), off-peak pricing (e.g. Francis and Stokes 1986), learning over time (e.g. Chung and Lindsay 1988), price cutting (e.g. Simon and Francis 1988), and client participation (e.g. Stein, Simunic, and O'Keefe 1994). Although the studies' findings are mixed with respect to some of these issues, in general the audit fee model is fairly robust across time periods, countries, and sample composition, and a number of results are consistent across the majority of audit fee studies. For instance, auditee size, auditee complexity, auditee asset composition, and auditee financial distress are all positively associated with audit fees. Furthermore, Big Eight/Six/Five/Four auditees pay significantly higher fees than non-Big Eight/Six/Five/Four auditees. Finally, most fee studies show high explanatory power, suggesting that the audit market is (price-) competitive: Yardley, Kaufmann, Cairney, and Albrecht $(1992,160)$ argue that a strong association between cost factors (the independent variables in the audit fee model) and audit fees can be expected in a competitive market with homogenous products and production processes.

Initial unavailability of data on audit production led researchers to base inferences about audit production on audit fees. However, evidence based on audit fees will permit only indirect testing of hypotheses concerning the production of audit services. After all, an audit fee is the product of quantity (audit effort exerted by various grades of labor) and price per unit of labor category. Therefore, a change in audit fees may not reflect pure changes in audit production, but merely changes in audit pricing. As a result, a test based on audit fees may be confounded by audit firms' pricing policies ( $O^{\prime}$ Keefe, Simunic, and Stein 1994, 242). In addition, using 
audit fee only makes it difficult to distinguish between competing explanations for issues investigated in prior fee studies. Data on audit production, in terms of the amount of audit effort spent on individual audits, both permit a direct test of audit production hypotheses and allow distinction between various explanations for issues unresolved by research using audit fees alone.

Audit production models build upon models from audit fee studies, using thata on client and engagement characteristics that have been shown to be important determinants of audit fees in prior research. Compared to audit fee studies, the number of production studies is rather limited. The earliest studies use total audit hours spent on an engagement as the dependent variable and include as independent variables those client and engagement characteristics that influence audit quantity (see Palmrose 1986a, 1989; Davis, Ricchiute, and Trompeter 1993; Davidson and Gist 1996). A number of other production studies extend these studies by using audit hours disaggregated by staff level (O'Keefe et al. 1994; Stein et al. 1994; Bell, Knechel, and Willingham 1994), or audit hours disaggregated by staff level and audit activity (Hackenbrack and Knechel 1997). According to O'Keefe et al. $(1994,245)$, the use of disaggregated hours spent on engagements is appropriate when factors have differential effects on the various types of labor. Using disaggregated hours allows to investigate whether (and which) factors impact on the amount as well as the mix of labor resources. Generalizing the results, the production studies find that factors important in explaining variation in audit fees are also important in explaining variation in audit production. In addition, the production studies that use disaggregated labor hours find that certain size and risk measures also significantly influence the mix of labor resources.

\subsubsection{The audit production problem}

An explanation of the audit production problem is important for the discussion of efficiency frontier techniques in Chapter 3 (see Section 3.4). Therefore this section discusses the concept of the audit production problem. This discussion is based on that of O'Keefe et al. (1994) and Stein et al. (1994).

A production function describes the (technical) relationship between the inputs and outputs of a production process (Coelli, Prasada Rao, and Battese 1998, 12). Inputs specify the amounts of resources necessary to produce a given level of output. Applied to the production of audit services, the inpuls of the audit production process are the units of labor necessary to produce a given level of output. ${ }^{3}$ Like for all service organizations, the output of an audit firm is difficult to define. O'Keefe et al. $(1994,241)$ describe the output of the audit production process as the level of assurance provided to financial statement users that these financial statements are not materially misstated. 
In their application of the audit production model, OKeefe et al. (1994, 243-244) make the following assumptions: (1) the level of assurance produced by an audit firm is not directly observable. It is assumed that this assurance level is implied by the audit firm's brand name; (2) any particular audit firm produces a fixed level of assurance at a moment in time. That is, a firm's audit quality level is assumed to be fixed at any moment in time; (3) the client firm's structure is taken as predetermined; 4 (4) a client firm's owners and managers will select an audit firm that will deliver the level of assurance demanded by the client firm; and (5) the audit firm operates in a competitive environment, motivating the firm to produce its output at minimum cost:

Based on these assumptions, O'Keefe et all (1994) describe the auditor's decision problem as a constrained cost minimization problem for a fixed level of assurance (Hackenbrack and Knechel 1997, 485). Formally, this can be written as:

$$
\begin{gathered}
\underset{\mathbf{m i n i m i z e} c(h, \gamma)}{\mathbf{h}} \\
\text { such that } \bar{q}=p(h, y)
\end{gathered}
$$

where:

$c$ () is the audit cost function;

$\mathbf{h}$ is the vector of audit service inputs, and $h_{j}$ represents the quantity of each input; $\gamma$ is a vector of client firm characteristics that are exogenous to the auditor; $\bar{q}$ is the level of assurance associated with the audit firm's brand name; and $p(\cdot)$ is the audit production function.

The inclusion of client characteristics in the above cost and production functions is common for service organizations (Fuchs 1968, 194; O'Keefe et al. 1994, 244).

Assuming that an audit firm's assurance level is fixed at a certain point in time, and that this level of assurance can in fact be produced by the audit firm in question, the optimum combination of audit services inputs $\mathbf{h}^{*}$ at that point in time can be estimated from the following equation:

$$
\mathbf{h}^{*}=p^{-1}(\bar{q}, \gamma)
$$

Under the assumption that an audit firm operates in a competitive market, this solution implies the following minimum cost level for the fixed level of assurance $\bar{q}$ :

$$
c\left(\mathbf{h}^{*}, \gamma\right)
$$


Be it implicitly or explicitly, all audit production studies reviewed in this chapter apply the audit production problem outlined above and use the audit production equation $\mathbf{h}^{*}$ as defined above.

\subsubsection{Effect of litigation risk}

In his audit fee model, Simunic (1980, 171-175) distinguishes three categories of factors influencing the audit fee: (1) determinants of loss exposure: factors that determine the incidence of losses borne by financial statement users due to defects in the financial statements; (2) factors affecting the assessed loss-sharing ratio: determinants of the division of losses borne by financial statement users between the auditor and the auditee; and (3) auditor production economies: factors associated with differences in auditor production functions. Be it implicitly or explicitly, all subsequent fee and production studies are based on this framework and have included factors from these three categories in their models. Factors from the first and second category may influence auditor litigation risk (see e.g. factors investigated in Stice 1991; Lys and Watts 1994; Pratt and Stice 1994; Krishnan and Krishnan 1997; Heninger 2001).

Prior research has proxied for determinants of loss exposure by using measures related to auditee size, auditee complexity (e.g. number of consolidated subsidiaries, diversification of activities, ratio of foreign assets to total assets), the ratio of auditee receivables and inventories to total assets, ownership control (public or private companies), and auditee industry type. In general, the results are consistent: auditee size, complexity and asset composition (i.e., the ratios of receivables and inventories to total assets) are all positively associated with audit pricing and audit production. For the majority of studies that include a proxy for ownership control the results indicate that publicly listed companies pay higher audit fees and/or require more audit effort. In some cases, however, ownership control has no significant effect (Davis et al. 1993; Stein et al. 1994; Langendijk 1997). Results for industry membership show that in most cases the industry in which the auditee operates has no significant influence on audit fees. There are, however, some exceptions. A number of studies have found that audit fees are significantly lower for auditees operating in the financial services industry (Simunic 1980, 1984; Palmrose 1986a, 1986b, 1989; Turpen 1990) and for public utilities (Palmrose 1986a, 1986b; Turpen 1990; Anderson and Zéghal 1994). Some of the production studies have also found that audit effort is lower for financial services chients (Palmrose 1989; Hackenbrack and Knechel 1997) and for utilities (Palmrose 1989). ${ }^{5}$ Lower fees and effort for both financial industry and utilities clients may be due to regulatory aspects (see Turpen 1990, 62). According to Ezzamel, Gwilliam, and Holland (1996, 9) regulated industries have a limited product range and operate more on a national than on 
international basis, implying less audit effort and (if passed on to the client) lower audit fees. In contrast Gist $(1992,81)$ indicates that lower fees may follow from specialized knowledge and related scale economies flowing to the Big Eight.

Prior research has proxied for determinants of the assessed loss-sharing ratio by auditee financial distress measures such as auditee profitability, an indicator for auditee loss in recent years, receipt of a qualified opinion in the current year, and risk assessments made by the auditor. In general, the results show that more profitable firms pay lower fees and require lower audit effort, and that auditees that have incurred losses in recent years, that have received a qualified opinion in the current year, and that are judged by their auditors to be more risky than average, pay higher fees and require more audit effort. Thus, overall, higher auditee financial distress results in higher fees and effort.

Generalizing, the discussion above shows that factors related to auditor litigation risk increase both audit fees and auditor effort. Simunic and Stein (1996) explicitly examine whether this increased fee results from more audit effort, a price premium, or both. Their results indicate that fee increases are mainly due to increases in audit effort rather than fee premiums. In a similar way, Chapter 4 will investigate how potential earnings management - as a factor increasing auditor litigation risk - affects audit fees and audit effort, as well as the interplay between the two.

\subsubsection{Effect of market structure}

As indicated in Section 2.2.1, the high explanatory power of most fee studies suggests that the audit market is competitive (see Yardley et al. 1992, 160). This finding is corroborated by results from the limited number of fee studies that have examined the effect of market structure on audit fees. ${ }^{6}$ Both Maher, Tiessen, Colson, and Broman (1992) and Sanders, Allen, and Korte (1995) have found that audit fees decrease in a period of increasing competition. Pearson and Trompeter (1994) and lyer and lyer (1996) have both studied the effect of (supplier) concentration on audit fees, motivated by concerns that lower levels of competition - supposedly evidenced by higher levels of concentration - may result in higher fees. ${ }^{7}$ Pearson and Trompeter (1994) report that increasing concentration significantly decreases audit fees, thus providing counterevidence to the above concerns. In contrast, Iyer and lyer (1996) find no significant relationship between concentration and audit fees. In general, these studies' findings support the suggestion that the audit market is (price-) competitive. More evidence on price competition is provided by fee studies investigating price cutting. Price cutting is a special case of low balling (Francis and Simon 1987, 155). Low balling involves setting initial fees at a level lower than total audit costs (DeAngelo 1981, 113), and is a competitive reaction to the presence of 
quasi-rents to incumbent auditors (Yardley et al. 1992, 160). A number of audit fee studies suggest that auditors engage in price cutting on initial audit engagements (see Francis and Simon 1987; Simon and Francis 1988; Turpen 1990; Gregory and Collier 1996). Thus overall, these studies suggest that the audit market is competitive.

\subsection{Data collection}

The dataset used in this dissertation was collected by means of a survey among engagement partners of a (then) Big Six audit firm. Based on an extensive review of prior audit fee and production studies (see Section 2.2), the survey instrument was designed in cooperation with the technical department of the audit firm, which also administered the survey. The instrument - in the form of an electronic spreadsheet was sent to the audit engagement partners of each of the firm's offices and was accompanied by a cover letter and an instruction. Prior to conducting the actual survey, instrument, cover letter and instruction were pilot tested. Some minor adjustments were made. ${ }^{8}$

Great care was taken to obtain high quality data. The instruction accompanying the survey instrument specified selection criteria for the engagements to be included in the sample, and contained directions for filling out the spreadsheet.

The selection criteria indicated that the engagements to be included in the sample: (1) are financial statement audits. Reviews, compilations or special assignments are not to be considered; (2) pertain to the most recent audit,; (3) concern clients in for-profit sectors. Prior audit fee research has shown that fee models for not-for-profit organizations differ from those using data for profit organizations (see e.g. Baber, Brooks, and Ricks 1987; Rubin 1988; Ward, Elder and Kattelus 1994; Sanders, Allen, and Korte 1995); (4) do not concern clients in the financial services industry. Again, prior studies have found that fee and production models differ significantly between financial service industry clients and clients in other industries (see Section 2.2.3)..$^{10}$ No other restrictions as to the client's industry were imposed; (5) concern listed and unlisted companies subject to a statutory audit requirement; (6) do not concern clients that are included in the Amsterdam Exchange Index (AEX) or the Amsterdam Midkap Index (AMX). Together, these indexes are comprised of the 50 most actively traded shares on the Amsterdam Stock exchange and include companies like Heineken, KLM and Philips. Many are fairly unique in their own right, and are likely to be outliers in the sample; ${ }_{r}^{11}(7)$ relate to clients that publish independent financial statements; and (8) are audits of either independent companies or subsidiaries. Holding companies should not be selected. The rationale for this last criterion is that the data on audit fees, audit hours, and hourly rates on the one hand, and the data on client characteristics on the other need 
to concern one and the same entity. Audits of holding companies are often conducted in cooperation with other offices of the firm, either within the same country or abroad, or with other audit firms. In such cases, especially obtaining all relevant fee and hour data is relatively complicated and may result in inaccurate data.

The directions for filling out the questionnaire asked the partners to retrieve the requested data from the firm's internal billing and time registration system (containing data on audit hours, internal hourly cost rates, and fees), and the firm's electronic filing system (in which all kinds of client characteristics are recorded during the performance of audits). In addition, the directions clarified which particular data were to be collected, so as to minimize ambiguities. Furthermore, the partners were told that the researcher would not be informed about the identity of the individual clients.

Each of the 25 offices of the firm received a request to supply data on 25 audit engagements, and 18 offices agreed to participate. The request initially resulted in 102 responses. A reminder resulted in another 55 responses, thus bringing the total to 157 responses. Of these, four responses are not usable because they do not meet the selection criteria discussed above, ${ }^{12}$ resulting in 153 responses that are usable for the empirical analyses. ${ }^{13} 14$

\subsection{Conclusion}

This chapter has reviewed prior research on audit pricing and audit production, and in doing so has particularly emphasized those topics that are important to the studies reported in Chapters 3, 4, and 5. Further, this chapter has discussed the collection of the dataset that is used in these empirical chapters. This discussion forms the basis for the next three chapters. 


\section{Notes}

'Besides their own additional background literature, see also Section 1.3 in the previous chapter.

\section{${ }^{2}$ See Section 4.2 in Chapter 4.}

${ }^{3}$ O'Keefe et al $(1994,245)$ indicate that they do not include capital inputs in their model of audit production "...(..). because we believe that these are of second-order importance.(...)". This may certainly be the case in a study that uses data from only one audit firm, like O'Keefe et al. (1994) and also this dissertation (see Section 2.3 on data collection). In addition, allocation of (the costs related to) these capital inputs to individual audits can be difficult, and could result in arbitrary allocations and thus inaccurate input measures. However, when more than one audit firm is considered, capital inputs may vary across firms and may therefore become important. For instance, the largest audit firms (Big Eight/Six/Five/Four) are generally assumed to have invested more capital in reputation/brand name and in industry specialization than the smaller firms (non-Big Eight/Six/Five/Four). Furthermore, there may also be differences in investments in these capital inputs among these largest audit firms. In these cases, capital imputs are important to consider.

4 This assumption is made to exclude endogeneity problems. The audit production model assumes that client characteristics, of which the client firm's structure is one, influence audlit production, and not the other way round. Assumption 3 is made by O'Keefe et al. (1994) to exclude this latter passibility.

5 Stein et al. (1994) also find that auditee industry membership significantly influences audit effort. However, unlike other studies, they do not lest for this effect by including industry indicators. Instead, they examine and find that the set of variables that explains audit hours for a sample of industrial firms differs from that for a sample of financial services firms.

${ }^{6}$ Note: no prior research has studied the effect of competition on audit production.

7 See also Section 5.1 in Chapter 5 .

" The data collected during this pilot test are not included in the final data set used in this dissertation.

9 This was for financial year 1997.

10 In addition, because of specific financial statement reporting requirements, computing potentiall earnings management measures that are based on accruals is problematic for firms in this industry. As indicated earlier, Chapter 4 examines the effect of potential earnings management on audit pricing and andit production. As explained in Section 4.3.3 of that chapter, the proxy for potential eamings management used in the study is based on a measure of accruals. As indicated, calculating accruals measures is difficult for companies in the financial industry, thus constituting an additional reas on for not including these types of companies in the sample.

"Including these types of companies in the sample would be problematic for the efficiency analysis in Chapter 3. As indicated earlier, efficiency analysis is a form of benchmarking (see Chapter 1 , 
Section 1.3). Benchmarking requires observations that are comparablle to some extent (Dopuch and Gupta 1997, 142). Therefore, including relatively unique companies like the ones mentioned in the text would not serve the purpose of the study.

In addution, including these large companies would also hinder studying the effect of local audit market structure on audit engagement profitability in Chapter 5. As discussed in Section 5.2 .3 of that chapter, for large companies, the entire country of the Netherlands can be considered one and the same local audit market. This does not allow to study the effect of local audit market structure on profitability. By excluding these large companies from the dataset, the remaining observations are of such a size that not just the other Big Six but also other, smaller, audir firms can be regarded as competitors for the Big Six audit firm providing the dataset. Since these smaller audit firms operate on a local tather than national audit market scale, the relewant audit market scale is local and the effect of local audit market structure on proftability can in fact be studied based on the dataset thus composed.

12 One response concerned an audit for consolidation purposes, another was a review, a third was a compilation, and a fourth was a holding company.

13 A number of prior studies have used samplles that are notably larger than the sample used here. These are mostly studies on audit pricing, not audit production. Data on audit pricing (i.e., audit fees) are usually easter to obtain than data on audit production (i.e, audit effort), especially for countries where audit fees are publicly available, such as the United Kingdom and Australia. Data on audit production are proprietary data, not publicly available, and therefore much harder to collect (see also Chapter 1, Section 1.2.2). For that reason the sample sizes in audit production studies are usually smaller than those in audit fee studies. A number of audit production studies have sample sizes that: are smaller than or comparable to that of this dissertation. See e.g. Davis et al. (1993), Stein et all. (1994), and Davidson and Gist (1996). This also applies to some of the fee studies; see e.g. Anderson and Zéghal (1994), Brinn, Peel, and Roberts (1994), Gist (1994), Firth (1997), and Gul and Tsui (1998).

14. Application of t-tests and Mann-Whitney and Wilcoxon tests (see Siegel and Castellan 1988, 128; results not further reported here) indicate that at conventional levels, there are no statistically significant differences in client and engagement characteristics (including the clependent and independent wariables used in Chapters 3,4 , and 5 ) between responses received after the first request and those received after the second request. Therefore, all 153 responses are considered usable for the anailyses. 


\section{CHAPTER 3}

\section{BENCHMARKING THE PRODUCTION OF}

AUDIT SERVICES: AN EFFICIENCY FRONTIER APPROACH

\subsection{Introduction}

The audit services market is becoming increasingly competitive. To offer audit services at competitive prices, information on the costs of conducting audit engagements is essential. More specifically, given a specific level of audit quality, audit firms need to know the minimum amount of costs necessary to effectuate particular audit engagements. In other words, information on the cost efficiency of audit engagements is wanted. Since audit firms are professilonal service organizations whose most important input is human capital, the majority of the costs associated with audit engagements consist of costs for use of labor hours. This implies that audit firms also need information on (the minimum amount of) labor hours to compete effectively with other audit firms on the dimension of audit pricing.

This chapter investigates the cost and labor efficiency of audit engagements employing an efficiency frontier techuique known as stochastic frontier analysis. Using efficiency frontier techniques is a form of relative performance evaluation (RPE). In applying RPE, information about the performance of other entities is used in assessing the performance of specific entities (Dopuch and Gupta 1997, 142). This is frequently termed "benchmarking". Translated to the current study, information about the performance of other audits is used to evaluate the performance of a specific audit.

Managerial and financial accounting research, and economics oriented research in general, has shown a wide area of benchmarking and RPE applications, in public and in priwate sectors, in manufacturing and in service organizations, at micro (individual employees, operational processes, organizational departments and 
branches, entire organizations), meso (industries) and macro levels (countries). Examples include executive compensation based on RPE (e.g. Lanen and Larcker 1992), cost and productive efficiencies of banks (Sherman and Gold 1985), cost efficiency of public schools (Dopuch and Gupta 1997), performance of local governments (de Borger and Kerstens 1996), performance of private and public utilities (Fâre, Grosskopf, and Logan 1985), efficiency of hospitals (Grosskopf and Valdmanis 1987), efficiency of labor use in insurance offices (Kubhamkar and Hjalmarsson 1995), and efficiency of European railway companies (Pestieau 1993).

However, the application of benchmarking and RPE to auditing is relatively new. There is a substantial body of research investigating the pricing of audit services and, to a lesser extent, the production of audit services (see Chapter 2). All of these studies implicitly assume that audit firms produce their services in an efficient manner and thus at minimum costs, as evidenced by the statistical techniques that they use. After all, ordinary least squares (OLS) regression fits a line through the center of a scatter plot, thus allowing to determine the average amount of audit effort needed to complete an audit for a particular client, or the average amount of costs incurred in conducting audits. Regression techniques, however, cannot be employed to determine the minimum amount of audit effort or the minimum amount of costs necessary to conduct an audit and are therefore unable to determine the (relative) efficiency of audit production and audit costs. The efficiency frontier techniques referred to earlier (and discussed further in a subsequent section) are able to do so. Therefore in this chapter an efficiency frontier technique is used to determine the (labor and cost) efficiency of audit services production.

Currently only one other study has applied benchmarking and RPE to audit services. Employing a data set from the late 1980s, Dopuch, Gupta, Simunic, and Stein (2000) use two efficiency frontier techniques - the statistical technique stochastic frontier analysis and the linear programming technique data envelopment analysis - to determine the minimum amount of audit effort, disaggregated by staff level, required for the production of audit services, as well as the minimum amount of (a surrogate for) audit costs associated with this production. ${ }^{2}$ As Dopuch et al. $(2000,8)$ indicate, studying each individual staff level separately provides information on the (in)efficiencies of labor for each of these individual staff levels. However, it does not indicate whether the mix of labor hours was efficient as well. Therefore, Dopuch et al. $(2000,8)$ use (a surrogate for) audit costs, in addition to audit hours disaggregated by staff level, to investigate whether the composition of the audit team in its entirety was efficient. This chapter follows Dopuch et al. (2000) in using both audit hours disaggregated by staff level and audit costs to study the efficiency of the production of audit services. However, the measure of audit costs used here differs from that of Dopuch et al. (2000). As argued in subsequent sections, this chapter's measure of audit costs is likely to present a more accurate picture of actual audit costs incurred by the firm in conducting their audit engagements. 
Additionally, as indicated, the dataset used by Dopuch et al. (2000) dates from the late 1980s. Since then, especially the large audit firms have re-engineered their audit approaches. This chapter uses data on financial statement audits conducted in 1997, presenting a more recent picture of the audit process.

The remainder of this chapter is organized as follows. Section 3.2 reviews prior research on the efficiency of audit services. Section 3.3 describes the variables and model used in the study. Section 3.4 discusses efficiency frontier techniques in general and stochastic frontier analysis in particular. Section 3.5 presents the data and the results, and Section 3.6 concludes.

\subsection{Prior research on the efficiency of audit services}

As stated in the introduction, prior research on the labor and cost efficiency of audit services is rather limited. In fact, only one other study, Dopuch et al. (2000), has investigated the labor and cost efficiency of audit services. There is, however, a substantial amount of research on audit pricing and audit production on which the study by Dopuch et al. (2000) is based. This literature was discussed in Chapter 2. To the same data set used in a number of prior audit production studies, ${ }_{r}{ }^{3}$ Dopuch et al. (2000) apply the efficiency frontier techniques of stochastic frontier analysis (SFA) and data envelopment analysis (DEA) to measure the relative efficiency of audit labor hours per staff level, as well as (a surrogate of) audit costs. ${ }^{4}$ As indicated in the introduction and as argued in a later section, the characteristics and assumptions of ordinary least squares regression techniques (used by all other production studies discussed in Chapter 2) render these techniques unsuitable for detecting possible inefficiencies in the production of audit services, in contrast to efficiency frontier techniques such as SFA and DEA. The SFA and DEA results of Dopuch et al. (2000) are rather contradictory: whereas the SFA results suggest that there are no labor or cost inefficiencies in the production of audit services, the DEA results suggest the opposite. To a large extent, this difference in results may be explained by the differences between the two efficiency frontier techniques. The specifics of efficiency frontier estimation will be discussed in a later section. Suffice it to state here that SFA measures the relative efficiency of a production process by assuming that the error term consists of two independent sources of errors: a one-sided error (truncated from below at zero) representing inefficiency, and a symmetric error representing random variation from the so-called efficiency frontier. ${ }^{5}$ Whereas SFA assumes that deviations from the frontier may consist of inefficiencies as well as random noise, DEA assumes that all deviations from the frontier represent inefficiencies. Therefore, application of DEA may result in more deviations from the frontier being labeled as inefficiencies than when SFA is used (Schmidt 1985-86, 304 and 319). ${ }^{6}$ 


\subsection{Variables and model}

Based on the prior literature discussed in Chapter 2 and Section 3.2 of the current chapter, a model was constructed to estimate the labor and cost efficiency of audit services. This section discusses the model and its variables.

The following disaggregated staff levels are studied in the analyses: (1) partner; (2) manager; (3) supervisor; (4) assistant; and (5) supporting activities. The latter category differs from the first four because the employees performing the supporting activities are not part of the audit team, but supporting staff at the audit firm's headquarters. The activities in this category are of a varied nature and represent a mix of secretarial and related activities, and support from the audit firm's technical department. In contrast to the other four categories, this category of activities cannot be characterized as audit fieldwork. It is therefore expected that the model specified below is less suitable for this category than for all other categories. Nevertheless, this category is included in the analyses to provide a complete picture of the audit production process and the related cost structure.

Besides labor hours disaggregated by staff level, the analyses are also performed for two composite measures, total audit hours and total audit costs. Total audit hours is simply an unweighted sum of the labor hours per staff level spent on a specific engagement. Total audit costs per engagement consist of the following components: (1) actual number of audit hours spent per staff member, multiplied by the internal hourly cost rate differentiated per staff member, summed over all staff members; and (2) out-of-pocket costs (see Davis, Ricchiute, and Trompeter 1993, 138). This measure of audit costs differs from the standard fee mentioned in O'Keefe, Simunic, and Stein $(1994,248)$ and Simunic and Stein $(1996,131)$ and used as a surrogate for audit costs in Dopuch et al. $(2000,8)$. This standard fee is described as the product of actual hours per staff level multiplied by standard billing rates per staff level, summed over all staff levels. However, this chapter does not use standard billing rates per staff level, but the actual intemal hourly cost rates per staff member charged to each individual audit engagement. ${ }^{7}$ Since the data indicate that for each staff level these actual rates per staff member cover a broad range, the use of differentiated (internal) rates to compute audit costs is considered more accurate than that of billing rates per staff level that are equal over all staff members in the same staff level for all engagements. ${ }^{8}$ In addition, out-of-pocket costs (representing costs like travel, lodging and meals, see Davis et al. 1993, 138) incurred per engagement are also included in this chapter's cost measure."

The selection of independent variables included in the analyses is based on a review of prior audit fee and audit production literature (see Chapter 2). Like models in prior studies, the models estimated here include factors related to client size, client complexity, client asset composition, client risk and financial distress, 
quality of client internal controls, auditor tenure, and the auditor's provision of nonaudit services. The specific variables used are shown in Table 3.1 below.

The expected signs are based on prior audit pricing and production research and are explained below.

Total assets is a proxy for client size. Previous studies have argued that larger firms enter into more financial transactions and thus require more effort, resulting in higher costs (and fees) (see e.g. Simunic 1980, 172; Anderson and Zéghal 1994, 196). Therefore, a positive sign for client size is expected. In accordance with prior research, a logarithmic transformation of total assets is used to reduce heteroscedasticity.

A fair number of variables in the models proxy for client risk. These are: the type of audit opinion (unqualified opinion or other); the extent of the client's foreign operations (measured as the ratio of foreign to total assets); the client's leverage (long-term liabilities divided by total assets); the client's asset composition (measured as the ratio of receivables and inventory to total assets); ${ }^{10}$ the client"s profit margin (net result divided by total sales); client inherent risk (an indicator variable: the auditors were asked to indicate whether this client's inherent risk was higher than average or not); the quality of the client's internal controls (again an indicator variable: the auditors were asked to indicate whether the quality of this client's internal control system was higher than average or not); client loss in the last two years (the client had a net loss in the last two years or not); and finally, listing status (the client was listed on the Amsterdam Stock Exchange or not). Prior research argues that higher risk induces the auditor to be more careful and thus spend more effort, resulting in higher audit costs and fees (again, see Simunic 1980, 173; or Francis 1984, 139-140). Consequently, the expected signs are positive for opinion type, foreign proportion of assets, leverage, the ratio of receivables and inventory to total assets, inherent risk, loss in the last two years, and listing status; and negative for profit margin and control quality.

Two variables proxy for audit complexity: the number of reports provided to management, and the number of locations visited by the auditor during the audit. More complex audits require more audit effort, leading to higher audit costs and fees (see e.g. Palmrose 1986a, 99-100). Therefore, the expected signs for both variables are positive. Again, to reduce heteroscedasticity a logarithmic transformation is applied to both variables.

Taken together, the four indicators first-year, second-year, third-year, and fourth-year client measure auditor tenure, or the number of years the client has used its current auditor. Auditor tenure is assumed to control for learning over time and is considered a source of auditor production economies (see Simunic 1980, 174). The specific form of the tenure indicators used here is taken from O'Keefe et al. (1994, 252-253). They argue that using tenure indicators in this form (instead of, e.g., a proxy that measures tenure as a continuously increasing variable, see Simunic 1980, 
Table 3.1

Variables Included in models based on prior audit fee and production research

\begin{tabular}{|c|c|c|}
\hline \multirow[b]{2}{*}{ Whdependent wantalloes: } & \multicolumn{2}{|c|}{ Fixpected sign } \\
\hline & $\begin{array}{c}\text { Total and } \\
\text { disaggregared } \\
\text { audit hours }\end{array}$ & Total audif costs \\
\hline 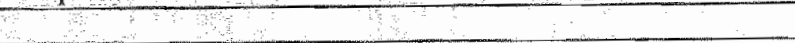 & & \\
\hline Asgetu (natival log) & + & + \\
\hline Nr of roponts provaded to management (nathral log) & + & + \\
\hline Nir of locetions visted by the auditor during the ahdit (natural log) & + & + \\
\hline Opinon type $(0,1)$, where 1 ind hates other than unqualified opinion & * & + \\
\hline Foreign proportion of assets & + & + \\
\hline Leveragge (Long-term labilites/Total assets) & + & + \\
\hline 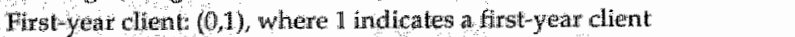 & tw & + \\
\hline Second-year client: $(0,1)$, where 1 indicates a second-year dient & + & + \\
\hline Thind year client: $(0,1)$, where 1 ndicates a third-year client & + & + \\
\hline Fourth-year client $(0,1)$, where 1 indicates a fourth-year client & + & + \\
\hline (Recevibles - Inventory)/Total ansets & + & + \\
\hline Proft margin (Ner resull/Tolal sales) & - & - \\
\hline Nonatit fee/Audit fee & - & - \\
\hline Inherent risk $(0,1)$, where I indicates greater than average risk & + & + \\
\hline Control qualiby: $(0,1)$, where 1 indicates higher than awerage quality & - & - \\
\hline $\begin{array}{l}\text { Loss in last two years: }(0,1) \text {, where } 1 \text { indicates an operating loss in the } \\
\text { last two years }\end{array}$ & + & 4 \\
\hline $\begin{array}{l}\text { Listed: (0, } 1) \text {, where I indicates a company listed on the Amsterdam } \\
\text { Stock Bxchange }\end{array}$ & + & + \\
\hline
\end{tabular}

175) emphasizes the audits that the audit firm has been conducting for relatively few years, when the majority of learning should take place. If learning occurs, the expected signs are positive and ordered as follows: first-year client $>$ second-year client $>$ third-year client $>$ fourth-year client."

Finally, the ratio of the nonaudit fee to the audit fee proxies for the auditor's provision of nonaudit services to the client. Prior research suggests that, like auditor learning, the provision of nonaudit services may also be a source of auditor production economies, due to knowledge spillovers (see e.g. Simunic 1984, 680). For instance, the provision of nonaudit services may reduce audit startup costs, which might lead to cost savings and/or audit fee reductions. Based on this argument, the expected sign for the ratio of nonaudit fee to audit fee is negative. ${ }^{12}$

The model specification used in this study is also based on those used in previous audit fee and production research. ${ }^{13}$ For audit hours, the model is as follows:

$$
\ln h_{i j}=\beta_{j 0}+\beta_{j 1} \ln A_{i}+\beta_{j 2} \ln R_{i}+\beta_{j 3} \ln L_{i}+\sum \beta_{j k} \gamma_{i k}+\varepsilon_{i}
$$


In this formulation, $h_{i j}$ represents the actual number of audit hours spent on an audit by the $j$ th staff level, or total audit hours, $A_{i}$ indicates client size, $R_{i}$ the number of reports provided to the management by the auditor, $L$ the number of client locations visited during the audit, and $\gamma$ all other client characteristics as shown in Table 3.1.

A similar model is used for the cost function:

$$
\ln c_{i}=\beta_{0}+\beta_{1} \ln A_{i}+\beta_{2} \ln R_{i}+\beta_{3} \ln L_{i}+\sum \beta_{k} \gamma_{i k}+\varepsilon_{i}
$$

where $c_{i}$ represents the total audit costs incurred by the audit firm for a specific audit, which were defined above, and all other variables are as above.

As an additional but important note, in line with O'Keefe et all $(1994,243)$ it is assumed that a particular audit firm produces a fixed level of assurance across audit engagements at a moment in time. ${ }^{14}$ That is, a firm's audit quality level is assumed to be fixed at any moment in time. Since the data in this study come from a single audit firm and concern audits conducted in a single year, a fixed level of assurance may also be assumed here. This implies that a difference in hours or costs across similar engagements, if any, is not associated with quality differences, but with differences in efficiency levels.

\subsection{Efficiency frontier techniques and stochastic frontier analysis}

As discussed in Chapter 2 (see Section 2.2.2), a production function describes the (technical) relationship between the inputs and outputs of a production process (Coelli, Prasada Rao, and Battese 1998, 12). It specifies the maximum quantities of realizable output given any level of inputs, or alternatively, for any level of output the minimum quantities of inputs needed for production (Thiry and Tulkens 1989, 22). Considering the formulation of the audit production problem in Chapter 2 , Section 2.2.2, the latter characterization applies here: examining the labor efficiency of audit engagements involves the minimization of audit labor hours given a number of client characteristics and a fixed level of assurance (where the latter is the output of the audit production process).

In the above context, the production function is also viewed as the frontier of the so-called production set (Pestieau 1993, 128; Greene 1997, 85). The elements that constitute this set are all the input-output combinations that are physically feasible to the producer. The frontier indicates the limits of what is achievable. Feasible productive activities that lie on the frontier are efficient; those that lie inside the production set are inefficient. The larger the distance from the frontier, the more inefficient the activity (Pestieau 1993, 130). The production frontier function acts as a norm, serving as a base for assessing efficiency (Thiry and Tulkens 1989, 23). It is to be emphasized that this norm is relative rather than absolute: the degree of 
(in)efficiency of any imput-output combination is evaluated relative to the most efficient observation in the data set. Therefore, the production frontier is often termed a "best practice" frontier (Greene 1997; 98),

The production function describing the relationship between inputs and outputs is called the primal function. Besides this primal function, one can also estimate the so-called dual functions of the production function: cost and profit functions. The choice for either of these two depends on the behavioral assumption that is made: cost minimization or profit maximization (Coelli et al. 1998, 22-23). As discussed in Chapter 2 , Section 2.22 , the audit production problem can be characterized as a cost minimization problem. Therefore, a cost rather than a profit function is the appropriate dual function here,

As indicated in the introduction, conventional ordinary least squares regression techniques are unable to determine whether an input-output combination is (cost) efficient, and to what extent Since these techniques fit a line through the center of a scatter plot of input-output combinations, they can be used to calculate average but not efficient production and cost levels. So-called efficiency frontier techniques, however, can do so. The literature distinguishes these techniques along the dimensions parametric-nonparametric and deterministic-stochastic (see e.g. Schmidt 1985-86; Lovell and Schmidt 1988; Thiry and Tulkens 1989; Pestieau 1993; Greene 1997).

Parametric approaches to estimating production or cost frontiers assume a particular functional form for the frontier and make use of econometric estimation methods. Stochastic frontier analysis (SFA), developed by Aigner, Lovell, and Schmidt (1977) and Meeusen and van den Broeck (1977), is an example of a parametric frontier estimation technique. Nonparametric approaches do not require a-priori specification of a functional form but rather make use of the formal properties that the points in the data set should satisfy, employing mathematical programming techniques. An example of a nonparametric approach is data envelopment analysis (DEA), developed by Charnes, Cooper, and Rhodes (1978), which uses linear programming techniques to estimate efficiency frontiers.

Another distinction is made between deterministic and stochastic frontier techniques. Deterministic techniques, such as DEA, take no account of the possible influence of measurement error, omitted variables, and other noise upon the frontier. All deviations from the frontier (i.e., the error terms) are assumed to be the result of inefficiencies. A more realistic approach is taken by stochastic frontier techniques like SFA, which account for two sources of errors: a one-sided error representing inefficiency, and a symmetric error representing random variation of the frontier.

This chapter uses a stochastic frontier technique, more specifically, a parametric stochastic frontier technique, to estimate production and cost frontiers. The stochastic approach is preferred to the deterministic approach here because it takes account of measurement errors, omitted variables, and other noise. The assumption 
that the error term is solely composed of inefficiency is unlikely (see Schmidt 198586, 308). Also, a parametric rather than a nonparametric approach is preferred here. A major disadvantage of nonparametric techniques is the inability to conduct conventional tests of hypotheses (Greene 1997, 93; Coelli et al. 1998, 245). In contrast, a parametric technique does allow for statistical inference since it employs econometric estimation methods. It is acknowledged that an often-mentioned disadvantage of parametric techniques is the need to specify a functional form for the production and cost function (see Coelli et al. 1998, 246). However, like Dopuch et al. $(2000,10)$ indicate as well, this is not considered a serious problem in the context of the audit production function since the relationship between audit fees (and to a lesser extent, audit hours) and client and engagement characteristics has been studied extensively, resulting in a robust log-linear specification. Another often-quoted disadvantage of (stochastic) parametric techniques concerns the need to specify a distributional form for the inefficiency term. This study tests two distributions, the half-normal and the truncated-normal (see below).

In conventional ordinary least squares regression, the error term $\varepsilon_{i}$ in the production and cost functions as defined in a prior section is assumed to consist of pure noise, randomly distributed with mean zero and variance $\sigma_{i}{ }^{2}$. In contrast, and as stated, the stochastic frontier technique assumes that $E_{i}$ is composed of two sources of error: $v_{i}$ and $u_{i}$. The first element $v_{i}$ is similar to the interpretation of $\varepsilon_{i}$ in ordinary least squares regression, representing measurement error, omitted variables, and other noise, and is assumed to be independent and identically distributed with mean zero and variance $\sigma_{v}{ }^{2}$. This random error is assumed to be distributed independently of the second element, $u_{i}$, a one-sided error representing inefficiency. This latter error is also assumed to be independent and identically distributed, following an asymmetric distribution. Usually the half-normal distribution (truncated from below at zero) is assumed, with mean zero and variance $\sigma_{i i}{ }^{2}$ (Berger and Humphrey 1997, 178). ${ }^{15}$ Both $v_{i}$ and $u_{i}$ are assumed to be distributed independently of the independent variables in the frontier production or cost model.

To determine whether the stochastic frontier models provide a better representation of the audit production process and the resulting cost structure than the ordinary least squares regression models, a test of the presence of labor and/or cost inefficiencies in the specified models is required. This involves testing the null hypothesis $H_{0}: \sigma_{u}^{2}=0$ versus the alternative hypothesis $H_{1}: \sigma_{i}{ }^{2}>0$. Acceptance of $H_{0}$ would mean that there are no (labor or cost) inefficiencies in the models, implying that the ordinary least squares regression models provide a valid representation of the production process or cost structure in that there are no inefficiencies present in the error terms but only random noise. Instead, rejection of $H_{0}$ would indicate that there are indeed inefficiencies in the production process or cost structure, suggesting that the stochastic frontier models are to be preferred over the ordinary least squares 
regression models. Additional details on stochastic frontier analysis are provided in Appendix $3 \mathrm{~A}$.

\subsection{Data and results}

This section presents the nesults for the models defined in Section 3.3. First, the data and some descriptives are discussed. Then the results of the OLS regression are reported Finally, the SFA estimation results and tests are presented.

\subsubsection{Data and descriptives}

The collection of the dataset used in this chapter was described in Chapter 2. As indicated in Section 2.3 of that chapter, the collection resulted in 153 usable responses. Since 39 observations of these have missing values, 114 responses are used in the subsequent analyses. The descriptive statistics for these 114 observations are shown in Table 3.2 below.

The data show that the observations cover a rather broad range, both in terms of the dependent and independent variables. Furthermore, the average (and median) client firm in the sample displays a fairly low amount of foreign activities; is financed by equity; has a positive net profit; has more than half of its total assets contained in receivables and inventory; does not obtain many nonaudit (as compared to) audit services from its audit firm; receives an unqualified opinion; is audited by this audit firm for over four years; has a less than average inherent risk; has a higher than average control quality; and finally, is an unlisted company. In addition, the mean and median audit hours spent per staff level logically reflect the hierarchical structure in an audit firm. Of all staff levels, partners have spent the least amount of time on a specific engagement, assistants spent the most time, and of the staff levels in between, supervisors have spent more time on a specific engagement than managers. ${ }^{16}$

\subsubsection{OLS regression results}

Table 3.3 below presents the results of the OLS regression of the dependent variables on the independent variables that were presented and defined in. Table 3.1.

Examination of pairwise correlations among the independent variables and of the variance-inflating factors (Gujarati 1995, 328) shows that multicollinearity is not a problem. Since application of Breusch-Pagan tests (Greene 2000, 509-510) indicates presence of heteroscedasticity for the models for total costs, total hours, partner 
Tabille 3.2

Descriptive statistics for 114 financial statement audits

\begin{tabular}{|c|c|c|c|c|c|c|}
\hline & Mean & St. dev. & Medinn & Minimum & Maximuna & \\
\hline \multicolumn{7}{|l|}{ Continnons whinbles: } \\
\hline Total audit costs (in NLG) & $90,866.28$ & $147,262.40$ & $56,237,50$ & $14,525,00$ & $1.248,970.00$ & \\
\hline Total audit hours & 477.24 & 631.10 & 346.38 & 79.00 & $5,388.00$ & \\
\hline Partiner hours & 2240 & 35.21 & 11.50 & 1.00 & 205.00 & \\
\hline Manager hours & 56.44 & 132.95 & 27.00 & 2.00 & $1,161,00$ & \\
\hline Superyisor hours & 134.31 & 256.48 & 86.00 & 1.00 & 2,635000 & \\
\hline Assistant hours & 256.30 & 279.11 & 198.00 & 28.50 & $2,601.00$ & \\
\hline Supporting hours & 1279 & 20.45 & 6.00 & 1.00 & 149.00 & \\
\hline Assets (in NLG 000's) & 190,00000 & $792,000.00$ & $32 ; 800.00$ & $4,633,29$ & $6,870,000000$ & \\
\hline Nr. of reports & 1.99 & 1.61 & 2.00 & 1.00 & 12.00 & \\
\hline Nr. of locations & 2.00 & 2.65 & 1.00 & 1.00 & 25.00 & \\
\hline Foreign proportion of assets & 0.04 & 0.15 & 0.00 & 0.00 & 1.00 & \\
\hline Leverage & 0.12 & 0.17 & 0.03 & 0,00 & 0.82 & \\
\hline $\begin{array}{l}\text { (Receivables + Inventory)/Total } \\
\text { assets }\end{array}$ & 0.56 & 0.26 & 0.59 & 0.04 & 1.91 & is \\
\hline Profit margin & 0.04 & 0,08 & 0.03 & -0.33 & 0.51 & \\
\hline Nonaudit fee/Audit fee & 0.46 & 0.91 & 0.16 & 0,00 & 6.20 & \\
\hline \multicolumn{7}{|l|}{ Calcgonical wariables: } \\
\hline Opinion type & 0.05 & 0.22 & 0.00 & 0.00 & 1.00 & \\
\hline First-yeat client & 0.02 & 0.13 & 0.00 & 0.00 & 1.00 & \\
\hline Second-yeant client & 0.04 & 0.21 & 0.00 & 0.00 & 1.00 & \\
\hline Third-year client & 0.05 & 0.22 & 0,00 & 0.00 & 1.00 & \\
\hline Fourth-year client & 0.04 & 0.21 & 0.00 & 0.00 & 1.00 & \\
\hline Inherent risk & 0.11 & 0.32 & 0.00 & 0.00 & 1.00 & \\
\hline Control quality & 0.61 & 0.49 & 1.00 & 0.00 & 1.00 & \\
\hline Loss in last two years & 0.11 & 0.31 & 0.00 & 0.00 & 1.00 & \\
\hline Listed & 0.18 & 0.38 & 0.00 & 0.00 & 1.00 & \\
\hline
\end{tabular}

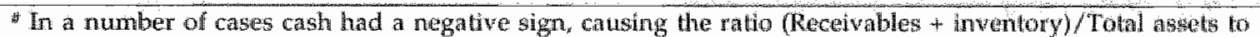
exceed one:

Nots or defindtions of the variables see Table 3.1 and Section 3.3 .

hours, supervisor hours and assistant hours, the t-ratios presented for these regressions are computed using White's heteroscedasticity-consistent covariance matrix estimation method (Greene 2000, 463). ${ }^{17}$

The table shows that all models are significant at the 0.01 level, except for supporting activities. This latter result is not surprising considering the deviating nature of the activities of this category compared to the other categories. The regression for supporting activities also has the lowest explanatory power of all models presented, as evidenced by its adjusted $R^{2}$. All other models have an adjusted $\mathrm{R}^{2}$ that is well inside the range of those reported by prior audit production studies (see Chapter 2 for these studies). It is notable though, that the explanatory power of models for total audit costs and total audit hours is much higher than for 


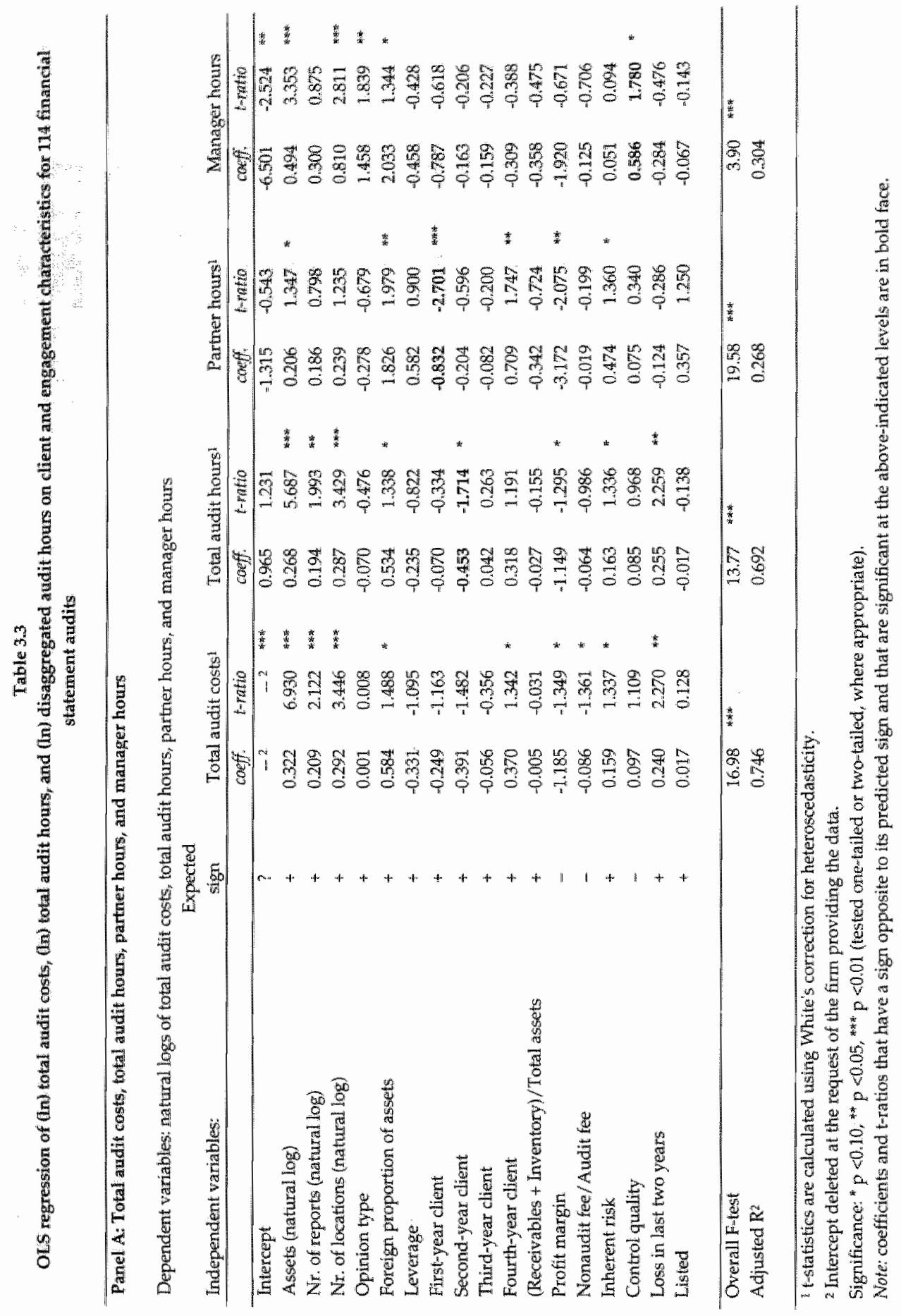




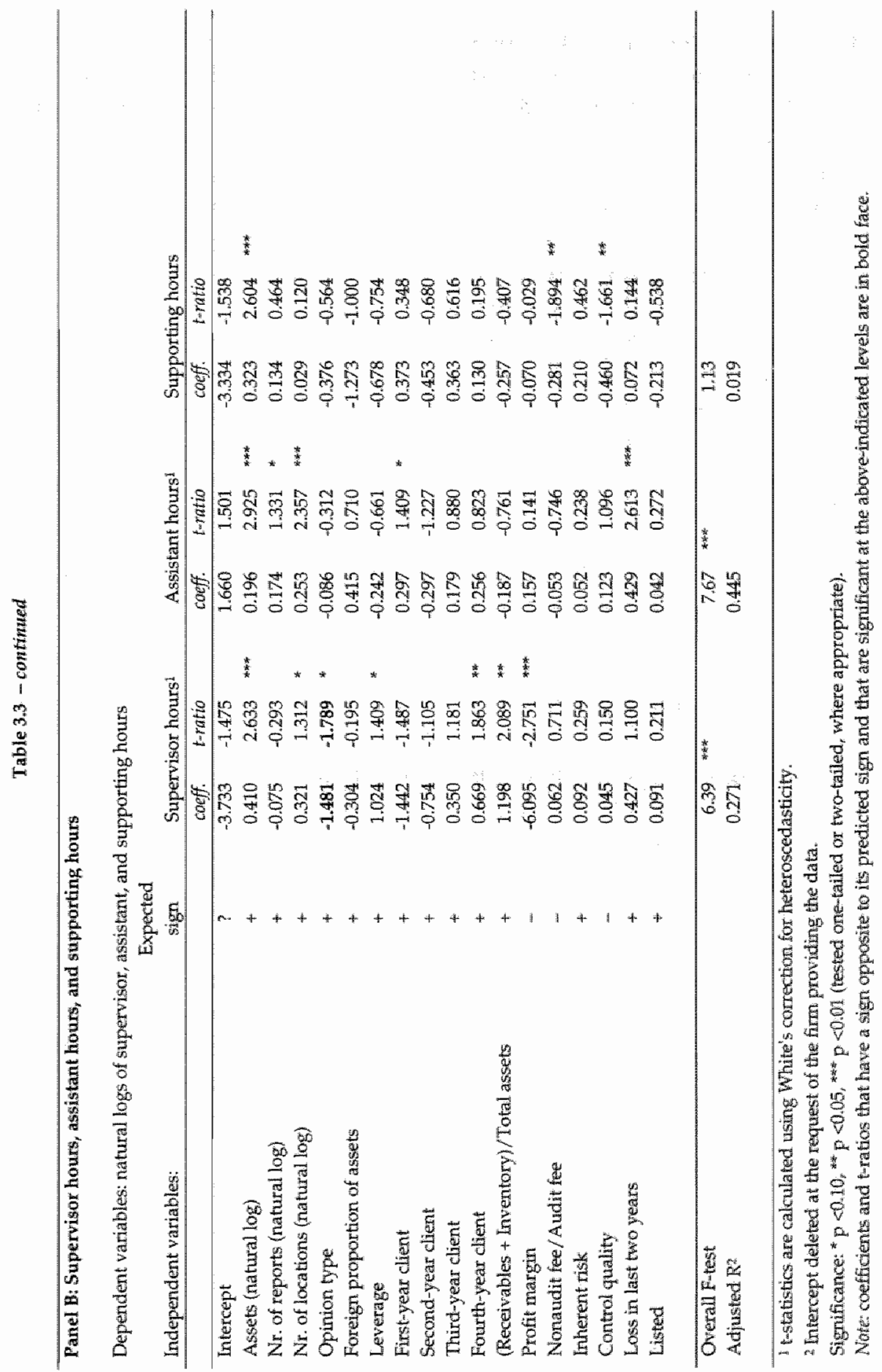


the disaggregated measures. Apparently, the model specification used here better explains the composite measures than the constituent parts of these measures. 18

Tuming to the independent variables, the results confirm prior audit production studies. Measures of client size, client complexity, client asset composition, client risk and financial distress, quality of client internal controls, auditor tenure, and the auditor's provision of nonaudit services are determinants of total audit costs, total audit hours and at least some category of disaggregated labor hours. Also in line with prior research, client size (proxied by total assets) seems to be the most important determinant of audit costs and (aggregated and disaggregated) audit hours. ${ }^{19}$ Table 3.3 also shows that for some variables the signs are opposite to the ones expected. ${ }^{20}$ For example, an other than unqualified opinion appears to decrease rather than increase the number of supervisor hours spent on an engagement. ${ }^{21}$ Also, a higher quality of the client's internal control system seems to increase rather than decrease the number of manager hours. Finally, auditor learning does not appear to take place in a consistent manner, ${ }^{22}$ judging by the significant negative sign for the first-year client indicator for partner hours, ${ }^{23}$ the significant negative sign for the second-year client indicator for total audit hours, and the fact that for most models the coefficients for the tenure indicators do not differ significantly from each other. ${ }^{24}$

\subsubsection{SFA results and tests ${ }^{25}$}

The stochastic frontier specification of the cost and production models was estimated using Frontier 4.1 (Coelli 1996). This program applies maximum likelihood estimation to obtain the vector of parameters of the models.

Table 3.4 reports the results of the estimation of the stachastic frontier models for total audit costs, total audit hours, and the disaggregated labor hours, as well as the results of testing $H_{0}: \sigma_{u}^{2}=0$ versus $H_{1}: \sigma_{u}^{2}>0.26$ This test indicates acceptance of $H_{b_{s}}$ implying indifference between the OLS and SFA specification of the cost and production models.27 These findings suggest that there are no cost and labor inefficiencies in the production of the audit engagements included in this study's sample, in that - at least for these particular clients of this particular audit firm at this particular point in time - these engagements could not have been produced for less costs and with less labor hours. ${ }^{28}{ }^{29}$ These results match the SFA results but not the DEA results of Dopuch et al. (2000). As discussed in Section 3.2, Dopuch et al. (2000) do not find inefficiencies in the production of audit services when using SFA. In contrast, results using DEA do show inefficiencies. ${ }^{30}$ As indicated earlier (see Section 3.2), this difference between SFA and DEA results is believed to be largely due to the differences in characteristics between the two frontier techniques. ${ }^{31}$

The sample used in this study represents only a small subset of clients of only one of the largest audit firms, and for only one financial year. This makes it difficult 
Table 3.4

Efficiency of tolal andit costs, total audit hours, and disaggregated audit hours ifor IIt financial stateinuent audits

\begin{tabular}{|c|c|c|c|c|c|c|c|}
\hline \multicolumn{8}{|c|}{ Panel A: Total audit costs and total audit hours } \\
\hline \multicolumn{8}{|c|}{ Dependent variable: natural logs of total audit costs and total andit hours } \\
\hline \multirow{3}{*}{ Independent variables: } & Expected & & & & \multirow{2}{*}{\multicolumn{3}{|c|}{ Total andithours: }} \\
\hline & sign & Total & andil cost & & & & \\
\hline & & $20 \mathrm{eg} / \mathrm{f}$ & Pratio & & couft & Dratis & \\
\hline Intercept & $?$ & $-a^{2}$ & $-m^{2}$ & 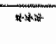 & 0.965 & 1.231 & \\
\hline Assets (natural log) & + & 0.322 & 6.930 & *** & 0.268 & 5.687 & $*$ \\
\hline Nr. of reports (matural log) & + & 0.209 & 2.122 & $* *$ & 0.194 & 1.993 & *n. \\
\hline Nr. of locations (natural log) & + & 0.292 & 3.446 & *atid. & 0.287 & 3.429 & 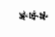 \\
\hline Opinion type & + & 0.001 & 0.008 & & $-0.0 \% 0$ & -0.476 & \\
\hline Foreign proportion of assels & + & 0.584 & 1.488 & * & 0.534 & 1.338 & $*$ \\
\hline Leverage & $*$ & -0.331 & $\times 1.095$ & & -0.235 & -0.822 & \\
\hline First-year client & + & -0.249 & -1.163 & & -0.070 & -0.334 & \\
\hline Second-year client & 4 & -0.391 & -1.482 & & -0.453 & -1.714 & *. \\
\hline Third-year client & 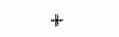 & $-0,056$ & 0.356 & & 0.042 & 0.263 & \\
\hline Fourth-year client & + & 0.370 & 1,342 & * & 0.318 & 1.491 & \\
\hline (Receivables + Imventory)/Total assets & + & -0.005 & -0.031 & & -0.027 & -0.155 & \\
\hline Profit margin & - & -1.185 & -1.349 & * & -1.149 & -1.295 & * \\
\hline Nonatidit fee/Audit fee & - & -0.086 & -1.361 & $*$ & -0.064 & -0.986 & \\
\hline Inherent risk & + & 0.159 & 1.337 & * & 0.163 & 1.336 & * \\
\hline Control quality & - & 0.097 & 1.109 & & 0.085 & 0.968 & \\
\hline Loss in last two years & + & 0.240 & 2.270 & $\$$ & 0.255 & 2.250 & 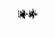 \\
\hline Listed & + & 0.017 & 0.128 & & -0.017 & -0.138 & \\
\hline Overall F-lest & & 16.98 & **a & & 13.77 & $* * *$ & \\
\hline Adjusted R? & & 0.746 & & & 0.692 & & \\
\hline Log likelihood constant only & & $-130,781$ & & & -118.966 & & \\
\hline Log likelihood model & & $-43,291$ & & & 42.569 & & \\
\hline Likelihood ratio test statistic & & 174980 & 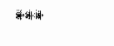 & & 152.795 & w & \\
\hline Log likelihood OLS model & & -43.291 & & & -42.569 & & \\
\hline Log likelihood $5 \mathrm{FA}$ model & & $-43,291$ & & & -42.569 & & \\
\hline Likelihood ratio test statistic OLS W. SF ${ }^{3}$ & & 0.000 & & & 0,000 & & \\
\hline \multicolumn{8}{|l|}{ Composed residwats } \\
\hline Skewness & & -0.414 & & & -0.462 & & \\
\hline Kuntosis & & 3.372 & & & 3.183 & & \\
\hline Jarque-Bera tes statistic & & 3.922 & $(0.141)$ & & 4.206 & $(0.122)$ & \\
\hline Shapiro-Wilk test statistict & & 0.977 & $(0.0469)$ & & 0.980 & $(0,082)$ & \\
\hline
\end{tabular}

\footnotetext{
${ }^{1}$ l-statistics are calculated using White ${ }^{*} s$ correction for heteroscedasticity.

2 Intercept delleted at the request of the firm prowiding the data.

3 This lest statistic is asymptotically distributed as a mixed $x^{2}$ distribution with degrees of freedom equal to the number of restrictions (in this case one). For $\alpha=0.05$, the critical walue is 2.71 (Coelli et all. 1998, 192. See Kadde and Palm (1986, 1246) for the specific critical values).

* p-value in parentheses. For both thes the reported probability is the probability that the test statistic (in absolute value exceds the observed value under the null hypothesils.

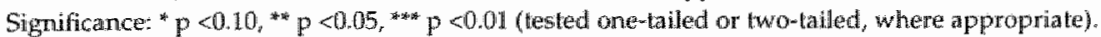

Nole; coefficients and twatios that have a sign opposite to its predicted sign and that are signiluctit at the aboweindicated levels are in bold face.
} 
Table $3.4-$ continutur

\section{Pand D: Parthet houra and manager hours}

Dependant vartable natural logs of partoer howirs and manager hours

\begin{tabular}{|c|c|c|c|c|c|c|c|}
\hline Indapendent wartibles: & $\begin{array}{l}\text { Expected } \\
\text { singrin }\end{array}$ & Pair & ver hours' & & Mar & ger how & \\
\hline 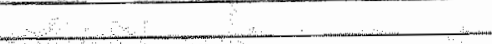 & & $\cos f$ & tratio & & coeff. & tyintio & \\
\hline horcept & $?$ & -1.315 & -0.543 & & -6.501 & -2.524 & +4 \\
\hline Asseks (naturat tog) & + & 0.206 & 1.347 & * & 0.494 & 3.353 & *ats \\
\hline Nr ofreports (natural log) & + & 0.186 & 0.798 & & 0.300 & 0.875 & \\
\hline Nr. of locations (nathral log) & + & 0.239 & 1.235 & & 0.810 & 2811 & 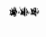 \\
\hline Ophinion type & 4 & -0.278 & -0.679 & & 1.458 & 1.839 & $\$$ \\
\hline Foneign ptoportion of assets & 4 & 1.826 & 1.979 & $*$ & 2.033 & 1.344 & * \\
\hline Leweriage & $*$ & 0.582 & 0.900 & & -0.458 & -0.428 & \\
\hline Filst-yeat client & $\#$ & -0.832 & -2.701 & *atis & -0.787 & -0.618 & \\
\hline Second-year client & $\sharp$ & -0.204 & -0.596 & & -0.163 & -0.206 & \\
\hline Third-year dient & + & -0.082 & -0.200 & & -0.159 & -0.227 & \\
\hline Fourth-year chent & + & 0.709 & 1.747 & *** & -0.309 & -0.388 & \\
\hline (Recervalbeg + Invernory)/Total assets & 4 & -0.342 & -0.724 & & -0.358 & -0.475 & \\
\hline Prafit margin & - & -3.172 & -2.075 & ** & -1.920 & $-0,671$ & \\
\hline Nonatudit fee/Audit fee & - & -0.019 & -0.199 & & -0.125 & -0.706 & \\
\hline Inherent risk & + & 0.474 & 1.360 & 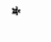 & 0.051 & 0.094 & \\
\hline Control quality & - & 0.075 & 0.340 & & 0.586 & 1.780 & * \\
\hline Loss in last two years & + & -0.124 & -0.286 & & -0.284 & -0.476 & \\
\hline Listued & t & 0.357 & 1.250 & & -0.067 & -0.143 & \\
\hline Overall F-test & & 19.58 & +4 & & 3.90 & (*) & \\
\hline Adljusted $\mathbb{R}^{2}$ & & 0.268 & & & 0.304 & & \\
\hline Log likelihood constant only & & -175.388 & & & -234.550 & & \\
\hline Log likedihood moded & & -148.328 & & & -204.592 & & \\
\hline Tukelihood ratio test statistic & & 54.119 & $m+\infty$ & & 59.916 & $x$ & \\
\hline Log likelihood ol 5 model & & -148.328 & & & -204.592 & & \\
\hline Log lithellitwod SI A nodel & & -148.328 & & & .204 .592 & & \\
\hline Wiketilnood ratio test statistic OLS ws. SPA2 & & 0.000 & & & 0.000 & & \\
\hline \multicolumn{8}{|l|}{ Composed residuals } \\
\hline Skewrness & & -1.407 & & & -0.284 & & \\
\hline Kurtosits & & 5.803 & & & 2,000 & & \\
\hline faroue-Bera lest statistic & & 74.951 & $(0.000)$ & & 6.285 & $(0,043)$ & \\
\hline Shapho Wilk test statistic & & 0.897 & $(0.000)$ & & 0,958 & $(0.001)$ & \\
\hline
\end{tabular}

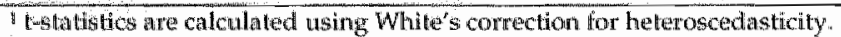

This test statistic is asymptotically distributed as a mixed $\chi^{2}$ distribution with degrees of freedom equal to the number of restrictions (in this case one). For $a=0,05$, the critical value is 2.71 (Coelli et al. 1998, 192. See Kodde and Palm (1986, 1246) lor the specific critical walutes).

${ }^{3}$ prature in parentheses. For both tests the reported probability is the probability that the tast statistic (in absolute value exceeds the obserwed value under the null hypothesis.

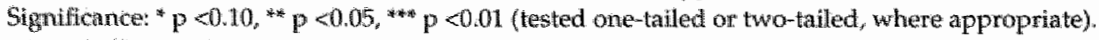

Not: coeffichents and tratios that have a sign opposite to its predicted sign and that are significant at the aboveindicated levels are in bold face.
} 
Table 3.4 - corrthunet

\section{Pamel C: Supervisor hours and assistant hours}

Dependent variable: natural logs of supervisor hours and assistant hours

\begin{tabular}{|c|c|c|c|c|c|c|c|}
\hline \multirow[t]{2}{*}{ Independent variables: } & \multirow[t]{2}{*}{$\begin{array}{c}\text { Expected } \\
\text { sign }\end{array}$} & \multicolumn{3}{|c|}{ Superwisor hourst } & \multicolumn{3}{|c|}{ Assistant hounst } \\
\hline & & $\cos$ & $t-f^{2} 1110$ & & adf & Amatio & \\
\hline Thteroept & $?$ & -3.733 & -1.475 & & 1.660 & 1.501 & \\
\hline Assets (natural log) & $*$ & 0.410 & 2.633 & W & 0.196 & 2.925 & 舟为 \\
\hline Nr. of reports (natural log) & + & -0.075 & -0.293 & & 0.174 & 1.331 & 車 \\
\hline N5. of locationus (matural log) & wit & 0.321 & 1.312 & * & 0.253 & 2.357 & : \\
\hline Opinion type & to & $* 1.481$ & -1.789 & * & -0.086 & -0.312 & \\
\hline Foreigg proportion of assets & $+*$ & -0.304 & $-0,195$ & & 0.415 & 0.710 & \\
\hline Leverage & tw & 1.024 & 1.409 & 4 & $-0,242$ & -0.661 & \\
\hline Pust-year client & + & -1.442 & -1.487 & & 0.297 & 1.409 & * \\
\hline Second-year dient & + & .0 .754 & -1.105 & & -0.297 & -1227 & \\
\hline Third-year client & + & 0.350 & 1.181 & & 0.179 & 0.880 & \\
\hline Fourth-year client: & + & 0.669 & 1.863 & 如娄 & 0.256 & 0.823 & \\
\hline (Recerwables + Inventory) / Total asse ts & tr & 1.198 & 2089 & 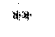 & -0.187 & 0.761 & \\
\hline Profyt margin & - & -6.095 & -2.751 & $n+\infty$ & 0.157 & 0.141 & \\
\hline Nonaudit lee/Audit fee & $-\ldots$ & 0.062 & 0.711 & & 0.053 & -0.746 & \\
\hline Wherent risk & th & 0.092 & 0.259 & & 0.052 & 0.238 & \\
\hline Control quality & - & 0.045 & 0.150 & & 0.11 .23 & 1.096 & \\
\hline Loss in last two years & + & 0.427 & 1.100 & & 0.429 & 2.613 & 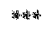 \\
\hline Listed & + & 0.091 & 0.211 & & 0.042 & 0.272 & \\
\hline
\end{tabular}

\begin{tabular}{|c|c|c|c|c|}
\hline Overall F-test & 6.39 & 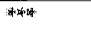 & 7.67 & *舟米 \\
\hline Adjusted $\mathbb{R}^{2}$ & 0.271 & & 0.44 .45 & \\
\hline Log likelihood constant only & $-213,289$ & & -118.442 & \\
\hline Log likelihood model & -185.970 & & -75.629 & \\
\hline Likelihood ratio kest statistic & 54.638 & 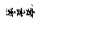 & 85.626 & Fis \\
\hline Log likelihood OLS modiel & -185.970 & & -75.629 & \\
\hline Log likeliltood SNA model & -185.970 & & -75.629 & \\
\hline Likelihood ratio tesit statistic OLS va. SFA? & 0.000 & & 0.000 & \\
\hline \multicolumn{5}{|l|}{ Composed residtuals } \\
\hline Skewness & -1.667 & & -0.876 & \\
\hline Kurtogis & 6.200 & & 4858 & \\
\hline Jarque-Bera test statistic ${ }^{3}$ & 101.416 & $(0,000)$ & 30.990 & $(0.000)$ \\
\hline Shapiro-Wilk tast statistic & 0.848 & $(0.000)$ & 0.955 & (0.001) \\
\hline
\end{tabular}

\footnotetext{
1. Iflatistios are calculated using White's correction for heteroscedasticity.

2 This test statistic is asymptotically distributed as a mixed $x^{2}$ distribution with degrefes of freedon equall to the number of restrictions (in this case one). For $\alpha=0.05$, the critical value is 2.71 (Coelli al 1998, 192. See Kodde and Palm (1986, 1246) for the specific critical vallues).

${ }^{3}$ p-value in parentheses. For both tests the reported probability is the probablity that the tegt statistic (in absolute value) exceds the observed value under the mull hypothesis.

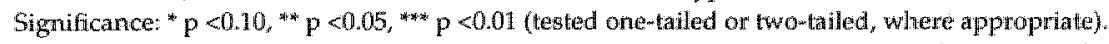

Note coefficients and $t$-ratios that hate a sign opposite to its predicted sign and that are significant at the above indicated levels are in bold face.
} 
Table $3,4-$ comtinued

\section{Fand D: Supporting hours}

Dependent wriable: naturall log of supporting hours

\begin{tabular}{|c|c|c|c|c|}
\hline Independur ynables: & $\begin{array}{l}\text { xpecter } \\
\text { sigh }\end{array}$ & \multicolumn{3}{|c|}{ Supporting hours } \\
\hline 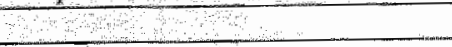 & & coeff. & itritio & \\
\hline Tritercept & $?$ & -3.334 & -1.538 & \\
\hline Assett (natural log) & H & 0.323 & 2.604 & * \\
\hline Wr, of reports (nawarl log) & + & 0.134 & 0.464 & \\
\hline Nri of locetions (natural log & + & 0.029 & 0.120 & \\
\hline Oplinton type & + & -0.376 & -0.564 & \\
\hline Toneign propoution af assets & + & -1.273 & $-1,000$ & \\
\hline Laverage & + & -0.678 & -0.754 & \\
\hline Rirst-year chent & $*$ & 0.373 & 0.348 & \\
\hline Second-yemr chent & + & -0.453 & 0.680 & \\
\hline Thind-year dient & + & 0.363 & 0.616 & \\
\hline Fourth-year client & + & 0.130 & 0.195 & \\
\hline (Recuivables to moentory)/Totall assens & \# & -0.257 & 0.407 & \\
\hline Proft margin & $\therefore$ & -0.070 & -0.029 & \\
\hline Monaudis fee / Audit fer: & - & -0.281 & -1.894 & $x *$ स \\
\hline Intherent risk & + & 0.210 & 0.462 & \\
\hline Control quality & - & -0.460 & -1.661 & $*$ \\
\hline Loss in lase two years & +4 & 0.072 & 0.144 & \\
\hline Listed & \rfloor & -0.213 & -0.538 & \\
\hline
\end{tabular}

$\begin{array}{lr}\text { Overall F-test } & 1.13 \\ \text { Adjusted } \mathbb{R}^{2} & 0.019 \\ \text { Log likelihood constant only } & -195.291 \\ \text { Log likelihood trodel } & -184.920 \\ \text { Likelihood ratio test statistic } & 20.742\end{array}$

\section{Log likelihood OLS model} log likelihond SF mordel

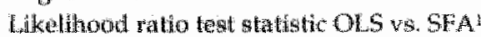

$-184.920$

$-194920$

0,000

\section{Contwesth risiduats}

\begin{tabular}{|c|c|}
\hline Skewness & -0.125 \\
\hline Kurtosis & 2098 \\
\hline Jaraterion test statistic & 4,161 \\
\hline Ghapiro Wath test stathstic & 0971 \\
\hline
\end{tabular}

This test statistic is aymplatically distributed as a mixed $x^{2}$ distribution with tegrees of foedom equal to the

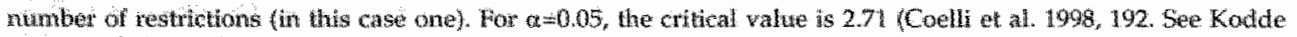
and Pan (1986, 1246 ) for the specific criticat values).

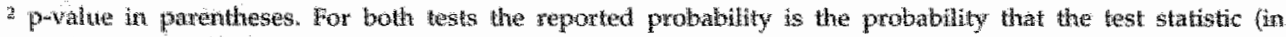
absotute watue exoed the observed value tuder the mull hypothesis.

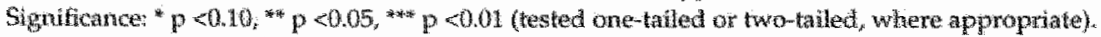

Note: coffichents and thatos that have a sign opposite to its predieted sign and that are significant at we abover undicated levels are in bold face. 
veneralize the results and prohbits conclusions as to the audit market as a whole. One could argae, however, that cost and labor effictent audit services correspond with a (price-)competitive audit market, disciplining auditors to conduct audits effichenty. ${ }^{32}$ Stll, these results are suprising, considering ${ }^{*} .(.$.$) .. the complexity of$ the audit process, diversity in the knowledge of anditors, and the fact that chent characteristics vary a gneat deal from engagement to engagement.(...) (Dopuch et a. 2000,23$)^{33}$

\subsection{Conclusions, Limitations, and suggestions for future research}

The aim of this chapter was to benchmark the production of audit services by investigating the cost and labor efficiency of a sample of (hen) Big Six audit engagements using the statistical technique of stochastic frontier analysis. The results show that the model specification of audit production used in wis chapter performs in a fashion similar to those of prior audit production studies, in that: (1) measures of client size, client complexity, client asset composition, client risk and financial distress, quality of client internal controls, auditor tenure, and the auditor's. provision of nonaudit services are shown to be important determinants of audit costs and audit production; and (2) chent size is the single most important factor explaining audit costs and audit production. In addition, the results suggest hat prior audit fee and production model specifications also provide good explanatory power for a model of audit costs, a model that until now only Davis et al. (1993) has tested, 34 though finding a much lower adjusted $\mathrm{R}^{2}$ than found here.

Tuming to the efficiency estimation, the results seem to suggest that for the sample used in this chapter, audits are labor and cost efficient. 35 This would seem consistent with a (price-)competitive market that forces auditors to be efficient. ${ }^{36}$ Given the nature of the audit production process, however, these resulls are surprising.

As a marginal but important note, it has to be stated that anecdotal evidence suggests that auditors frequently engage in underreporting of time to meet time budgets, a suggestion also confirmed by research (see Kelley and Margheim 1987, 1990; Otley and Pierce 1996; Akers, Horngren, and Eaton 1998-99). Although the audit firm that provided the data indicates that their employees are urged to report actual hours worked, and not underreport to meet the budget, it is of course not certain that this is indeed the case for the engagements in this study's sample. Even so, iff the auditors in this sample have actually underreported, the findings in this chapter would suggest that hours are consistently underreported for all clients.

Another limitation ensues from the fact that data from only one audit firm and for only one year are used. This limits the generalizability of the findings, and it is very well possible that results for other firms and/or for other periods of time (or a 
combination of these) would be different. Therefore, more research in this area is warranted, the more so since prior research on this interesting and important subject is rather scanty. For instance, future research could consider using data from a number of audit firms at the same time (cross-section), or data from one and the same audit firm for consecutive time periods (time-series). ${ }^{37}$ This way, comparisons of efficiency could also be made across audit firms and/or time periods.

In doing so, future research could use the efficiency frontier technique that was used here, stochastic frontier analysis, but other techniques as well, including data envelopment analysis discussed in Section 3.4. This would also allow comparisons of the performance of the various available efficiency techniques in detecting (in)efficiencies in audit costs and audit production, an area in which application of these techniques is rather new.

In this respect, it might also be interesting to investigate the effect of audit technology on the efficiency of audit production. Cushing and Loebbecke (1986) compare the audit approaches of 12 audit firms and classify these in terms of the amount of structure. They argue that a structured approach may improve audit efficiency, resulting in better control of audit costs. In line with this argument, Gist (1994) finds that firms with a structured audit approach charge lower audit fees than firms with an intermediate or unstructured audit approach. However, neither he nor any other prior study has the disposal of audit production and/or cost data to directly investigate the argument made by Cushing and Loebbecke (1986). Future studies that do have production and cost data at their disposal as well as data with respect to audit firms' audit approaches could investigate the effect of audit structure on audit efficiency directly.

As a final suggestion, and in relation to the remarks made above, future research does not have to be limited to the largest audit firms, but might include many medium-sized or smaller audit firms as well. Most past and current research on audit production (and audit pricing) is limited to the largest audit firms. Although these firms make up a large part of the audit market, the role and importance of smaller audit firms should not be overlooked. The audit market is generally characterized by a dual market structure, with a few large audit firms and many small audit firms (see Yardley, Kauffman, Cairney, and Albrecht 1992, 154). This is also true for the Netherlands: the majority of the Dutch audit market still consists of very small audit firms (most are single proprietorships; see Bröcheler 1999, 25). Considering the economic importance of these small audit firms, it would be interesting to extend the type of research as conducted in this chapter to the smaller segment of the audit market. 


\section{Appendix 3A Stochastic frontier analysis}

\section{A.1 Introduction}

The stochastic frontier technique used in this chapter was (independently) developed by both Aigner et a1. (1977) and Meeusen and van den Broeck (1977). This Appendix provides some econometric detalls on the stochastic frontier cost and production functions that were estimated in this chapter. ${ }^{38}$ For additional details, see Forsund, Lowell, and Schmidt (1980), Greene (1997), and Coelli et al. (1998).

\section{A.2 Stochastic frontier analysis}

Assume the following cost function:

$$
\ln c_{i}=\beta_{k} x_{i k}+\varepsilon_{i}, \quad \quad i=1,2, \ldots, N
$$

In this formulation, $c_{i}$ represents the actual amount of audit costs spent on an audit engagement and $x_{i k}$ the client characteristics as shown in Table 3.1. As indicated earlier in Section 3.4, the residual error $\varepsilon_{\text {in }}$ is assumed to be composed of two independent sources of error: $v_{i}$ and $u_{i}$. The first element $v_{i}$ represents measurement error, omitted variables and other noise, and is assumed to be independent and identically distributed with mean zero and constant variance $\sigma_{v}{ }^{2}$, independent from the second element, $u_{i .}$. This is a one-sided error representing inefficiency, and is also assumed to be independent and identically distributed, following an asymmetric distribution. As discussed in Section 3.4, usually the half-nomal distribution (truncated from below at zero) is assumed, with mean zero and variance $\sigma_{i}{ }^{2}$.39 Both $v_{i}$ and $u_{i}$ are assumed to be uncorrelated with the independent variables in the model.

In this chapter, the parameters of the model in equation (3A.1) ${ }^{40}$ were estimated by means of the maximum-likelihood method, which maximizes the log-likelikood function for the model. Aigner et al. (1977) derived the log-likelihood function for models such as those in (3A.1). Adapted to the formulation of the cost function and assuming a half-normal distribution for $u_{i}$, this function is equal to (Mester 1997, 233):

$$
\ln L=N / 2 \ln (2 / \pi)-N \ln \sigma+\sum_{i=1}^{N} \ln \left[\Phi\left(\varepsilon_{i}, \lambda / \sigma\right)\right]-\left(1 / 2 \sigma^{2}\right) \sum_{i=1}^{N} \varepsilon_{i}^{2}
$$


where:

$\mathbb{N}$ is the number of audit engagements in the sample;

$c_{i}=v_{i}+u_{i}=\ln c_{i}-\beta_{k}, x_{i k}$

$\sigma^{2}=\sigma_{i t}^{2}+\sigma_{i}^{2}$

$\lambda=\sigma_{i} / \sigma_{i}$

and $\Phi()$ is the distribution function of a standard normal random variable.

The maximum likelihood estimates $\beta_{k} \sigma^{2}$, and $\lambda$ can be obtained by maximizing the likelthood function as defined in (3A.2). According to Aigner et al. (1977, 28), these estimators are consistent and asymptotically efficient.

\section{A.3 Mean efficiency}

Given the assumption of a half-normal distribution for the inefficiency term $u_{i,}$ the mean efficiency for all audit engagements in the sample can be calculated as follows (Mester 1997, 233):

$$
\hat{E}\left(u_{i}\right) \equiv \sqrt{(2 / \pi)} \hat{\sigma}_{t a}
$$

where $\hat{\sigma}_{u}$ is the estimate of $\sigma_{t i}$.

\section{A.4 Efficiency per observation}

Besides the mean techrical efficiency for all audit engagements in the sample, the individual efficiency per audit engagement is also of interest. The inefficiency per audit engagement $u_{i}$ itself is not observable, only the composite $\varepsilon_{i} \equiv y_{i}+u_{i}$ is. The best predictor for $w_{i}$ is the conditional expectation of $u_{i}$ given the value of $v_{i}+w_{i}$ (Mester (1997, 233), adapted from Jondrow, Lovell, Materov, and Schmidt (1982, 234) for a cost formulation). Again assuming a half-nomal distribution for the ineficiency term $u_{i}$, the conditional distribution of $u_{i}$ given $g_{i}$ is a normal distribution truncated at zero: $N\left(\mu_{*}, \sigma_{*}\right)$, where $\mu_{*}=\left(\varepsilon_{i n} \sigma_{m}^{2}\right) / \sigma^{2}$ and $\sigma_{*}=\left(\sigma_{i s}^{2} \sigma_{b}^{2}\right) / \sigma^{2}$.

The density function is:

$$
\left.f\left(u_{i} \mid \varepsilon_{i}\right)=\left[\left(\sigma_{u} \sigma_{v} / \sigma\right) \phi\left(\sigma / \sigma_{n} \sigma_{v}\right)\left(u_{i} \mid \varepsilon_{j}\right)-\left(\varepsilon_{i} \lambda / \sigma\right)\right)\right] /\left[1-\Phi\left(-\varepsilon_{i} \lambda / \sigma\right)\right]
$$

Where:

$\left.\left(u_{i}\right), b_{i}\right)>0$;

and $\phi()$ is the density function of a standard normal variable.

The mean of the conditional distribution and thus the efficiency per audit engagement is given by: 


$$
E\left(u_{i} \mid \varepsilon_{i}\right)=\left(\sigma_{i u} \sigma_{p} / \sigma\right)\left[\left(\phi\left(\varepsilon_{i} \lambda / \sigma\right) / \Phi\left(\varepsilon_{i} \lambda / \sigma\right)\right)+\varepsilon_{i} \lambda / \sigma\right]
$$

\section{A.5 Tests of hypotheses}

As indicated in Section 3.4, to examine whether there are no inefficiencies in the model defined in (3A.1), the null hypothesis $H_{0}: \sigma_{i}^{2}=0$ needs to be tested versus the alternative hypothesis $H_{1}: \sigma_{i f}^{2}>0$. These hypotheses can be tested using the Wald statistic. The test is performed as a one-sided test since $\sigma_{i}{ }^{2}$ cannot take negative values, and can be conducted using the one-sided generalized likelihood-ratio test. First the model is estimated under both $H_{0}$ and $H_{1}$. Under $H_{0}$ the model estimated using maximum likelihood is equivalent to the model estimated using OLS, which alssumes that there is no inefficiency effect. Then the Wald test statistic is computed as follows (see Coelli et al. 1998, 191):

$$
L R=-2\left\{\ln \left[L\left(H_{0}\right) / L\left(H_{1}\right)\right]\right]=-2\left\{\ln \left[L\left(H_{0}\right)\right]-\ln \left[L\left(H_{1}\right)\right]\right\}
$$

where $L\left(H_{0}\right)$ and $L\left(H_{1}\right)$ are the values of the likelihood function under $H_{0}$ and $H_{1}$, respectively.

The test statistic (LR) is asymptotically distributed as a mixed $\chi^{2}$-distribution with degrees of freedom equal to the number of restrictions (in this case one). The critical value for a test of size $\alpha$ is equal to $x_{1}^{2}(2 \alpha)$. Thus, $H_{0}$ should be rejected in favor of $H_{1}$ if the $L R$ statistic exceeds $\chi_{1}^{2}(2 \alpha)$. For $\alpha=0.05$, the critical value is 2.71 (Coelli et al. 1998,192 . See Kodde and Palm $(1986,1246)$ for the specific critical values). Rejection of $H_{0}$ (i.e., acceptance of $H_{1}$ ) would imply that there are inefficiencies, and thus that the stochastic frontier model is a better representation than the OLS model. Alternatively, acceptance of $H o$ would mean that there are no inefficiencies in the model, indicating that the maximum likelihood estimation is equivalent to the OLS estimation. 


\section{Notes}

1 The term "entities" should be interpreted in a very broad sense. RPE has been applied to individuals, teams, orgarization units and departments, firms, districts, countries and many other cases.

2 A discussion of this paper is provided in the next section.

3 See OKeefe, Simunic, and Stein (1994), Stein, Simunic, and OKeefe (1994), and Bell, Knechell, and Willingham (1994).

4. Ag stated earlier, the measure of audit costs used in the current study is likely to present a more accurate picture of the actual audit costs incurred by the audit firm in conducting audit engagements than the measure of costs used by Dopuch et al. (2000). This issue will be elaborated on in a later section.

5i In contrast, ordinary least squares regression techniques assume that the error term consists of random noise only and, as stated earlier, are therefore unable to detect possible inefficiencies.

"In a paper surveying a large number of studies that have investigated the efficiency of financial institutions, Berger and Fumphrey $(1997,185)$ raise similar arguments.

'According to the audit firm providing the data, these internal hourly rates are the cost rates at which hours are (internally) charged to each individual audit engagement. Per staff level $r$ each individual staff member has his or her" "own" cost rate at which the hours worked by that staff member are charged to the specific engagements. The firm indicates that these rates differ from the rates used in billing the hours to the client (i.e., billing rates, which Simunic and Stein (1996) and Dopuch et al. (2000) use). Thus, it can be expected that the rates used in this chapter are not billing rates but cost rates, the use of which results in a more accurate measure of audit costs than when using standard billing rates. However, since these cost rates are not market-determined rates, and since data on the composition of the hourly rates are unavailable, the true "cost" nature of these rates cannot be perified. For instance, it is possible that these cost tates contain some mark-ups for costs other than human resource costs, or for other types of investments. To the extent that these mark-ups are - in a relative sense - equal over all engagements in the sample, this fact need not distort the results presented in this chapter (or those presented in Chapter 5 , where the same measure of audit costs is used). However, since the presence and nature of these potential mark-ups is unknown, the comments made here should be borne in mind when interpreting the results.

${ }^{8}$ As Dopuch al. $(2000,8)$ themselves indicate, a weakness of their surrogate (i.e., standard fees) is that the level of costs and standard fees may vary geographically.

"It may be noted that the bullk of this cost measure consists of costs related to human capital. Since audit firms are professional service organizations where human capital is the most important input, this is not considered inappropriate. Therefore, the majority of costs associated with audit engagements consist of the costs related to the use of labor hours. This is in line with the argument made by OKeefe et all. $(1994,245)$, who do not consider capital inputs in their study on the 
production of audit services, as they feel that these are of second-order importance. This may also be a valid assumption in this case, since like in $\mathrm{O}^{\prime} \mathrm{Keefe}$ et al. (1994) data from only one audit firm are used here. Furthermore, as also indicated in Chapter 2 (endnote 3) allocation of the costs related to these capital inputs to individual audit engagements may be difficult, and could result in arbitrary allocations and thus inaccurate cost measures:

10 Prior research has also considered client asset composition as a proxy for audit complexity: receivables and inventory are more difficult and timeconsuming to audit than other accounts on the balance sheet (see e.g. Anderson and Zéghal 1994, 196). However, other research has also argued that these two balance sheet accounts (i.e, receivables and inventory) also present a greater risk to the auditor (Simunic 1980, 173). For instance, Feroz, Park, and Pastena (1991) find that of all balance sheet accounts, misstatements are most common in receivables and inventory. Therefore, the ratio of receivables and inventory to total assets is considered as a proxy for risk here.

I1 Note: clients who have been audited by this audit firm for five years or more are included in the intercept.

12 Note that the measure of nonaudit services prowision that is used here, the ratio between notnaudit and audit fee, could entail endogeneity problems. Although this ratio is not regressed on audit fee in the subsequent analyses, it is on audit costs, a measure which is significantly and positively correllated with audit fee (Pearson product-moment correlation coefficient $0.969, \mathrm{p}<0.01$ ). However, this type of measure has been used frequently in prior audit pricing and production research (see Chapter 2 for references). Other types of measures, such as the natural. $\log$ of nonaudit fees, are less suitable since they do not adequately reflect the extent of nonaudit services provision relative to audit services provision. Nevertheless, the remarks above need to be borne in mind when interpreting the resilts in subsequent sections.

13. These modell specifications are "......). motivated by three basic issues" (1) to highlight the crucial role of client size as a determinant of audit effort, (2) to linearize the rellationship between labor hours (or audit fees) and client size; and (3) to reduce heteroscedasticity.(...)" (Hackenbrack and Knechel $1997,485)$.

14 See also the discussion of the audit production problem in Chapter 2, Section 2.2 .2 .

15. The argument here is that the inefficiencies must have a truncated, asymmetric distribution since they cannot be negative (Berger and Humphrey 1997, 178). Alternative, more general distributions: than the half-normal have been specified, such as the truncated-normal distribution. This distribution. is a generalization of the half-normal distribution in that it is obtained by truncating the normal distribution at zero. It has a mean $\mu$ and variance $\sigma_{u}{ }^{2}$. In the case where $\mu=0$, the truncated-normal is equal to the half-normal distribution (see Coelli et al. 1998, 200). Despite the availability of alternative distributional forms, most empirical applications of the stochastic frontier technique have used the half-normal distribution for $u_{i}$ (Greene 1997, 104). The results reported in this thapter are for modgls with the half-normal distribution. However, the models were also tested using the truncated-normal distribution, and the results were virtually identical. 
16 As discussed in Section 3.3 of this chapter, the category supporting hours stands out in that the activities in this category are noil performed by the audit team but by supporting staff at the audit firm 's headiduarters.

Wote that the correlations, wariance-inflating factors, and Breusch-Pagan tests are not reported here.

18 Pethaps this is due to possible substitution effects between the warious staff levels, see also endnote 29.

${ }^{4}$ In fact, a regression of total costs, total audit hours, partner hours, manager hours, supervisor hours, assistant hours and supporting hours on (the natural log of total assets yields an $\mathbb{R}^{2}$ of 0.65 . $0.59,0.25,0.28,0.19,0.40$, and 0.07 respectively. All these models are significant at the 0.01 level (Ftest). This confirms prior studies, "..... (.) which have shown that client size alone can explain more than 50 percent of cross-sectional variability in audit fee. $(. .$.$) (Hackenbrack and Knechel 1997, 496).$

20 These effects are in bold face type when they are statistically significant.

21 Note that for this sample there were only two types of opinions: unqualified opinions and disclaimers. In Dutch audit practice, a disclaimer is rather common, especially for smaller clients (Deunes 1999, 311). Due to their smaller size, these clients generally hawe weaker internal control systems, making it harder to verify the completeness of revenues (see Meuwissen and Majoor 1994, 13). In the Netherlands, the audit objective completeness of revenue recognition is considered more important than in most Anglo-Saxon countries. Consequently, due to uncertainties resulting from inadequate internal control systems the auditor may not be able to express an opinion in these cases, thus inducing him to issue a disclaimer (Metuwissen and Matjoor 1994, 16). In this situation, an inadequate control system could imply less audit work since there are less internal control measures to audit, simply because these measures are not present. This could result in a negative relationship between the issuance of a disclaimer and the number of audit hours spent on the audit (perhaps particularly so for supervisors, who are directly involved in the conduct and supervision of audit engagements).

The data for the sample used in this chapter seem to suggest an explanation in line with the above argumentation. First of all, the data show that clients receiwing a disclaimer are significantly smaller $(\mathrm{p}<0.10$; results of t-tests and Mann-Whitney tests not further reported here. Size was measured in terms of assets, nevenues, and number of employees; the three criteria contained in relevant Dutch company law - Title 9. Book 2 of the Civil Code - to distinguish between snuall, medium-sized and large companies) than clients receiving an ungualified opinion (recall that disclaimers and unqualified opinion where the only two types of opinions present in the sample), thus confirming the notion that disclaimers are usualiy issued to smaller clients.

Second, the data also show that clients receiving disclaimers have a significantly lower quality of controls than clients receiving unqualified opinions $\left(p<0.05\right.$; results of $\chi^{2}$-tests not further reported here, thus also suggesting that disclaimers are issued becausie of inadequate control systems.

Findly, the data indicate that auditors have spent relatively more time on substantive tests and relatively less time on systems tests for clients receiving disclaitners compared to clients receiving unqualified opinions ( $\mathrm{p}<0.01$; results of t-tests and Mann-Whitney tests not further reported here). This latter result might suggest that auditors spend less time on auditing the (inadequate) internal control systems of clients that receive a disclaimer. 
Taken together, these findings provide support for the negative relationship between the issuance of an other than unqualified opinion (i.e, in this case, a disclaimeat) and the number of (supervisor) hours spent on an audit engagement.

22 As indicated earlier in Section 3.3, if auditor learning occurs, the signs of the year-client indicators are positive and ordered as follows: first-year client $>$ second-year client $>$ third-year client $>$ fourthyear client (see $\mathrm{O}^{\prime}$ Keefe et al. 1994, 253).

23. An explanation for this might be the following: prior to client acceptance, auditors extensively evaluate and screen a new client (see Knechel 2001, 91). The work performed during this acceptance stage may effectively reduce the necessary effort to be expended during the planning stage. Since client-acceptance work is performed before the client is actually a client, it is possible that as a practical matter this work is not recorded in the audit firm's client records and therefore does net end up in the registration of hours. If the audit hours spent on a client are properly recorded in the client records after a company has been accepted as a client (i.e, for second-year, third-year, fourthyear, and moreyear clients), this might lead to a negative effect on audit hours.

24 That is "the first-year client indicator does not differ significantly from the second-year client indicator, from the third-year client indicator, and from the fourth-year client indicator, etcetera (results not reported here). Removal of outliers identified by robust regression (Berk 1990) did not change these findings.

25 As indicated in endnote 15 above, the results reported here are for models where the half-normal distribution was specified for the inefficiency term. As also noted, the models were also tested using the truncated-normal distribution for the inefficiency term, and results were nearly identical.

26 These tests are performed as one-sided generalized likelihood-ratio tests (Coelli et al. 1998, 191) and are reproduced in each panel.

27 This finding is corroborated by the fact that there are no differences in the intercepts, coefficient parameters, and associated levels of significance between OLS and SFA for each of the equations. Since the OLS and SFA results are identical, only the OLS results are reported in Table 3.4.

Note that this does not imply that in general this audit firm as a whole is (cost and labor) efficient in the production of its audit services. The findings presented here only indicale that relatioe to comparable audit engagements of this particular audit firm at this particular point in time, the audit engagements included in this study's sample are labor and cost efficient. As indicated earlier in Section 3.4, efficiency frontier techniques - such as SFA used here - can only determine relation but not absolute efficiency (see also Ondrich and Ruggiero 2001, 437). The efficiency of an observation (in this case, an individual audit engagement) can only be examined relative to the most efficient observation in the sample. Even though the audit engagements in the sample examined here may seem labor and cost efficient in a relative sense, it is very well possible that these engagements are inefficient when compared to engagements performed by other audit firms and/or at another point in time. Note also that deterimining absolute efficiency is rather difficult in an auditing context, since most audit decisions cannot be compared with some absolute external criterion or benchmark. This needs to be borne in mind while interpreting the results reported here. 
2. Note that the composed residuals for total audit costs, total audit hours and supporting hours follow a distribution that closely resembles the normal distribution (see the Jarque-Bera and ShaproWilk test statistics in Table 3.4; see Dufour, Farhat, Gardiol, and Khalaf (1998) for information on these tests), which explains finding no inefficiencies for these models.

As Wagstaff (1989, 668) indicates, absence of skewness (thus, a nomal distribution) is usually interpreted as absence of inefficiencies: none of the variation in the dependent variables and the residuals can be attributed to variation in inefficiency, but has to be regarded as measurement error, omitted variables, and other noise (i.e., random error). From a statistical point of view, absence of skewnes also mears that maximum likelihood estimates (i.e., SFA results) are equal to OLS estimates (Wagstaff 1989, 669)

Since the composed residuals of total audit costs, totall audit hours and supporting hours are not positively skewed but normally distributed, and since these models' OLS results are equal to their SFA results (see end note 27 ), the above interpretation also applies to these models.

The above argumentation does not apply to the models for partner, manager, supervisor, and assistant hours, since the normality tests in Table 3.4 inidicate that the composed residuals for these models are not normally distributed. Instead, the negative values for these models' third moments suggest that their composed residuals are negatively skewed (instead of the expected positive skewness should inefficiencies be present; see above). Like for normally distributed composed residuals, models with negatively skewed composed residuals have maximum likelihood (i.e., SFA) estimator that is equal to OLS for the slope vector (Waldman 1982, 277 and 279 ; adapted for cost models and for production models that require minimization, such as the models estimated in this chapter). As Carree $(2002,106)$ indicates, negative skewness has usually been considered evidence of absence of inefficiencies. This could also apply here for the models for partner, manager, supervisor, and assistant hours. Carree $(2002,102)$, however, also argues that negative skewness could indicate a negatively skewed asymmetric inefficiency distribution.

An explanation, at least a partial one, for the negative skewness of the composed residuals of the abovementioned distiggregated labor models might be found by examining the correlation between the residuals of these models. Negative correlations, suggesting substitution effects between staff levels, could explain negative skewness. Examination shows that the residuals of the models for manager and supervisor hours are significantly and negatively correlated (Pearson product-moment correlation coefficient $-0.189, p<0.05$ ), suggesting presence of substitution effects between these two neighboring staff levels. Substitution between these levels is not uncommon considering the similarity in duties for these levels. Negative correlations were also present between the residuals of partner and supervisor hours and between the residuals of supervisor and assistant hours, but these were not significant.

(For the saike of completeness, note that positive correlations were found between the residuals of partner and manager hours, between the residuals of manager and assistant hours, and between the residuals of partner and assistant hours. Only the latter correlation was significant at conventional levels (Pearson product-moment correlation coefficient $0.439, \quad \mathrm{p}<0.01$ ), suggesting a complementary elfect between these wo levels).

30 A preliminary analysis applying DEA to the data used here indicates similar differences.

1 Since in these types of analyses the true level of efficiency is not known, it is not possible to indicate which efficiency frontier technique performs better (Berger and Humphrey 1997, 179). As noted earlier in Section 3.4, each type of frontier techniques has its advantages and disadvantages. It is a matter of preference which disadvantages receite more weight and are considered more problematic.

Gontined... h 
As indicated in Section 3.4, the fact that in contrast to deterministic techniques, stochastic techniques make allowance for random error, and the fact that in contrast to nonparametric techniques, parametric techniques facilitate the conduct of conventional tests of hypotheses, have motivated the choice for a stochastic and parametric technique in this study.

32. Again, note that efficiency frontier techniques like the one used here can provide an indication of relative efficiency only. They can and do not indicate that the firm itself is (cost and labor) efficient in an absolute sense in its production of audit services.

23 As indicated in endnote 15, these results are robust to the choice between the half-normal and the truncated-normal distribution for the error term that represents inefficiency.

The robustness of the results could also be evaluated by re-performing the analyses for two subsamples: small clients and large clients. These two subsamples can be obtained by partitioning the sample by means of the median of total assets. In this case, however, this test cannot be carried out: the partitioning would result in 57 observations per subsample. These subsamples are too small to perform the test since the model includes 17 independent variables.

Is As discussed earlier, the surrogate cast measure used by Dopuch et al. (2000) differs from the measure of audit costs used in this chapter, which is considered more accurate.

35 However, take into account that the efficiency technique used in this chapter can only examine relative efficiency, not absolute efficiency (see also endnote 28). Also note that the residuals of the total audit costs and total audit hours equations were found to be normally distributted, suggesting that unexplained costs and hours are due to random disturbance rather than inefficiency effects. (see also endnote 29).

36 However, recall that the efficiency technique used in this chapter can onlly examine relatioe efficiency, not absolute efficiency. In addition, consider that the limitations of the dataset used here (subset of clients, of only one audit firm, and for only one year) do not permit generalization (see allso below in the main text).

${ }^{37} \mathrm{Or}$, of course, pooled data: data for multiple audit firms for multiple time periods.

34 As noted earlier, in the context of the audit production problem the determination of the cost and labor efficiency of audit engagements involves the minimization of both audit costs and audit lhours. The discussion below centers on the cost model, but equally applies to the production models that were estimated in this chapter.

${ }^{39}$ As indicated earlier (see endnote 15), alternative, more general distributions have been specified, such as the truncated-normal distribution, a generalization of the half-nomal distribution obtained by truncating the normal distribution from below at zero. As also indicated, the results reported in this chapter are for models with the half-nomal distribution. However, the model was also tested using the truncated-normal distribution, and the results were virtually identical to those using the half-normal distribution.

40. Note: of course this does not only apply to the cost function, but to the production functions defined in this chapter as well. 
a

48

$\therefore \quad$

:

. 


\section{CHAPTER 4}

\section{THE IMPACT OF POTENTIAL EARNINGS MANAGEMENT ON THE PRICING AND PRODUCTION OF AUDIT SERVICES}

\subsection{Introduction}

Although financiall statements have to comply with financial accounting rules, many of these rules allow companies substantial discretion in the choice of accounting methods and measurement of accounting estimates. On the one hand, prior research argues that this financial reporting discretion makes accrual-based earnings in financial statements more informative to investors than cash-based measures (see e.g. Healy and Palepu 1993, 2; Dechow 1994, 4; Subramanyam 1996, 249). On the other hand, however, a large body of literature claims that companies (may) misuse their discretion by manipulating earnings. This literature suggests a number of incentives that companies and managers may have for managing earnings, including explicit contracts, such as bonus and compensation plans (Healy 1985) and debt agreements (DeFond and Jiambalvo 1994); implicit contracts between the firm and its many stakeholders, such as dividends (Kasanen, Kinnunen, and Niskanen 1996) and general stakeholder relationships (Bowen, DuCharme, and Shores 1995); political and regulatory motivations, such as taxation (Guenther 1994) and import relief (Jones 1991); the need for external financing (Dechow, Sloan, and Sweeney 1996); and other, specific, circumstances like labor union negotiations (Liberty and Zimmerman 1986), management buyouts (DeAngelo 1986), and proxy contests (DeAngelo 1988).

Besides incentives for earnings management, prior research also proposes and tests for a number of constraints on earnings management. These include internal governance mechanisms such as audit committees (DeFond and Jiambalvo 1991), characteristics of the Board of Directors (Dechow et al. 1996), and internal controls (DeFond and Jiamballvo 1991); ownership structure (Warfield, Wild, and Wild 1995); 
prior accounting decisions (Sweeney 1994); costs imposed on the firm when earnings manipulation is revealed (Jiambalvo 1996); and the (quality of the) external audit (Becker, Defond, Jiambalvo, and Subramanyam 1998). This chapter focuses on this latter constraint.

According to Francis and Krishnan $(1999,159)$, rational auditors can respond to companies' (potential) earnings management in a number of ways. ${ }^{1}$ First of all, they may decide to report more conservatively by issuing more modified reports to firms that are more likely to have managed earnings. Second, they can screen out clients that pose a higher risk in terms of manipulation of earnings. Third, auditors can increase audit effort. Fourth, they can charge a fee premium to clients with a higher risk of potential earnings management. Finally, they can negotiate with these clients, leading to adjustments in their financiall statements. ${ }^{2}$

Although a number of studies have investigated some of these options, prior research in this area is rather scarce. This particularly applies to the third and fourth option mentioned above, i.e., increasing audit effort and charging a fee premium. This chapter focuses on these two options. The dataset used in this study (see Chapter 2, Section 2.3) offers the unique possibility to investigate the effect of potential earnings management on both audit effort and audit fees, and to study the interplay between the two options. For instance, when potential earnings management results in a higher audit fee, it is possible to examine whether this higher fee follows from more audit effort, a fee premium, or both (see Simunic and Stein 1996, 128).

Considering the recent developments involving companies such as Enron, WorldCom, Xerox, Qwest, and in a European context Lernaut and Hauspie and, very recently, Ahold, the issue of how auditors can or should deal with the risk of companies' (potential) earnings management is very timely, as not only the companies suspected of misusing financial reporting discretion are scrutinized but also these companies' auditors who should have prevented or detected and corrected for this misuse, as evidenced by the recent disintegration of Andersen.

The remainder of this chapter is organized as follows: Section 4.2 reviews relevant prior research. Section 4.3 discusses the variables and model used in this study. Section 4.4 presents the data and the results, and Section 4.5 concludes.

\subsection{Prior research}

A number of studies suggest that (the potential for) earnings management increases auditor litigation risk. For instance, Lys and Watts (1994) find that firms' total accruals are positively associated with lawsuits against auditors, and Heninger (2001) shows that abnormal income-increasing accruals increase the probability of 
auditor litigation. ${ }^{3}$ These studies argue that the extent to which reported eamings diverge from cash flows increases the risk that earnings may be misstated.

As indicated in the introduction, Francis and Krishnan $(1999,159)$ suggest five ways in which auditors can deal with this risk: (1) issuing more conservative audit reports;

(2) screening out higher-risk clients; (3) increasing auditor effort; (4) charging a fee premium; and (5) negotiating adjustments in the clients' financial statements. This section reviews prior research that has investigated these options. Since the current study concentrates on the two options charging a fee premium and increasing audit effort, prior research on audit pricing and audit production, and especially the effect of litigation risk in this respect, is also relevant. This literature was discussed in Chapter 2 (see Sections 2.2 .1 and 2.2.3).

\subsubsection{Issue more conservative audit reports}

Francis and Krishnan (1999) investigate the first option, i.e., whether a client's engagement in earnings management increases its likelihood of receiving a more conservative audit report. With respect to the latter they specifically focus on the modified audit report.4 Using various measures based on total accruals as a proxy for earnings management, and controlling for other variables associated with the issuance of modified opinions, their results show that firms with high accruals are more likely to receive a modified opinion from their auditors. ${ }^{5}$ This effect is significant for Big Six auditees only. Francis and Krishnan $(1999,157)$ interpret this latter result as consistent with Big Six auditors having greater incentives for reporting conservatism because they have greater reputation capital to protect than other auditors. In a paper evaluating the ability of several discretionary accruals models to detect earnings management, Bartov, Gul, and Tsuil (2000) find that qualified opinions are positively associated with discretionary accruals. These results confirm those of Francis and Krishnan (1999) by suggesting that earnings management increases auditors' likelihood to issue more conservative opinions." However, Bartov et al.'s (2000) results do not differ across Big Six and non-Big Six auditees.?

DeFond and Subramanyam (1999) also investigate the relationship between earnings management - proxied by a measure of discretionary accruals - and modified opinions. They investigate two alternative hypotheses: first, in accordance with Francis and Krishnan (1999), the issuance of a modified report is the auditor's response to companies' earnings management and is therefore associated with income-increasing discretionary accruals; second, a modified opinion increases litigation risk, leading the auditor to require income-decreasing discretionary accruals choices from management once a modified report is deemed appropriate. This latter hypothesis refers to the fifth option suggested by Francis and Krishnan (1999, 159): 
negotiate with clients for adjustments in the financial statements. DeFond and Subramanyam (1999) find that income-decreasing discretionary accruals are positively associated with modified audit reports, consistent with the second hypothesis. According to DeFond and Subramanyam (1999, 19), their findings complement those of Francis and Krishnan (1999): while Francis and Krishnan (1999) demonstrate that auditors are more likely to issue a modified opinion to clients with larger values of total accruals, DeFond and Subramanyam's (1999) results suggest that the issuance of such a modified report may subsequently induce the auditor to insist on income-decreasing discretionary accruals choices by the client. ${ }^{8}$

Similar to DeFond and Subramanyam (1999), Butler, Leone, and Willenborg (2002) find that companies with modified opinions have significantly negative abnormal accruals. This effect is mainly due to firms with "troubled-company" opinions (e.g. going concern opinions), and does not differ across auditor type. Butler et al. (2002, 22) argue that their results are inconsistent with earnings management and auditor conservatism rationales, but seem to be due to companies' liquidity-erhancing strategies. ${ }^{9}$ Thus, the results do not seem to conform to either the first or the fifth option as suggested by Francis and Krishnan $(1999,159)$.

Finally, in a study examining the role of both sell-side analysts and auditors in informing investors about high-accrual firms, Bradshaw, Richardson, and Sloan (2001) also investigate the relationship between earnings management and auditor reporting. To their surprise, and inconsistent with the findings of Francis and Krishnan (1999) and Bartov et al. (2000), they find that firms with clean opinions have higher levels of accruals than firms with modified opinions. According to the authors, this result is consistent with the claim that the current audit process is ineffective in warning investors about firms' earnings management (Bradshaw et al. $2001,47) .1^{10}$

Generalizing is difficult without a large body of literature on this topic, but it might be safe to say that the results of prior research are rather mixed." Although some studies seem to suggest that more earnings management induces the auditor to report more conservatively (see Francis and Krishnan 1999, Bartov et al. 2000), another finds that, unexpectedly, more earnings management leads to more clean opinions (Bradshaw et al. 2001). Furthermore, two studies find that modified opinions are associated with less earnings management, one explaining this as the auditor requiring income-decreasing accruals choices from management in response to higher litigation risk due to the issuance of a modified opinion (DeFond and Subramanyam 1999, 4), and the other as an effect due to troubled companies (Butler et al. 2002, 18). 


\subsubsection{Sicreen out high-risk clients}

Screening out high-risk clients may concern either new or continuing audit clients (Krishnan and Krishnan 1997, 542). The decision to screen out new audit clients is also known as the client-acceptance decision (see Knechel 2001, 86). The decision to screen out continuing audit clients refers to the client-retention decision, or the auditor-resignation decision (Krishnan and Krishnan 1997, 540).

Evidence on auditors screening out clients due to higher risk associated with potential earnings management is rather scanty. Until now no study has directly investigated the effect of earnings management on the client-acceptance decision, the decision to screen out new audit clients. Only three papers have studied the effect of potential earnings management on auditor changes. Auditor changes may be initiated by either the auditor resigning from an engagement, or the client dismissing the auditor (Krishnan and Krishnan 1997, 540). The decision to resign refers to decision to screen out continuing audit clients.

In addition to examining the relationship between earnings management and modified audit opinions (see Section 4.2.1 above), Bradshaw et al. (2001) also study the effect of accruals on auditor changes, claiming that auditors are likely to resign or be dismissed before they actually issue a modified opinion. Contrary to their expectations; they find that higher levels of accruals are associated with a lower frequency of auditor changes. According to Bradshaw et al. (2001, 70) this implies that auditors apparently do not resign from audit engagements with a high potential for earnings management and the risk of loss of reputation and lawsuits that may ensue from this potential, but are more likely to continue serving these clients.

DeFond and Subramanyam (1998) also investigate the relationship between potential earnings management (using a measure of discretionary accruals) and auditor changes. They find that discretionary accruals are significantly incomedecreasing in the last year before the change, and generally insignificant in the first year after the change. Furthermore, firms with the highest expected litigation risk have larger magnitudes of negative discretionary accruals. DeFond and Subramanyam $(1998,65)$ explain these results as indicating that, motivated by litigation risk concerns, the previous auditor required income-decreasing accruals choices from the client, which in turn induced management to dismiss the auditor, hoping to find a more lenient successor auditor. Thus, according to the authors, in this case it is not the auditor who resigns, but the client that dismisses.

Krishnan and Krishnan (1997) argue that auditors can offset their litigation risk by adjusting their client portfolios. Auditors can become more careful in accepting new clients, as well as in retaining continuing clients. Krishnan and Krishnan (1997) study the latter option by comparing auditor resignations to auditor dismissals on variables that are expected to increase the probability of litigation. One of these variables is a proxy measuring accruals intensity. In general, they find that auditors 
are more likelly to resign than be dismissed due to litigation concems. However, contrary to expectations, the accruals measure is negatively related to resignations. The authors attempt to explain this by indicating that accruals may also reflect financial distress (Krishnan and Krishnan 1997, 553).

A number of other papers study the effect of (litigation) risk on the decision to screen out clients. As stated at the beginning of this section, a number of papers argue that litigation risk may be associated with earnings management. In that respect the studies discussed below may also be relevant.

Johnstone (2000) investigates how auditors evaluate and adapt to risks in the client-acceptance decision (i.e., the decision to screen out new audit clients). According to Johnstone $(2000,3-4)$ the relevant risks consist of the client's business risk, audit risk, and the auditor's business risk. The latter risk includes the risk of potential litigation (Palmrose 1987). Results from an experiment among Big Five audit partners show that auditors adapt to these risks by screening out high-risk clients. They do not seem to adapt to higher risk by using what Johnstone (2000) calls proactive strategies (such as adjusting the audit fee or audit planning).

Francis and Reynolds (2001) document evidence that Big Six audit firms have used risk-based sereening strategies in the period 1976-1997. ${ }^{12}$ Using criteria that reflect the auditor's business risk - which, as stated above, includes litigation risk they find that Big Six auditees generally pose less auditor business risk than non-Big Six auditees. However, results do not show that this strategy has become more prevalent in the period after 1990, contradicting claims by the Big Six firms that riskbased client screening has increased in this period.

Again, generalization is difficult without ample prior research, but it seems that most prior research suggests auditors screen out high-risk clients ${ }_{t}^{13}$ either when deciding to accept new clients (see Johnstone 2000), to retain continuing clients (Bradshaw et al. 2001; Krishnan and Krishnan 1997), or both (Francis and Reynolds 2001).

\subsubsection{Increase audit effort}

Until now no study has directly investigated the effect of potential earnings management on auditor effort. As indicated in the discussion of prior pricing and production research in Chapter 2 (see Section 2.2.3), fee and production models have included some (litigation or other) risk measures, but each of these risk measures represents a more or less composite measure of risk since they also capture other risk aspects besides the risk associated with potential earnings management (see Johnstone 2000, 4). Therefore, these risk indicators might not be considered to specifically reflect the risk associated with potential earnings management. 
Some of the specific risk measures included in prior fee and production models are so-called asset composition measures - mainly the levels of inventories and receivables relative to total assets. As argued later on in Section 4.3 .3$, prior earnings management research has used specific components of accruals as proxies for earnings management. However, prior research has also argued that composite earnings management measures provide a more complete picture of (potential) earnings management than do measures that focus on specific accruals components, as managers can be expected to use several accruals components to manage earnings (Jones 1991, 194). Also, composite measures rather than measures based on specific components are preferable when there are no a-priori arguments for expecting management of a particular balance sheet or income statement account. Furthermore, measures of (potential) earnings management based on accruals generally refer to changes in rather than levels of (particular components of) accruals.

\subsubsection{Charge a fee premium}

As indicated in the previous section, like audit production models, prior fee models have included some - litigation or other - risk measures (including asset composition measures), ${ }^{14}$ but prior research using (direct and composite) measures of potential earnings management is scarce. In fact, until now only Gul, Tsui, and Chen (1998) have directly investigated the effect of potential earnings management on audit fees. Using data on public Hong Kong companies and employing a discretionary accruals measure as a proxy for potential earnings management, their results show that, as expected, this measure has a significant positive effect on audit fees. 15 The authors assume that this finding is due to the effect of potential earnings management on auditor effort being passed on to the client through fees (Gul et al. $1998,5)$. However, since they do not also study the effect of potential earnings management on auditor effort, it is hard to say whether the positive effect of their earnings management proxy on fees indeed reflects more auditor effort being passed on to the client, and nothing more (i.e., potential earnings management affects both fees and effort to the same extent); or whether this positive effect is due to a fee premium (i.e., potential earnings management either has an effect on fees but not on effort, or has an effect on both fees and effort, but the effect on fees is larger than that on effort). As indicated earlier, the data used in this study (see Chapter 2, Section 2.3) do allow to distinguish between these competing explanations, should a positive effect on fees be present. 


\subsubsection{Negotinate adjustments}

The fifth and last option stuggested by Francis and Krishnan (1999, 159) concerns the possibility to negotiate with clients that pose a high earnings management risk, leading to adjustments in these dients financial statements. Research in this area is scarce as well. There are a number of studies that provide indirect evidence on earings management and negotiation of adjustments. Firstly, based on a survey requesting audit partners to describe a real negotiation situation, Gibbins, Salterio, and Webb (2001) report that issues subject to negotiation primarily relate to income measurement and balance sheet valuation. Although the study does not specifically focus on eamings management, its results do suggest that issues related to earnings management are considered in auditor-client negotiations.

Secondly, DeFond and Jiambalvo (1993) study factors related to client-auditor disagreements preceding auditor changes. ${ }^{16}$ Disclosure of disagreements that occur prior to auditor changes is required by the Securities and Exchange Commission. The majority of these reported disagreements relate to auditors objecting to management's choice of income-increasing accounting methods. Comparing clients that changed auditor and reported a disagreement prior to the auditor change to clients that changed auditor but did not report a disagreement, DeFond and Jambalvo (1993) find that clients reporting disagreements are more likely to have violated debt covenants; have higher leverage; have experienced an earnings decline; and are audited by Big Eight auditors. The first three factors relate to motivations for managers to choose (income-increasing) accounting methods that their auditors do not agree with. The last factor relates to auditor independence: Big Eight auditors are expected to be more independent, and will therefore be more likely to oppose questionable accounting method choices. Even though the study does not explicitly consider the negotiation of adjustments in the context of earnings management, its results with respect to disagreements at least provide a suggestion as to which accounting method issues were subject of negotiation.

Thirdly, based on a meta-analysis of nine data sets used in prior audit-related adjustment studies Kinney and Martin (1994, 151) conclude that overall, the adjustments have a downward effect on recorded earnings and net assets. The mean aggregate adjustments are between two to eight times a material amount. These results seem to imply that the audit reduces a substantial positive bias in earnings and assets, consistent with adjustments of financial statements being a rational response to risks related to income-increasing earnings management.

Evidence on auditor-client negotiations and/or adjustments more explicitly linked to earnings management comes from two studies. One study has already been discussed in Section 4.2.1. In examining the relationship between eamings management and auditor reporting, DeFond and Subramanyam (1999) find that income-decreasing accruals are positively related to the issuance of modified audit 
reports. They interpret these findings as consistent with auditors requiring incomedecreasing choices from management subsequent to the issuance of modified opinions, as these opinions are expected to increase auditor litigation risk (DeFond and Subramanyam 1999, 6). ${ }^{17}$

A second study related to negotiations in the context of earnings management is Nelson, Elliott, and Tarpley (2002). By means of a survey among audit partners and audit managers from a Big Five audit firm they elicited these auditors experiences with companies attempting to manage earnings. The results show that auditors are less likely to adjust earnings management attempts (i.e., these attempts become earnings management in the financial statements) when it decreases current-year income; is governed by an imprecise financial accounting standard; concerns a transaction that is structured to comply with a financial accounting standard; is considered immaterial; and finally, relates to a large client. Auditors require adjustment of less than half of the earnings management attempts. ${ }^{18}$

Summarizing, although prior research directly linking earnings management to negotiation and adjustments in financial statements is scarce, results of related research suggest that auditors do negotiate with their clients on issues related to earnings management $t_{r}$ and that auditors require income-decreasing adjustments in the financial statements.

\subsection{Variables and model}

Based on the prior literature, a model was constructed to explain the effect of potential earnings management on audit fees, audit effort and the interaction between the two. The current section discusses the model and its variables.

\subsubsection{Dependent variables}

To investigate the effect of potential earnings management on audit fees, audit effort and the interplay between fees and effort, three types of dependent variables are used.

Obviously, to study the effect on audit fees the dependent variable is total audit fee, the actual audit fee paid to the audit firm by the client.

To study the effect of potential earnings management on audit effort, the actual number of audit hours spent on each engagement is used. More specifically, the total number of hours spent on an engagement, as well as hours per engagement disaggregated by staff level are used. Like in Chapter 3 , the following staff levels are distinguished: (1) partner; (2) manager; (3) supervisor; (4) assistant; (5) supporting activities. As indicated in that same chapter (see Section 3.3), the nature of activities 
performed by the latter category differs from the other four, and therefore the model may be less suited for this category than for all other categories. Like in Chapter 3, however, this category is included in the analysis to provide a complete picture of the audit production process. ${ }^{19}$

Like in most prior audit fee and production studies, a logarifhmic transformation of both audit fees and audit hours is used to reduce heteroscedasticity.

To study the effect of potential earnings management on the interaction between audit fees and audit effort, a measure devised by Simunic and Stein $(1996,131)$ - and also used by Dopuch, Gupta, Simunic, and Stein (2000) - is used, which they call realization rate. They define this rate as the ratio of actual to standard total audit fee. The actual total audit fee is the actual fee paid by the client (see the audit fee measure above), and standard total audit fee is the fee charged to the client if actual audit labor hours were billed at the firm's standard billing rates (see also Chapter 3). Thus, this standard audit fee is a weighted sum of all audit hours spent on an engagement, where the weights are the standard billing rates per staff level. In the current study, the same numerator as Simunic and Stein (1996) and Dopuch et al. (2000) is used. The denominator, however, differs somewhat from theirs. As stated, both Simunic and Stein (1996) and Dopuch et al. (2000) use standard billing rates per staff level in weighing the audit hours spent on an engagement by each staff level. These billing rates differ from staff level to staff level (e.g., partner hours are obviously charged at a higher price than assistant hours), but per staff leoel these rates are equal over all staff members (i.e., all staff members for a certain staff level are charged at the same standard rate). The dataset used in this study also provides information on hourly rates (see also Chapter 2, Section 2.3). However, these rates are not only differentiated per staff level, as in Simunic and Stein (1996) and in Dopuch et al. (2000), but also per staff member for each staff level (see also Chapter 3, Section 3.3). Using these differentiated rates in the denominator of the realization rate would not allow to determine the effect of potential earnings management on the interaction of fees and hours. When both hours and rates can differ from staff member to stalf member (and thus from engagement to engagement), it is not possible to indicate whether the effect of potential earnings management on the realization rate is either due to an effect on hours or to an effect on fees (or on both, or on neither), as in such cases a change in the denominator could be due to a change in hours, a change in rates, or both. The confounding effect of potential changes in staff rates is removed here by using - per staff level - the average of the differentiated rates per staff member. 2021 Thus, the realization rate measure is computed here as the ratio between audit fees and weighted total audit hours, where the weights are the average hourly rates per staff level. ${ }^{22}$ 


\subsubsection{Independent variables from prior audit fee and production studies}

The selection of variables to be included in the models is based on the fee and production studies discussed in Chapter 2 and concerns factors related to client size, client complexity, client asset composition, client risk and financial distress, quality of client internal controls, auditor tenure, and the auditor's provision of nonaudit services. The specific variables used are the same as those used in Chapter 3 and are shown in Table 4.1 below.

The expected signs for audit fees and unweighted and weighted audit hours are based on prior fee and production research and were explained in Chapter 3, Section 3.3. The expected signs for the realization rate are explained below.

Based on the suggestion (e.g. by Simunic and Stein 1990, 336; 1996, 128) that auditors may adjust fees for differences in their business risk, the realization rate might be expected to be positively related to risk indicators. Starting from this premise, foreign proportion of assets, client leverage, the ratio of receivables and inventories to total assets, client inherent risk, client loss in last two years, and listed (versus unlisted) client company have an expected positive sign, and the risk indicators client profit margin and client control quality have an expected negative sign. For audit opinion type no sign is hypothesized. As indicated earlier, reporting more conservatively is a way for auditors to deal with increased risk. So are increasing audit effort and charging a fee premium. Although the higher risk associated with the issuance of an other than unqualified opinion may lead to both higher fees and more audit effort (for an explanation, see Chapter 3, Section 3.3), this does not imply that it will also lead to a higher realization rate (i.e., a fee premium). The higher risk may have required the auditor to spend more effort, and this effort may have been passed on to the clients by means of higher fees. However, it is unclear whether this risk should be more than passed to the client by means of a fee premium, when this risk has already been dealt with by issuing an other than qualified opinion. Therefore, no sign is hypothesized for audit opinion type.

The hypothesized signs for the auditor tenure indicators are negative, based on evidence from a number of audit fee studies that suggest auditors engage in price cutting (see Chapter 2 for a number of these studies). ${ }^{23}$

Client size may be hypothesized to be positively related to the realization rate, based on the expectation that audit firms have relatively greater bargaining power with larger clients (see Dopuch et al. 2000, 21). This may be due to a higher valuation of the auditor's services by larger clients, the more limited supply of audit firms for larger clients, or both. Alternatively, a larger client represents a greater economic interest to the audit firm, which, as DeAngelo $(1981,117)$ argues, may decrease the auditor's independence with respect to this client. Effectively, this increases the client's (compared to the auditor's) bargaining power, implying a negative relationship between the realization rate and client size. Since there is no a priori 
Taible 1

Variables included in models based on prior audit fee and producturom research

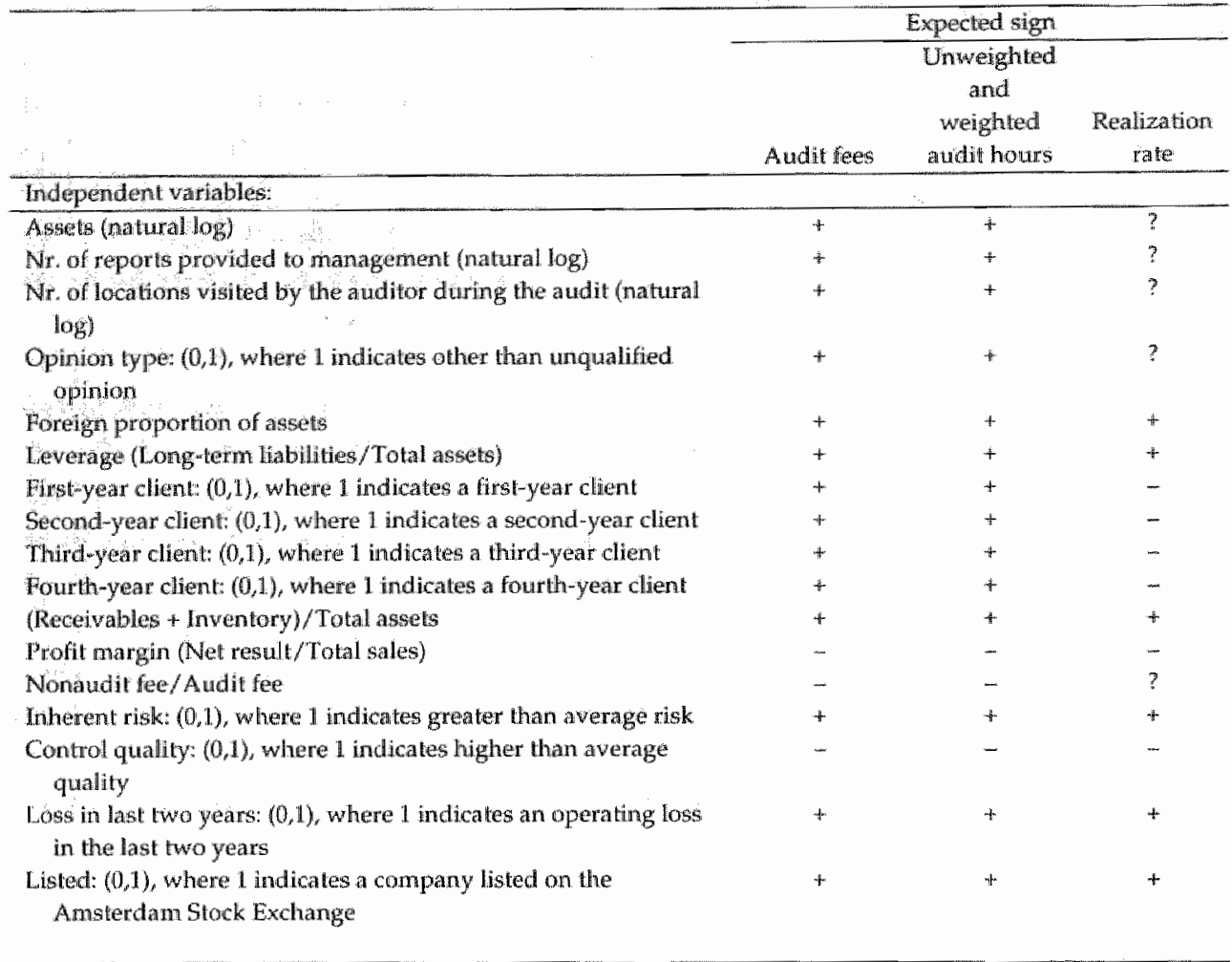

reason to expect one effect to dominate the other, no sign is hypothesized for client size.

For nonaudit services no sign is hypothesized either. On the one hand, just like for client size, the audit firm's bargaining power may increase with the provision of nonaudit services to their clients, implying an expected positive sign. On the other hand, prior research on nonaudit services argues that the audit may serve as a lossleader for nonatidit services (see e.g. Hillison and Kennelley 1988, 33; Firth 1997, 512), implying an expected negative sign. Again, since theory does not suggest one effect to dominate the other, no sign is hypothesized for nonaudit services.

Finally, no signs are hypothesized for number of reports provided to management and number of locations visited by the auditor during the audit. Although these measures are expected and have been found to be positively associated with both audit fees and audit hours, it is not clear how this will affect the ratio of audit fees to (weighted) audit hours, as it depends on the extent to which the effect of these measures on audit hours is passed on to the clients through the fees. If 
the entire effect is passed on to the clients through fees, there may very well be no effect on the ratio of fees to hours at all. However, if the effect is passed on only partially, the effect on the realization rate may be negative. Since there is no a priori reason to expect one effect to dominate the other, no sign is hypothesized for these complexity measures.

\subsubsection{A measure for potential earnings management}

Prior earnings management research has used a number of different measures to proxy for earnings management. Most studies have used aggregate accruals models (McNichols 2000, 319). These range from simple models that consider (the change in) total accruals in its entirety as discretionary (see e.g. Healy 1985; DeAngelo 1986) to the more complicated models that attempt to divide total accruals into discretionary and nondiscretionary parts (see e.g. Jones 1991; Dechow and Sloan 1991; DeFond and Jiambalvo 1994; Dechow, Sloan, and Sweeney 1995). A number of studies have evaluated the specification and power of these models in detecting earnings management (see Dechow et al. 1995; Thomas and Zhang 2000; Bartov et al. 2000). In general, the Jones (1991) model and the Jones model as modified by Dechow et al. (1995) appear to outperform the other models, either in the time-series version or in the cross-sectional version (see DeFond and Jiambalvo 1994). However, at the same time it is argued that the absolute performance of these models is still not strong, and that they generate low power tests for earnings management of economically plausible magnitudes (Dechow et al. 1995, 194; Thomas and Zhang 2000, 372).

As an alternative, other studies have modeled specific components of discretionary accruals, mostly in (one or more) particular industry settings (see e.g. McNichols and Wilson 1988; Petroni 1992; Gaver and Paterson 2001). Using institutional knowledge and GAAP to specify the nondiscretionary part of an accrual, these studies separate this specific accrual into its discretionary and its nondiscretionary components. Although it is argued that this approach may result in more accurate proxies of earnings management, the aggregate accruals models are believed to generate more encompassing measures of earnings management, as managers can be expected to use several accruals components to manage earnings (Jones 1991, 194; see also Section 4.2.3).

Studies have also examined (changes in) the choice of accounting methods to infer earnings management (see e.g. Healy 1985; Sweeney 1994; Bowen et al. 1995). According to Healy $(1985,103)$, changing accounting procedures may be a less suitable instrument to manage earnings than using accruals. First, such changes are inherently more visible than accruals manipulation since these have to be disclosed in the financial statements. Second, companies cannot change accounting methods too often due to the consistency requirement (Burilovich and Kattelus 1997, 10; Scott 
2000, 357). Managers may therefore have greater flexibility to change accruals rather than accounting methods. This could explain why Healy (1985) finds that in response to bonus plan incentives earnings were managed by means of accruals but not by means of policy changes. These findings could imply that changes in accounting method choices are a less suitable proxy for earnings management.

Finally, a number of studies have examined the statistical distribution of reported earnings for evidence of earnings management (see e.g. Burgstahler and Dichev 1997; Degeorge, Patel, and Zeckhauser 1999). These studies investigate the behavior of earnings around certain benchmarks for discontinuity in the frequency distribution of observations above and below these thresholds. In general, the results show a discontinuous distribution of earnings around zero: managers seem to avoid reporting losses and earnings declines.

In accordance with the majority of prior research, in this chapter (potential) earnings management is proxied by means of an aggregate accruals measure. Measures of aggregate accruals are comprehensive in that they capture the effect of all accounting decisions (i.e., (changes in) the choice of accounting methods, as well as estimations of accruals (Watts and Zimmerman 1990, 138; Becker et al. 1998, 10)), as well as operating, financing and investment choices as they affect accruals (Jiambalvo 1996, 40). A measure based on total rather than discretionary accruals is used. Due to data limitations, the data do not allow the use of discretionary accruals models, models of specific components of discretionary accruals, accounting method choices, or statistical properties of earnings as measures of earnings management. However, this is not considered a limitation to the study. Each measure of (potential) earnings management has its pros and cons, and as indicated above, many of the other proxies for earnings management suffer from limitations as much as the measure used here may do. For instance, some researchers argue that total accruals measures do not take into account the fact that some changes in total accruals are due to changes in a company's economic condition rather than to accruals manipulation (see e.g. Dechow et al. 1995, 198; Heninger 2001, 112). Thus, they prefer the use of discretionary accruals models, which, as discussed above, separate total accruals into its discretionary component (manipulation) and nondiscretionary component (changes in economic condition). However, the appropriateness of discretionary accruals models as proxies for earnings management critically depends on the ability of the model to properly separate total accruals into its discretionary and nondiscretionary components (Guay, Kothari, and Watts 1996, 84; Subramanyam 1996, 252). Therefore, as a counterargument, one could also state that measures based on total (rather than discretionary) accruals do not suffer from errors of a misspecified discretionary accruals model (see Callaway Dee, Lulseged, and Nowlin, 2002, 25). ${ }^{24}$

In this chapter total accruals are defined as net income minus cash flow from operations, and operating cash flows are calculated as follows: working capital from 
operations minus changes in accounts receivable, minus changes in inventories, minus changes in other current assets, plus changes in accounts payable, plus changes in tax payable, plus changes in other current liabilities (see Francis and Krishnan 1999, 160). Since Francis and Krishnan $(1999,144)$ argue that short-term accruals represent more uncertainty for auditors than total accruals, the tests are also performed with short-term accruals. Short-term accruals are accruals generated only from working capital accounts, excluding long-term charges such as depreciation. Following Francis, Maydew, and Sparks $(1999,22)$, short-term accruals are computed as follows: the change in [current assets minus cash] minus the change in [current liabilities minus the current portion due of long-term debt]. The accruals measures are scaled by sales to control for firm-specific income statement effects. ${ }^{25}$

The two accruals measures, total accruals and short-term accruals, are tested both on an absolute and a signed basis. According to Warfield et al. $(1995,78)$, when there is no explicit prediction with respect to the direction of the (possible) manipulation, earnings management is best proxied by the absolute value of accruals, as it represents the combined effect of income-increasing and incomedecreasing earnings management. Alternatively, based on auditor litigation research it can be argued that auditors are more concerned with income-increasing earnings management than with income-decreasing earnings management (see e.g. St.Pierre and Anderson 1984, 257; Lys and Watts 1994, 70), suggesting the use of a signed as opposed to an absolute accruals measure. This study tests for both.

The hypothesized signs for the earnings management measures for audit fees, audit hours and the realization rate are shown in Table 4.2 below.

For both audit fees and (aggregated as well as disaggregated) audit hours, the sign for the accruals measures is expected to be positive. After all, as Francis and Krishnan $(1999,159)$ indicate, auditors can respond to increased risk due to (potential) earnings management by charging a fee premium or by increasing audit effort.

As indicated earlier (see Section 4.3.2), Simunic and Stein (1990, 336; 1996, 128) argue that auditors may adjust their fees for differences in their business risk, suggesting a positive sign for the measures of (potential) earnings management in the realization rate model. ${ }^{26}$ However, the measures for earnings management are the experimental variables in this study, and since no prior research has studied the effect of (potential) earnings management on the interaction between fees and hours (i.e., the realization rate), it is an empirical question as to how it will affect the realization rate. If the entire effect of potential earnings management is passed on to the client through the fees (i.e., both (weighted and unweighted) hours and fees are affected to the same extent), then there may very well be no effect on the realization rate at all. ${ }^{27}$ However, if the effect is passed on only partially (i.e., both hours and fees are affected, but hours are affected more than fees: a fee discount), then the effect on the realization rate may be negative..$^{28}$ Alternatively, if the effect is more 
Table 42

Measures of potential earnings management

\begin{tabular}{|c|c|c|c|}
\hline \multirow{3}{*}{ s. } & \multicolumn{3}{|c|}{ Expected sign } \\
\hline & \multicolumn{3}{|c|}{$\begin{array}{l}\text { Unweighted and } \\
\text { wreighted audit }\end{array}$} \\
\hline & Audit fees & hours & Realization rate \\
\hline \multicolumn{4}{|l|}{ Independent wariables: } \\
\hline Signed total accruals & + & + & $?$ \\
\hline Signed short-lerm accruals & + & + & ? \\
\hline Absolute total accruals & + & H & $?$ \\
\hline Absolute shortierm accruals & + & 4 & $?$ \\
\hline
\end{tabular}

Signed total accruals are computed ats net income minus cash flow from operations. Cash flow from operations is working capital from operations minus changes in accounts receivable, minus changers in inventories, minus changes in other current assets, plus changes in accounts payable, plus changes in tax payable, plus changes in other current liabilities. Stgned total accruals are scaled by sales.

Signed short-term accruals are computed as the change in [current assets minus cash], minus the change in (current liabilitities minus the current portion due of long-term debt). Signed short-term accruals are scaled by saless.

Absolutie total accruals is the absolute value of signed total accruals, scaled by sales.

Absolute shortuterm accruals is the absolute value of signed shorttierm accruals, scaled by sales.

than passed on to the clients (i.e, both hours and fees are affected, but fees are affected more than hours: a fee premium), then the effect on the realization rate may be positive. ${ }^{29}$ Since there is no a priori reason to expect one effect to dominate the others, no sign is hypothesized for the effect of the measures of potential earnings management on the realization rate.

\subsubsection{Recapitulation}

To study the effect of potential earnings management on audit fees and audit effort, and the interplay between the two, three models are constructed. The independent variables are the same for all three models and include variables from prior fee and production research (see Table 4.1 above), as well as a measure for (potential) earnings management. Two measures of earnings management are tested: total accruals and short-term accruals. As indicated above, these measures are tested both on an absolute and a signed basis (see Table 4.2).

To investigate the effect of potential earnings management on audit fees, the dependent variable is (the natural $\log$ of) audit fees. To see whether potential earnings management leads to increased audit effort, the dependent variables are 
(the natural log of) audit hours, on an aggregated basis as well as disaggregated by staff level. To study the effect of potential earnings management on the interplay between fees and hours (i.e., does a potential higher fee follow from more audit effort, a fee premium, or both?), the dependent variable is the so-called realization rate. This realization rate is defined as the ratio of audit fees to weighted audit hours, where the weights are the average hourly rates per staff level (see Section 4.3.1).

The model specifications are based on those in previous fee and production research. For audit fees, the model can be expressed as follows:

$$
\ln f_{i}=\beta_{0}+\beta_{1} \ln A_{i}+\beta_{2} \ln R_{i}+\beta_{3} \ln L_{i}+\sum \beta_{k} \gamma_{i k}+\varepsilon_{i}
$$

In this formulation, $f_{i}$ represents the actual audit fee paid to the audit firm by the client, $A_{i}$ indicates client size, $R_{i}$ the number of reports provided to the management by the audlitor, $L_{i}$ the number of client locations visited during the audit, and $y_{i k}$ represents all other client characteristics as shown in Table 4.1 , as well as a measure for potential earnings management (see Table 4.2). The hypothesized signs for the variables were discussed above and shown in Tables 4.1 and 4.2 .

For audit effort the model is:

$$
\ln h_{i j}=\beta_{j 0}+\beta_{j 1} \ln A_{i}+\beta_{j 2} \ln R_{i}+\beta_{j 3} \ln L_{i}+\sum \beta_{j k} \gamma_{i j}+\varepsilon_{i}
$$

In this formulation, $h_{i j}$ represents the actual number of audit hours spent on an audit by the jth staff level, or unweighted total audit hours, or weighted total audit hours, and all other variables are defined as above. Again, the hypothesized signs for the variables were discussed above and depicted in Tables 4.1 and 4.2.

Finally, for the realization rate the model is:

$$
r_{i}=\beta_{0}+\beta_{1} \ln A_{i}+\beta_{2} \ln R_{i}+\beta_{3} \ln L_{i}+\sum \beta_{k} \gamma_{i k}+\varepsilon_{i}
$$

Here, $r_{i}$ represents the realization rate, defined as the ratio between audit fees and weighted audit hours, and all other variables are defined as above. Again, the hypothesized signs for the variables were discussed above and shown in Tables 4.1 and 4.2 .

Like in Chapter 3 (see Section 3.3), a fixed audit quality level is assumed here. This implies that any differences in audit fees, audit effort, or the realization rate across engagements are not associated with quality differences. 


\subsection{Data and results}

This section reports the results for the models developed in Section 4.3. First, the data and some descriptive statistics are discussed. Then the results for the models excluding measures of potential earnings management are presented. Finally, results are reported for the models including proxies for potential earnings management.

\subsubsection{Data and descriptives}

Table 4.3 below presents the descriptive statistics for the dependent variables and client and engagement characteristics (excluding measures of potential earnings management) for the 114 observations that are used in the analyses. These are the same 114 observations that were used in the analyses in Chapter 3. A discussion of the descriptives for the independent variables and the hours variables was provided in Section 3.5.1 of that chapter. In addition, the descriptives for the realization rate here show that on average the hours spent on an engagement are more than passed on to the client through the fees, suggesting a small fee premium..$^{30}$

For the same 114 observations, Table 4.4 below shows the descriptive statistics for the accruals measures discussed in Section 4.3.3. Similar to the other independent variables shown in Table 4.3, the accruals measures cover quite a range. Furthermore, the means and medians of both signed measures are slightly negative. This finding is in line with prior research (see e.g. Subramanyam 1996; Thomas and Zhang 2000).

\subsubsection{Models excluding measures of potential earnings management}

Table 4.5 below presents the OLS results for the models excluding measures of potential earnings management. Note that for (unweighted) total audit hours and disaggregated audit hours these are the same results as reported in Table 3.3 in the previous chapter, since these same models were also estimated in that chapter. Thus, a number of the remarks made below were discussed in Chapter 3 as well (see Section 3.5.2).

Examining pairwise correlations among the independent variables and varianceinflation factors (Gujarati 1995, 328) suggests that multicollinearity is not a problem. Application of Breusch-Pagan tests (Greene 2000, 509-510) indicates presence of heteroscedasticity for all models tested except for the manager and supporting hours. Therefore, the t-ratios for the models concerned are computed using White's heteroscedasticity-consistent covariance matrix estimation method (Greene 2000. $463)^{31}$ 
Table 43

Descriptive statistics for audit fees, unweighthed total andit howrs, weightied lotal audit hours, disaggregated (unweighted) audit hours, realization rate and client and engagement characteristics excluting accruals measures for 114 fimancial statement audits

\begin{tabular}{|c|c|c|c|c|c|}
\hline & Mean & St. dev. & Medían & Minimum & Maximanm \\
\hline \multicolumn{6}{|l|}{ Conumpus wariables } \\
\hline Andit fees (in NLG) & $84,544.63$ & $136,917.30$ & 54,000000 & 11,50000 & $1,249,000,00$ \\
\hline Unweighted total audit hour & 477.24 & 631.10 & 346.38 & 79.00 & $5,388.00$ \\
\hline $\begin{array}{l}\text { Weighted to tal andit hours (in } \\
\text { NLG) }\end{array}$ & $83 ; 224.49$ & $127,940.80$ & $51,080.71$ & $13,172,51$ & $1,140,1105.00$ \\
\hline Parmer hours & 22.40 & 35.21 & 11.50 & 1.00 & 205.00 \\
\hline Mannger hours & 56.44 & 132.93 & 27.00 & 200 & $1,161,00$ \\
\hline Superyisor hours & 134.31 & 256.48 & 86.00 & 1.00 & $2,635.00$ \\
\hline Assistant hours & 256.30 & 279.11 & 198.00 & 28.50 & $2,601.00$ \\
\hline Supporting hours & 1279 & 20.45 & 6.00 & 1.00 & 149.00 \\
\hline Realization ratte & 1.02 & 0.19 & 11,02 & 0.43 & 1,69 \\
\hline Assets (in NLG 000's) & $190,000,00$ & 792,000000 & $32,800.00$ & $4,633.29$ & $6,870,000.00$ \\
\hline Nr. of reports & 1.99 & 1.61 & 2.00 & 1.00 & 12.00 \\
\hline Nr: of locations & 200 & 2.65 & 4.00 & 1.00 & 2500 \\
\hline Foreign proportion of assets & 0.04 & 0.15 & 0.00 & 0.00 & 1.00 \\
\hline Leverage & 0.12 & 0.17 & 0.03 & 0.00 & 0.82 \\
\hline $\begin{array}{l}\text { (Receivablles + Inventory)/ Total } \\
\text { assets }\end{array}$ & 0.56 & 0.26 & 0.50 & 0.04 & 1.91 \\
\hline Protit margin & 0.04 & 0,08 & 0.03 & -0.33 & $0.5 \|$ \\
\hline Nonaudit fee / Audit tee & 0.46 & 0.91 & 0.16 & 0.00 & 6.20 \\
\hline \multicolumn{6}{|l|}{ Caluequical warinbles } \\
\hline Opinion type & 0.05 & 0.22 & 0.00 & 0.00 & 1.00 \\
\hline First-year client & 0.02 & 0.13 & 0.00 & 0,00 & 1.00 \\
\hline Second-year client & 0.04 & 0.21 & 0.00 & $0: 00$ & 1.00 \\
\hline Thid-year client & 0.05 & 0.22 & 0.00 & $0: 00$ & 1.00 \\
\hline Pourth-year dient & 0.04 & 0.21 & 0.00 & 000 & 1.00 \\
\hline Inlwerent rissk & 0.11 & 0.32 & 0.00 & 0.00 & 1.00 \\
\hline Control quality & 0.61 & 049 & 1.00 & 0.00 & 1.00 \\
\hline Loss in last wo years & 0.11 & 0.31 & 0.00 & 0.00 & 1.60 \\
\hline Luisted & 0.18 & 0.38 & 0.00 & 0.00 & 1.00 \\
\hline
\end{tabular}

"In a number of cases cash had a negative sign, causing the ratio (Receivables + inventory)/Total assets to exceed onve.

Note: for definitions of the variables see Table 4.1 and Sections 4.3 .1 and 4.3.2.

Except for supporting activities, all models are significant at the 0.01 level. Keeping in mind the divergent nature of these supporting activities, this result does not come as a surprise. As shown by its adjusted $\mathbb{R}^{2}$, the model for supporting activities also has the lowest explanatory power. All other models have an adjusted $\mathbf{R}^{2}$ well inside the range reported by prior studies (see Chapter 2). However, similar to the analyses in Chapter 3, when focusing on effort (hours) models it is striking that the explanatory power of the models for (unweighted and weighted) total audit hours is 
Table 4.4

Descriptiwe statigtics for accruals measures for 114 financial statement audits

\begin{tabular}{lrrrrr}
\hline & Mean & St. dew. & Median & Minimam & Maximum \\
\hline Signed total accrtals & -0.0642 & 0.1865 & -0.0418 & -0.7899 & 0.6234 \\
Signed shortterm accruals & -0.0052 & 0.1008 & -0.0038 & -0.4724 & 0.5194 \\
Absolute total accruals & 0.1322 & 0.1459 & 0.0688 & 0.0015 & 0.7899 \\
Absolute short-term accruals & 0.0568 & 0.0832 & 0.0287 & 0.0002 & 0.5194 \\
& & & & & \\
\hline
\end{tabular}

Nole: for definitions of the variables see Table 4.2 and Section $4.3,3$.

much higher than that of the disaggregated hours models. The model specification apparently provides a better fit for the composite measures than for the parts that together constitute these measures. ${ }^{32}$ This also applies to the audit fee model, which explanatory power is much higher than that of the disaggregated hours models as well.

As for the effects of the independent variables on the fees and hours, the results seem to confirm previous research. Measures of client size, client complexity, client asset composition, client risk and financial distress, quality of client internal controls, auditor tenure, and the auditor's provision of nonaudit services are determinants of audit fees, unweighted total audit hours, weighted total audit hours, and one or more categories of disaggregated hours. Furthermore, client size (proxied by total assets) is likely the most important determinant of audit fees and audit hours. The results for unweighted (total and disaggregated) audit hours also show that the signs for some variables are opposite to the ones expected. ${ }^{33}$ These were discussed in Chapter 3 , Section $3.5 .2 .^{34}$

Focusing particularly on the indicators of litigation risk in the fee and effort models (see Chapter 2, Section 2.2.3 for a discussion of relevant prior research), the results confirm prior research. Although not all risk indicators are significant in all models, of those that are most are significant in the expected direction. The exceptions are the unexpected positive effect of higher quality internal control on manager hours, and the unexpected negative effect of the issuance of an other than unqualified opinion on supervisor hours. ${ }^{35}$ For all other significant risk indicators the results suggest that, as expected, higher risk leads to higher fees and more effort. ${ }^{36}$

Turning to the realization rate model, the explanatory power of the realization rate model is decidedly lower than that of the audit fee model and the weighted total audit hours model, the two measures that together constitute the realization rate. Apparently the factors that are able to explain audit fees and weighted total audit 


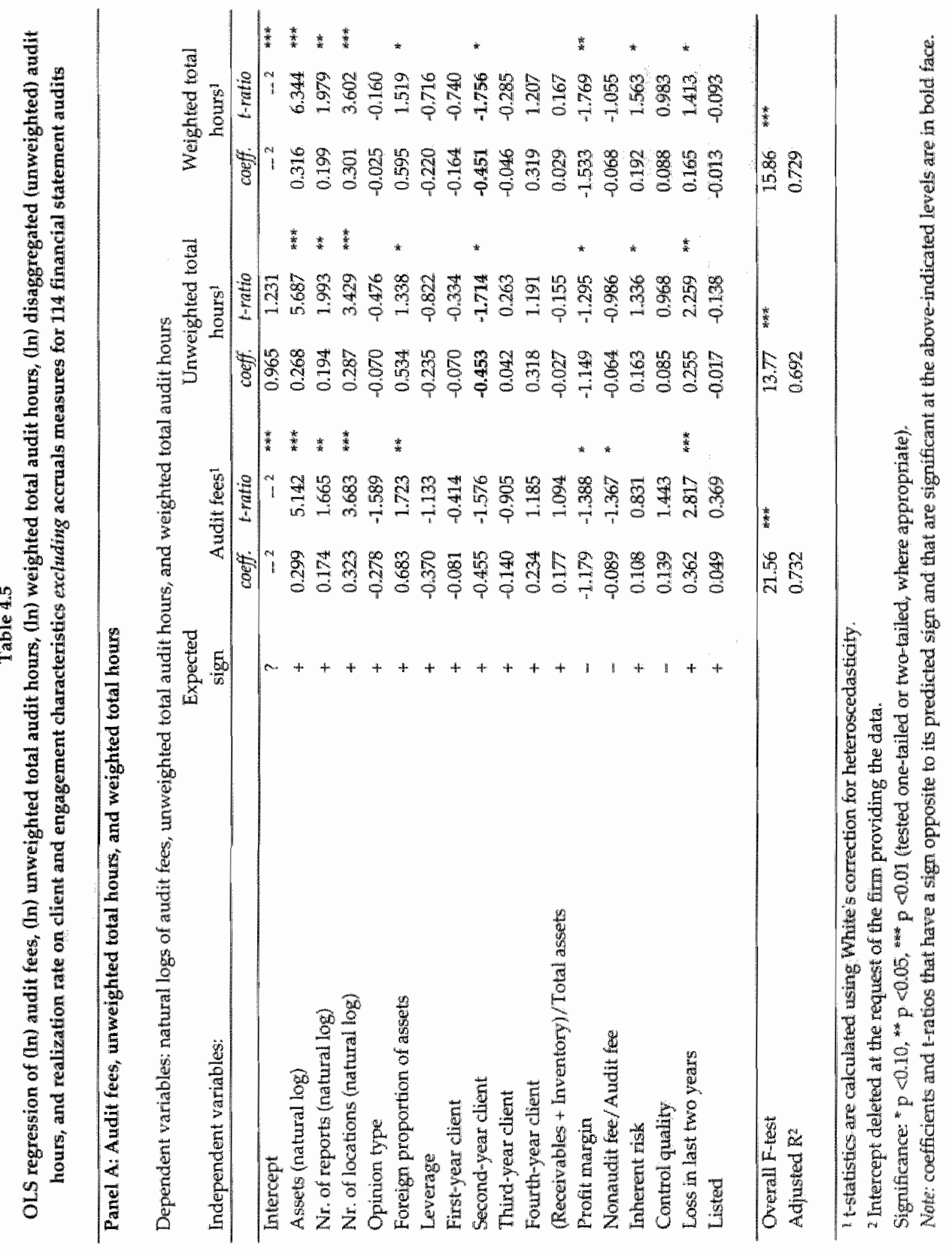




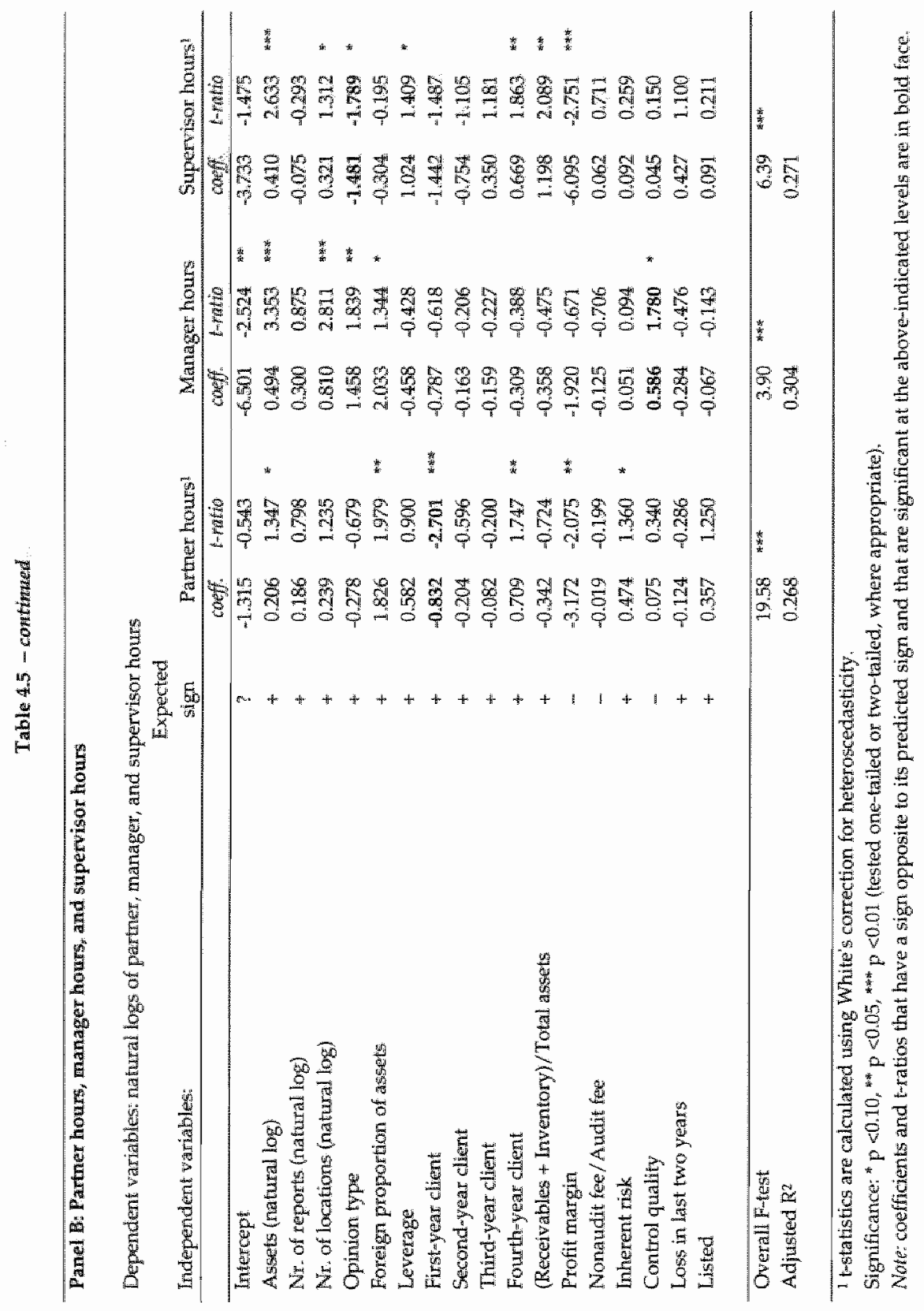




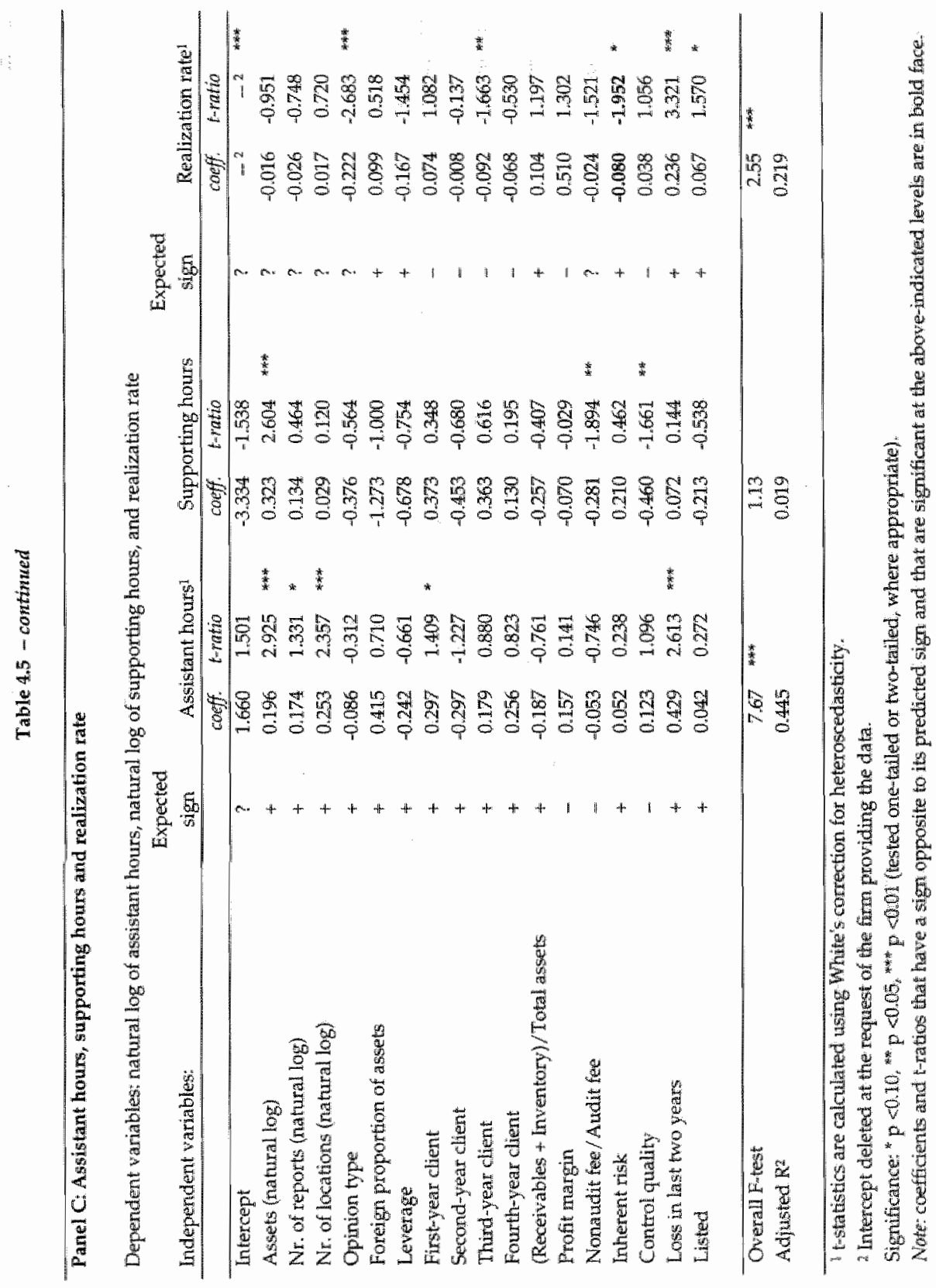


hours reasonably well, do not seem capable of doing so for the ratio of fees to weighted hours. This confirms results by Simunic and Stein (1996) and Dopuch et al. $(2000)^{37}$ and suggests that the effects of most independent variables on (unweighted and weighted) audit effort are entirely passed on to clients through the fees, and that hours and fees are affected to the same extent by these variables (see also the rationale in Section 4.3.3).

There are but a few factors that have an impact on the realization rate. An other than unqualified opinion has a significant negative effect on the realization rate, suggesting that weighted total hours are affected more than audit fees. However, the opinion indicator does not have a significant effect on either audit fees or weighted total audit hours. This also applies to the third-year client indicator: this variable has a significant negative effect on the realization rate, ${ }^{38}$ but neither fees nor weighted audit hours are significantly affected by it. Furthermore, the indicator for a listed (versus unlisted) company has a significant positive effect on the realization rate but again this indicator has no significant effect on either fees or weighted audit hours.

In contrast, the significant negative effect of the inherent risk indicator is corroborated by the finding that this factor has a significant positive effect on weighted total audit hours, but no effect on audit fees. Taken together, these results suggest that the (expected) positive effect of higher inherent risk on effort is not passed on to the client through fees.

Finally, the risk indicator loss in the last two years has a significant positive effect on audit fees and effort (as expected), as well as on the realization rate. This seems to indicate that the higher effort resulting from higher risk is more than passed on to the client through audit fees, suggesting a fee premium.

As can be inferred from the discussion above, there are four risk indicators that affect the realization rate: client inherent risk, client loss in the last two years, listed (versus unlisted) company indicator, and audit opinion type, where the effect of the latter two factors on the realization rate is not supplemented by their effects on fees and effort. These findings contrast with those of Simunic and Stein (1996) and Dopuch et al. (2000), who find that most risk indicators affect both fees and effort, but have no effect on the realization rate. As indicated earlier, their results seem to suggest that these risk indicators affect fees and effort to the same extent, and that the (positive) effect of higher risk on effort is passed on to the client through the fees, without charging a fee premium.

\subsubsection{Models including measures of potential earnings management}

As discussed in Section 4.3.3, four proxies for potential earnings management were tested: total accruals and short-term accruals, both on a signed and an absolute basis. Of these four measures, only signed short-term accruals had significant effects (these 
specific effects are discussed below). When either of the other three accruals measures were used as a proxy for potential earnings management, their effects were insignificant. More specifically, when signed total accruals were added to the fee, hours, and realization rate models discussed in Section 4.4 .2 (the "base" models), the variable itself was insignificant in all models, and the models' respective adjusted $\mathbb{R}^{2}$ generally decreased. The same can be said for absolute short-term accruals. In contrast, addition of absolute total accruals to the base models did increase the models' respective adjusted $R^{2}$, but again the variable itself was insignificant. ${ }^{39}$

Taken together, these findings suggest that it is the short-term part of total accruals that auditors take into account in the pricing and/or production of audit services, in line with the argument by Francis and Krishnan $(1999,144)$ that short-term accruals represent more uncertainty for auditors than total accruals. 40 These results also suggest that in addition to the size of the possible manipulation (as proxied by accruals), the direction of that manipulation is important as well, since only signed, and not absolute, short-term accruals were significant.

Table 4.6 below presents the results for the models including signed short-term accruals as a proxy for potential earnings management. Again, multicollinearity does not seem to be a problem, as evidenced by pairwise correlations between the independent variables and the variance-inflation factors (Gujarati 1995, 328). Like for the models in Section 4.4.2, application of Breusch-Pagan tests (Greene 2000, 509-510) suggests presence of heteroscedasticity for all models except those for manager and supporting hours. The t-ratios for the models concerned are calculated using White's heteroscedasticity-consistent covariance matrix estimation method (Greene 2000, 463). 41

For ease of comparison, the results for the models excluding measures of potential earnings management tested in Section 4.4 .2 are presented alongside those for models including signed short-term accruals as a proxy for earnings management. As can be inferred from Table 4.6, for most models addition of signed short-term accruals increases the models' adjusted $\mathrm{R}^{2}$, albeit slightly. ${ }^{42}$

Apart from the significance of the accruals measure, the inclusion of this measure does not effectively change the results of the base models in that all models are still significant at the 0.01 level, again with the exception of the model for supporting hours. ${ }^{43}$

However, inclusion of the accruals measure does change the significance levels for some of the independent variables that were also included in the base models. For some of the production (effort) models, variables that were significant at conventional levels in the base models lost this significance due to inclusion of the accruals measure. Conversely, in some models variables that were not significant at conventional levels in the base models gained significance after addition of the proxy for potential earnings management. This is most striking for the realization rate model, where both the ratio of receivables and inventory to total assets and 
Table 4.6

OLS regression of (In) audit fees, (1n) unweighted total audit howrs, (In) weighted total audit hours, (In) disiggregated (unweighted) audut hours, and realization rate on client and engagement characteristacs moluding am accruals measime for 114 financial stattement audits

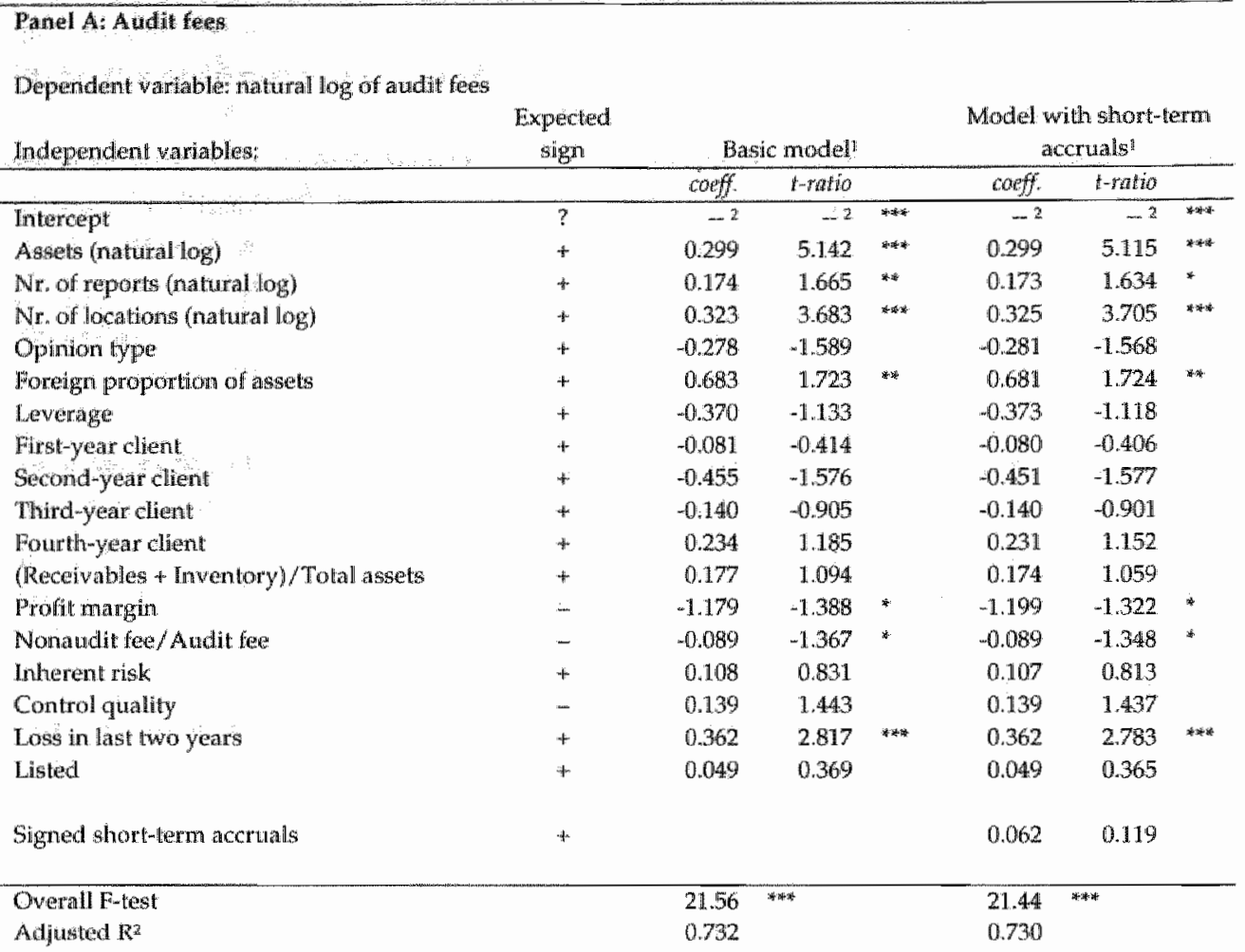

\footnotetext{
It isytatistic are calculated ushe White's correction for heteroscedasticity.

2Intarept dafedted the request of the firm providing the data.

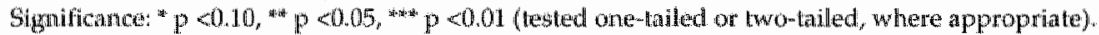

Note: coefficients and thatios that have at sign opposite to its predicted sign and that are signifitant at the aboveIndleated levels are in bold face.
}

profit margin reach conventional significance levels when the accruals measure is added to the model. Both variables have a significant positive sign, implying that higher levels of the ratio of receivables and inventory to total assets and higher levels of the profit margin influence fees more than they influence weighted total hours. ${ }^{44}$ However, for the ratio of receivables and inventory to total assets neither audit fees nor weighted total hours are significantly affected by this variable. Furthermore, the profit margin has a negative effect on both audit fees and weighted total hours (as expected), whereas the effect on the realization rate is positive. This result may seem strange at first. However, application of Wald tests (Greene 2000,620) shows that the 
Table $4.6-$ continud

Panel B: Unweighted total audat hours

Dependent: variable: natharal log of unweighted total audit hours

\begin{tabular}{|c|c|c|c|c|c|c|c|}
\hline \multirow[t]{2}{*}{ Independent variables: } & \multirow[t]{2}{*}{$\begin{array}{c}\text { Expected } \\
\text { siggr } \\
\end{array}$} & \multicolumn{3}{|c|}{ Basic model? } & \multicolumn{3}{|c|}{$\begin{array}{l}\text { Model with shont-termy } \\
\text { accrutals! }\end{array}$} \\
\hline & & coeff & Ispatia & & note & Stratio. & \\
\hline Intercept & $?$ & 0.965 & 1.231 & & 0.995 & 1238 & \\
\hline Assets (nattrat log) & + & 0.268 & 5.687 & $*$ & 0.268 & 5.623 & *⿻一𠃋十 \\
\hline Nt. of reports (natural log) & 4 & 0.194 & 1.993 & *** & 0.186 & 1898 & Hit \\
\hline Nr. of locations (natural log) & +4 & 0.287 & 3.429 & 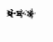 & 0.305 & 3.532 & * \\
\hline Opinian type & + & -0.070 & -0.476 & & -0.095 & $-0,620$ & \\
\hline Foneign proportion of assets & + & 0.534 & 1.338 & *. & 0.516 & 1.303 & * \\
\hline Leverage & + & -0.235 & -0.822 & & $-0.26 \pi$ & -10.881 & \\
\hline First-year chient & + & -0.070 & -0.334 & & $-0,057$ & $-0,285$ & \\
\hline Second-year client & + & -0.453 & -1.714 & * & -0.415 & -1.592 & \\
\hline Third year client & + & 0.042 & 0.263 & & 0.043 & 0.276 & \\
\hline Fourth-year client: & + & 0.318 & 1.191 & & 0.287 & 1.091 & \\
\hline (Receivables + Inwentory)/Total assers & + & -0.027 & -0.155 & & -0.059 & -0.336 & \\
\hline Profit margin & - & -1.149 & -1.295 & $*$ & -1.346 & -1.515 & $*$ \\
\hline Nonatudil fee / A udit ree & - & -0.064 & -0.986 & & -0.063 & -0.892 & \\
\hline Intwerent risk & + & 0.163 & 1.336 & * & 0.153 & 1.236 & \\
\hline Control guality & - & 0.085 & 0.968 & & 0.084 & 0.979 & \\
\hline Loss in last two years & + & 0.255 & 2.259 & $* *$ & 0.261 & 2.372 & 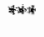 \\
\hline Listed & + & -0.017 & -0.138 & & $-0,022$ & 0.187 & \\
\hline Sigreed short-term acoruals & + & & & & 0.600 & 1,318 & $*$ \\
\hline Overall Fi-fest & & 13.77 & & & 16.31 & 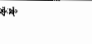 & \\
\hline
\end{tabular}

1 t-statistics are calculated using White's correction for heteroscedasticity.

Significance: $\mathrm{p}<0.10 * * 0.05, * * 0.01$ (tested onewaled or two tailed, where appropriate).

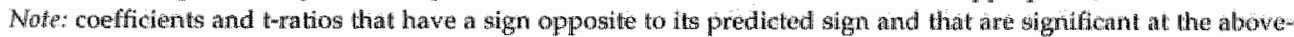
indicated levels ane int bold face:

negative effect of the profit margin on weighted total hours (the denominator of the realization rate) is larger (i.e., more negative) than its negative effect on audit fees (the numerator of the realization rate). This might explain the positive effect of profit margin on the realization rate. ${ }^{45}$

Turning to the proxy for potential earnings management, the results show that the accruals measure has no significant impact on audit fees. Apparently, this factor neither increases nor decreases fees. This result differs from that of Gul et al. (1998), who find that their proxy for potential earnings management (discretionary accruals) has a significant positive effect on audit fees. Perhaps this difference is due to a difference in the proxy for potential earnings managenent that is used.

As indicated in Section 4.2.4, since Gul et al. (1998) do not also investigate the effect of potential earnings management on auditor effort, it is not possible to indicate 
Table $4.6-$ continued

\begin{tabular}{|c|c|c|c|c|c|c|c|}
\hline \multicolumn{8}{|c|}{ Fotere $\mathrm{C}$ Weighted total aud it hours } \\
\hline \multicolumn{8}{|c|}{ Dependent variable: natural log of wetghted total audut hours } \\
\hline \multirow{2}{*}{ Indogerdent vanablest } & \multirow[t]{2}{*}{$\begin{array}{c}\text { Expected } \\
\text { sign }\end{array}$} & \multicolumn{3}{|c|}{ Basic model } & \multicolumn{3}{|c|}{$\begin{array}{c}\text { Model with short-lerm } \\
\text { accruals }\end{array}$} \\
\hline & & $\cos f$ & i-ratio & & coeff. & E-ratio & \\
\hline Intercept & $?$ & $-{ }^{2}$ & -2 & 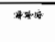 & -2 & -2 & 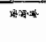 \\
\hline Ashers (natural log) & + & 0.316 & 6.344 & $*$ & 0.317 & 6.279 & w. \\
\hline N: of reports (matural log) & + & 0.199 & 1.979 & $*$ & 0.190 & 1.892 & w*er \\
\hline Nu, of locations (natural log) & + & 0.301 & 3.602 & +4 & 0.320 & 3.706 & w \\
\hline Opinion type & s. & -0.025 & -0.160 & & -0.051 & -0.308 & \\
\hline Foreign proportion of assets & สุें & 0.595 & 1.519 & * & 0.577 & 1.478 & $*$ \\
\hline Leverage & + & -0.220 & -0.716 & & -0.247 & -0.781 & \\
\hline Fivest year client & + & -0.164 & -0.740 & & -0.150 & $\infty 0,714$ & \\
\hline Second year dient & + & -0.451 & -1.756 & $*$ & -0.412 & -1631 & \\
\hline Thind oyear client & + & -0.046 & 0.285 & & -0.045 & -0.281 & \\
\hline Fourth-year client & + & 0.319 & 1.207 & & 0.287 & 1.130 & \\
\hline (Recenwables + Inventory)/Total assets & + & 0.029 & 0.167 & & -0.005 & 0.027 & \\
\hline Protit margin & - & -1.533 & -1.769 & * & -1.737 & -2.021 & $*$ \\
\hline Nonaludil feo/Audil fee & - & -0.068 & -1.055 & & .0 .067 & -0.950 & \\
\hline Inherent risk & + & 0.192 & 1.563 & * & 0.182 & 1.476 & $*$ \\
\hline Comblnol quality & - & 0.088 & 0.983 & & 0,088 & 0.994 & \\
\hline Loss in last two years & + & 0.165 & 1.413 & * & 0.171 & 1.481 & * \\
\hline Ligted & 4 & -0.013 & -0.093 & & -0.018 & -0.138 & \\
\hline Signed shon-term accruals & H & & & & 0.625 & 1.369 & $*$ \\
\hline Overall F-test & & 15.86 & 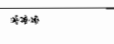 & & 16.86 & Fitis & \\
\hline Adjusted $\mathbb{R}^{2}$ & & 0.729 & & & 0.732 & & \\
\hline
\end{tabular}

\footnotetext{
I-sitatistics are calculated using White's correction for heteroscedasticity.

Intercept deleted at the request of the firm prowiding the dita.

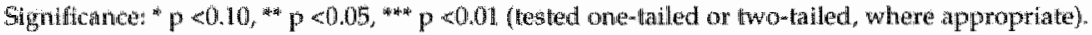

Note coffictents and tratos that have a sign opposite to itg predicted signand that are significant at the aboveinclicated levels ate in bold face
}

whether their positive effect is due to more auditor effort being passed on to the client, but nothing more than that (i.e., both fees and effort are affected to the same extent); or to a fee premium (either effort is not affected but fees are, or both fees and effort are affected, but fees are affected more than effort).

In contrast to the finding for audit fees, the proxy for potential earnings management does significantly increase both unweighted and weighted total audit hours, suggesting that, as expected, the potential for earnings management prompts auditors to increase audit effort. ${ }^{* 6}$ Inspection of the results for the disaggregated hours models reveals that this increase in effort is mainly due to supervisors, who are directly involved in the conduct and supervision of audit engagements, and 
Table 4.6 - continued

\section{Panel D: Partner hours}

Dependent wariable: natural log of partner hours

\begin{tabular}{|c|c|c|c|c|c|c|c|}
\hline \multirow[t]{2}{*}{ Independent wariables: } & \multirow[t]{2}{*}{$\begin{array}{l}\text { Expected } \\
\text { sign } \\
\end{array}$} & \multicolumn{3}{|c|}{ Basic model } & \multicolumn{3}{|c|}{$\begin{array}{l}\text { Model with short-term } \\
\text { accruals! }\end{array}$} \\
\hline & & coeff. & 1-sentio & & $\cos f$ & pratho & \\
\hline Intercept & $?$ & -1.315 & -0.543 & & 1.260 & -0.520 & \\
\hline Assets (natural log) & + & 0.206 & 1.347 & * & 0.206 & 1.357 & * \\
\hline Nr of reports (natural log) & + & 0.186 & 0.798 & & 0.171 & 0.722 & \\
\hline Nr. of locations (natural log) & + & 0.239 & 1.235 & & 0.274 & 1.322 & * \\
\hline Opinion type & + & -0.278 & $-0,679$ & & 0.323 & -0.759 & \\
\hline Foreign proportion of assets & + & 1.826 & 1.979 & was & 1.793 & 1.964 & $* *$ \\
\hline Leverage & + & 0.582 & 0.900 & & 0.533 & 0.838 & \\
\hline Firstyear client & + & -1.832 & -2.701 & in: $x+$ & -0.807 & -2.518 & $* *$ \\
\hline Second-year client: & + & -0.204 & -0.596 & & 0.135 & -0.362 & \\
\hline Third-year client & + & -0.082 & -0.200 & & -0.079 & -0.198 & \\
\hline Fourth-year client & + & 0.709 & 1.747 & wis & 0,651 & 1.836 & ** \\
\hline (Receivables + Inventory)/Total assets & + & -0.342 & 0.724 & & -0.403 & -0.868 & \\
\hline Profit margin & - & -3.172 & $-2,075$ & $*$ & -3.536 & -2.338 & *:* \\
\hline Nonaudit fee/Audit fee & - & -0.019 & $\triangle 1.199$ & & $-0,017$ & -0.168 & \\
\hline Inlherent risk & + & 0.474 & 1.360 & * & 0.456 & 1.327 & *. \\
\hline Control quality & - & 0.075 & 0.340 & & $0.0 \% 4$ & 0.338 & \\
\hline Loss in last two years & + & -0.124 & -0.286 & & -0.114 & -0.255 & \\
\hline Listted & + & $0.35 \%$ & 1.250 & & 0.347 & 1.241 & \\
\hline Signed short-term accruals & + & & & & 1.112 & 1.226 & \\
\hline Owerall $\mathbb{F}$-trest & & 19.58 & $* * *$ & & 13,93 & (1) & \\
\hline Adjusted $R^{2}$ & & 0.268 & & & 0.269 & & \\
\hline
\end{tabular}

It-statistics are calculated using White"s correction for heteroscedasticity.

Significance: ${ }^{*}<0.10, * * 0<0.05 * * * p<0.01$ (tested one-tailed or twowlailed, where appropriate).

Note; coefficients and t-ratios that have a sign opposite to its predicted sign and that are significant at the above. indicated leyels are in bold face.

supporting activities, which besides secretarial assistance also includes support from the audit firm's technical department. ${ }^{47}$

The findings for fees combined with those for hours suggest that in response to an increase in the (litigation) risk associated with potential earnings management as proxied by signed short-term accruals - auditors increase the effort expended on engagements, but that they do not pass on this effect to the client through fees. This finding is corroborated by the results for the realization rate model, which show that the accruals measure has a significant negative impact on this realization rate: (weighted) hours are affected more than fees ${ }^{48}$ This result is similar to the finding with respect to inherent risk as a risk indicator, but not to those for other risk indicators. Perhaps these risk indicators are of a different nature than the proxy for potential earnings management. The results for the accruals measure also differ from 
Table 46 - contrined

\begin{tabular}{|c|c|c|c|c|c|c|c|}
\hline \multicolumn{8}{|c|}{ Pand E: Manager hout } \\
\hline \multicolumn{8}{|c|}{ Dependent wariable: natural log of manager hours } \\
\hline \multirow{2}{*}{ Independent variables: } & \multirow[t]{2}{*}{$\begin{array}{l}\text { Expected } \\
\text { sign }\end{array}$} & \multicolumn{3}{|c|}{ Basic model } & \multicolumn{3}{|c|}{$\begin{array}{l}\text { Model with short-term } \\
\text { accruals }\end{array}$} \\
\hline & & $\operatorname{cotff}$ & trallio & & $\cos 8 \mathrm{fit}$ & toratio & \\
\hline Intercept & $?$ & -6.501 & -2.524 & ** & -6.537 & -2.526 & 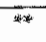 \\
\hline Asisets (natarallog) & f & 0.494 & 3.353 & watios. & 0.494 & 3.338 & $\omega * *$ \\
\hline Wr. of reports (natural log) & ff & 0.300 & 0.875 & & 0.310 & 0.898 & \\
\hline Nr. of locations (natural log) & * & 0.810 & 2.811 & *⿻一𠃋十 & 0.787 & 2.678 & 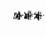 \\
\hline Opintion type & . & 1.458 & 1.839 & 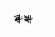 & 1.487 & 1.861 & $*$ \\
\hline Foreign proportion of assets & $\star$ & 2.033 & 1.344 & $*$ & 2.054 & 1.352 & * \\
\hline Deveratoge & + & -0.458 & $-0,428$ & & -0.426 & $-0,396$ & \\
\hline Mrst yean dient & + & .0 .787 & -0.618 & & -0.804 & 0.628 & \\
\hline Second year ollent & + & -0.163 & -0.206 & & 0.208 & -0.260 & \\
\hline Third year client & + & -0.159 & -0.227 & & -0.161 & -0.228 & \\
\hline Fourdi-year dient & + & -0.309 & -0.388 & & 10.272 & -0.338 & \\
\hline (Recerinbles + Liventory)/Total assets & + & -0.358 & -0.475 & & -0.318 & -4.48 & \\
\hline proffit marein & - & -1.920 & .0 .671 & & -1.684 & -0.576 & \\
\hline Nonatudit fee/Andit fee & - & -0.125 & -0.706 & & -0.126 & -0.710 & \\
\hline Inthenent risk & + & 0.051 & 0.094 & & 0.063 & 0.115 & \\
\hline Control quality & - & 0.586 & 1.780 & * & 0.566 & 1.773 & \# \\
\hline Loss in last two years & + & -0.284 & -0.476 & & -0.290 & -0.485 & \\
\hline listed & $\psi$ & -0.067 & -0.143 & & -0.061 & -0.129 & \\
\hline Signed shortetem acoruals & + & & & & -0.720 & -0.428 & \\
\hline Overall F-test & & 390 & 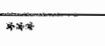 & & 3.67 & - & \\
\hline Adjusted $\mathrm{R}^{2}$ & & 0.304 & & & 0.298 & & \\
\hline
\end{tabular}

Significance: * $p<0.10$ * $p<0.05 *$ * $p<0.01$ (tested one-tailed or two-kalled, where appropriate).

Note: coefficients and the rios that have sit sign opposite to its predicted sign and that are significant at the abover

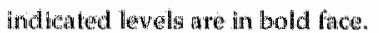

those in. Simunic and Stein (1996) and Dopuch et al. (2000), who find that higher risk increases fees as well as hours, but has no effect on the realization rate. Their findings suggest that risk has a similar effect on both fees and effort, and that the effect on effort is passed on to the client through the fees, without charging a fee premium. Of course, the comparability of this chapter's results regarding the accruals measure as a risk indicator to the findings of Simunic and Stein (1996) and Dopuch et al. (2000) is limited, since these last two papers do not explicitly include a measure for potential earnings management in their models. 
Table $4.6-$ oontinted

\section{Panel Fu Supervisor hours}

Dependent variable: natural log of supervisor hours

\begin{tabular}{|c|c|c|c|c|c|c|c|}
\hline \multirow[t]{2}{*}{ Independent wariables: } & \multirow[t]{2}{*}{$\begin{array}{c}\text { Expected } \\
\text { sign }\end{array}$} & \multicolumn{3}{|c|}{ Basic model } & \multicolumn{3}{|c|}{$\begin{array}{c}\text { Model with shortherm } \\
\text { coctrualst }\end{array}$} \\
\hline & & ogef. & Thitio & & $\cos f$ & 4-ingtive & \\
\hline Intercept & $?$ & -3733 & -1.475 & & -3.637 & -1.453 & 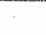 \\
\hline Assets (nathural log) & H & 0.410 & 2.633 & 祭的 & 0.410 & 2.640 & intises \\
\hline Nr. of reports (natural log) & + & 0.075 & -0.293 & & -0.101 & $-0,389$ & \\
\hline Nr. of locations (natural log) & + & 0.321 & 1.312 & $*$ & 0.380 & 1.436 & in \\
\hline Opinion type & + & -1.481 & -1.789 & * & -1.557 & -1.892 & * \\
\hline Foreign proportion of assets & + & -0.304 & -0.4 .95 & & -0.359 & -0.233 & \\
\hline Leverage & + & 1.024 & 1.409 & * & 0.941 & 1.240 & \\
\hline First-year client & + & -1.442 & -1.487 & & -1.399 & -1.502 & \\
\hline Second-year client & + & -0.754 & -1.105 & & -0.637 & -0.965 & \\
\hline Thind-year client & + & 0.354 & 1.181 & & 0.354 & 1.170 & \\
\hline Fouruth-year client & \# & 0.669 & 1.863 & $* * *$ & 0.57 & 1.803 & *t. \\
\hline (Receivables + Inventory)/Total assets & 4 & 1.198 & 2,089 & $* *$ & 1.096 & 1.880 & wat \\
\hline Profit matgin & - & -6.095 & -2.751 & $4 * *$ & -6.711 & -3.094 & 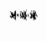 \\
\hline Nonandit fee/Andit fee & - & 0.062 & 0.711 & & 0.065 & 0.724 & \\
\hline Whitenten risk & 小 & 0.092 & 0.259 & & 0.061 & 0.169 & \\
\hline Control quality & - & 0,045 & 0.150 & & 0.044 & 0.149 & \\
\hline Loss in last two years & 4 & 0.427 & 1.100 & & 0.444 & $1 . \pm 21$ & \\
\hline Luisted & 4 & 0.09 & 0.211 & & 0.074 & 0.170 & \\
\hline Signed short-term accrulals & + & & & & 1.881 & 1.428 & * \\
\hline Overall F-test & . & 6.39 & 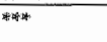 & & 6.88 & & \\
\hline Adjusted $\mathrm{R}^{2}$ & & 0.271 & & & 0.277 & & \\
\hline
\end{tabular}

t-statistics are calculated using White's correction for heleroscedasticity.

Significance: $p<0,10, * 0.05$, $p<0$ * $p<01$ (tested one-tailed or wotailed, where appropria te).

Note: cotficients and tratios that have a sign opposite to its predicted sign and that are whriflicant at the abovem indicated levels are in bold face.

\subsection{Conclusions, limitations, and suggestions for future research}

This final section summarizes the study's results, discusses its limitations, and provides suggestions for further research. As the discussion will show, many suggestions are related to the limitations and logically follow from these.

As suggested by Francis and Krishnan $(1999,159)$, rational auditors can respond to the (litigation) risk associated with (potential) earnings management by reporting more conservatively, screening out higher-risk clients, increasing auditor effort, charging a fee premium, and/or negotiating adjustments in the financial statements of these clients. This study has investigated two of these options: increasing audit effort and charging a fee premium. The dataset used in this study allows to 
Table 4.6- continned

\begin{tabular}{|c|c|c|c|c|c|c|c|}
\hline \multicolumn{8}{|l|}{ Panel $\mathrm{G}$ : Assiistant hours } \\
\hline \multicolumn{8}{|c|}{ Dependent variable: naturail log of assistant hours } \\
\hline \multirow{2}{*}{ Independent variables: } & \multirow[t]{2}{*}{$\begin{array}{l}\text { Expected } \\
\text { sign }\end{array}$} & \multicolumn{3}{|c|}{ Basic modell } & \multicolumn{3}{|c|}{$\begin{array}{l}\text { Model with short-term } \\
\text { accruals? }\end{array}$} \\
\hline & & cogff. & t-ratio & & $\cos f f$ & tratio & \\
\hline Intercept & 7 & 1.660 & 1.501 & & 1,684 & 1.496 & \\
\hline Assets (raturall log) & 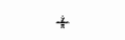 & 0.196 & 2.925 & *⿻:木 & 0.196 & 2.919 & *** \\
\hline Nr. of reports (natural log) & + & 0.174 & 1.331 & * & 0.167 & 1.258 & \\
\hline Nr. of locations (natural log & * & 0.253 & 2.357 & $* * *$ & 0.267 & 2.421 & **** \\
\hline Opinion type & + & -0.086 & -0.312 & & -0.106 & -0.375 & \\
\hline Foreign proportion of assets & + & 0.415 & 0710 & & 0.401 & 0.690 & \\
\hline Leverage & + & $-0,242$ & -0.661 & & -0.263 & -0.706 & \\
\hline First-year client & + & 0.297 & 1.400 & * & 0.308 & 1.486 & * \\
\hline Second yean client & + & .0 .297 & -1.227 & & 0.267 & -1.074 & \\
\hline Third-year client & + & 0.179 & 0.880 & & 0.180 & 0.891 & \\
\hline Fourth-year client & + & 0.256 & 0.823 & & 0.231 & 0.725 & \\
\hline (Receivables + Inventory)/Total assets & + & -0.187 & -0.761 & & -0.213 & -0.837 & \\
\hline Profit margin & - & 0.157 & 0.141 & & 0.001 & 0.001 & \\
\hline Nonandit fee / Audit fee & - & -0.053 & -0.746 & & -0.053 & -0.693 & \\
\hline Inherent risk & $*$ & 0.052 & 0.238 & & 0.045 & 0.201 & \\
\hline Control quality & - & 0.123 & 1.096 & & 0.123 & 1.098 & \\
\hline Loss in last two years & + & 0.429 & 2.6113 & 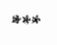 & 0.433 & 2.684 & $* * * *$ \\
\hline Lististed & 小 & 0.042 & 0.272 & & 0.038 & 0.250 & \\
\hline Signed short-term accruals & is & & & & 0.476 & 0.794 & \\
\hline Overall Firestit & & 7.67 & $x: * 4$ & & 10.07 & **1010 & \\
\hline Adjusted R2 & & 0.445 & & & 0.443 & & \\
\hline
\end{tabular}

"t-statistics are calculated using White's correction for heteroscedasticity.

Significince: * $p<0.10, * 0<0.05, * * * 0.01$ (tested one-tailed or two-tailed, where appropriate).

Note: coufficients and twratios that have a sign opposite to its predicted sign and that are significant at the aboveindicated levels are in bold face.

investigate the effect of potential earnings management on both fees and effort, to study the interplay between the two, and thus also find out whether a higher fee follows from more auditor effort, a fee premium, or both.

Based on prior audit fee and production literature and previous research on earnings management, a model was constructed for audit fees, auditor effort, and the relationship between audit fees and (weighted) auditor effort (i.e., the realization rate). Subsequently, this model was tested empirically on a sample of 114 audit engagements from one of the (then) Big Six audit firms. The results show that the fee and production models confirm findings from prior research in this area. Furthermore, the proxy for potential earnings management (signed short-term accruals) significantly increases audit effort (in particular, effort exerted by supervisors on the audit team and by supporting staff), but has no significant impact 
Table $4.6-$ conthowed

\section{Panel If: Supporting hours}

Dependent wariable: natural log of supporting hours

\begin{tabular}{|c|c|c|c|c|c|c|c|}
\hline \multirow[t]{2}{*}{ Independent varjables: } & \multirow[t]{2}{*}{$\begin{array}{c}\text { Expected } \\
\text { sign } \\
\end{array}$} & \multicolumn{3}{|c|}{ Basic model } & \multicolumn{3}{|c|}{ 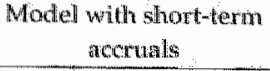 } \\
\hline & & $\cos f$ & Tratio & & coeff & t-trabio & \\
\hline Intercept & $?$ & .3 .334 & $\sim 1.538$ & & -3.184 & -1.495 & \\
\hline Assets (natural log) & 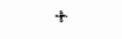 & 0.323 & 2.604 & $*$ & 0.323 & 2653 & * \\
\hline Nr. of reports (natural log) & 年 & 0.134 & 0.464 & & 0.095 & 0,333 & \\
\hline Nr. of locations (natural log) & + & 0.029 & 0.120 & & 0.121 & 0.500 & \\
\hline Opinion type & * & -0.376 & -0.564 & & -0.496 & -0.755 & \\
\hline Foreign proportion of assets & 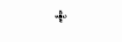 & -1.273 & -1.000 & & -1.358 & -1.086 & \\
\hline Leverage & + & -0.678 & -0.754 & & -0.808 & -0.912 & \\
\hline First-year client & + & 0.373 & 0.348 & & 0.41 & 0.418 & \\
\hline Second-year client & + & -0.453 & -0.680 & & -0.269 & -0.408 & \\
\hline Third-year client & + & 0.363 & 0.616 & & 0.370 & 0.639 & \\
\hline Fourthwyear client & + & 0.130 & 0.195 & & -0.022 & -0.033 & \\
\hline (Receiwables * Invertory)/Total assets & + & -0.257 & -0.407 & & -0.4118 & $\sim 0.668$ & \\
\hline Prolit margin & - & -0.070 & $-0,029$ & & -1.035 & -0.430 & \\
\hline Nonaudit fee/Audit fee & - & -0.281 & -1.894 & +4 & -0.276 & -1.896 & (4) \\
\hline Wherent risk & * & 0.210 & 0.462 & & 0.161 & 0.360 & \\
\hline Control quality & - & -0.460 & -1.661 & *⿻一亅八 & -0.461 & -1.695 & * \\
\hline Loss in last two years & \# & 0.072 & 0.144 & & 0.099 & 0.200 & \\
\hline Listed & $*$ & -0.213 & -0.538 & & -0.239 & -0.615 & \\
\hline Signed short-term acciuals & * & & & & 2.946 & 2.129 & * \\
\hline Overall F-test & & 1.13 & & & 1.36 & & \\
\hline Adjusted $\mathrm{R}^{2}$ & & 0.019 & & & 0.054 & & \\
\hline
\end{tabular}

Significance: * $p<0.10, * * p<0.05$, *** $\mathrm{p}<0.01$ (tested one-tailed or two-tailed, where appropriate). Note: coefficients and t-ratios that have al sign opposite to its predicted sign and that are significant at the above. indicated levels are in bold face.

on audit fees. These results suggest that an increase in risk associated with potential earnings management prompts auditors to increase auditor effort, which is not passed on to clients through higher fees. The finding that potential earnings management has a significant negative effect on the realization rate (i.e., the ratio between fees and (weighted) audit hours) seems to support this.

The findings for the risk indicator potential earnings management are different from those for most of the other risk indicators in this chapter's models. These findings are also different from those of (the few) prior studies that also investigate the effect of litigation risk on audit fees, audit effort, and the realization rate, but that did not include a measure for risk associated with potential earnings management in their models. Perhaps this difference in result is due to a difference in nature of risk for the various risk indicators. Since prior research on the effect of potential earnings 
Table $46-$ contimud

\begin{abstract}
Panel Ir Realization rate
\end{abstract}
Dependent varibiles ratho of a udit fee to wetheted tolat audil hours

\begin{tabular}{|c|c|c|c|c|c|c|c|}
\hline \multirow[t]{2}{*}{ Hodependant variables: } & \multirow[t]{2}{*}{$\begin{array}{l}\text { Expected } \\
\text { silgn }\end{array}$} & \multicolumn{3}{|c|}{ Basic modell } & \multicolumn{3}{|c|}{$\begin{array}{c}\text { Model with short term } \\
\text { accruals }\end{array}$} \\
\hline & & $\cos f$ & t-ratio & & cotest & Tratio & \\
\hline Intercept & $?$ & -2 & -2 & $* 4+4$ & -2 & -2 & सteitif \\
\hline Assutg (natural log) & $?$ & -0.016 & -0.95 & & $-0,016$ & -0.952 & \\
\hline Nr. of reports (natural log) & $?$ & -0.026 & -0.748 & & -0.020 & -0.615 & \\
\hline Nr. of locations (natural log) & $?$ & 0.017 & 0,720 & & 0.9003 & 0.114 & \\
\hline Opinion type & $?$ & -0.222 & -2.683 & w*t: & $-0,203$ & -2.753 & 政事 \\
\hline Horeign proportion of assets & + & 0.099 & 0.518 & & 0.113 & 0.592 & \\
\hline Leverage & + & -0.167 & -1.454 & & -0.147 & -1.289 & \\
\hline Firgt year client & - & 0.074 & 1.082 & & 0.063 & 1.101 & \\
\hline Second-year client & - & $-0,008$ & -0.137 & & -0.037 & -0.564 & \\
\hline Third-year cient & $\rightarrow$ & -0.092 & -1.663 & *:* & -0.093 & -1.702 & 的 \\
\hline Pourthyear dient & - & -0.068 & -0.530 & & -0.044 & -0.464 & \\
\hline (Rectivables + laventory)/Total assets & $\#$ & 0.104 & 1.197 & & 0.130 & 1.465 & $*$ \\
\hline Profit maxgin & - & 0.510 & 1.302 & & 0.664 & 1.875 & . \\
\hline Nonaudil fee/Andit free & $?$ & -0.024 & -1.521 & & -0.025 & -1.563 & \\
\hline Inherent risk & + & -0.080 & -1.952 & *. & -0.072 & -1.726 & $\$$ \\
\hline Control quality & - & 0.038 & 1.056 & & 0.038 & 1.076 & \\
\hline Loss in last two years & + & 0.236 & 3.321 & $* * 4$ & 0.232 & 3.651 & and \\
\hline Listed & 4 & 0.067 & 1.570 & 4 & 0.071 & 1.693 & 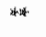 \\
\hline Signed short-term accruals & $?$ & & & & -0.470 & -2.211 & *⿻一亅八 \\
\hline Ovenall Fitest & & 2.55 & 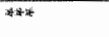 & & 287 & 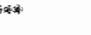 & \\
\hline Adjusted $\mathrm{R}^{2}$ & & 0.219 & & & 0.271 & & \\
\hline
\end{tabular}

\footnotetext{
It-statistics are calculated using White's correction for heteroscedasticity.

2 Intercept delleted at the request of the firm providing the data.

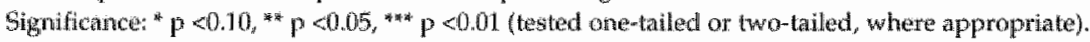

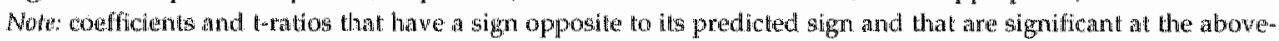
indicaled levels are in bold face.
}

management on audit fees, auditor effort, and its interplay is scarce, more research in this area could shed some light on this issue.

Of course the results critically depend on the accuracy of the accruals measure in reflecting potential earnings management. As indicated in Section 4.3.3, the dataset used in this study only allows to proxy for potential earnings management by means of measures based on total accruals. It is very well possible that other proxies would generate different results (e.g., see the difference between this study's results for audit fees and those found by Gul et al. 1998). Therefore, future research could investigate the effect of potential earnings management on fees and hours using other, perhaps more accurate, measures of potential earnings management. 
Another limitation might result from the fact that prior research suggests auditors frequently underreport to meet time budgets (see also Chapter 3 , Section 3.6). If this were true for the data in this sample, this would have decreased the observed amount of effort spent for those engagements on which underreporting has taken place relative to accurately reported engagements. Similarly, this would have increased the realization rate for underreported relative to accurately reported engagements. As indicated in Chapter 3 , although the audit firm providing the data indicates that they urge their employees to report actual hours worked, and not underreport to meet the budget, this is no guarantee that they do not do so. However, results from Chapter 3 for the same sample would suggest that if auditors have underreported for engagements in this study's sample, at least they have done so consistently for all engagements in the sample. This implies that relative labor use (i.e., labor use on one engagement relative to all other engagements) and relatioe realization rates (i.e., realization rate for one engagement relative to all other engagements) should not have to be distorted. In this case, potential underreporting of time should not negatively limit the results of the current chapter.

A further limitation is inherent to using data from audited financial statements, as this study has done.49 Post-audit information only contains earnings management that auditors either did not detect or did detect but not prevent (see Nelson et al. 2002,178 ). It is therefore possible that measures of earnings management based on audited financial data (as is the case here) understate the extent of earnings management investigated and detected by the auditor. This should be borne in mind when interpreting the results.

Of course this limitation also provides a suggestion for future research, in that preaudited financial statements could be used to identify actual earnings management attempted by companies and test for its effect on audit fees and auditor effort. In addition, pre-audit and post-audit information could be compared to see to what extent auditors have been successful in preventing earnings management from ending up in the audited financial statements (see Becker et al. 1998, 7), and how this has affected audit fees and auditor effort.

Another limitation follows from the fact that this study uses data from only one audit firm and for only one year, which restricts the generalizability of the study's findings (see also Chapter 3, Section 3.6). Combined with the fact that prior research on the effect of potential earnings management on audit fees and auditor effort is scarce, this suggests that more research on this topic is warranted, all the more so considering the recent developments on the audit market in the wake of the accounting crisis of which Enron, WorldCom, Xerox, Qwest, and Ahold seem to be but a few exponents. The data used in this study are from 1997, well before signs of the current crisis began to emerge. It would be interesting to investigate if and how the results would change due to these recent developments and the potential measures taken by respective authorities in response to these developments. This 
suggestion also extends to the other options suggested by Francis and Krishnan (1999, 159). Although the discussion of prior studies on these options has shown that these have been investigated more than the options studied in this chapter, prior research is still rather limited, and it might also be interesting to see how the recent developments affect auditors in issuing modified opinions, screening out high-risk clients, and/or negotiating adjustments in the financial statements with their clients.

A final suggestion for future research also relates to the options suggested by Francis and Krishnan $(1999,159)$. Although it is interesting to study each of these options in isolation, more insight could be gained by investigating one or more options together. Some studies have already done so, as evidenced by the discussion of prior research in Section 4.2 (see DeFond and Subramanyam 1999; Bradshaw et al. 2001; Butler et al. 2002), and of course the current study. It would be interesting to extend this research by investigating more options in one study and to examine when, how, and based on what criteria an auditor chooses which option. 


\section{Notes}

Francis and Krishnan $(1999,159)$ discuss these options in this order. This order will also be used in the discussion in this chapter.

2 Note that the first and the last option more or less imply an auditor's response to earnings management after the client has (likely) engaged in earrings manipulation (in other words, these are auditors ${ }^{\prime}$ ex-post responses, or reactions, to earnings management), whereas the other three options are ways in which auditors can anticipate comparies' earnings management (in other words, these are auditors" ex-ante responses to earnings management). In these latter cases, it is the risk of potential earnings management, rather than earnings management per se, that the anditor responds to. After all, the auditor is yet to find out whether the client has actually engaged in earnings management. Therefore, when discussing the first and the last option this chapter will refer to carnings management, and when discussing the other three options the chapter will refer to potential aarnings management.

${ }^{3}$ As will be discussed in Section 4.3 .3 of the current chapter prior research has used a number of proxies for earnings management. These include the wo proxies mentioned here, total accruals and abnormal or discretionary accruals, as well as proxies using specific components of accruals, (changes in) accounting method choices, and the statistical distribution of earnings after management.

4ore specifically, Francis and Krishnan (1999, 139) consider modified reports for either asset realization uncertainties or going concern problems.

Note that this applies to modified reports for asset realization uncertainties as well as for going concern problems.

6 This effect is significant after controlling for potentially confounding variables. Bartov et al. (2000) find that only the cross-sectional Jones madel and the cross-sectional modified Jones model are able to consistently detect earnings management.

7 Bartov et al. $(2000,446)$ indicate that this might be due to the low number of non-Big Six auditees in their sample.

* This latter option may not be uncommon in the US setting of DeFond and Subramanyam's (1999) paper. Howewer, it may apply less to a Dutch setting (in which this dissertation is set), which is substantially less litigious than a US setting.

9 Butler et al. (2002) argue that firms with "troubled-company" opinions have unusual levels of accruals due to their underlying economic performance, not for reasons associated with earnings management and/or auditor conservatism. They state $(2002,7):$ " $\ldots(\ldots)$. given that financial trouble is essentially a first-order condition for observing a going-concern opinion [i.e, a "troubled-company" opinion] and that financially-troubled firms have large negative accruals, it is likelly that companies with certain modified opinions have high (negative) accruals simply because they are troubled.(...)". [bracketed words added]. Their finding that clients receiving "troubled-company" opinions are smaller, less profitable, and have lower liquidity, in addition to having more negative accruals, seems 
to be consistent with this. To substantiate their argument, the authors distinguish two broad categories of accruals: those due to income transactions and those due to liquidity transactions. Accrtals due to income transactions pertain to accruals that have an income effect. Accruals due to liquidity transactions are accruals that are due to liquidity issues, but that have little or no impact on income. Examples in this latter category cited by the authors are factoring receivables, delaying payables, and reducing short-term debt. If negative accruals are mainily due to liquidity transactions, which hawe little or no effect on income, thather than income transactions, then these accruals are not caused by either eamings management or auditor conservatism. The authors daim that descriptives for their sample of firms with "troubled-company" opinions indicate that the negative abnormal accruals are mainly due to the liquidity transactions mentioned above.

10 Bradshaw et al $(2001,46)$ suggest three interpretations of this ineffectiveness: (1) auditors are not sufficiently competent to understand the implications of large accruals; (2) auditors may have colluded with management to increase future earnings expectations by increasing current accruals and current earnings; and (3) earnings quality issues are beyond the scope of the current audit, i.e., auditors understand the consequences of inflated accruals but are not currently required to warm investors about this by means of the audit opinion.

II Of course the studies differ in focus and (therefore) apply different methodologies and approaches, which might contribute to the differences in results.

12 Francis and Reynolds (2001) base their tests on examinations of incoming, ongoing, and outgoing clients, which implies that they study the screening out of both new and continting audit clients (i.e., both the client-acceptance and the client-retention decision).

19 As can be inferred from the discussion above, it should be noted that not in all studies that were discussed here this litigation risk includes the risk associated with earnings management.

14 Therefore, the remarks made in Section 4.23 regarding audit production models also apply to audit fee models.

15 The results also show that this effect is more positive for Big Six auditees than for non-Big Six auditees. According to the authors this finding is consistent with the Big Six delivering higher audit quality because they have more reputation capital to protect (see also Section 4.2 .1 of this chapter).

wh Asted earlier, anditor changes can either be client-initiated or auditor-initiated In their study Defond and Jiambalvo $(1993,429)$ explicitly consider the changes to be client-initiated, since they state in their footnote 1 that "......... Our study does not prowide evidence regarding why, following the disagreement over the proposed procedure, the client firm decides to chonge auditors.(...). A possibility ... is so-called opinion shopping. That is, the chent changes to find an auditor either who is willing to accept the disputed controversial method or who is expected to be more compliant on future issues than the predecessor auditor. (...)" (emphasis added).

It is therefore considered inappropriate to (also) discuss this paper in the context of the option to screen out high-risk clients, since DeFond and Jiambalvo so explicitly indicate that it is the client, and not the auditor, who decides to change auditor. In contrast, although in their paper on auditor changes and discretionary accruals DeFond and Subramanyam (1998) conclude that the incomedecreasing accruals choices required by the auditor may have induced management to change 
auditors (i.e. dismissal rather than a resignation), they do not consider up front that these changes are client rather than auditor-initiated. Contrary to the DeFond and Jiambalwo (1993) paper, therefore, it is considered appropriate to include the DeFond and Subramanyam (1998) paper in the discussion of the option to screen out high-risk dients.

17 In contrast, although as discussed in Section 42.1. Butler et al. (2002) find results simular to those of DeFond and Subramanyam (1999), they explain these as being due to comparies' liquidity-enthancing strategies rather than as consequence of anditor-client negotiations in response to higher litigation risk.

18 Based on the auditors" experiences with earnings management attempts by companies, the paper also examines managers' decisions to attempt earnings management, besides auditors' decisions to waive these attempts. The study finds that the structuring of transactions to comply with financial accounting standards occurs relatively infrequently; that when it does occur it does so with respect to precise rather than imprecise accounting standards; that the majority of attempts that affect currentyear income are incone-increasing; and that earnings management attempts increase current-year income when accounting standards are precise and/or when transactions have been structured to comply with these standiards.

19 Sensitivity analyses show that results using hours excluding those spent on supporting activities are not significantly and qualitatively different from those using hours including the supporting activities. Therefore, to preserve the complete picture of the audit production process, results including the hours for supporting activities are reported here.

20 Just using the audit hours without multiplying these by rates (i.e, unweighted total audit hours) would also solve this problem, but it would create another as well. If hours per staff level would be added without multiplying them by their respective rates (be they differentiated only per staff level or per staff level and staff member), one would implicitly assume that all hours are equally expensive and thus ignore the fact that some hours are more costly than others. Using hourly rates that differ from staff level to staff level, but are equal over all staff members per level solves both problems.

21 As discussed in the previous (and also the next) chapter, the dataset also includes a measure of socalled out-of-pocket expenses (see Davis, Richiute, and Trompeter 1993, 138) made per engagentent. For the same reason as stated in the main text for not using rates that are differentiated per staff member (bust just per staff level), these out-of-pocket expenses are not included in the denominator of this study"s realization rate measure either. This may decrease the accuracy of mensure of costs per engagement, but this is not considered to hinder the analysis. After all, in contrast to the purpose of the next chapter, the current chapter does not intend to explain the profitability of audit engagements, which would indeed nequire as accurate a representation of audit costs per engagement as possible. Instead, the aim of the curtent chapter is to see how potentiall earnings management affects fees, hours, and the interaction between fees and hours, which does not require a measure of audit costs.

However, tests were performed to see whether the results were affected by the inclusion of out-of pocket costs in the denominator of the realization rate. Since they were not, the results for the realization rate are presented excluding out-ol-pocket costs from the denominator. 
22. As a sensitivity teet, the analyses were also performed with median rates as the weights. Since these results are not qualitatively different from those with average rates as the weights, only the latter are reported here:

23 Based on these prior studies, the (negative) coefficients for the auditor tenure indicators are expected to be ordered as follows: first-year client < second-year client < third-year client < fourthyear chent.

2. On a more theoretical level, Francis and Krishnan $(1999,160)$ motiwate their use of a total rather than discretionary accruals measure by pointing out that Lys and Watts (1994) argue that auditor are more concemed with total rather than discretionary accruals when assessing risk.

25. Francis and Krishnan (1999, 148) argue that sales are better for scaling than earnings since earnings are influenced by the combined effect of all accruals. In addition, they also argue that sales are better for scaling than other size scalars such as total assets since sales are more directly related to earnings. Prior research also scales accruals measures by lagged total assets (see e.g. Dechow et al. 1996). Therefore, the tests were also performed with accruals scaled by lagged total assets. Since the results for accruals measures scaled by lagged total assets do not qualitativelly differ from those for accruals meastures scaled by sales, only the results for accruals scaled by sales are reported.

26 After all, as indicated earlier, the auditor business risk includes the auditor litigation risk. In addition, it was also discussed that the potential for earnings management increases this auditor litigation risk. Therefore, it may be expected that indicators of potential earnings management are positiwely related to the realization tate as well.

27 Of course, this result could also follow from neither hours nor fees being affected by potential earnings management. This can be werified by comparing the findings for the realization rate with those for both hours and fees.

28 This finding could also result when hours are affected but fees are not affected at all. Again, by comparing the findings for the realization rate with those for both hours and fees this can be verified.

3imilarly, this could also result when fees are affected but hours are not affected at all. Again, by comparing the findings for the realization rate with those for both hours and fees this can be verified.

3t Of course, this does not imply that on average the atidit firm (more than) recovers the costs made per engagement. This study investigates how potential earnings management affects audit fees, atudit effort, and the interaction between these two. To study the latter, the realization rate measure relates audit fees to weighted total audit hours, where hours per staff level are weighed by the average rates per staff level. This denominator is not measure of costs per engagement and therefore, this study's realization rate measure is not a measure of profitability per engagement. A mensure of profitability per engagement requires that revenues generated per engagement (i.e., audit fees) be related to at measure of costs spent per engagement. The next chapter studies the profitability of audit engagements and comptutes the costs per engagement as the sum of (1) the hours spent on an engagement by each staff member, multiplied by the internal hourly rate differentiated per staff member ${ }_{*}$ summed over all staff members; and (2) out-ol-pocket costs (see Davis, et al. 1993, 138). This cost measture was also used in Chapter 3 in studying the cost efficiency of audit services. This 
measure differs from that used in the current chapter in that the hourly rates in the cost measure are not only differentiated per staff lexiel but also per staff member in each of the staff levels. Furthermore, out-of-pocket costs are included. Thus, although the measure in the current chapter contains some elements of costs per engagement, it is not accurate enough to warrant conclusions with respect to the recovery of costs, since it does not include all elements of costs per engagement. See also endnote 21.

3ote that the correlations, variance-inflating factors, and Breusch-Pagan tests are not reported here.

32. As noted in endnote 18 in Chapter 3 , this could be due to possible substitution effects between the various staff levels.

33 These effects are in bold face type when they are statistically significant:

34 As was also indicated there, removal of outliers identified by robust regression (Berk 1990) did not change these results.

${ }_{35}$ For a possible explanation, see endnote 21 in Chapter 3 , Section 3.52 .

36 Again, removal of outliers did not change these results.

37 Simunic and Stein (1996) do not test the same model for audit fees and the realization rate (and note: they do not test any standard fee model), as their audit fee model contains a number of complexity measures in addition to the risk indicators that are included in the realization rate model. Therefore, a direct comparison between their audit fee and their realization rate model cannot be made. However, as an indication, their audit fee model has an adjusted $R^{2}$ of 0.85 , and their realization rate model an adjusted $\mathrm{R}^{2}$ of 0.051 .

Dopuch et al. (2000) test similar models for the standard fee and the realization rate model (but note: the realization rate model includes inefficiency indicators that the standard fee model does not), but they do not thest an audit fee model. However, using nearly the same dataset, O'Keefe, Simunic, and Stein (1994) do test an audit fee model, using the same independent variables that Dopuch et al. (2000) use in their standard fee model. Therefore, a direct comparison cannot be made, but again, as an indication, the audit fee model has an adjusted $R^{2}$ of 0.86 , the standard fee model has an adjusted $\mathrm{R}^{2}$ of 0.84 , and the realization rate model has an adjusted $R^{2}$ of 0.13 .

38 As indicated earlier in Section 4.3 .2 (and in endnote $23 \mathrm{~m}$ that section), significant inegative signs in the realization rate model for the tenure indicators could be ewidence of auditor price culting. Since prior research suggests that price cutting occurs mone in earlier-year engagements than in later-yoars engagements, the (negative) coefficients for the tenture indicators are expected to be ordered as follows: first-year client < second-year client < third-year client < fourth-year client. The finding of a significant negative sign here for the third-year client indicator agrees with this expectation, but considjering that it is the only tenure indicator that is significant, this does not provide consistent evidence of price cutting.

It should be noted that addition of any of these three proxies (i.e., signed total accruals, absolute total accruals, and absolute short-term accruals) did not qualitatively alter the results found in Section 4.4.2 for the other explanatory variables. 
*) Note: addition of long-term accuals to the models including short-term accruals (whether absolute or signed) did mot significantly change the results for the models including those short-term accruals. In particular, the models" adjusted $\mathbb{R}^{2}$ did not increase by adding long-term accruals (rather: these (decreased), the variable long-term accruals itself was not significant, and the results for short-term accruals remained unaltered. This supports the suggestion that it is the higher uncertainty associated with the short-term part of total accruals that prompts auditors to take action by either charging a fee premilum, increasing auditor effort, or both.

41 Again, note that the correlations, variance-inflating factors, and Breusch-Pagan tests are not reported here.

42 Note that the addition of signed short-term accruals (the proxy for potential earnings management) does not alter the conclusions from Chapter 3. When the stochastic frontier analysis is performed for hours and costs models wholuding the measure for potential earnings management, the results still imply that there are no cosit and labor inefficiencies for this sample of audit engagements. As in Chapter 3, the stochastic frontier analysis (SFA) results are still virtually identical to the OLS results, and application of the test described in Section 3.4 shows that the inefficiency term is not significantly different from zero (these results are not reported here). In a sense, this also suggests robustness of the results reported in Chapter 3 (also refer to endnote 33 of that same chapter).

4. Although the model is still not significant, it should be noted that its adjusted $R^{2}$ and $F$-value do increase with the addition of the accruals measure, and that the model nearly reaches conventional significance levels (its specific $p$-value now is 0.1729 ).

44 For the profit margin this is against the expectation that a higher risk, as evidenced by a lower profit margin, is passed on to clients through higher fees.

45 Note that the results of these Wald tests are not further reported here.

46 In fact, using mean values for all other independent variables, when signed short-term accruals increase from the median value $(-0.0038)$ to the $75^{\text {th }}$ percentile value $(0.0268)$, total wnweighted hours increase by $1.8 \%$, and total weighted hours by $1.9 \%$.

4: Similiarly, when signed short-term accruals increase from the median value $(-0.0038)$ to the $75^{\text {th }}$ percentile value $(0.0268)$, superviser hours increase by $5.9 \%$, and supporting hours by $9.4 \%$.

18: In relation to the previous two end notes: when signed short-term accruals increase from the median value $(-0.0038)$ to the $75^{\text {th }}$ percentile value $(0.0268)$, the realization rate decreases by $1.4 \%$.

49 'These financial statement data are part of the client characteristics that are recorded in the firm's electronic filing system during the performance of audit engagements (see Chapter 2, Section 2.3). Of course other client and engagement data besides financial statement data were used in the analyses as well. 


\section{CHAPTER 5 \\ DETERMINANTS OF THE PROFITABILITY OF AUDIT ENGAGEMENTS}

\subsection{Introduction}

The merger between the (then) Big Six firms Price Waterhouse and Coopers and Lybrand and the recent disintegration of Andersen have once again stimulated the discussion on the competitiveness of the audit market. Since the late 1970s, concerns regarding the (lack of) competition on the audit market have been expressed regularly, based on trends of increasing concentration of suppliers in this market (see e.g. Danos and Eichenseher 1986). ${ }^{1}$ The general argument is that increasing concentration facilitates collusion and monopoly behavior, allowing firms to raise price above costs (see Shepherd 1990, 105; Yardley Kauffman, Cairney, and Albrecht 1992, 159; Martin 1993a, 196-197; Carlton and Perloff 1994, 331). A direct test of this argument would be an assessment of the influence of market structure on the relationship between price and costs (i.e., profitability). In the field of industrial organization and industrial economics, many studies relating market structure to profitability have been conducted for a multitude of industries. However, such studies are scant with respect to the audit industry. ${ }^{2}$ This paucity is mainly due to the unavailability of data on audit profitability, and more specifically audit costs (see Dopuch and Simunic 1980, 78; Dopuch and Simunic 1982, 416; Yardley et al. 1992, 160, 174). Therefore, audit market research has attempled to investigate the issue of competitiveness in other ways. Besides studies that simply document the extent of seller concentration in the audit market (see e.g. Rhodle, Whitsell, and Kelsey 1974; Tomczyk and Read 1989; Tonge and Wootton 1991; Wootton, Tonge, and Wolk 1994), these are mainly studies on audit fees and audit production, which were reviewed in Chapter 2. As discussed in that chapter, the results from these studies generally suggest that the audit market is competitive. 
This chapter attempts to investigate directly whether higher market concentration allows firms to raise price above cost. Based on insights from the audit fee and production literature, industrial organization research, and the relatively recent studies on local and regional (rather than national) audit markets, a model for explaining audit engagement profitability is constructed and tested empirically. Prior research in this area is scarce. As discussed in the previous chapter, both Simunic and Stein (1996) and Dopuch, Gupta, Simunic, and Stein (2000) have examined the impact of a number of factors on a ratio of audit fees to a surrogate for audit costs." However, as indicated in that same chapter, these tests were performed as ancillary analyses in studying audit pricing issues, and are thus more or less byproducts rather than examinations of audit engagement profitability in their own right. As a result, these studies tell only part of the story and a proper investigation of audit engagement profitability is yet to be performed. This chapter aims to do so by integrating insights from the audit fee and production literature, industrial organization research, and studies on local audit markets.

On a more practical note, this study might also be relevant for audit firm policymaking. If research indicates that certain clients are more profitable to the audit firm than others, the firm can take this into account in its client-acceptance and/or pricing policies.

The remainder of this chapter is structured as follows. Section 5.2 reviews prior research. Section 5.3 discusses the variables and model. Section 5.4 describes the data collection. Section 5.5 presents the analysis and the results, and Section 5.6 concludes.

\subsection{Prior research}

Prior research on the profitability of audit engagements is scarce. As indicated in the introduction of the current chapter and discussed in Chapter 4, Simunic and Stein (1996) and Dopuch et al. (2000) have tested the impact of a number of factors from prior fee and production research on the ratio between audit fees and a surrogate for audit costs, a measure which they call realization rate. The primary goal of these tests was to supplement analyses of audit pricing issues, 5 and as the authors indicate, in this respect the realization rate represents a fee discount (when audit fees are lower than the surrogate for audit costs) or a fee premium (when audit fees are higher than the surrogate for audit costs). However, since the realization rate effectively reflects the extent to which price is raised above cost, it could also be considered a proxy for profitability, ${ }^{6}$ and the results of the two studies can also be interpreted as such.7

The fact that the two papers have examined the realization rate as ancillary tests in studying audit pricing issues rather than as analyses of profitability per se has 
limited the scope of these studies, particularly with respect to the explanatory variables included in the realization rate model. Both Simunic and Stein (1996) and Dopuch et al. (2000) have only examined variables from prior audit fee, production, and costing research. Since profitability measures relate revenues to costs, prior research on audit fee, audit production, and audit costing is obviously relevant in explaining audit engagement profitability. ${ }^{\circ}$ It is, however, not sufficient and tells only part of the story. Therefore, besides reviewing the studies by Simtinic and Stein (1996) and Dopuch et al. (2000), this section will also discuss other areas of research. More specifically, it will discuss insights from industrial organization research on the relationship between market structure and profitability, as well as (the relatively recent) literature on local or regional (as opposed to national) audit markets.

\subsubsection{Prior research on audit engagement profitability}

As indicated above, although the studies by Simunic and Stein (1996) and Dopuch et al. (2000) were not primarily intended as profitability studies, their findings can be interpreted as such. In investigating the relationship between litigation risk and audit pricing, Simunic and Stein (1996) also test the effect of auditee size and a number of risk measures on the realization rate. ${ }^{9}$ Auditee size was the only significant variable, and the explanatory power of the model was rather poor, certainly when compared to that of the audit fee and audit production model. The latter also applies to the model tested by Dopuch et al. (2000). Their realization rate mode] was more extensive than that of Simunic and Stein (1996) and included measures of auditee size, auditee complexity, auditee risk, auditor tenure, reliance on internal control, provision of nonaudit services, and the relative (in)efficiency of audit production. Significant variables were auditee size, auditor tenure indicators for first- and second-year engagements, reliance on internal control, variables indicating the provision of nonaudit services, and those measuring the relative (in)efficiency of audit production.

Additional discussion of these studies can be found in Section 5.5, where the results of the current study are presented. 10

\subsubsection{Prior industrial organization research}

As indicated in the introduction, industrial organization and industrial economics research has studied the relationship between market structure and profitability for a multitude of industries. The work of Bain (1951) is generally seen as the foundation of empirical work in this field (Martin 1993a, 196). For a cross-section of industries, he hypothesizes and finds that entry conditions and market concentration have a 
significant effect on industry profits. His study has seen many replications and extensions, both on a market (i.e., inter-industry) and industry (i.e., intra-industry) level. All these studies have tested similar models relating market structure variables such as market share, market concentration and entry barrier conditions, and other variables such as growth and capital intensity to profitability. The earlier studies focus on the profitability of entire industries and basically employ two approaches: an industry-based approach using industry-wide data, and a company-based approach using individual company data (Shepherd 1990, 108). In a review of early inter-industry studies Weiss $(1971,365)$ concludes that most studies exhibit a significant positive relationship between market concentration and profitability. However, Schmalensee $(1989,976)$ finds that the more recent inter-industry studies show that the relationship between concentration and profitability is weak at best and that the effect is usually small. Furthermore, when market share is added to the model, the effect of concentration on profitability is found to become insignificant, suggesting that market share effects dominate concentration effects (Geroski 1988, 11.0; Scherer and Ross 1990, 429). According to Carlton and Perloff $(1994,355)$ crosssectional (inter-industry) studies have two serious shortcomings: (1) it may not be realistic to presume that the same relationship between market structure and profitability holds across all industries. This may be due to differences in regulation, product differentiation, the nature of sales transactions, concentration of buyers, and the way in which profitability is computed (Besanko, Dranove, and Shanley 1996, 311-312); (2) concentration ratios published by official government agencies (in this case, US Census) may not correspond to concentration ratios for relevant economic markets. This has led researchers to focus on industry-specific studies, over time or at different locations using firm-level or line-of-business-level data (Carlton and Perloff 1994, 356). These studies confirm results from cross-section studies in that the relationship between concentration and (proxies for) entry barriers on the one hand and profitability on the other is weak at best (Carlton and Perloff 1994, 357), that the positive effect of market share on profitability is larger than that of concentration (indeed if any), and that market share dominates concentration in its effects on profitability if both concentration and market share measures are present in the same model.

Both inter-industry and intra-industry studies suffer from a number of measurement problems with respect to measures of profitability, market share and concentration, and other explanatory variables such as entry barriers. Hypotheses on the relationship between market structure and profits refer to economic profits. However, since measures of economic profits are not easily obtainable, researchers have resorted to surrogate measures based on accounting profits. To correct for differences between economic and accounting profits (Clarke 1985, 104; Schmalensee 1989, 962; Geroski 1988, 111), many researchers have added control variables to their profitability model, such as capital, advertising, and R\&D (Clarke 1985, 106; Carlton 
and Perloff 1994, 358). Also, measures of concentration and market share are likely to be biased because of improper market definitions that do not rellect relevant economic markets (Carlton and Perloff 1994, 347). A market definition needs to be broad enough to include substitutes, but also narrow enough to exclude

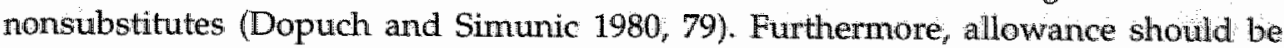
made for the fact that many markets are local or regional rather than national (see Shepherd 1972, 29), and for import and export competition (Carlton and Perloff 1994, 348). Also, many of the proxies for entry barriers are not exogenous and/or frequently have substantial measurement bias (Carlton and Perloff 1994, 348). Finally, measures of profitability and market share and concentration are often biased because of incorrect aggregation across products. Hence, product-level data are preferable to firm-level or industry-level data (Carlton and Perloff 1994, 358).

On a more conceptual level, industrial organization researchers have debated about the interpretation of a positive association between market structure and profitability (see e.g. Martin 1993b, 486). Mainstream industrial organization research has a structuralist view and considers the positive relationship between market structure and profitability a consequence of the firm's market power: higher profitability follows from collusion or monopoly behavior, which is facilitated by higher concentration and/or market share. In contrast, the Chicago-UCLA efficiency school (see Demsetz 1973) claims that both higher concentration and/or market share and higher profitability result from the superior efficiency of larger firms. Proponents of both views maintain that the empirical evidence supports their hypothesis, but effectively, the evidence has a hard time discriminating between the market power and efficiency hypothesis. Practically speaking, the distinction between these two explanations has no implications for the construction of the audit engagement profitability model, since both views suggest the same explanatory variables be included in the model. In addition, and more importantly, the data used here do not allow to distinguish between the two explanations, as data on more than one firm (and preferably: all firms) in an industry are needed to be able to do so. The aim of this study is more modest, as it simply tries to develop a model that can explain the profitability of audit engagements.

\subsubsection{Local/regional versus national audit markets}

As briefly indicated above, many markets are local or regional rather than national (see Shepherd 1972, 29). For instance, in an overview of studies on the relationship between market structure and profitability for banks, Gilbert (1984) indicates that the proper measure for market structure for banks is concentration in local market areas: "..(...).. relevant market areas for banking services are substantially smaller than states of the nation.(...)" (Gilbert 1984, 629). A number of recent auditing studies 
suggest that the same might true for audit services. In motivating their study in which they compare the concentration on local markets (defined here as single Metropolitan Statistical Areas) for the accounting, advertising and law industry, Penno and Walther $(1996,90)$ indicate that local rather than national concentration rineasures are more appropriate for professional services industries since "goods" in these types of industries are generally less transportable than in other industries (such as manufacturing), and the availability of professional services firms depends on the location of their personnel. Similarly, Francis, Stokes, and Anderson (1999, 186) argue that it is the city-based (instead of national) offices of Big Six firms that contract for audils, oversee the performance of these audits, and issue audit reports for clients located in the same area. They find considerable variation in Big Six market shares across local (city-specific) audit markets, suggesting that the reputation of the Big Six audit firms is not standard but varies from one local market to another. In that case, the use of national rather than local market share data could hide important differences in market shares between local markets. Based on Francis et al.'s (1999) argument, a number of other recent studies have investigated audit market issues on a local rather than national market basis. For instance, Barkess and Stokes (2000) study the role of local audit markets (east versus west of Australia) in auditor-selection and auditor-switching decisions by clients, stating that the choice for an audit firm is made from among audit firms that operate in the same local market. Their finding that auditor choice models for local markets have a much higher explanatory power than for national markets seems to confirm this and suggests that this issue is better studied on a local than on a national market level. Reynolds and Francis (2001) examine whether economic dependence on clients (in terms of fee revenues) affects auditors' reporting decisions. They argue that this issue should be studied on office- rather than firm-level, as the loss of a client may have a small effect on the atudit firm as a whole, but a much larger impact on the audit firm's individual practice office that is concerned. Their results seem to confirm this, since only dependence measured using local office-level data has significant effects on auditor reporting decisions. Measures based on national-level data have no significant effects. Finally, Ferguson, Francis, and Stokes (2002) investigate the impact of industry leadership in (Australian) city-specific audit markets on audit pricing, again arguing that local rather than national audit market level is the appropriate level of analysis. Their results suggest that this is a valid argument: whereas industry leadership in city-level audit markets has a significant positive effect on audit fees, industry leadership in national markets has no significant association with audit pricing.

In short, the studies' results confirm those of Penno and Walther (1996) and Francis et al. (1999) in that they imply that it is more informative to examine many audit market research issues in a local market context rather than in a national market context. Of course one could wonder whether this argumentation also 
applies to a small country - certainly when compared with the US and Australia like the Netherlands. Particularly for larger companies, the whole country (or very large parts of the whole country) could be considered one and the same local audit market. As indicated in Chapter 2 (see Section 2.3), however, these large companies have explicitly not been included in the dataset used in this dissertation. Therefore, it could be argued that the companies that are included are of such a size that not just the other Big Six audit firms but also other, smaller, audit firms could be considered competitors for the Big Six audit firm supplying the dataset. These smaller audit firms operate less on a national and more on a local market scale. Viewed this way, the relevant scale of the audit market could indeed be considered local or regional rather than national for the companies included in the dataset. Therefore, in this chapter the effect of local rather than national audit market structure on audit engagement profitability is examined. Since no prior research has investigated the Dutch audit market at a local market level, three different definitions of local markets - increasing in individual local market size - are tested for. These three definitions are discussed in Section 5.3.5.

\subsection{Variables and model}

Based on the prior literature discussed in Chapter 2 and Section 5.2 of the current chapter, a model was constructed to explain audit engagement profitability. The current section discusses the model and its variables.

\subsubsection{Measurement bias and market definition}

This chapter studies the profitability of a sample of individual audit engagements conducted by one of the (then) Big Six audit firms. Thus, this is not only an intraindustry, but also an intra-firm study. As Carlton and Perloff $(1994,357)$ suggest, and as discussed earlier, many studies investigating the relationship between market structure and profitability suffer from measurement biases with respect to the market structure and profitability measures that these studies use. These biases are mainly due to incorrect aggregation across products. Therefore, product-level data are preferable to firm- or industry-level data. Using data for individual audit engagements corresponds to using product-level data, allowing the computation of an audit engagement profitability measure that is not biased by other, nonaudit, services. ${ }^{11}$ As discussed in Section 5.4 on data collection, the data used for computing market structure measures allow to calculate measures that also only concern audit services and exclude other, nonaudit, services. Thus, the profitability measure on the one hand and the market structure measures on the other can be expected to be 
reasonably well-matched. Additionally, the market definition used in this study does not seem to suffer from the definition problems often cited in the industrial organization literature (see e.g. Cubbin 1988, 28-29; Scherer and Ross 1990, 423; Martin 1993b, 452). After all - and keeping in mind Bain's $(1951,298)$ definition of an industry - there are no close substitutes for a statutory financial audit. Since the sample used in this study was purposely restricted to financial statement audits for companies subject to a statutory audit requirement (reviews, compilations and special assignments were not considered; see Chapter 2, Section 2.3), the collected data reflect a very clear-cut audit market definition. The fact that, as discussed later on in Section 5.4, the market structure measures used in this study only pertain to Dutch audit firms and not to firms from foreign audit markets does not alter this. Due to national auditor licensing regimes and country-specific auditing knowledge requirements, Dutch audit firms only compete within and not across national borders (see Section 5.3.4). Similarly, foreign audit firms do not compete with audit firms in the Netherlands. Therefore, import and export competition do not apply, and only audit firms located in the Netherlands are relevant for the audit market definition.

\subsubsection{Dependent variable: a measure for profitability}

Prior industrial organization literature has shown the use of a number of different profitability measures, such as rates of return, price-cost margins, and Tobin's q ratio (see e.g. Carlton and Perloff 1994, 333-344; Shepherd 1990, 113-116; Scherer and Ross 1990, 415-422). As discussed in Section 5.2.2, the literature has also shown that there are many problems in measuring profitability. The profitability measure used in the current study is adapted from the realization rate measure used by both Simunic and Stein (1996) and Dopuch et al. (2000), defined as the ratio between audit fee and (a surrogate for) audit costs. ${ }^{12}$ As indicated in Section 5.2 , both papers have primarily used this measure in tests that supplement analyses of audit pricing issues, and in that sense the realization rate represents a fee discount or premium. However, provided proper proxies for both fees and costs per engagement are used, this measure can also serve as a proxy for profitability since it reflects the extent to which price (audit fee) is raised above costs (audit costs).

As stated above, Simunic and Stein $(1996,131)$ and Dopuch et al. $(2000,2)$ define the realization rate as the ratio between audit fee and (a surrogate for) audit costs. The audit fee is the actual fee paid to the audit firm by the client. The surrogate for atidit costs is termed standlard fee and defined by both papers as the fee charged to the client if the actual audit labor hours were billed at the firm's standard billing rates. This measure was also discussed in Chapter 4, Section 4.3.1. 
The measure for fees used in the profitability measure in this chapter is the same as in Simunic and Stein (1996) and Dopuch et al. (2000): the actual fee paid by the client to the audit firm.

The proxy for audit costs, however, is different from theirs and consists of the following two components: (1) actual number of audit hours spent per staff member, multiplied by the internal hourly cost rate differentiated per staff member, summed over all staff members, ${ }^{13}$ and out-of-pocket costs (see Davis, Ricchiute, and Trompeter 1993, 138).14 This audit cost measure differs in two respects from the surrogate (standard fee) that both Simunic and Stein $(1996,131)$ and Dopuch et al. $(2000,8)$ use. First of all, obviously, this chapter's measure of audit costs includes out-of-pocket costs incurred per engagement; whereas the standard fee measure does not. The second difference pertains to the rates with which the staff hours are multiplied. The standard fee measure uses (standard billing) rates that are differentiated per staff level but equal over all staff members in the same staff level. In contrast, the cost measure used in this chapter (and in Chapter 3) uses (cost) rates that are not only differentiated per staff level, but also per staff member for each staff level. The standard fee measure may be a sufficient proxy for audit costs in investigating audit pricing issues, as both Simunic and Stein (1996) and Dopuch et al. (2000) have done..$^{15}$ However, when assessing the profitability of audit engagements, the measure of audit costs used in this chapter provides a more accurate and appropriate proxy than the standard fee measure. ${ }^{16,17}$

\subsubsection{Independent variables from prior audit fee and production studies}

Prior audit fee and production studies (see Chapter 2) suggest a number of variables that influence audit fees and audit costs. Since this study's audit engagement profitability measure is computed as the ratio between audit fees and audit costs, and to the extent that the variables may differentially influence fees and costs, it may be expected that these variables also influence audit engagement profitability. The selection of variables included in the profitability model is based on the review of prior audit fee and production studies in Chapter 2 and concerns factors related to client size, client complexity, client asset composition, client risk and financial distress, quality of client internal controls, auditor tenure, and the auditor's provision of nonaudit services. The specific variables used are the same as those in Chapter 3 and 4 , and are shown in Table 5.1 below.

For the same sample of audit engagements as used here, Chapter 3 suggests that these are cost and labor efficient. Therefore, in contrast to Dopuch et al. (2000), who do find inefficiencies in their sample, no inefficiency measures are included in this study's model. 
Table 5.1

Variables included in models based on puion andit fee and production sesearch

\begin{tabular}{|c|c|c|c|}
\hline \multirow{3}{*}{ 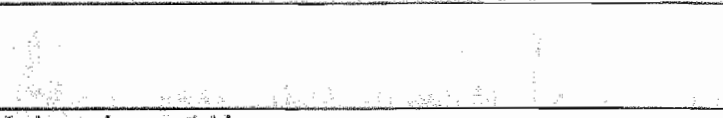 } & \multicolumn{3}{|c|}{ Expected sign } \\
\hline & \multicolumn{3}{|c|}{ Total audit } \\
\hline & Audil lees & costs & Profitability \\
\hline \multicolumn{4}{|l|}{ Independent vatiables: } \\
\hline Assets (natturil log) & + & + & $?$ \\
\hline Nr. of reports prowided to management (natural $\mathrm{log}$ ) & * & + & $?$ \\
\hline $\begin{array}{l}\text { Nri of locations visited by the auditor during the audre (natural } \\
\text { log) }\end{array}$ & + & + & $?$ \\
\hline $\begin{array}{l}\text { Opinion type }(0,1) \text {, where } 1 \text { indicates other than unqualified } \\
\text { opinion }\end{array}$ & + & + & $?$ \\
\hline Foreign proportion of assets & * & + & + \\
\hline Loverage (Longaterm liabilities, /Total assets) & कै. & \#. & + \\
\hline First-yenr client: $(0,1)$, where 1 indicates a first-year client & + & * & - \\
\hline Becond-year client: $(0,1)$, where 1 indicates a second-year client & * & + & - \\
\hline Third-year client: $(0,1)$, where 1 indicates a third-year client & + & * & - \\
\hline Fourth-year client $(0,1)$, where 1 indicates a fourth-year client & + & * & - \\
\hline (Receivables + Inventory)/Total assets & + & + & + \\
\hline Profit margin (Net nesult/Total sales) & - & - & - \\
\hline Nonatidit fee/Audit fee & - & - & ? \\
\hline Inherent risk: $(0,1)$, where 1 indicates greater than average risk & * & + & + \\
\hline $\begin{array}{l}\text { Control quality: }(0,1) \text {, where } 1 \text { indicates higher than average } \\
\text { quality }\end{array}$ & - & - & - \\
\hline $\begin{array}{l}\text { Loss in last two years: }(0,1) \text {, where } 1 \text { indicates an operating loss } \\
\text { in the last two years }\end{array}$ & + & + & + \\
\hline $\begin{array}{l}\text { Listed: }(0,1) \text {, where } 1 \text { indicates a company listed on the } \\
\text { Amsterdam Stock Exchange }\end{array}$ & * & + & 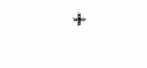 \\
\hline
\end{tabular}

The expected signs for audit fees and audit costs are based on prior fee and production research (see Chapter 2) and were explained in Chapter 3, Section 3.3. The expected signs for the profitability model were explained in Chapter 4 , Section 4.3.2.18

\subsubsection{Independent variables from prior industrial organization research}

Prior industrial organization research (see Section 5.2.2) has included a number of variables in its profitability models, either as experimental or as control variables. The experimental variables fall into three broad categories: market share and market concentration, entry barrier conditions, and other variables such as growth and capital intensity. Control variables are added to correct for differences between economic and accounting profits, to remedy incorrect market definitions, and to control for imports and exports and for locality (instead of nationality) of many markets. 
The setting of the current study precludes many of the variables mentioned above from inclusion in the audit engagement profitability model. Since the study focuses on one industry, and even one firm, factors included in prior research that vary across firms and industries, such as advertising and capital intensity and scale barriers, cannot be included in this study's model..$^{19}$ In addition, factors that do not vary across local markets cannot be included in the profitability model either. The most salient example is regulation and legislation. The data used here are from the Netherlands, where laws and regulations relevant to the current study have national enforcement and legitimacy.

Furthermore, the study's focus on the audit industry renders a number of factors irrelevant. This mainly applies to issues such as import and export competition and audit licensing and certification requirements. ${ }^{20}$ In the country setting of this study import and export audit market competition are prevented by two types of barriers (see European Commission 1996; Buijink, Maijoor, and Meuwissen 1998, 401): (1) national barriers in the form of national licensing regimes and restrictions on the foreign ownership and management of audit firms; and (2) the requirement of country-specific auditing knowledge resulting from national differences in business practices, social security systems, tax regimes, and applicable laws and regulations.

While national licensing regimes may prevent or hinder auditors in competing across national borders, they do not restrain competition within national borders. Although licensing and certification requirements limit the right to provide audit services to qualified individuals (see Dopuch and Simunic 1980, 83), they are not likely to restrict competition, as there are many opportunities to obtain a license (Maijoor, Buijink, van Witteloostuijn, and Zinken 1995, 170). Furthermore, evidence that net entry into the Dutch audit market was substantial under the licensing regime and even higher than during the pre-licensing period suggests that the regime does not present a major barrier to entry into the audit market (Maijoor et al. 1995, 170). Experience requirements were not yet in place in the year for which the data for this dissertation were collected, rendering this possible barrier irrelevant for this study.

The variables suitable for inclusion in the audit engagement profitability model, then, are market concentration and/or market shares. Industrial organization research suggests a number of measures (Scherer and Ross 1990, 422; Carlton and Perloff 1994, 344; Besanko et al. 1996, 285-287): (1) the N-firm concentration ratio (usually written as $\mathrm{CRn}$ ), representing the combined market share of the $\mathrm{N}$ largest firms in the market. The most commonly used ratios are the four-firm (CR4) and eight-firm (CR8) concentration ratio; (2) the Herfindahl index (or H), equaling the sum of the squared market shares of each firm in the market. Whereas the N-firm concentration ratio only focuses on the $\mathrm{N}$ largest firms in the market, the Herfindahl index takes all firms in the market into consideration. Furthermore, the Herfindahl index takes the relative size of each firm into account; and (3) market share, which is 
simply the share of each individual firm in the market. Each of these measures has also been used extensively in studies on auditor market concentration (see e.g. Eichenseher and Danos 1981; Moizer and Turley 1987; Tomczyk and Read 1989; Wootton et al. 1994; Weets and Jegers 1997), and will therefore also be tested in this study's audit engagement profitability model. ${ }^{21}$ Following industrial organization research, the relationship between each of these market structure measures and audit engagement profitability is expected to be positive. As stated earlier, whether a (possible) positive association is a sign of market power or efficiency cannot be determined within the scope of this study.

\subsubsection{Local audit market definition}

As indicated in Section 5.2.3, audit markets seem to be local or regional rather than national Therefore, in this study the market concentration and market share measures discussed above will be measured on a local instead of national level. Three definitions of local markets are tested for. In order of increasing individual locall market size these are: (1) the so-called COROP definition, developed around 1970 by the Coördinatie Commissie Regionaal Onderzoeksprogramma (Coordination Commission Regional Research program), to which it owes its name. In this definition, the Netherlands is subdivided into 40 areas according to the nodal principle of classification, in which the range of influence of a central place and the functional relationship between these central places is taken into consideration; (2) the so-called RBA definition, revised in 1996, which divides the Netherlands into 18 areas for the Regionale Besturen voor de Arbeidsvoorziening (Regional Administrations for Labor provision). Both definitions are definitions at the mesolevel, and are used extensively by the Centraal Bureau voor de Statistiek (Statistics Netherlands; the Dutch Central Bureau of Statistics) in publishing statistics on a wide range of subjects. Both the COROP definition and RBA definition are part of the hierarchically composed Nomenclature of "Territorial Units for Statistics (NUTS) created by the European Office for Statistics (Eurostat) used for presentation of regional statistics within the European Community (Raets and van Batenburg, 1983, 117; Centraal Bureau voor de Statistiek 1997a, 6; 1997b, 5); and (3) the distinction between the so-called Randstad and the area outside the Randstad. The Randstad is the dense central area in the western part of the Netherlands, including the relatively close cities of Amsterdam, Den Haag (The Hague), Rotterdam and Utrecht. The Randstad contrasts sharply with the rest of the Netherlands in terms of (the type of) economic activity, employment, and contribution to the national product. Although the Randlstad covers only $20 \%$ of Dutch territory, nearly half of the Dutch people live and work in the area: $44 \%$ of the Dutch population is housed in the Randstad, $48 \%$ of all jobs are located there, and in 1997 almost $49 \%$ of the Gross National Product is 
earned in the area (Centraal Bureau voor de Statistiek 2000a). More than half of the jobs in the Randstad are in commercial services, a proportion that is significantly higher than the national average (Centraal Bureau voor de Statistiek 2000b). Taken together, these differences between the Randstad and the area outside the Randstad might affect the (nature of the) local audit market structure and this structure's effect on audit engagement profitability.

\subsubsection{Recapitulation}

The audit engagement profitability model used in this study can be presented as follows: the dependent variable audit engagement profitability defined as the ratio of audit fees to total audit costs, is expected to be related to a number of independent variables derived from prior audit fee and production research (see Table 5.1 above), and a measure for (local) market concentration and/or market share derived from prior industrial organization literature. The specification is based on models used in previous audit fee and production research, with the exception that, following Simunic and Stein (1996), Dopuch et al. (2000), and industrial organization research, no natural $\log$ transformation is used for the dependent variable. Thus, the model can be expressed as follows:

$$
p_{i}=\beta_{0}+\beta_{1} \ln A_{i}+\beta_{2} \ln R_{i}+\beta_{3} \ln L_{i}+\sum \beta_{k} \gamma_{i k}+\varepsilon_{i}
$$

In this formulation, $p_{i}$ represents the profitability of a specific audit engagement, $A_{i}$ indicates client size, $R_{i}$ the number of reports provided to the management by the auditor, $L_{i}$ the number of client locations visited during the audit, and $\gamma$ includes all other client characteristics as shown in Table 5.1, as well as a measure for local audit market structure. The hypothesized signs for each of the variables included in the model were discussed above.

Like in Chapters 3 and 4, a fixed level of audit quality is assumed for the audit engagements included in the sample, implying that any differences in profitability across engagements are not associated with quality differences. ${ }^{22}$

\subsection{Data collection}

Data on the profitability measure and all other client and engagement characteristics described in the previous section were obtained from the survey discussed in Chapter 2. Data on local audit market structure measures were obtained from a membership list of the Dutch professional organization of auditors. 
In industrial organization research measures of concentration and market shares are usually based on sales revenues of the firms in the industry under consideration (see e.g. Scherer and Ross 1990, 422; Carlton and Perloff 1994, 344). Applied to the auditing industry, this would imply the use of audit fee as a measurement base. Unfortunately, for many countries data on audit fees are not readily available. The Netherlands are no exception: although data on audit fees are avallable, they are so only for a limited number of larger audit firms (see Buijink et al. 1998, 392). The unavallability of fee data necessitates the use of surrogate measures. Prior audit market research has used a number of these surrogates as measurement bases: number of audits, client assets or sales, square root of client sales, and number of auditors per audit firm (see e.g. Eichenseher and Danos 1981, 481-482; Moizer and Turley 1987, 118-119; Penno and Walther 1996, 91; Weets and Jegers 1997, 777). In the curnent study, the latter is used as the base for calculating the concentration and market share measures. Buijink et al. $(1998,392-393)$ mention three arguments in favor of using this measurement base: (1) it is a direct measure of audit firm size, since it is the employment of auditors that allows audit firms to offer services in the market. There is no a priori reason to expect audil fee to be a better proxy for firm size than a headcount, (2) since the audit industry is labor-intensive, there is likely to be a direct relationship between a firm's fees and the number of auditors it employs. Prior research confirms this: see Zind and Zeghal (1989) for the Canadian market and Meuwissen (1992) for the Dutch market; and (3) the effects of nonaudit services rendered by audit firms can be largely excluded. As discussed below, the Dutch membership lists from which data on the number of auditors per firm are obtained distinguish between auditors working in public practice and auditors involved in other activities, allowing to obtain an audit firm size measure which only reflects the firm's audit activities and excludes other, nonaudit, activities.

By using a headcount the total population of auditors working in public practice can be obtained. Whereas prior studies using client data as measurement bases examine only a subset of the audit market (usually audit firms that serve larger clients or clients listed on stock exchanges), using the number of auditors per firm allows covering the nearly complete audit market (see Maijoor et al. 1995, 156).

Data on the number of auditors per audit firm were obtained from a membership list of the Dutch professional organization of auditors. ${ }^{23}$ The nembership list used was for the same year (i.e., 1997) as the year for which the audit engagement data were collected.

Each membership list contains an auditor list with the following information per auditor: name, home address, home phone number, education, industry (i.e., public practice or not), level (partner or employee), name of the organization where the auditor is employed, and work phone number. The membership list also contains a listing of all audit firms and its offices/locations in the Netherlands, including the offices' phone numbers. By combining this information with the work phone 
number indicated for each auditor, the location of the audit firm's office where the auditor works in public practice can be determined. ${ }^{24}$. This allows calculation of the number of auditors per location/office per firm, based on which the concentration and market share measures per local market can be computed. Using information provided on the firm"s local offices that performed each engagement in the sample the appropriate local concentration and market share measures can easily be linked to the individual audit engagements.

\subsection{Analyses and results}

This section discusses the tests of the model developed in Section 5.3. After showing some descriptive statistics, the results for the profitability model excluding the variables for market concentration or market share are presented first. For purposes of comparison, this model is also tested on audit fees and total audit costs, the measures that together constitute the profitability measure as defined in this chapter. Then the results are reported for the profitability model including the concentration or market share measures.

\subsubsection{Descriptives}

Table 5.2 shows the descriptive statistics on audit engagement profitability, audit fees, total audit costs and client and engagement characteristics for the 114 observations used in the analyses. These are the same 114 observations that were used in Chapters 3 and 4.

The most salient finding is that although the profitability numbers cover a wide range, overall this audit firm seems to make a loss per individual audit engagement: on awerage, only $95 \%$ of the costs per engagement are recovered. 2526 Of course, additional analyses are necessary to explain this finding, but at first sight this result seems to indicate that, at least for this sample of audit engagements from this audit firm, profitability per audit engagement is slightly negative ${ }^{27} 28$

The descriptives for the client and engagement characteristics were discussed in Chapters 3 and 4 , showing that the observations in the sample cover a rather broad size range.

Table 5.3 below presents the descriptive statistics on the market concentration and market share measures discussed in Section 5.3.4, for the 114 observations used in the analyses. ${ }^{29}$

At first sight the measures may seem rather low when compared to concentration and market share measures found in prior audit market structure studies. However, as Buijink et al. $(1998,396)$ remark, measures based on numbers of 
Table 5.2

Descriptive slatistics for audit engagement profitability, audil fees, total atdit costs and chent and engagement characteristics for 114 financial statement andils

\begin{tabular}{|c|c|c|c|c|c|c|}
\hline$\therefore \quad \square$ & Mean & St dev. & Median & Minimum & Maximuadi & \\
\hline \multicolumn{7}{|l|}{ Conthinches parables } \\
\hline Proftability & 0.95 & 0.16 & 0.98 & 0.42 & 1.43 & \\
\hline 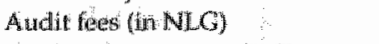 & $84,544,63$ & $136,917,30$ & $54,000.00$ & $11,500.00$ & $1,249,000.00$ & \\
\hline Total andit costs (in NUG) & $90,866,28$ & $147,262.40$ & $56,237.50$ & $14,525.00$ & $1,248,970.00$ & \\
\hline Assefs (in NLC OOO's) & 190,00000 & $792,000.00$ & $32,800.00$ & $4,633.29$ & $6,870,000.00$ & \\
\hline Nr of reports & 1.99 & 1.61 & 2.00 & 1.00 & 12.00 & \\
\hline Nir. of lowations & 200 & 2.65 & 1.00 & 1.00 & 25.00 & \\
\hline Foreign proportion of assetis & 0.04 & 0.15 & 0.00 & 0.00 & 1.00 & \\
\hline Lewerage & 0.12 & 0.17 & 0.03 & 0.00 & 0.82 & \\
\hline $\begin{array}{l}\text { (Receiwables + linventony)/licilal } \\
\text { asisets }\end{array}$ & 0.56 & 0.26 & 0.59 & 0.04 & 1.91 & 妾 \\
\hline Profit margin & 0.04 & 0.08 & 0.09 & -0.33 & 0.51 & \\
\hline Wonadit fee/Audit feo & 0.46 & 0.91 & 0.16 & 0.00 & 6.20 & \\
\hline \multicolumn{7}{|l|}{ Categratical viriadoles } \\
\hline Opimion type & 0.05 & 0.22 & 0.00 & 0.00 & 1.00 & \\
\hline Wirst-year dient & 0.02 & 0.13 & 0.00 & 0.00 & 1.00 & \\
\hline Second-year client & 0.04 & 0.21 & 0.00 & 0.00 & 1.00 & \\
\hline Third-year client & 0.05 & 0.22 & 0.00 & 0.00 & il. 00 & \\
\hline Fourth-year client & 0.04 & 0.21 & 0.00 & 0.00 & 1.00 & \\
\hline Inlherent risk & 0.11 & 0.32 & 0.00 & 0.00 & 100 & \\
\hline Control quality & 0.61 & 0.49 & 1.00 & 0.00 & 1.00 & \\
\hline Loss in last wo years & 0.11 & 0.31 & 0.00 & 0.00 & $\mathbb{1 1 . 0 0}$ & \\
\hline Listed & 0.18 & 0.38 & 0.00 & 0.00 & 1.00 & \\
\hline
\end{tabular}

"In a number of cases cash had a negative sign, causing the ratio (Receivables + inventory)/Total assets to exceexd one.

Notz: for definilions of the variables see Table 5 . 1 and Section 5.3 .3 .

auditors are generally lower than measures using other bases. Furthermore, the levels of the concentration and market share measures for the local market definitions used in this chapter are very well comparable to those reported by Buijink et al. (1998) for the national market. Nevertheless, the measures do cover some range, suggesting that there is some variation in concentration and market shares across local markets. A final remark with respect to Table 5.3 concerns the measures for the Randstad local market definition. Using this local market definition effectively reduces the concentration and market share measures to dummy variables. Therefore, the minimum and maximum values indicated for this local market definition represent the 0 and 1 , respectively, for each dummy variable. Without exception, the minimum value represents the value for the nonRandstad area, and the maximum value the value for the Randstad area. 
Table 5.3

Descriptive statistics for market concentration and market shame measures for 114 finamciall gtatement audits

\begin{tabular}{|c|c|c|c|c|c|}
\hline & Mearit & St. dev. & Median & Mirnimam & Maximnem \\
\hline \multicolumn{6}{|c|}{$\begin{array}{l}\text { COROP local warket defintion } \\
\text { CR4 }\end{array}$} \\
\hline CR4 & 0.51 & 0.11 & 0.49 & 0.40 & 0.84 \\
\hline CR8 & 0.71 & 0.10 & 0.67 & 0.53 & 1.00 \\
\hline Herfindaht index & 0.09 & 0.03 & 0.09 & 0.05 & 0.23 \\
\hline Audit firm market shane & 0.14 & 0.05 & 0.13 & 0.015 & 0.23 \\
\hline \multicolumn{6}{|l|}{ RBA local market defintition } \\
\hline $\mathrm{CR} 4$ & 0.46 & 0.07 & 0.45 & 0.40 & 0.61 \\
\hline CR8 & 0.65 & 0.07 & 0.63 & 0.52 & 0.79 \\
\hline Herfindahl index & 0.07 & 0.02 & 0.07 & 0.05 & 0.11 \\
\hline Audit firm market share & 0.13 & 0.03 & 0.13 & 0.03 & 0.21 \\
\hline \multicolumn{6}{|c|}{ Rimdstad local market defmition } \\
\hline$C R 4$ & 0,44 & 0.06 & 0.40 & 0.40 & 0.53 \\
\hline CRB & 0.57 & 0.05 & 0.53 & 0.53 & 0.64 \\
\hline Herfindah index & 0,06 & 0.01 & 0,05 & 005 & 0.08 \\
\hline Audit finm manket share & 0.11 & 0.02 & 0.09 & 0.09 & 0.14 \\
\hline
\end{tabular}

Note: for definitions of the market concentration and maxket shave measures, see Section 5.3 .4 . For defintions of the local audit markets, sete Section 5.3 .5 .

\subsubsection{Profitability model excluding market concentration and/or market share variables}

Table 5.4 below shows the OLS results for the audit fee, audit costs, and profitability model excluding the market structure variables. Note that for audit fees these are the same results as reported in Table 4.5 in Chapter 4 (see Section 4.4.2), since the same model was also estimated there. Similarly, for audit costs, these are the same results as reported in Table 3.3 in Chapter 3 (see Section 3.5.2) since the same model was also estimated there. Thus, a number of the remarks below were also discussed in Chapter 4 (see Section 4.4.2) and Chapter 3 (see Section 3.5.2).

Pairwise correlations among the independent variables and variance-inflation factors (Gujarati 1995, 328) indicate that multicollinearity does not seem to be a problem. Since application of Breusch-Pagan tests (Greene 2000, 509-510) indicates presence of heteroscedasticity for the models tested, the t-ratios presented are computed using White's heteroscedasticity-consistent covariance matrix estimation method (Greene 2000, 463). ${ }^{30}$

The table shows that all models are significant at the 0.01 level. The results for audit fees and total audit costs confirm the results from prior research in that their 
adjusted $\mathrm{R}^{2}$ is well within the range of those of previous research (see Chapter 2 for these studies). Furthermore, measures of client size, client complexity, client asset composition, client risk and financial distress, quality of client internal controls, auditor tenure and the auditor's provision of nonaudit services are determinants of both audit fees and totall audit costs. Additionally, like in prior studies, client size (measured by total assets) seems to be the most important determinant of audit fees and total audit costs.

Even though the model itself is significant, the adjusted $\mathrm{R}^{2}$ for the profitability model is notably lower than for the audit fee and audit cost model. It seems that the factors that explain audit fees and audit costs quite well, are not able to do so for the ratio of audit fees to audit costs. This corresponds to the results by Simunic and Stein (1996) and Dopuch et al. (2000). ${ }^{31}$ However, the findings regarding the independent variables differ considerably from those of both papers.

In contrast to both Simunic and Stein (1996) and Dopuch et al. (2000), no evidence of a positive effect of client size on the profitability measure is found. And contrary to the findings of Dopuch et al. (2000), nor is there for the provision of nonaudit services. It seems that for the sample used here, the hypothesized effect of audit firm bargaining power on profitability is not present. Rather, for client size the effects of audit firm bargaining power and client bargaining power may have cancelled each other out. Likewise, for nonaudit services the audit firm bargaining power explanation and the loss-leader argument may appear to be equally strong (or weak, for that matter).

Whereas the results by Dopuch et al. (2000) seem to be consistent with price cutting in the initial two years of the audit engagement (without any accompanying systematic reduction in audit effort as evidenced by their results for audit production regressions), the results for the current study's sample allow no such conclusion. Although results for audit production regressions for the same sample reported in Chapters 3 and 4 agree with those of Dopuch et al. (2000) in that there seems to be no systematic reduction in audit effort, the resullts of the current study for the profitability model suggest an increase (rather than a decrease) in price relative to costs in the first year of the engagement, followed by a decrease in price relative to costs in the third year of the engagement. ${ }^{32}$

Dopuch et al. (2000) find that reliance on internal control has an effect in the direction opposite to the one expected, as it appears to increase rather than decrease the realization rate. The findings here neither confirm nor disaffirm this result, as the related variable control quality is not significant. ${ }^{33}$

As already discussed in Chapter 4 (see Section 4.4.2), Simunic and Stein (1996) and Dopuch et al. (2000) find no evidence regarding the effect of risk indicators. In contrast, the findings for the sample used in this study do provide results on this matter. The risk indicator loss in last two years as well as the ratio of receivables and inventory to total assets have a significant positive sign, as expected. Recall that no 


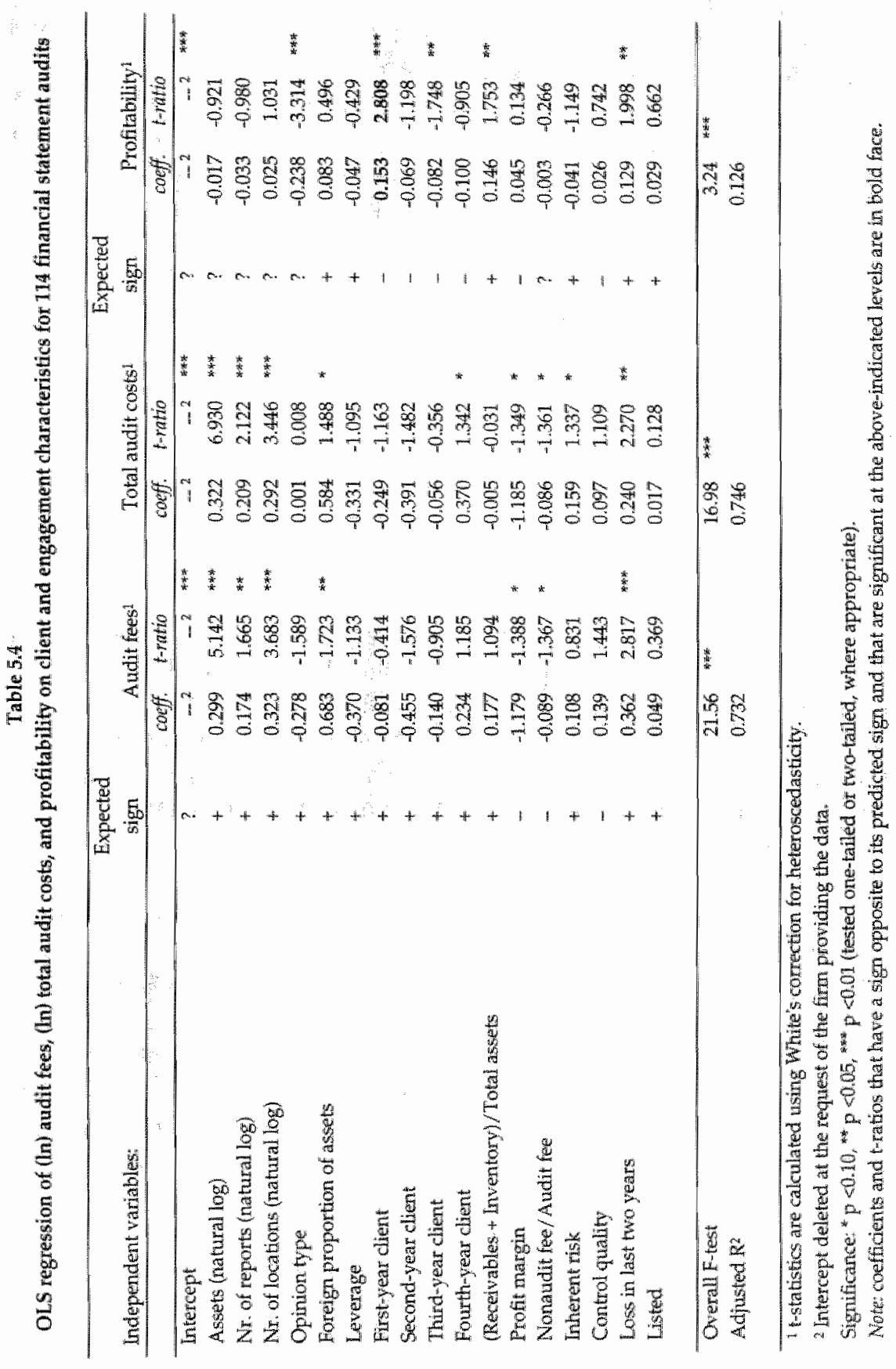


sign was hypothesized for audit opinion type. The results in Table 5.4 show a negative coefficient for this variable, implying that the issuance of an other than unqualified opinion decreases audit engagement profitability. ${ }^{34}$

As indicated earlier in Sections 5.2.1 and 5.3.3, Dopuch et al. (2000) include measures representing cost and labor (in)efficiency of the engagements in their realization rate model. They find a significantly positive relationship between the efficiency measures and the realization rate, which they interpret as indicating that excess costs and labor hours do indeed represent inefficiencies for their sample. More efficient audits should lead to a higher ratio of fees to costs, and inefficiencies lead the firm to discount its billing rates, thus rendering these inefficiencies costly to the audit firm. As noted, the audit engagements in this study's sample seem to be cost and labor efficient (see Chapter 3). Therefore no inefficiency measures were included in this study's model.

\subsubsection{Profitability model including market concentration and/or market share variables}

In Section 5.3 a number of concentration and market share measures were suggested for inclusion in the audit engagement profitability model, for a number of different local market definitions. The measures are: the concentration ratio for the four largest firms (CR4), the concentration ratio for the eight largest firms (CR8), the Herfindahl index $(\mathrm{H})$, and firm market share. The local market definitions are: the 40-area COROP definition, the 18-area RBA definition, and the distinction between the Randstad area and the area outside the Randstad. For most measures and local market definitions, addition of a concentration or market share measure to the audit engagement profitability model did not lead to a substantial increase of the model fit. ${ }^{35}$ In fact, and more specifically, addition of such a measure generally led to a decline of the adjusted $R^{2}$. Evidently, in such cases the added concentration or market share measure was not significant at conventional levels. The exception to this general finding was for measures with the Randstad local market definition. ${ }^{36}{ }^{37}$

Table 5.5 below presents the results for the profitability model for each of the three local market definitions. As can be seen, the specific market structure measure used here is market share. Apart from the specific coefficient values, for each model similar results were obtained using any of other the market structure measures mentioned in Section 5.3.4. Therefore any of the available concentration or market share measures could have been used. However, since prior industrial organization research indicates that market share measures seem to have more explanatory power than concentration measures, the market share measure is the measure shown in Table 5.5. ${ }^{38}$ 
Again, examination of pairwise correlations among the independent variables and of the variance-inflation factors (Gujarati 1995, 328) suggests that multicollinearity is not a problem. Since application of Breusch-Pagan tests (Greene $2000,509-510$ ) indicates presence of heteroscedasticity, the t-ratios presented are computed using White's heteroscedasticity-consistent covariance matrix estimation method (Greene 2000, 463).39

Addition of a market share measure for any of the three local market definitions does not effectively change the results of the profitability model excluding market structure measures as reported in Table 5.4. The models are again significant at the 0.01 level, and except for the specific coefficient values the results for the other explanatory variables, which were discussed above in Section 5.5.2, are unchanged. Furthermore, the results for these other explanatory variables do not differ across the models for the three local market definitions as shown in Table 5.5.

As indicated above, however, the results for the market share measures do differ across the three local market definitions: whereas market share for either the COROP or the RBA local market definition has no significant effect on audit engagement profitability, ${ }^{40}$ the market share variable for the Randstad local market definition is significantly positive and thus appears to increase profitability. ${ }^{41}$ The effect of local market share thus seems to be dependent on the local market definition. These results are difficult to interpret. The results for both the COROP and RBA local market definition could suggest that either the audit firm does not have enough market power to increase profitability, or if it does it is not using it (structuralist view, see Section 5.2.2); or that either the audit firm is not efficient enough to raise price above costs, or if it is, it is not benefiting from it through higher profitability (Chicago-UCLA efficiency view, see also Section 5.2.2).42 43 Either way, for both the COROP and RBA local market definition higher market share does not seem to increase (or decrease) audit engagement profitability. ${ }^{44}$

As noted above, however, the results for the Randstad local market definition seem to suggest that higher market share (or concentration for that matter) leads to an increase in audit engagement profitability, consistent with the expectation expressed in Section 5.3.4. In fact, in the Randstad area the profitability per audit engagement is a little over $6 \%$ higher than the profitability per audit engagement in the area outside the Randstad. ${ }^{45}$ t6 These findings could indicate that higher market share (or concentration) allows this audit firm to raise price above cost.

Alternatively, however, the positive coefficient for the market share measure may simply be due to differences between the Randstad area and the area outside the Randstad. As stated, using the Randstad-nonRandstad dichotomy effectively reduces the market share measure to a dummy variable. Therefore, this variable may very well be capturing other issues than just market structure differences. For instance, the price level in the Randstad area may be higher than outside this area. ${ }^{47}$ Alternatively, it is possible that clients in the Randstad area have a higher ability to 


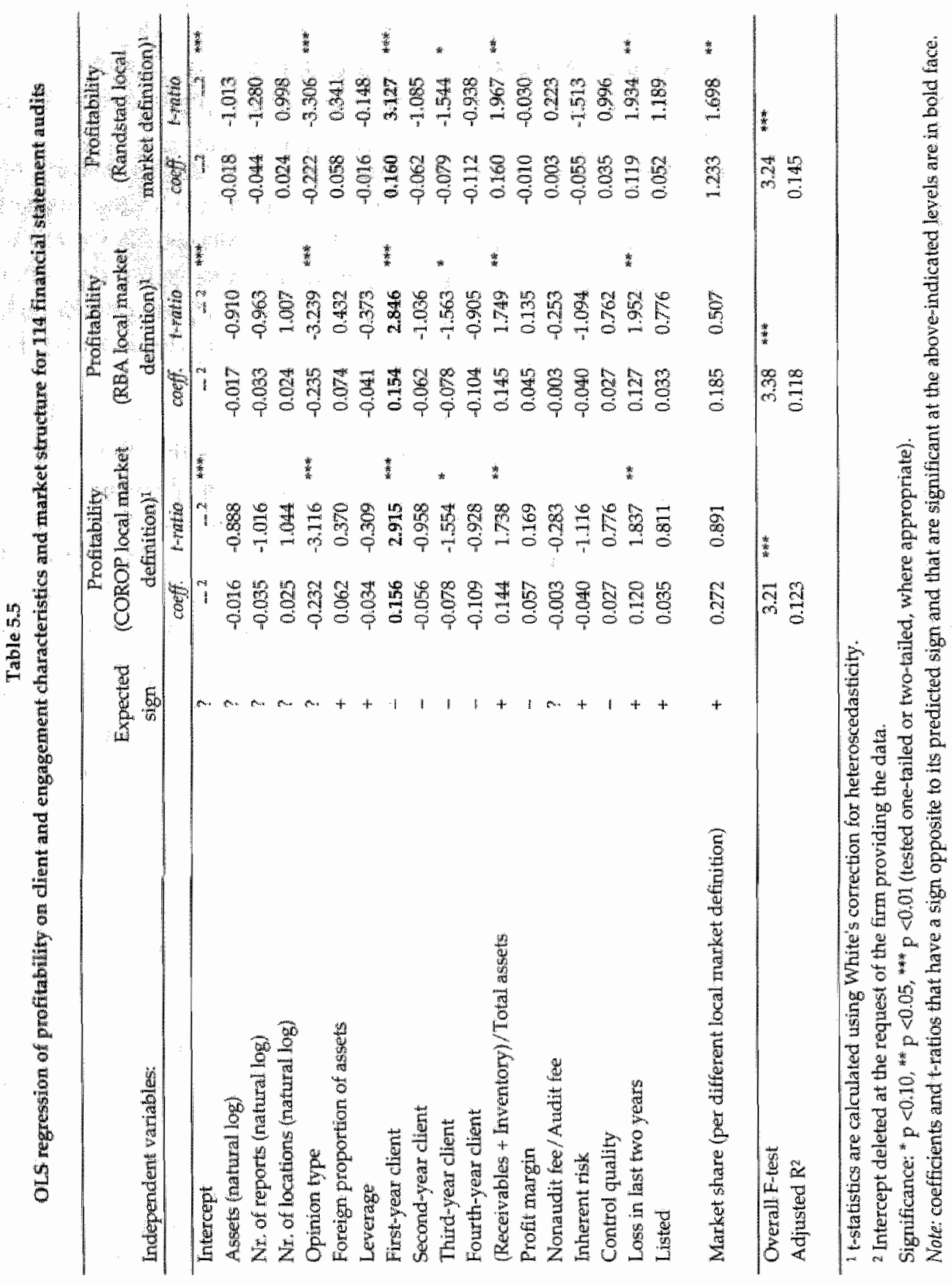


pay than clients outside this area.48 ${ }^{40}$ Howerer the variable profit margin, which is generally considered a measure to control for ability to pay effects (see Taylor and Baker 1981, 57; Brinn, Peel, and Roberts 1994, 107), does not differ sîgnificantly between clients in the Randstad and those outside the Randstad. Also, profit margin is included in the profitability model shown above, but it is insignificant. Furthermore, the correlation between client profit margin and the Randstad dummy is low and insignificant, suggesting that this ability to pay effect may not hold for this sample. Of course it is possible that for this sample profit margin is not a good proxy for ability to pay, and that other proxies might perform better. ${ }^{50}$

Taken together, the results reported above seem to suggest that the effect of local market share on audit engagement profitability depends on the local market definition: for the COROP and RBA definitions, market share has no significant effect on profitability, whereas for the Randstad definition market share seems to significantly increase profitability. A number of interpretations of these findings were offered above. The data used here do not allow to distinguish between these interpretations. Using data on more clients, from more audit firms, and perhaps for more time periods, future research could attempt to shed some more light on this issue. In doing so, this future research might also consider testing for other local market definitions than the ones used here. ${ }^{51}$ Relatedly, future research could also ask auditors how "local" they perceive their audit market to be, and what they consider to be separate local audit markets.

Finally, although addition of the market share measure for the Randstad local market definition seems to increase the explanatory power of the model to some extent $_{r}{ }^{52}$ the model fit is still relatively poor ${ }^{\prime \prime}$ certainly compared to that for audit fee and audit cost - and audit production - models. The majority of the variation in the profitability measure remains to be explained, suggesting the model could be extended. Some suggestions for extensions (that may be considered in future research) will be discussed in the following section. Alternatively, and more conceptually, the low explanatory power of the profitability model may also be an indicator of a competitive market. Based on mictoeconomic theory it can be expected that for a cross-section, profit is a tandom error term if markets are perfectly competitive. This is analogous to the presumption and finding by Fama and French (2000, 161) that for time-series, competition in the market induces mean-reverting profitability. Again, future research is needed to explore this issue.

\subsection{Conclusion, limitations, and suggestions for future research}

This final section presents a conclusion to the chapter by summarizing the study"s findings, discussing its limitations, and providing suggestions for future research. 
As the discussion will show, many suggestions are related to the limitations and logically follow from these.

This chapter has investigated the profitability of audit engagements. Prior research on this subject is scarce and draws its models mainly from audit fee and production research. This chapter has attempted to provide a more complete picture by integrating insights from audit fee and production studies, industrial organization research, and the fairly recent literature on local (rather than national) audit markets. The model thus constructed was tested on a sample of 114 audit engagements from one of the (then) Big Six audit firms. The findings indicate that variables known from prior audit fee and production research may be very well able to explain the measures that together constitute this study"s profitability measure (viz audit fees and total audit costs), but not this profitability measure itself, as the adjusted $\mathrm{R}^{2}$ for the profitability model is decidedly lower than that of either the audit fee model or the audit cost model. This finding confirms the scarce prior research in this area. However, the results for the independent variables do not always agree with this prior research, as this study: (1) does not find an expected effect of audit firm bargaining power on profitability; (2) shows no evidence of price cutting in the initial two years of the engagement, but rather an increase in price relative to costs in the first year of the engagement and a decrease in price relative to costs in the third year of the engagement; (3) does not indicate an effect of internal control quality on audit engagement profitability; but (4) does show effects of risk indicators on audit engagement profitability.

The effect of market structure on audit engagement profitability was tested for three different local market definitions: (1) the COROP definition, dividing the Netherlands into 40 areas; (2) the RBA definition which divides the Netherlands into 18 areas; and (3) the distinction between the Randstad area in the western part of the Netherlands and the rest of the country. Results show that for the COROP and RBA. definitions market structure (more specifically, market share) has no significant impact on audit engagement profitability. In contrast, for the Randstad definition, the effect of market share on profitability is significantly positive, suggesting that for this particular market definition higher market share seems to increase audit engagement profitability. A number of interpretations and alternative explanations for these findings were suggested. Since the data used here cannot distinguish between these interpretations and explanations, future research - using a more extensive dataset - is necessary to do so.

Although the model fit improves somewhat after adding the market structure measure for the Randstad local market definition, ${ }^{53}$ the explanatory power is still relatively low. Most of the variation in the profitability measure remains to be explained and suggests the model could be extended. For instance, Behn, Carcello, and Hermanson (1999) have investigated the effect of client satisfaction with the 
auditor and the audit team on audit fees. This factor might also have an impact on profitability.

Furthermore, industrial organization research suggests that in addition to supplier market power, buyer market power could be an important countervailing influence that could lead to a downward pressure on prices (see e.g. Martin 1993b, 478-479; Carlton and Perloff 1994, 348). A slightly different but related issue is the finding by Kwon (1996) that concentration in the client industry impacts on the client's auditor-selection decision. More specifically, higher client concentration increases the clients' preference to select auditors different from those of the clients' competitors. Competition of audit firms does not seem to be homogenous across client industries served by the audit firms. This result suggests that client concentration could also have an effect on audit engagement profitablity.

Another issue that might impact on audit engagement profitability is product differentiation. Prior fee research has shown that Big Eight/Six/Five/Four auditees generally pay higher fees than do non-Big Eight/Six/Five/Four auditees (see e.g. Francis 1984; Francis and Stokes 1986; Palmrose 1986a; Turpen 1990). Furthermore, evidence indicates that there are also some pricing differences among the Big Eight/Six/Five/Four firms (see e.g. Simunic 1980; Firth 1993; Gist 1994). In combination with a competitive market (which is generally suggested by prior audit fee research, see Chapter 2, Section 2.2.4), these differences in pricing could indicate auditor product differentiation (see Simunic 1980, 171). Based on these findings one could also expect an effect of product differentiation on audit engagement profitability. However, testing this effect once again requires data on more than one audit firm.

A related matter is the possible effect of industry expertise on audit engagement profitability. Again, prior research indicates that industry expertise increases audit fees (see e.g. Craswell, Francis, and Taylor 1995), suggesting that industry expertise could have a similar effect on audit engagement profitability. Size and (industry) composition of the sample used here precludes from testing for this effect, and more observations (per industry) than available for this study are necessary to do so. 54

Alternatively, as suggested at the end of Section 5.5.3, the low explanatory power of the profitability model may simply indicate that the audit market is competitive, since profits in a perfectly competitive market are hypothesized to be a random error term. This is also an interesting issue for future research.

Some of the limitations of this study have already been discussed above and in earlier chapters. As this study only considers data from one audit firm, and for one year, the generalizability of the conclusions is limited. Therefore, additional research on audit engagement profitability using data on more than one audit firm and for more than one year is necessary. As stated, this might also allow to distinguish between the various explanations provided for the results presented in this chapter. Furthermore, future research could also test for more, or other, local market 
definitions than the definitions investigated here. Additionally, as indicated, future research could also ask auditors how large they consider their local audit markets to be and what they regard as separate local audit markets.

Another limitation concerns the measures for concentration and market share used in this study. As indicated in Section 5.4 , the base for calculating this measure in this study is the number of auditors per audit firm. Although research has shown that this base might be just as good (or as bad, for that matter) as any other base for computing these measures, it is very well possible that the measures used in this study misrepresent actual concentration and/or market share. Future research might provide answers by testing for this.

A related, more fundamental issue is whether concentration and market share measures accurately reflect competition on the market. Discussion on this matter is not new and has been brought up many times, also in the auditing context (see e.g. Simunic 1980, 159; Dopuch and Simunic 1980, 78; Dopuch and Simunic 1982, 403). Buijink et al. $(1998,399)$ show that high concentration does not necessarily imply less competition, as high mobility in audit firm market shares - an indicator of a high degree of market competition - coexists with high levels of market concentration for their sample. ${ }^{55}$ As a suggestion for further research, future studies could consider using these dynamic - rather than the conventional static - measures of market structure. Of course, this would again require data for more years and more firms.

Finally, as also noted in Chapters 3 and 4, prior audit research suggests that auditors frequently engage in underreporting of time to meet time budgets. Applied to this study, this would increase the observed profitability relative to the true profitability, and decrease the profitability of accurately reported engagements relative to engagements for which time is underreported (see also Dopuch et al. 2000,8 ). As noted in Chapter 3, the audit firm supplying the data states that they urge their employees to report actual hours worked, and not to underreport. However, it is not certain that they did not do so here. Nevertheless, and in line with the argument made in Chapter 4 on that subject, results from Chapter 3 for the same sample would suggest that if auditors have underreported, at least they have done so consistently for all engagements in the sample, implying that relative profitability (i.e., profitability of one engagement relative to all other engagements) should not have to be distorted. 


\section{Notes}

${ }_{1}^{1}$ Note, however, that Doogar and Easley (1998) show that this current pattern of market shares and concentration in the audit market - with higher market shares and concentration for the Big Six audit firms - can be predicted from a model of pure price competition. This suggests that that the higher shares and concentration for the Big Six firms do not necessarily reflect a lack of competition. See also Buijink, Maijoor, and Meuwissen (1998), who also show that high concentration does not need to imply a lack of competition.

${ }^{2}$ However, as discussed in Chapter 2, Section 2.2.4, a number of studies have related (measures of) market structure to audit fees.

I In fact, until now only Davis, Ricchiute, and Trompeter (1993), Dopuch, Gupta, Simunic, and Stein (2000) and this dissertation have been able to use data on (surrogates for) audit costs.

4 This ratio could be considered a measure for profitability since it reflects the extent to which price is raised above costs. See more on this in Section 5.2 and 5.3 .2 of this chapter.

5More specifically , Simunic and Stein (1996) examined the relationship between litigation risk and audit pricing, and Dopuch et al (2000) studied the relationship between production efficiency and audit pricing. The previous chapter has used this measure in a similar fashion in examining the effect of potential earnings management on audit fees, audit effort, and the interaction between the two.

After all, a premium also indicates higher profit, and a discount also indicates lower profit.

${ }^{7}$ Again, for an interpretation of their results in terms of fee premiums/discounts and a similar use of the realization rate in this dissertation, see Chapter 4.

shis literature was discussed in Chapter 2.

9 As indicated earlier, the realization rate is computed as the ratio between audit fees and a surrogate for audit costs.

10 Recall that these studies were also discussed in Chapter 4. However, since these studies were considered in the context of the effect of earnings management on (the interaction between) audit fees and audit effort (i.e., the realization rate), the discussion in that chapter (see Section 4.4 .2 in particular) was limited to the effects of (indicators of) litigation risk on the realization rate (recall that earnings management is believed to increase auditor litigation risk - see Section 4.2 in Chapter 4).

11 However, as indicated further on in this section, the possible effects of nonaudit services on this profitability measure are tested for.

12. As a sensitivity test the profitability model - to be described in the next sections - was also tested with the price-cost margin as the dependent variable (due to data limitations and given the getting of the current study, neither the rate of retum nor Tobin's $q$ can be used as profitability measures). Industrial organization literature defines the price-cost margin as the difference between revenue and 
variable cost, divided by revenue (Schmalensee 1989, 960). Applied to audit engagements, this is the difference between audit fee per engagement and audit cost per engagement, divided by the audit fee per engagement. Apart from slight differences in significance levels, the results for this modlel - not reported here - are similar to those for the model with the (adapted) realization rate as the profitability measure, which results are reported in Section 5.5 of this chapter.

13 As discussed in Chapters 3 and 4 , members in the following staff levels are distinguished: partner, manager, supervisor, assistant, and supporting activities. As indicated in the same chapters, the activities in the latter category differ from those in the first four since these cannot be characterized as audit fieldwork. The costs of this category are nonetheless included in the audit cost measure so as to provide a complete picture of the costs related to the audit production process.

14 As noted in Chapter 3 , where the same measure for audit costs was used in studying the cost efficiency of audit services, the majority of this cost measure consists of costs related to human capital. As indicated in endnote 9 of that chapter, this is not considered inappropriate, since audit firms are professional service organizations where human capital is the most important input. Other, capital, inputs are considered of second-order importance, an assumption that is not inappropriate in the onefirm setting here. In addition, as noted earlier (again, see endnote 9 in Chapter 3), allocation of the costs related to capital inputs to individual audits may be difficult, and could result in arbitrary allocations and thus inaccurate cost measures.

${ }_{15}$ And like the previous chapter has done. Again, see the previous chapter, in particular Section 4.3.1. The profitability measure used in the current chapter differs from the realization rate measure used in Chapter 4 in a similar fashion as it does from the realization rate measure used by Simunic and Stein (1996) and Doptuch et al. (2000). First of all, for the profitability measure, the rates with which staff hours are muttiplied are differentiated both by staff level awd staff member. In contrast, the rates used in Chapter 4 's realization rate are only differentiated by staff level, but are equal over all staff members in each staff level. Second, the profitability measure used here includes out-of-pocket costs, which are not included in the realization rate measure used in Chapter 4 . Thus, although there is a likeness between the two measures, they do actually differ in the two important respects mentioned here. A more detailed motivation for these differences is provided in Chapter 4, Section 4.3.1 (and endnotes 21 and 30 of that chapter), but suffice it to state here that the differing purposes of the two chapters necessitate the use of different measures.

Tit needs to be noted that in all likelihood, Simunic and Stein (1996) and Dopuch et: al (2000) did not have more accurate proxies of aludit costs at their disposal and were therefore not able to use any other proxy for audit costs than the one actually used. Since, as indicated, more accurate information was available here, an improvement of the audit cost proxy was possible for the study at hand.

17. However, bear in mind the remarks made in endnote 7 in Chapter 3 , Section 3.3 on the "cost" nature and accuracy of the hourly rates used to compute the measure of audit costs. As indicated there, the andit firm that provided the data for this dissertation has stated that internal hourly rates are the cost rates at which hours are (internally) charged to each individual audit engagement. The firm has also indicated that per staff level, each individual staff member has his or her "own" cost rate at which the hours worked by that staff member are charged to the specific engagements. According to the audil firm, these rates differ from the rates used in billing the hours to the dient (i.e., billing rates, which Simunic and Stein (1996) and Dopuch et al. (2000) use). Thus, it can be expected that the 
rates used in this chapter (and in Chapter 3) are not billing rates but cost rates, the use of which results in a more accurate measure of audit costs than when standard billing rates are used. However, as also indicated in endnote 7 in Chapter 3 , the true "cost" nature of these rates cannot be verified since these cost rates are not market-determined rates, and data on the composition of the hourly rates are unavailable. For instance, as stated it is possible that the cost rates contain some mark-ups for costs other than luman resource costs, or for other types of investments. To the extent that these mark-ups are - in a relative sense - equal over all engagements in the sample; this fact need not distort the results presented in this chapter (and in Chapter 3). However, since the presence and nature of these potential mark-ups is unknown, the comments made here should be taken into account when interpreting the results presented later on in Section 5.5 .

${ }_{18}$ As noted earlier (see endnote 15 above), due to the diftering purposes of Chapters 4 and 5 , the realization rate measure used in Chapter 4 differs in two respects from the profitability measure used here. However, despite these differences large parts of both measures are similar. Therefore the expected signs for the realization rate model from Chapter 4 also apply to the profitability model tested here.

19 As indicated in Chapters 2 and 3 , investments in capital are also considered of less importance in this one-firm setting, following O'Keefe, Simunic and Stein $(1994,245)$. However, it is of course possible that clients in certain industries (e,g, technologically more complex industries such as hightech, or regulated industries) require more capital investments than clients in other industries. Relatedly, if an audit firm specializes in certain industries, the audit firm's capital investments are potentially higher in those industries. However, determining which industries this andit firm is specialized in (other than by examining the specializations claimed by the audit firm itselr, e.g. on its website on the internet) is difficult, since it requires information on the audit firm's market share in each industry (see eg. Craswell and Taylor 1991, Craswell, Francis, and Taylor 1995), information which is not readily available in this case. Furthermore, the (client) industry composition of this strudy's sample does not allow to test for an industry effect, if any, since the observations are distributed over many different industries, and the number of observations for each industry (or group of industries) is too small to permit tests that are statistically meaningful.

20 Like most laws and regulations in the Netherlands, regulation with respect to auditor licensing and certification has national enforcement. Therefore, even if this regulation were to be an entry barvier (which, as the discussion below in the main text will show; it very likely is not), its effect would not differ across local audit markets and thus could not be included in this sttwity's profitability model.

21 Of course, these variables will be measured on a local rather than national market level. The definitions of local markets used here will be explained in the next section in the main text.

22. For an argumentation of this fixed audit quality level assumption, see Chapter 2, Section 2.2 .2 , and Chapter 3, Section 3.3.

23 Currently, two types of professionals are permitted to perform statubory audits in the Netherlands (see Meuwissen 1999, 148-149): (1) registered auditors, associated with the Royal Dutch Institute of Registered Auditors (Koninklijk Nederlands Instituut van Registeraccountants, or Koninklijk NIwA), who were granted this right according to the 1962 Act on Registered Auditors; and (2) certified accountants, listed with the Dutch Association of Certified Accountants (Nederlandse Orde van 
Accountants-Administratieconsulenten, NOVAA), according to the 1993 Act on Certified Accountants. Prior to this 1993 Act, only registered auditors (listed with Koninklijk NIvRA) were allowed to prowide audit services.

Research commissioned by Koninklijk NIVRA (see Koninklijk NIWRA 2000) has shown that in 1997 (the year for which data used in this study were collected), four years after the 1993 Act came into force, $98 \%$ of the companies subject to a statutory audit requirement have their financial statements audited by a registered auditor. Certified accountants andit only $2 \%$ of the companies subject to a statutory audit requirement. Therefore, in this chapter only the membership list for the registered anditors listed with the Koninklijk NIVA is used for determining concentration and market share measures.

24 If auditor's work for more than one firm, they were counted with the largesit of the firms, following Buijink et al. $(1998,400)$. If an auditor is listed with more than one of the firm's offices in the audit firm list, the auditor was counted with the office to which the auditor's work phone number belongs. As a sensitivity test, the analyses described in Section 5.5 were also performed with concentration and market thare measures for which auditors working for mone than one firm and/or office are allocated equally to the firms and/or offices for which they work. This makes no difference to the results and conclusions.

25. Note that this finding differs from the results in Chapter 4 (see Section 4.4 .1 ), which showed that the realization rate amounted to 1.02 , implying that on average the hours spent on an engagement are more than passed on to the client through fees, suggesting a small fee premium. As also noted in Chapter 4 (see endnote 30 in that chapter), this does not imply that on average the audit firm more than recovers the costs associated with each engagement, since as indicated in that endnote the realization rate measure does not reflect the relationship between audit fees and audit costs, but rather between audit fees and weighted audit hours. This latter measure contains some, but not all (available) elements of costs per" engagement. In contrast, the measure of audit costs used in the profitability measure of this chapter does. This difference between the realization rate measure used in Chapter 4 and the profitability measure used in the current chapter therefore also provides an explanation for the difference between the results reported here and in Chapter 4.

26 Note that for 51 of the 114 engagements included in the sample, the profitability measure was greatier than 1, implying that for each of these engagements tees are higher than audit costs and thus that the audit furm more than recovered the costs associated with that engagenent. However, overall, the average profitability per audit engagement is slightly below 1.

27 Note that this chapter does not imply that this audit firm as a whole is making a loss. To do so would require data on all clients of the firm, and on all (i.e., both audit and nonatidit) services provided to those clients. This study only has data on a (small) subset of the entive population of clients of this audit firm at its disposal, and its focus is on the profitability of individual audit engagements. Whereas this chapter does investigate the effect of the provision of nonaudit services on this profitability, it does not attempt to examine the overall profitability (i.e, resulting from both audit and nonaudit services) per client. Therefore, consistent with the aim of this chapter, the results reported here only provide an indication of the profitability on awd it services per indiofdual audit engagement and not of the overall profitability of the entire audit firm: it compares the revenues (i.e., the audit fees) per audit engagement to (a proxy for) the audit costs per audit engagement. 
28 However, take into account the renarks made in endnote 17 above about the cost nature of the audit cost measure used in computing audit engagennent profftability:

29 Of course, only a subset of the available concentration and market share measures wete used in computing these descriptives: only those for the local markets associated with the observations in the sample.

30 Note that the correlations, variance-inflating factors, and Breusch-Pagan tests are not teported here.

31 And to the results for the realization rate model reported in Chapter 4 . See also endnote 37 in Chapter 4 .

32 An explanation for the positive effect of the first-year indicator on profitability might be the following (compare with endnote 23 in Chapter 3). Prior to client acceptance, auditors extensively evaluate and screen a new client (see Knechel 2001, 91). The work performed during this acceptance stage may effectively reduce the necessary effort to be expended during the planning stage. Since the client-acceptance work is performed before the client is actually a client, it is possible that as a practical matter this work is not recorded in the audit firm's client records and therefore does net end up in the costs, but it might in the fees. This suggestion would be corroborated by the data if there would be a positive effect of the first-year indicator on audit fees and no effect on costs. Examining the audit fee and audit cost regressions in Table 5.4, however, shows that the first-year indicator has no effect on either audit fees or audit costs, thus suggesting that the above argumentation may not apply to the sample used here.

33 The measure control reliance used by Dopuch et al. (2000) can be expected to be related to the measure control quality used in the current chapter in the sense that according to the audit risk model (see e.g. Arens and Loebbecke 2000,269 ) a higher quality of controls would result in a lower assessed control risk, implying more reliance on these controls, an increase in the planned detection risk,

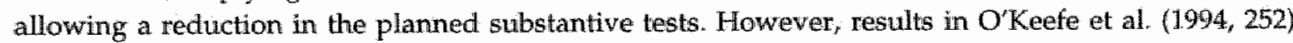
for the same sample as used in Dopuch et al. (2000) show that for over 90 percent of the sample no or limited reliance was placed on controls, and that in some cases no reliance whatsoever was placed on controls of excellent quality. Since data on control reliance are not available for the sample used here, it cannot be verified whether this finding also holds for this sample. In addition, due the unavailability of control reliance data the variable control quality (which is availablle for this sample) rather than reliance on controls is used in the profitability model here.

34 As indicated in Chapter 3 (see endnote 21 in Section 3.5 .2 of that chapter), there were only two types of opinions for this samplle: unqualified opinions and disclamers. Thus, effectively, the issuance of a disclaimer seems to decrease audit engagement profitability. An explanation for this might be related to the audit contract type used by the audit firm (see Palmrose 1989, 489). A cost-reimbursement contract implies that the cosits associated with an audit engagement are largely reflected in the audit fees since these fees are determined after the audit is conducted. In contrast, under fixed-fee contracts the audit firm and the client agree upon the fee before the audit has commenced. Thusi, in the latter case, any extra work not foreseen at the outset of the audit will not end up in the fee but may result in costs to be borne by the audit firm. This extra work could be caused by a higher than average risk associated with the issuance of an other than ungualified opinion, for example. If the extra work due to this risk factor increases audit costs, but does not end up in the andit fee because the audit firm 
uses a fixed-fee contract, the effect on profitability (i.e, the ratio between audit fees and audit costs) could be negative. However, since the audit firm supplying the data for this dissertation did not provide information on the audit contract type of the audit engagements in the sample, the validity of this argumentation cannot be verified.

Wheri both a concentration and market share measure (both for the same locall market definition) were added to the same basic profitability model, model fit did not increase either, as both the concentration and market share measures were insignificant at conventional levels. This contradicts findings from prior industrial organization research that generally show a significant positive effect for market share measures, that in addition dominates the effect of concentration measures.

36 For this sample, $33 \%$ of the audits were performed in the Randstad area, and $67 \%$ outside this area.

37 As noted in Section 5.51 , using the Randstad-nonRandstad dichotomy effectively reduces the market structure measure for this local market definition to a dummy variable. This fact precludes testing whether, in line with prior industrial organization research, the effect of market share dominates that of concentration, since inclusion of both a concentration and market share measure results in one of the two being dropped from the regression equation (compare with endnote 35 above).

3* Note that addition of the measure for potential earnings management examined in Chapter 4 (signed short-term accruals) does not effectively change the results reported in this and the previous section. Although adding the earnings management proxy leads to a negative and significant sign for this variable in the profitability models (like it did in the realization rate model analyzed in Chapter" 4), as well as a corresponding increase in the models' adjusted $\mathrm{R}^{2}$, the restilts for the other explanatory wariables in the models are virtually unchanged, apart from the specific coefficient values (these results are not reported here). In a way, this also suggests robustness of the results reported here.

39 Again, note that the correlations, variance-inflating factors, and Breusch-Pagan tests are not: reported here.

40 In line with this finding, market share for both market definitions did not increase the profitability's nodel adjusted $\mathbb{R}^{2}$. In fact, as noted above addition of market share rather decreased model fit. As can be seen from Table 5.5, addition of market share for the COROP local market definition decreased the adjusted $\mathrm{R}^{2}$ from 0.126 to 0.123 , and addition of market share for the RBA definition decreased the adjusted $\mathrm{R}^{2}$ from 0.126 to 0.118 .

4i Consistent with this result, the adjusted $\mathrm{R}^{2}$ for this model increased from 0.126 to 0.145 .

4 Results from Chapter 3 seem to suggest that relative to comparable audit engagements, the engagements in the sample used here are produced efficiently (see Section 3.53 ). Recall, however, that these results only provide an indication of efficiency relative to comparable audit engagements. The results from Chapter 3 do not (and cannot) indicate that the audit firm as a whole is efficient, nor do (or can) they indicate that this audit firm is more efficient than other firms (see also endnote 28 in Chapter 3). Therefore, the efficiency results from Chapter 3 are not necessarily inconsistent with those for the current chapter regarding the (nonsignificant) effect of market share for the COROP and RBA local market definition on audit engagement profitability. 
4 Note, however, that as indicated earlier, the current chapter does not and cannot distinguish between the structuralist view and the Chicago-UCLA efficiency wiew in explaining the results on the relationship between market structure and profitability. The dataset used here do not allow doing so since data on more (and preferably, all) firms, and for more than one year, in the audit industry are necessary for these kind of analyses. Note also that for the same reason the current chapter does not intend to make any general claims as to (the functioning of) the audit market, nor to the extent of competition on this market.

4. Another possible explanation is that both the COROP and RBA local market definition divide the country into too many (and therefore too small) individual local markets, even more so because, as indicated in Section 5.2.3, the Netherlands is a small country, certainly compared to the US or Australia (the only two other countries for which, until now, audit research has investigated local audit markets, again see Section 5.2 .3 of this chapter). For both the COROP and the RBA definition there is substantial variation in the market concentration and market share measures in general. However, it is of course possibie that the distribution of the 114 engagements in the sample over the local markets is such that this variation is reduced, perhaps leading to insignificance of the concentration and market share measures for the COROP and RBA definitions in the profitability model.

45 Using mean values for all other independent variables in the audit engagement profitability model, mean profitability per audit engagement amounts to 0.99 for engagements in the Randstad area, and 0.94 for engagements outside this area.

4/ Again, note that this does not imply that the firm's werall results are $6 \%$ higher in the Randstad compared to the area outside the Randstad. As indicated in endnote 27 above, the findings discussed here only concem the profitability per individual chient, not the audit firm as a whole, and they only concern profitability on audit services, not profitability for all (i.e, audit as well as nonaudit') services provided to the client.

47 It is not possible to test for this. As discussed earlier, using the Randstad-nonRandstad dicholomy has effectively reduced the local market share measure to a dummy variable. A variable capturing differences in the price level between the Randstad and the area outside the Randstad would allso effectively be a dummy variable. Inciusion of both the market share measure and a price level measure in the model would result in one of the two variables being dropped from the regression. Compare with end note 37 .

* Exidence from the Centraal Bureau voor de Statistiek (Statistics Netherlands; the Dutch Central Bureau of Statistics) shows that all areas of the Netherlands that have the highest disposable income are located in the Randstad area (Centraal Bureau voor de Statistiek 1999).

$49 \mathrm{p}=0.59$ for an independent samples $t$-test, and $\mathrm{p}=0.421$ for a Mann-Whitney test.

${ }_{50}$ Note that additional examination of the data (by means of $t$-tests, Mann-Whitney tests, and $x^{2}$-tests; results not further reported here) shows that the other independervt variables do not differ: significantly between Randstad clients and nonRandstad clients at conventional significance levels. 
${ }^{51}$ E. g. local market definitions "between" the RBA and the Randistad definition: with less than 18 but more than 2 individual local markets:

52 And note explanatory power decredses when market structure measures for either of the other two local market definitions ane added to the model.

53 Remember fit decreasses after adding market structure measures for the COROP and RBA local market definitions.

34 See also endnote 19 above.

95. It should be noted that ${ }_{f}$ as indicated earlier in Section 5.4, Bujink et al. (1998) also use the number of auditors per audit firm as the base for calculating their concentration and mobility measures. 


\section{CHAPTER 6}

\section{SUMMARY AND DISCUSSION}

\subsection{Introduction}

This dissertation has examined the pricing and production of audit services. In particular, it has investigated the following three topics: (1) efficiency in the production of audit services; (2) the effect of potential earnings management on audit pricing and audit production; and (3) the profitability of audit services. Chapter 1 introduced the subjects of this dissertation and positioned these within existing audit research taxonomies. Chapter 2 discussed prior research on audit pricing and audit production, as well as the method of data collection. Chapters 3 to 5 reported the results of the empirical studies on the three topics referred to above: Chapter 3 studied the labor and cost efficiency of audit services, Chapter 4 investigated the effect of potential earnings management on audit pricing and production, and Chapter 5 examined the profitability of audit services.

This final chapter provides a summary and discussion, and is structured as follows. Section 6.2 summarizes the three empirical studies. Section 6.3 discusses the limitations of the studies and provides suggestions for future research. The discussion will show that many of these suggestions are related to the limitations and follow naturally from these. Finally, Section 6.4 provides some policy implications.

\subsection{Summary}

This dissertation has examined three issues related to the pricing and production of audit services: efficiency in the production of audit services, the effect of potential earnings management on audit pricing and audit production, and the profitability of audit services. Although there is a large body of research on audit pricing and audit production in general, the three specific topics mentioned above have been relatively 
under-researched, primarily because of the proprietary nature of the data needed to investigate these types of issues. As discussed in Chapter 2, the dataset used in this dissertation contains detailed information on audit fees, audit effort, and client and engagement characteristics for audit engagements performed by a (then) Big Six audit firm, allowing to investigate these interesting and important topics.

Although the three empirical chapters of this dissertation are related in that they build on the same literature (i.e., prior research on audit pricing and audit production, discussed in Chapter 2) and use the same dataset, each empirical chapter investigates a distinct, specific topic, has its own additional background literature, and can therefore be regarded as a separate, independent study. The results of these studies are summarized below.

\subsubsection{Benchmarking the production of audit services: An efficiency frontier approach}

An investigation into the efficiency of audit services production may provide important information to audit firms operating in an increasingly competitive audit market. If audit firms want to compete on the dimension of audit pricing, they need information on audit costs - more specifically, the minimum audit costs necessary to conduct an audit. Since for professional service organizations such as audit firms the majority of costs relate to use of labor, audit firms may also need information on the minimum amount of audit effort needed to perform an audit engagement. The study discussed in Chapter 3 has examined the cost and labor efficiency of audit services.

Based on prior audit pricing and production literature, a model for both audit production (effort) and audit costs was constructed. Subsequently, the labor and cost efficiency of audit services was evaluated by applying an efficiency frontier technique known as stochastic frontier analysis. Prior audit production studies have always implicitly assumed that the competitive audit market has disciplined auditors into efficient production, since they have used ordinary least squares regression to estimate audit production models. Ordinary least squares regression fits a line through the center of a scatter plot and can therefore compute the average, but not the minimum (i.e., efficient) amount of costs and/or hours necessary to conduct an audit. In contrast, efficiency frontier techniques can do so. As indicated, one of these techniques, stochastic frontier analysis, was used here. The results suggest that, at least for the sample of audit engagements used here, audit services seem to be cost and labor efficient, implying that, relative to comparable engagements, these engagements could not have been produced with less audit hours and/or for less costs. ${ }^{1}$ 


\subsubsection{The impact of potential eamings management on the pricing and production of audit services}

Current developments involving companies such as Enron, WorldCom, and very recently Ahold, have shown how important it is that auditors carefully consider the risk associated with potential earnings management. After all, not only the companies suspected of earnings manipulation are under heavy criticism, but also their auditors who should have prevented or detected and corrected this manipulation. ${ }^{2}$

Francis and Krishnan $(1999,159)$ suggest fiwe ways in which rational auditors can deal with the risk of (potential) earnings management: (1) report more conservatively by issuing more modified opinions to higher-risk clients" (2) screen out high-risk clients; (3) increase audit effort for these clients; (4) charge a fee premium to these clients; and (5) negotiate with these clients for adjustments in their financial statements. The study reported in Chapter 4 has investigated two of these options: increase audit effort and charge a fee premium. It has also studied how potential earnings management affects the interplay between these two options. For example, when potential earnings management leads to a higher fee, it is important to find out whether this higher fee follows from more audit effort, a fee premium, or both.

Again, prior audit pricing and production research was used to construct a base model for audit fees and audit effort. To this base model, a measure for potential earnings management was added. Two proxies were tested: total accruals and shortterm accruals, both on an absolute and a signed basis. Only signed short-term accruals had significant effects, in accordance with the argument by Francis and Krishnan $(1999,144)$ that short-term accruals represent more uncertainty to auditors than total accruals. Furthermore, in addition to the size of the manipulation, the direction of the potential manipulation seems important to auditors as well, since only signed, and not absolute, short-term accruals were significant.

The results show that the accruals measure significantly increases audit effort (in particular, hours spent by supervisors, who are directly involved in the conduct and supervision of an audit, and supporting activities, which includes support from the audit firm's technical department), but has no impact on audit fees. These results suggest that an increase in the risk associated with potential earnings management induces auditors to spend more effort on the audit, but that this effect is not passed on to the clients through fees. This finding is supported by the significant negative effect of the accruals measure on the realization rate. The realization rate is defined as the ratio of audit fees to (weighted) atidit hours, and allows to investigate the effect of potential earnings management on the interplay between audit fees and audit effort. The negative sign for the measure for potential earnings management suggests that (weighted) audit hours are affected more than fees by this measure. 
The findings for the measure for potential earnings management are different from those for most of the other (litigation) risk measures included in the models. Perhaps this points to a difference in the nature of the risk captured by each of the measures.

\subsubsection{Determinants of the profitability of audit engagements}

Examining the profitability of audit engagements, and in particular the factors that affect this profitability, may be relevant for audit firm management. If an audit firm knows which types of clients are more and which are less profitable to the firm, it can take this into consideration in its policymaking, e.g. in client-acceptance or pricing policies.

On a more conceptual level, the study discussed in Chapter 5 was motivated by the frequently expressed concern regarding the lack of competition on the audit market. The argument is that increasing concentration facilitates collusion and monopoly behavior, enabling audit firms to raise price above cost. The study has examined this argument by testing how elements of market structure - as well as other factors - affect the relationship between price and cost (i.e., profitability).

Based on prior audit pricing and production literature, industrial organization research, and studies on local (versus national) audit markets, a model for explaining audit engagement profitability was constructed. Audit engagement profitability was defined as the ratio between audit fees and audit costs. The elements of market structure considered were market concentration and/or market share, where the measurement base was the number of auditors per audit firm. Three definitions of local markets were tested for, each increasing in individual local market size. These were: (1) the COROP definition, dividing the Netherlands into 40 areas; (2) the RBA definition, dividing the Netherlands into 18 areas. Both the COROP and RBA definition are used by the Dutch Central Bureau of Statistics in publishing statistics on a wide range of subjects; and (3) the distinction between the Randstad and the area outside the Randstad. The Randstad is the dense central area in the west of the Netherlands, containing the cities of Amsterdam, The Hague, Rotterdam, and Utrecht. This area differs considerably from the rest of the country in terms of economic activity, employment, and contribution to the national product.

The results show that on average, the individual audit engagements represent a loss to the audit firm since overall only $95 \%$ of the costs per engagement are recovered. ${ }^{3}$ Furthermore, important determinants of audit fees, audit effort, and audit costs also seem to be significant determinants of audit engagement profitability. These relate to client risk and financial distress, auditor tenure, and client complexity. The results also suggest that the effect of local market structure is dependent on the local audit market definition that is used: whereas market share for either the COROP or RBA definition has no significant effect on audit 
engagement profitability, market share for the Randstad local market definition seems to increase profitability. Although a number of explanations for these findings are suggested, the data used here cannot distinguish between these, and further research is necessary to do so.

\subsection{Limitations and suggestions for future research}

This section discusses limitations of the three empirical studies and supplies suggestions for future research. A number of these suggestions are related to the limitations and follow from these.

Many of the limitations and suggestions provided here were also discussed in each of the empirical chapters. A limitation that applies to all three studies relates to the dataset that is used. Although the dataset contains unique, proprietary data that allow to investigate important issues on which prior research is scarce, data from only one audit firm and for only one year were available, limiting the generalizability of the results. Results for other firms and/or for other periods of time may result in different findings. Therefore more research in this area is warranted, especially considering the relevance but scarcity of research on the issues investigated in this dissertation. More specifically, research on the efficiency of audit services would benefit from considering more than one audit firm and/or data for more than one year, to see whether efficiency differs across firms and/or across time. In doing so, future research could use one or more of the efficiency frontier techniques discussed in Chapter 3, thereby also allowing to compare the performance of the various available efficiency techniques in detecting (in)efficiencies in audit costs and audit production, an area in which application of these techniques is rather new.

Data on more than one firm and/or for more than one year would also be beneficial for research on the effect of potential earnings management on audit pricing and audit production, especially when taking the recent developments involving major companies such as Enron, WorldCom, and Ahold into account. The data used in this dissertation are from 1997, well before signs of the current crisis were noticeable. Therefore, it might be interesting to study if and how the results obtained here would change due to these recent developments and the potential measures that are being taken. This also applies to the other options suggested by Francis and Krishnan $(1999,159)$ for auditors to deal with the risk associated with (potential) earnings management.

Finally "data for more firms and/or more time periods could also further research on the profitability of audit services. As indicated, the results in Chapter 5 suggest that effect of local market structure on audit engagement profitability is dependent on the local audit market definition. Using data on more firms and/or more time 
periods would allow to determine whether this finding extends to other firms and periods, or is specific to this dataset. Furthermore, more data would also allow to investigate whether a potential positive relationship between market structure and profitability can be attributed to either market power (the mainstream structuralist view, see Chapter 5, Section 5.2.2) or efficiency (Chicago-UCLA view, see also Section 5.2.2). The dataset used in this dissertation does not allow to do so.

Related to the above, this dissertation has used data from one of the largest audit firms in the Netherlands. Given the economic importance of many small and medium-sized audit firms, future research that considers using data for more than one audit firm need not be limited to the largest audit firms, but could examine these small and medium-sized firms as well. That way, a more complete picture of (the functioning of) the audit market can also be had.

Another limitation that is related to the dataset and applies to all three studies might result from the fact that prior research has suggested that auditors frequently engage in underreporting of time. If auditors would have underreported on the audit engagements included in the sample used here, this would have (1) decreased the observed amount of effort spent for engagements for which underreporting has taken place relative to accurately reported engagements; thus (2) increased the observed (versus the true) efficiency for these "underreported" engagements; (3) increased the observed (versus the true) realization rate for underreported engagements; and (4) increased the observed (versus the true) profitability for underreported rather than accurately reported engagements. Although the audit firm that has supplied the data has indicated that they urge their auditors to report the actual hours worked and not underreport to meet the time budget, there is no guarantee that underreporting indeed did not occur. Even so, if the auditors in the sample have actually underreported, the results from Chapter 3 would suggest that hours are consistently underreported for all clients. This implies that the relative labor use and realization rate in Chapter 4 and the relative profitability in Chapter 5 should not have to be distorted and therefore not limit the results from these chapters.

A last limitation with respect to the data specifically applies to Chapter 4 . In that chapter, data from audited financial statements (captured in the audit firm's electronic filing system) are used to measure potential earnings management. Postaudit information only contains earnings management not detected and/or prevented by the auditors, thereby possibly understating the true extent of earnings management investigated and detected by the auditor. Future research could contemplate using pre-audited financial statements to: (1) identify actual earnings management attempts by managers; (2) evaluate the extent to which auditors have been successful in detecting and preventing earnings management, by comparing pre- and post-audited information; and (3) assess the effect of both on audit fees, audit effort, and the interplay between the two. 
A number of limitations and suggestions apply to only one of each of the empirical chapters: A suggestion for research on the efficiency of audit services production (Chapter 3 ) is related to the suggestion to use data for more than one firm and/or more than one year, and focuses on the effect of audit technology. Prior research has shown that audit firms differ in their audit approach, and anecdotal evidence suggests that these approaches also change over time. It is argued that at structured approach may improve audit efficiency, and thus lead to better control of (i.e., lower) audit costs. If data for more than one firm were available, and the audit approaches for these firms differed; or if data for more than one year were available, and the audit approach of the firm(s) changed over time; then the effect of (differences and/or changes in) audit structure on audit efficiency could be examined.

A limitation (and ensuing suggestion) of the study reported in Chapter 4 relates to the measure used in that chapter as a proxy for potential earnings management. The dataset that was used limited the available proxies to those based on total accruals. Other proxies might generate different results, and therefore future research should consider using and evaluating other measures for potential earnings management.

Another suggestion for further research related to Chapter 4 concerns the difference that was found between the effects of the risk associated with potential earnings management and the other (litigation) risk indicators included in the models. This difference might be due to differences in the nature of risk for the various indicators, and future research could elaborate on this issue.

A final suggestion for future research following from Chapter 4 relates to the options suggested by Francis and Krishnan $(1999,159)$ for auditors to respond to the risk associated with (potential) earnings management. As suggested above, future research could investigate how the recent accounting crisis has impacted on auditors' use of these options. As an additional suggestion, further research could not only examine these options in isolation, but also study one or more options together and thus investigate when, how, and based on what criteria an auditor chooses which option.

A limitation to the results from Chapter 5 relates to the measures for market concentration and market share used in that chapter. The base for calculating these measures was the number of auditors per audit firm. Prior research implies that this base is just as good as any other, but of course it is possible that the measures used here misrepresent actual market concentration and market share. Future research might evaluate this by using other (or multiple) bases. Relatedly, previous research has argued that concentration and market share measures do not reflect actual competition on the market. Buijink, Maijoor, and Meuwissen $(1998,399)$ claim that high concentration does not automatically imply less competition. They find that high concentration goes together with high mobility in audit firm market shares, 
where the latter is an indicator of a competitive audit market. Thus, future research might use these dynamic measures of market structure, rather than the conventional static ones. Evidently, cata for more years and more firms are needed to do so.

In addition, future research could also consider using more, or other, definitions for local audit markets. As indicated, the results from Chapter 5 regarding the effect of local audit market structure on audit engagement profitability are dependent on the local market definition that is used. As discussed earlier in the current section, future research using data on more firms and/or more time periods could verify whether this also holds for other datasets. Alternatively, or additionally, future research could contemplate using other local market definitions to assess how the findings from Chapter 5 extend to these other definitions. ${ }^{5}$

Final suggestions follow from the relatively low explanatory power of the profitability models estimated in Chapter 5 . Even after addition of the market share measure for the Randstad local market definition the model fit is rather poor, ${ }^{6}$ stiggesting that the model be extended. A number of possibilities to consider are: (1) the inclusion of measures reflecting client satisfaction with the auditor and/or audit team; (2) examining the effect of buyer (in addition to supplier) market power; (3) taking into account the fact that many clients do not want to have the same auditor as their competitors; (4) investigating the effect of auditor product differentiation; and (5) relatedly, the potential effect of industry expertise on audit engagement profitability. Again, investigating these possibilities requires data on more than on audit firm.

Alternatively, however, the poor fit of the profitability model could allso be an indicator of a competitive audit market, since in a competitive market profits are hypothesized to be a random error term. Future research could also pursue this interesting issue.

In sum, although there is a lot of prior research on the pricing and - to a lesser extent - the production of audit services, research on the specific pricing and production issues studied in this dissertation is rather scarce, and a fair number of interesting possibilities for future research in these areas are still available.

\subsection{Policy implications}

This last section provides some policy implications following from the empirical results reported in this dissertation. More specifically, Section 6.4.1 discusses implications for audit firms and the audit profession, Section 6.4 .2 discusses implications for audit clients, and Section 6.4.3 discusses implications for regulators. Section 6.4 .4 concludes.

Note that the policy implications provided in this section are subject to the limitations discussed in Section 6.3 above. In particular, the dataset used in this 
dissertation contains client and engagement characteristics for a limited sample of audit clients from offices of only one of the larger audit firms, and for one financial year only. As indicated, this limits the generalizability of the results, and therefore also any policy implications following from these results. This needs to be borne in mind while interpreting the implications discussed below.

\subsubsection{Implications for audit firms and the audit profession}

The empirical results reported in this dissertation may have a number of implications for audit firms and the audit profession. Results from Chapter 3 on the efficiency of audit services production suggest that for the sample of audit engagements used in this dissertation, this audit firm seems to have produced its audits efficiently. That is, the audits could not have been conducted with fewer hours and/or for less audit costs. ${ }^{7}$. As indicated in Chapter 1 (Section 1.1) and the introduction to Chapter 3 (Section 3.1), information on the minimum amount of costs and hours needed to complete an audit is necessary to compete effectively on the audit market and to offer audit services at competitive prices. Therefore, the audit firm can use information on minimum hours and costs in pricing its audits. Of course this does not only apply to the audit firm supplying the data for this dissertation. Any other audit firm could use (one or more of the efficiency techniques described in Chapter 3 to determine whether it has produced its audits efficiently and use this information in pricing its services. Additionally, if evidence of inefficiencies is found in these cases, audit firms could focus their attention on areas where these inefficiencies are most apparent to try and improve performance, lower audit costs, and thus compete more effectively on the audit market. Furthermore, identification of inefficient audits can also help an audit firm focus on those clients where the firm runs the largest risk of being replaced by another, more efficient auditor (see Dopuch, Gupta, Simunic, and Stein 2000, 23). Evidently, the use of efficiency frontier techniques does not need to be limited to comparing performance across individual audit engagements. Audit firms could also use these techniques to compare performance across partners, audit teams, offices, or other entities. In addition, on a larger scale, the audit profession in general might be able to use these techniques to benchmark performance across audit firms and improve general audit performance.

Recent developments underline the timeliness and importance of the issues studied in Chapter 4: the effect of potential earnings management on audit pricing and audit production. The results from this chapter may also have a number of implications for audit firms. In particular, the results show that, as expected, the risk of potential earnings management increases audit effort. However, this increased audit effort is not passed on to the client through fees. The same result is found for 
another litigation risk indicator, inherent risk. In contrast, for a number of other risk indicators higher risk results in more audit effort, which is passed on to clients through fees. ${ }^{8}$ These results indicate that for the majority of risk indicators included, higher risk implies more audit effort, suggesting that at least in these cases audit quality is not compromised. However, the results also suggest that, particularly for the risk associated with potential earnings management and for inherent risk, the audit firm does not take these risks (and the resulting increase in audit effort) into account in its pricing policies. This fact may require the audit firm's attention. This does not only apply to this or other individual audit firms, but also to the audit profession as a whole. Auditors in general should be aware of the effects of litigation risk on their audit quality as well as their pricing policies. The importance of dealing with the particular risk associated with earnings management has evidently been shown by the recent developments involving companies like Enron, WorldCom and Ahold, and the disintegration of Andersen.

Finally, the results from Chapter 5, which investigated determinants of the profitability of audit engagements, may also have a number of implications for audit firms and the audit profession. First, the results from Chapter 5 indicate that neither client size nor the auditor's provision of nonaudit services affects audit engagement profitability. Servicing larger clients and providing nonaudit services is usually assumed to increase the audit firm's bargaining power. The results seem to suggest that the audit firm's bargaining power is insufficiently large to result in higher profitability, thus requiring the audit firm's attention. However, on a more positive note, the results for the provision of nonaudit services do not imply either that the audit serves as a loss-leader for nonaudit services, thus suggesting that the audit firm does not suffer an additional loss from providing nonaudit services to a client in addition to audit services (see Section 4.3.2 in Chapter 4 for an argumentation).

Second, it seems that the issuance of a disclaimer rather than an unqualified opinion results in a decrease of audit engagement profitability. A possible explanation suggested in Chapter 5 is related to the type of audit contract used by the audit firm. Although no information on the type of contract was available, the results obtained here suggest the use of a fixed-fee contract. Under a fixed-fee contract the audit firm and the client agree upon the fee before the audit has commenced. Any extra work not foreseen at the outset of the audit will not end up in the fee but may result in costs to be borne by the audit firm. If the extra work increases audit costs but does not end up in the audit fee because the audit firm uses a fixed-fee contract, the effect on profitability could be negative. As indicated, no information on the type of audit contracts was available here, but if the audit firm uses fixed-fee contracts, an implication might be to make sufficient allowance for extra work unforeseen at the start of the audit so as not to suffer from any additional costs arising from this extra work. 
Third, the results presented in Chapter 5 do not suggest any evidence of price cutting or low balling in the first year of the engagement. In contrast, the results rather suggest an increase in price relative to costs in the first year. A possible explanation provided in Chapter 5 is related to client-acceptance work, i.e, work performed before the client is actually a client. As a practical matter, since the client is not yet a client at this point, it is possible that the work performed in this stage is not recorded in the firm's client records, and therefore does not end up in the costs, but it might in the fees. This implies that the audit firm may want to review its client-acceptance procedures, in particular the way in which work performed durings this stage is recorded.

Finally, since the results from Chapter 5 suggest that the effect of local market structure on audit engagement profitability is dependent on the local market definition that is used, it is hard to suggest implications for audit firms based on these findings. As indicated, future research using more data and/or other local market definitions may be able to provide less ambiguous indications in this respect.

\subsubsection{Implications for audit clients}

Implications for audit clients mainly follow from Chapters 3 and 4 . Those ensuing from Chapter 3 are in line with the implications for audit firms and the audit profession discussed above. Like audit firms and the audit profession, clients can use information on the cost and labor efficiency (and thus efficiency frontier techniques) to determine what is the minimum amount of effort and costs necessary to complete the audit. By comparing this with the fee paid, they can determine the fairness and competitiveness of the fee charged by the firm. In addition, by comparing the minimum with the actual amount of effort and costs spent by the audit firm, they can evaluate the performance of the audit firm. If the audit firm has not performed the client's audit efficiently, the client might either decide to bargain for a lower fee or opt to switch auditors. Thus, like for auditors, information on cost and labor efficiency may provide clients with important knowledge for decision making.

The results from Chapter 4 also have a number of implications for audit clients. In particular, the results suggest that some risk indicators increase audit effort, which is passed on to the client through fees. In particular, a higher profit margin results in less effort, passed on to the client through lower fees. Similarly but conversely, more effort is spent on clients with losses in the last two years, and this effect is passed on to clients through higher fees. Clients can use this information to assess the consequences of their risk profiles and attempt to adjust these where possible in response. This also applies to the finding that the risk associated with potential earnings management as well as inherent risk do result in increases in effort, but not in corresponding increases in fees. Of course, clients could conclude 
that thigher risk in these areas is relatively unimportant since ultimately, it does not seem to increase fees. However, these risks, and the client's attitude towards these risks, may also have other consequences the client should not ignore. For instance, the audit firm may require adjustments in the financial statements, modify its audit report, or ultimately, decide to resign from the engagement (see Francis and Krishnan 1999, 159), 9

\subsubsection{Implications for regulators}

Pinally, the results reported in this dissertation may also have a number of implications for regulators. Since regulators are usually concerned with the functioning of entire markets rather than with the individual firms that make up this market considered in isolation, it is hard to suggest implications for regulators based on findings that result from an examination of a dataset containing data from only one single audit firm, and for one year only. This particularly applies to issues related to the competitiveness of the audit market. Although the topics studied in Chapters 3 and 5 could provide indications as to the functioning of the audit market in general, and issues of competitiveness in particular, the limitations of the dataset do not allow any conclusions in this respect. Data on much more than just one audit firm (and preferably: all audit firms) and for more than one year are required to do so.

The implications for regulators that can be drawn from this dissertation chiefly ensue from Chapter 4 , which studied the effect of potential earnings management on audit pricing and audit production. Especially in recent times, (accounting) regulators are very concerned with companies' potential earnings management and the way their auditors have dealt with this risk. Results presented in Chapter 4 suggest that the fact that auditors do not charge risk premiums to clients with a higher risk in terms of potential earnings management should not be an immediate cause for concern for regulators. After all, results from Chapter 4 also indicate that the higher risk associated with potential earnings management does result in more effort being spent by the auditor, suggesting that, as indicated earlier in Section 6.4.1 above, audit quality is not necessarily compromised in these cases. ${ }^{10}$ Of course, a subsequent matter of concern is how auditors have followed up on this risk, if indeed they have. That is, when the risk is sufficiently large and has materialized, thave the auditors required adjustments in the financial statements from the client in question; have they modified their audit reports accordingly; have they decided to resign from the engagement (see Francis and Krishnan 1999, 159); or have they not done anything of the kind?"1 These are important considerations for regulators, and therefore important issues for future research. 


\subsubsection{Conclusion}

The discussion above has shown that the results reported in this dissertation may have a number of implications for audit firms and the audit profession, audit clients, and policy makers and regulators. As indicated earlier, the limitations discussed in Section 6.3 need to be taken into account when interpreting these implications. When future research addresses these limitations, it can be assessed whether the implications discussed here still hold. 


\section{Notes}

Note: bear in mind the remarks made in Chapter 3, endrote 7 , about the cost nature of the rates used in computing the audit cost measure used in that chapter, and those made in endrote 29 of the same chapter about the distribution of the composed residuals of the cost and production models.

Also note that efficiency frontier techniques, such as stochastic frontier analysis used in Chapter 3 , can only determine relatide, but not absolute efficiency. Thus, the cost and labor efficiency of an audit engagement can only be examined relative to the most efficient engagement in the sample. No indication as to the absolute efficiency of the audit engagements included in this study's sample is implied here (see also endnote 28 in Chapter 3 ).

a Consider the recent downfall of Andersen as an immediate consequence of the aforementioned developments.

3 Again, take into account remarks about the cost nature of the cost measure used in computing audit engagement profitability (see endnote 17 in Chapter 5 .

* In fact, within the Randstad profitability per engagement is aboul $6 \%$ higher than outside this area. Note that some alternative explanations for the positive effect of market share for the Randstad local market definition on audil engagement profitability were suggested in Chapter 5 (see Section 5.5 .3 of that chapter', as were interpretations of the findings for the COROP and RBA definitions.

"As suggested in endmote 51 in Chapter 5, these could be local market definitions "between" the RBA and Randstad local market definitions (i.e., less than 18 but more than 2 indvidual local markets).

6 Adding market share for the Randstad llocal market definition increased the explanatory power of the profitability model, albeit slightly. In contrast, recall that addition of market structure measures for either of the other two local market definitions actually decreased model fit.

"However, keep in mind the remarks made in endnote 1 above.

"This particularly applies to the risk indicators profit margin and loss in the last two years. A thigher profil margin results in less audit effort, passed on to the clients through lower fees. Similarly, more elfort is spent on a client that has experienced a loss in the last two years, and this additional effort is passed on to the client through hagher fees.

"Of contse, since this dissertation has not investigated these three options, as of yet no definite claims can be made in this respect. As indicated in Section 6.3 , future research could consider investigating one or more of these other options and thus provide some evidence on this.

${ }^{10}$ However, although audit effort is increased for higher risk associated with earnings management even when the andit fee is not, the question remains whether this increase in audit effort was sufficient. 
I1 Again, since this dissertation has not incestigated these three options, as of yet no definite claims can be made in this respect. As discussed in Section 6.3, future research could consider investigating one or more of these other options and thus provide some evidence on this. 


\section{REFERENCES}

A

Aigner, D., Lovell, C.A.K., and Schmidt, P. (1977). Formulation and estimation of stochastic frontier models. Joumal of Econometrics, 6(1), 21-37.

Akers, M.D., Horngren, C.T., and Eaton, T.V. (1998-1999). Underreporting: chargeable time: A continuing problem for public accounting firms. Jowrnal of Applied Business Research, 15(1), 13-20.

Anderson, T, and Zéghal, D. (1994). The pricing of audit services: Further evidence from the Canadian market. Accounting and Business Research, 2495), 195-207.

Arens, A.A., and Loebbecke, J.K. (2000). Auditing: An Integrated Approach. Upper Saddle River, New Jersey, US: Prentice-Hall, Inc.

Ashton, R.H., and Ashton, A.H. (Eds.). (1995). Judgment and Decision-making Research in Accounting and Auditing. New York, New York, US: Cambridge University Press.

\section{B}

Baber, W. Brooks, E., Ricks, W. (1987). An empirical investigation of the market for audit services in the public sector. Journal of Accounting Research, 25(2), 293-305.

Bain, J.S. (1951). Relation of profit rate to industry concentration: Americam manufacturing, 1936-1940. The Quarterly Joumal of Economics, 65(3), 293-324.

Barkess, L., and Stokes, D. (2000). The Relevance of Audit Fim Reputations in Local Markets for Auditor Choice. Working Paper, University of Technology, Sydney, New South Wales, Australia, March.

Bartov, E., Gul, F.A., and Tsui, J.S.L. (2000). Discretionary-accruals models and audit qualifications. Journal of Accounting and Economics, 30(3), 421-452.

Becker, C., DeFond, M., Jiambalvo, J., and Subramanyam, S. (1998). The effect of audit quality on earnings management. Contemporary Accounting Research, 15(1), 1-24. 
Behn, B., Carcello, J.V., Hermanson, D.R., and Hermanson, R.H. (1999). Client satisfaction and Big 6 audit fees. Contemporary Accounting Research, 16(4), 587608.

Bell, T.B., Knechel, W.R., and Willingham, Jr., J.J. (1994). An Exploratory Analysis of the Determinants of Audit Engagement Resource Allocations. In R.P. Srivastava (Ed.), Audit Symposium XII: Proceedings of the 1994 Deloitte E Touche/Kansas Symposium on Auditing Problems (pp.49-67). Lawrence, Kansas, US: University of Kansas Press.

Berger, A.N., and Humphrey, D.B. (1997). Efficiency of financiall institutions; International survey and directions for future research. European Joumal of Operational Research, 98(2), 175-212.

Berk, R.A. (1990). A Primer on Robust Regression. In J. Fox and J.S. Long (Eds.), Modern Methods of Data Analysis (pp.292-324). Newbury Park, California, US: Sage Publications.

Besanko, D., Dranove, D., and Shanley, M. (1996). Strategy and Economics. New York, New York, US: John Wiley \& Sons, Inc.

Borger, de, B., and Kerstens, K. (1996). Radial and nonradial measures of technical efficiency: An empirical illustration for Belgian local governments using and FDH reference technology. Journal of Productivity Analysis, 7(1), 41-62.

Bowen, R.M., DuCharme, L., and Shores, D. (1995). Stakeholders" implicit claims and accounting method choices. Journal of Accounting and Economics, 20(3), 255-295.

Bradshaw, M.T., and Richardson, S.A., and Sloan, R.G. (2001). Do analysts and auditors use information in accruals? Jowrnal of Accounting Research, 39(1), 45-74.

Brinn, T., Peel, M.J., and Roberts, R. (1994). Audit fee determinants of independent and subsidiary unquoted companies in the UK: An exploratory study. British Accounting Review, 26(2), 101-121.

Brobcheler, V.K. (1999). Firm Dynamics in the Dutch Audit Industry: An Empirical Investigation into Longevity, Exit and Spinoff between 1880 and 1992. Dissertation. Maastricht, The Netherlands: Maastricht University.

Buckley, J., and Weston, F. (Eds.). (1980). Regulation and the Accounting Profession. Belmont, California, US: Lifetime Learning Publications.

Buijink, W.F.J., Maijoor, S.J., and Meuwissen, R.H.G. (1998). Competition in auditing: Evidence from entry, exit, and market share mobility in Germany versus The Netherlands. Contemporary Accounting Research, 15(3), 385-404.

Burgstahler, D., and Dichev, I. (1997). Earnings management to avoid earnings decreases and losses. Journal of Accounting and Economics, 24(1), 99-126.

Burilovich, L.S., and Katelus, S.C. (1997). Auditors influence on earnings management: Evidence from the alternative minimum tax. Journal of Applied Business Research, 13(2), 9-22. 
Butler, M.B., Leone, A.J., and Willenborg, M. (2002). An Empirical Analysis of Auditor Reporting and Its Association with Abnormal Accruals. Working paper, University of Rochester, Rochester, New York, US, January.

C

Callaway Dee, C., Lulseged, A., and Nowlin, T.S. (2002). Earnings Quality and Auditor Independence: An Examination Using Non-Audit Fee Data. Working paper, Virginia Commonwealth University, Richmond, Virginia, US, January.

Carlton, D.W., and Perloff, J.M. (1994). Modern Industrial Organisation. New York, New York, US: Harper Collins College Publishers.

Carree, M.A. (2002). Technological inefficiency and the skewness of the error component in stochastic frontier analysis. Economics Letters, $77(1), 101-107$.

Centraal Bureau voor de Statistiek [Statistics Netherlands] (Ed.). (1983). CBS Select 2: Statistische Opstellen [CBS Select 2: Statistical Essays]. The Hague, The Netherlands: 's-Gravenhage Staatsuitgeverij [The Hague State Publisher's].

Centraal Bureau voor de Statistiek [Statistics Netherlands] (1997a). Bevolking der Gemeenten van Nederland op 1 Januari 1997 [Population of Municipalities in the Netherlands on January 1, 1997]. Voorburg/Heerlen, The Netherlands: Centraal Bureau voor de Statistiek [Statistics Netherlands].

Centraal Bureau voor de Statistiek [Statistics Netherlands] (1997b). Plaatsnamen in Nederland, 1997 [Place-names in the Netherlands, 1997]. Voorburg/Heerlen, The Netherlands: Centraal Bureau voor de Statistiek [Statistics Netherlands].

Centraal Bureau voor de Statistiek [Statistics Netherlands] (1999). Inkomensverschillen aanzienlijk [Differences in income considerable]. Index, 5, 20-21.

Centraal Bureau voor de Statistiek [Statistics Netherlands] (2000a). De Randstad en de rest [The Randstad and the rest]. Index, 8, 22-23.

Centraal Bureau voor de Statistiek [Statistics Netherlands] (2000b). Banen in de Randstad vooral in dienstverlening [Jobs in the Randstad mainly in services]. Webmagazine, October 2. Retrieved June 16, 2001, from the World Wide Web: http://www.cbs.nl/nl/nieuws/artikelen/2000/0617k.htm.

Charnes, A., Cooper, W.W., and E. Rhodes (1978). Measuring the efficiency of decision making units. European Journal of Operational Research, 2(6), 429-444.

Chung, D.Y., and Lindsay, W.D. (1988). The pricing of audit services: The Canadian perspective. Contemporary Accounting Research, 5(1), 19-46.

Clarke, R. (1985). Industrial Economics. Oxford, United Kingdom: Basil Blackwell, Ltd. Coelli, T. (1996). A Guide to FRONTIER Version 4.1: A Computer Program for Stochastic Frontier Production and Cost Function Estimation. Working paper 96/07, Centre for Efficiency and Productivity Analysis, University of New England, Armidale, New South Wales, Australia. 
Coelli, T., Prasada Rao, D.S., and Battese, G.E. (1998). An Introduction to Efficiency and Productivity Analysis. Norwell, Massachusetts, US: Kuwer Academic Publishers.

Craswell, A.T., Francis, J.R., and Taylor, S.L. (1995). Auditor brand name reputations and industry specializations. Journal of Accounting and Economics, 20(3), 297-322.

Craswell, A.T. and Taylor, S.L. (1991). The market structure of auditing in Australia: The role of industry specialization. Research in Accounting Regulation, 5, 55-77.

Cubbin, J.S. (1988). Market Structure and Performance: The Empirical Research. Chur, Switzerland: Harwood Academic Publishers.

Cushing, B.E., and Loebbecke, J.K. (1986). Comparison of Audit Methodologies of Large Accownting Firms. Sarasota, Florida, US: American Accounting Association.

D

Danos, P., and Eichenseher, J.W. (1986). Longterm trends toward seller concentration in the US audit market. The Accownting Review, 61(4), 633-650.

Davidson, R.A., and Gist, W.E. (1996): Empirical evidence on the functional relation between audit planning and total audit effort. Journal of Accounting Research, $34(1), 111-124$.

Davis, L. Ricchiute, D., and Trompeter, G. (1993). Audit effort, audit fees, and the provision of nonaudit services to audit clients. The Accounting Review, 68(1), 135 150.

DeAngelo, L.E. (1981). Auditor independence, "low balling", and disclosure regulation. Journal of Accounting and Economics, 3(2), 113-127.

DeAngelo, L.E. (1986). Accounting numbers as market valuation substitutes: A study of management buyouts of public stockholders. The Accounting Review, 61(3), $400-420$.

DeAngelo, L.E. (1988). Managerial competition, information costs and corporate governance: The use of acounting performance measures in proxy contests. Jownal of Accownting and Economics, 10(1), 3-36.

Dechow, P.M. (1994). Accounting earnings and cash flows as measures of firm performance: The role of accounting accruals. Journal of Accounting and Economics, $18(1), 342$.

Dechow, P.M., and Sloan, R.G. (1991). Executive incentives and the horizon problem: An empirical investigation. Jourmal of Accounting and Economics, 14(1), 51-89.

Dechow, P.M., Sloan, R.G., and Sweeney, A.P. (1995). Detecting earnings management. The Accownting Review, 70(2), 193-225.

Dechow, P.M., Sloan, R.G., and Sweeney, A.P. (1996). Causes and consequences of eamings manipulation: An analysis of firms subject to enforcement actions by the SEC. Contemporary Accounting Research, 13(1), 1-36.

DeFond, M.L., and Jiambalvo, I. (1991). Incidence and circumstance of accounting errors. The Accounting Review, 66(3), 643-655. 
DeFond, M.L., and Jiambalvo, J. (1993). Factors related to auditor-client disagreements over income-increasing accounting methods. Contemporary Accounting Research, 9(2), 415-431.

DeFond, M.L., and Jiambalvo, J. (1994). Debt covenant violation and manipulation of accruals. Journal of Accounting and Economics, 17(1-2), 145-176.

DeFond, M.L., and Subramanyam, K.R. (1998). Auditor changes and discretionary accruals. Journal of Accounting and Economics, 25(1), 35-67.

DeFond, M.L., and Subramanyam, K.R. (1999). Modified Audit Opinions, Litigation Risk and Discretionary Accruals. Working paper, University of Southem California Los Angeles, California, US, November.

Degeorge, F., Patel J., and Zeckhauser, R. (1999). Earnings management to exceed thresholds. Journal of Business, 72(1), 1-33.

Demsetz, H. (1973). Industry structure, market rivalry and public policy. The Joumal of Law and Economics, 16(1), 1-9.

Deumes, R.W.J. (1999). Accountantscontrole bij kleine en middelgrote ondernemingen: Een onderzoek naar de afgifte van verklaringen van oordeelonthouding bij middelgrote ondernemingen in Nederland [Auditing small and medium-sized businesses: A study on the issuance of disclaimers to medium-sized businesses in the Netherlands]. Maandblad voor Accountancy en Bedrijfseconomie [Monthly Journal of Accountancy and Business Econonics], 73(6), 309-316.

Dogramaci, A, and Färe, R. (Eds.). (1988). Applications of Modern Production Theory: Efficiency and Praductivity. Dordrecht, The Netherlands: Kluwer Academic Publishers.

Doogar, R., and Easley, R.F. (1998). Concentration without differentiation: A new look at the determinants of audit market concentration. Journal of Accounting and Economics, 25(2), 235-253.

Dopuch, N., and Gupta, M. (1997). Estimation of benchmark performance standards: An application to public school expenditures. Joumal of Accounting and Economics, 23(2), 141-161.

Dopuch, N., Gupta, M., Simunic, D., and M. Stein. (2000). Production Efficiency and the Pricing of Audit Services. Working paper, Washington University in St. Louis, St. Louis, Missouri, US, May.

Dopuch, N., and Simunic, D. (1980). The Nature of Competition in the Auditing Profession: A Descriptive and Normative View. In J. Buckley and F. Weston (Eds.), Regulation and the Accounting Profession (pp.77-94). Belmont, California, US: Lifetime Learning Publications.

Dopuch, N. and Simunic, D. (1982). Competition in Auditing: An Assessment. In Symposium on Auditing Research (Ed.), Symposium on Auditing Research IV: Papers Presented by an Audit Group at the University of Illinois at Urbara-Champaign, 
(pp.401-450). Urbana-Champaign, Illinois, US: Department of Accountancy, University of Hlinois at Urbana-Champaign.

Dufour, J-M., Farhat, A., Gardiol, Li, and Khalaf, L. (1998). Simulation-based finite sample normality tests in linear regressions. Econometrics joumal, 1(1), 154-173.

\section{E}

Eichenseher, J.W., and Danos, P. (1981). The analysis of industry-specific auditor concentration: towards an explanatory model. The Accounting Review, 56(3), 479492.

European Commission (1996). The Role, Position, and Liability of the Statutory Auditor within the European Union. Study commissioned by DG XV of the European Commission. Luxembourg: ESC-EC-EAEC.

Ezzamel, M., Gwilliam, D.R., Holland, K.M. (1996). Some empirical evidence from publicly quoted UK companies on the relationship between the pricing of audit and non-audit services. Accounting and Business Research, 27(1), 3-16.

F

Fama, E.F., and French, K.R. (2000). Forecasting profitability and earnings. Journal of Business, 73(2), 161-175.

Färe, R., Grosskopf, S., and Logan, J. (1985). The relative performance of publiclyowned and privately-owned electric utilities. Journal of Public Economics, 26(1), 89-106.

Ferguson, A., Francis, J.R., and Stokes, D. (2002). Industry Leadership and Audit Pricing in City-Specific Audit Markets. Working paper, University of Technology, Sydney, New South Wales, Australia, May.

Feroz, E.H., Park, K., and Pastena, V. (1991). The financial and market effects of the SEC's accounting and auditing enforcement releases. Journal of Accounting Research, 29(Supplement), 107-142.

Firth, M. (1993). Price setting and the value of a strong brand name. International Journal of Research in Marketing, 10(4), 381-386.

Firth, M. (1997). The provision of non-audit services and the pricing of audit fees. Journal of Business, Finance and Accounting, 24(3-4), 511-525.

Forsund, F.R., Lovell C.A.K, and Schmidt, P. (1980). A survey of frontier production functions and their relationship to efficiency measurement. Journal of Econometrics, $13(1), 5-25$.

Fox, J., and Long, J.S. (Eds.). (1990). Modern Methods of Data Analysis. Newbury Park, California, US: Sage Publications.

Francis, J.R. (1984). The effect of audit firm size on audit prices: A study of the Australian market. Journal of Accounting and Economics, 6(2), 133-151.

Francis, J.R., and Krishnan, J. (1999). Accounting accruals and auditor reporting conservatism. Contemporary Accounting Research, 16(1), 135-165. 
Francis, J.R., Maydew, E.L., and Sparks, H.C. (1999). The role of Big 6 auditors in the credible reporting of accruals. Auditing: A Journal of Practice and Theory, 18(2), 1734.

Francis, J.R, and Reynolds, J.K. (2001). Do Large Accountintg Firms Screen Out Risky Clients? Working paper, University of Missouri-Columbia, Columbia, Missouri, US, October.

Francis, J.R., and Simon, D.T. (1987). A test of audit pricing in the small-client segment of the US audit market. The Accounting Review, 62(1), 145-157.

Francis, J.R., and Stokes, D.J. (1986). Audit prices, product differentiation and scale economies: Further evidences from the Australian market. Joumal of Accounting Research, 24(2), 383-393.

Francis, J.R., Stokes, D.J., and Anderson, D. (1999). City markets as a unit of analysis in audit research and the re-examination of Big 6 market shares. Abacus, 35(2), 185-206.

Fuchs, V. (1968). The Seroice Economy. New York, New York, US: National Bureau of Economic Research.

\section{G}

Gaver, J.J., and Paterson, J.S. (2001). The association between external monitoring and earnings management in the property-casualty insurance industry. Journal of Accounting Research, 39(2), 269-282.

Geroski, P.A. (1988). In pursuit of monopoly power: Recent quantitative work in industrial economics. Joumal of Applied Econometrics, 3(2), 107-123.

Gibbins, M., Salterio, S., and Webb, A. (2001). Evidence about auditor-client management negotiation concerning client's financial reporting. Journal of Accounting Research, 39(3), 535-563.

Gilbert, R.A. (1984). Bank market structure and competition. Journal of Money, Credit and Banking, 16(4), 617-660.

Gist, W.E. (1992). Explaining variability in external audit fees. Accounting and Business Research, 23(89), 79-84.

Gist, W.E. (1994). Empirical evidence on the effect of audit structure on audit pricing. Auditing: A Journal of Practice and Theory, 13(2), 25-40.

Greene, W.H. (1997). Frontier Production Functions. In M.H. Pesaran and P. Schmidt (Eds.), Handbook of Applied Econometrics: Microeconomics (pp.81-166). Oxford, UK: Blackwell Publishers.

Greene, W.H. (2000). Econometric Analysis. New Jersey, New Jersey, US: PrenticeHall, Inc.

Gregory, A., and Collier, P. (1996). Audit fees and auditor change: An investigation of the persistence of fee reduction by type of change. Joumal of Business, Finance and Accounting, 23(1), 13-28. 
Grosskopf, S., and Valdmanis, V. (1987). Measuring hospital performance: A nonparametric approach. Joumal of Health Economics, 6(2), 89-107.

Guay, W.R., Kothari, S.P., and Watts, R.L. (1996). A market-based evaluation of discretionary accruals models. Journal of Accounting Research, 34(Supplement), 83105.

Guenther, D.A. (1994). Earnings management in response to corporate tax rate changes: Evidence from the 1986 Tax Reforms Act. The Accounting Review, 69(1), 230-243.

Gujarati, D.N. (1995). Basic Econometrics. New York, New York, US: McGraw-Hill, Inc.

Gul, F.A., and Tsui, J.S.L. (1998). A test of free cash flow and debt monitoring hypotheses: Evidence from audit pricing. Journal of Accounting and Economics, $24(2), 219-237$.

Gul, F.A., Tsui, J.S.L., and Chen, C.J.P. (1997). Agency Costs and Audit Pricing: Evidence on Discretionary Accruals. Working paper, City University of Hong Kong, Hong Kong, April.

H

Hackenbrack, K., and Knechel, W.R. (1997). Resource allocation decisions in audit engagements. Contemporary Accounting Research, 14(3), 481-499.

Healy, P.M. (1985). The effect of bonus schemes on accounting decisions. Journal of Accounting and Economics, $7(1-3), 85-107$.

Healy, P.M., and Palepu, K.G. (1993). The effect of firms' financial disclosure strategies on stock prices. Accounting Horizons, 7(1), 1-11.

Heninger, W.G. (2001). The association between auditor litigation and abnormal accruals. The Accounting Review, 76(1), 111-126.

Hillison, W., and Kennelley, M. (1988). The economics of nonaudit services. Accounting Horizons, 2(3), 32-40.

I

Intriligator, M.D. (Ed.). (1971). Frontiers of Quantitative Economics. Amsterdam, The Netherlands: North-Holland Publishing Company.

Iyer, V.M., and Iyrer, G.S. (1.996). Effect of the Big 8 mergers on audit fees: Evidence from the United Kingdom. Auditing: A Journal of Practice and Theory, 15(2), 123132.

$\mathbf{J}$

Jiambalvo, J. (1996). Discussion of: Causes and consequences of earnings manipulation: An analysis of firms subject to enforcement actions by the SEC. Contenporary Accounting Research, 13(1), 37-47. 
Johnstone, K.M. (2000). Client-acceptance decisions: Simultaneous effects of client business risk, audit risk, auditor business risk, and risk adaptation. Auditing: A Journal of Practice and Theory, 19(1), 1-25.

Jondrow, J., Lovell, C.A.K., Materov, IIS, and Schmidt, P. (1982). On the estimation of technical inefficiency in the stochastic frontier production function model. Journal of Econometrics, 19(2-3), 233-238.

Jones, J. (1991). Earnings management during import relief investigations. Journal of Accounting Research, 29(2), 193-228.

K

Kasanen, E., Kinnunen, J., and Niskanen, J. (1996). Dividend-based earnings management: Empiricall evidence from Finland. Jourtal of Accounting and Economics, 22(1-3), 283-312.

Kelley, T., and Margheim, L. (1987). The effect of audit billing arrangement on underreporting of time and audit quality reduction acts. Advances in Accounting, 5, 221-233.

Kelley, T., and Margheim, L. (1990): The impact of time budget pressure, personality, and leadership variables on dysfunctional auditor behavior. Auditing: A Joumal of Practice and Theory, 9(2), 21-42.

Kinney, W.R., and Martin, R.D. (1994). Does auditing reduce bias in financial reporting? A review of audit-related adjustment studies. Auditing: A Journal of Practice and Theory, 13(1), 149-156.

Knechel, W.R. (2001). Auditing: Assurance and Risk. Cincinnati, Ohio, US: SouthWestern College Publishing.

Kodde, D.A., and Palm, F.C. (1986). Wald criteria for jointly testing equality and inequality constraints. Econometrics 54(5), 1243-1248.

Koninklijk Nederlands Instituut van Registeraccountants [Royal Dutch Institute of Registered Auditors] (2000). In de markt: Wie certificeert? [In the market: Who performs statutory audits?] RA View, 3,2.

Krishnan, J., and Krishnan, J. (1997). Litigation risk and auditor resignations. The Accounting Review, 72(4), 539-560.

Kumbhakar, S.C., and Hjalmarsson, L. (1995). Labour-use efficiency in Swedish social insurance offices. Journal of Applied Econometrics, 10(1), 33-47.

Kwon, S.Y. (1996). The impact of competition within the client's industry on the auditor selection decision. Auditing: A Journal of Practice and Theory, 15(1), 53-70.

$\mathbf{L}$

Lanen, W.N., and Larcker, D.F. (1992). Executive compensation contract adoption in the electric utility industry. Journal of Accounting Research, 30(1), 70-93.

Langendijk, H. (1997). The market for audit services in the Netherlands. The European Accounting Review, 6(2), 253-264. 
Liberty, S.E., and Zimmerman, J.L. (1986). Labor union contract negotiations and accounting choices. The Accounting Review, 61(4), 600-620.

Lovell, C.A.K., and Schmidt, P. (1988). A Comparison of Alternative Approaches to the Measurement of Productive Efficiency. In A. Dogramaci and R.Färe (Eds.), Applications of Modern Production Theory: Efficiency and Productivity (pp.3-32). Dordrecht, The Netherlands: Kluwer Academic Publishers.

Lys, T., and Watts, R.L. (1994). Lawsuits against auditors. Journal of Accounting Research, 32(Supplement), 65-93.

M

Maher, M.W, Tiessen, P., Colson, R., and Broman, A.J. (1992). Competition and audit fees. The Accounting Review, 67(1), 199-211.

Maijoor, S.J., Buijink, W., van Witteloostuijn, A., and Zinken, M. (1995). Long-term concentration in the Dutch audit market: The use of auditor association membership lists in historical research. Abacus, 31(2), 152-177.

Maijoor, S., Meuwissen, R., and Quadackers, L. (2000). The effects of national institutions on audit research: Evidence from Europe and North America. The European Accounting Review, 9(4), 569-587.

Martin, S. (1993a). Industrial Economics. Oxford, United Kingdom: Blackwell Publishers Ltd.

Martin, S. (1993b). Advanced Industrial Economics. Oxford, United Kingdom: Blackwell Publishers Ltd.

McNichols, M.F. (2000). Research design issues in earnings management studies. Journal of Accounting and Public Policy, 19(4-5), 313-345.

McNichols, M, and Wilson, G.P. (1988). Evidence of earnings management from the provision for bad debts. Iournal of Accounting Research, 26 (Supplement), 1-31.

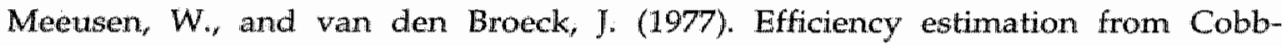
Douglas production functions with composed error. International Economic Review, 18(2), 435-444.

Mester, L.]. (1997). Measuring efficiency at U.S. banks: Accounting for heterogeneity is important. European Journal of Operational Research, 98(2), 230-242.

Meuwissen, R.H.G. (199.2). De Meting van Omvang van Accountantskantoren: Een Empirische Studie [Measuring the Size of Audit Firms: An Empirical Study]. Research Memorandum, University of Limburg, Maastricht, The Netherlands.

Meuwissen, R.H.G. (1999). The Economics of Auditor Careers and Audit Markets. Dissertation no.99-44. Maastricht, The Netherlands: Maastricht University.

Meuwissen, R.H.G., and Maijoor, S.J. (1994). Accountantscontrole bij Kleine en Middelgrote Ondernemingen: Een Vergelijkend Onderzoek van Internationale Opvattingen en Gehanteerde Controleprogramma's [Auditing Small and Medium-Sized Businesses: A Study Comparing International Views and Audit Programs Used in practice]. NOvAA-publikatie 13 [NovAA-publication 13], 's-Gravenhage, The 
Netherlands: Nederlandse Orde van Accountants-Administratieconsulienten [Dutch Association of Certified Accountants].

Moizer, P., and Turley, S. (1987). Surrogates for audit fees in concentration studies. Auditing: A Journal of Practice and Theory, 7(1), 118-123.

N

Nelson, M.W., Elliott, J.A, and Tarpley, R.L. (2002). Evidence from auditors about managers" and auditors" earnings management decisions. The Accounting Rewiew, 77 (Supplement), 175-202.

$\mathrm{O}$

O'Keefe, T.B., Simunic, D.A., and Stein, M.T. (1994). The production of audit services: Evidence from a major public accounting firm. Journal of Accounting Research, 32(2), 241-261.

Ondrich, J., and Ruggiero, J. (2001). Efficiency measurement in the stochastic frontier model. European Journal of Operational Research, 129(2), 434-442.

Otley, D.T., and Pierce, B.J. (1996). The operation of control systems in large audit firms. Auditing: A Joumal of Practice and Theory, 15(2), 65-84.

$\mathbf{P}$

Palmrose, Z.-V. (1986a). Audit fees and auditor size: further evidence. Journal of Accounting Research, 24(1), 97-110.

Palmrose, Zn-V. (1986b). The effect of nonaudit services on the pricing of audit services: further evidence. Journal of Accounting Research, 24(2), 405-411.

Palmrose, Z.-V. (1987). Litigation and independent auditors: The role of business failures and management fraud. Auditing: A Journal of Practice and Theory, 6(2), $90-103$.

Palmrose, Z.-V. (1989). The relation of audit contract type to audit fees and audit hours. The Accounting Review, 64(3), 488-499.

Pearson, T., and Trompeter, G. (1994) Competition in the market for audit services: The effect of supplier concentration on audit fees. Contemporary Accounting Research, 11(1-1), 115-135.

Penno, M, and Walther, B.R. (1996). The concentration of local markets: A study of accounting, advertising and law. Accounting Horizons, 10(2), 88-99.

Pesaran, M.H. and Schmidt, P. (Eds.). (1997). Handbook of Applied Econometrics: Microeconomics. Oxford, UK: Blackwell Publishers.

Pestieau, P. (1993). Performance and competition in services. European Economy; Social Europe; Market Services and European Integration: The Challenges for the 1990s, 3, 125-148.

Petroni, K.R. (1992). Optimistic reporting in the property-casualty insurance industry. Journal of Accounting and Economics, 15(4), 458-508. 
Pratt $_{j} \mathrm{~J}_{2}$, and Stice, J.D. (1994). The effects of client characteristics on auditor litigation risk judgments, required audit evidence, and recommended audit fees. The Accounting Review, 69(4), 639-656.

$\mathbf{R}$

Raets, H.J.T.M., and van Batenburg, D.J.C. (1983). Regionale Indelingen [Regional classifications]. In Centraal Bureau voor de Statistiek [Statistics Netherlands]. (Ed.), CBS Select 2: Statistische Opstellen [CBS Select 2: Statistical Essays] (pp.117132). The Hague, The Netherlands: 's-Gravenhage Staatsuitgeveri] [The Hague State Publisher's].

Reynolds, J.K., and Francis, J.R. (2001). Does size matter? The influence of large clients on office-level auditor reporting decisions. Joumal of Accounting and Economics, 30(3), 375-400.

Rhode, J.G., Whitsell, G.M., and Kelsey, R.L. (1974). An analysis of client-industry concentrations for large public accounting firms. The Accounting Review, 49(4), $772-786$.

Rubin, M.A. (1988). Municipal audit fee determinants. The Accounting Review, 63(2), 219-236.

\section{$S$}

Sanders, G., Allen, A, and Korte, L. (1995). Municipal audit fees: Has increased competition made a difference? Auditing: A Journal of Practice and Theory, 14(1), 103-114.

Scherer, F.M., and Ross, D. (1990). Industrial Market Structure and Economic Perfornance. Boston, Massachusetts, US: Houghton Mifflin Company.

Schmalensee, R. (1989). Inter-Industry Studies of Structure and Performance. In R. Schmalensee and R.D. Willig (Eds.), Handbook of Industrial Organization, Volume II (pp.952-1009). Amsterdam, The Netherlands: Elsevier Science Publishers B.V.

Schmalensee, R. and Willig, R.D. (Eds.). (1989). Handbook of Industrial Organization, Volume II. Amsterdam, The Netherlands: Elsevier Science Publishers B.V.

Schmidt, P. (1985-1986). Frontier production functions. Econometric Reviews 4(2), 289328.

Scott, W.R. (2000). Financial Accounting Theory. Scarborough, Ontario, Canada: Prentice-Hall Canada, Inc.

Shepherd, W.G. (1972). The elements of market structure. The Review of Economics and Statistics, 54(1), 25-37.

Shepherd, W.G. (1990). The Economics of Industrial Organisation. Englewood Cliffs, New Jersey, US: Prentice-Hall International, Inc.

Sherman, H.D., and Gold, F. (1985). Bank branch operating efficiency: Evaluation with data envelopment analysis. Journal of Banking and Finance 9(2), 297-315. 
Siegel, S., and Castellan, Jr., N.J. (1988) Nomparametric Statistics for the Behavional Siciences. New York, New York, US: McGraw-Hill Book Company.

Simon, D.T., and Francis, J.R. (1988): The effects of auditor change on atidit fees: Tests of price cutting and price recovery. The Accounting Review, 63(2), 255-269.

Simunic, D.A. (1980). The pricing of audit services: Theory and evidence. fournal of Accounting Research, 18(1), 161-190.

Simunic, D.A. (1984). Auditing, consulting and auditor independence. Journal of Accounting Research, 22(2), 679-702.

Simunic, D.A., and Stein, M.T. (1990). Audit risk in a client portfolio context. Contemporary Accounting Research, 6(2-1), 329-343.

Simunic, D.A., and Stein, M.T. (1996). The impact of litigation risk on audit pricing: A review of the economics and the evidence. Auditing: A Journal of Practice and Theory, 15(Supplement), 119-134.

Smith, G., and Krogstad, J.L. (1984). Impact of sources and authors on Auditing: A Journal of Practice and Theory - A citation analysis. Auditing: A Journal of Practice and Theory, 4(1), 107-117.

Smith, Gr, and Krogstad, J.L. (1988). A taxonomy of content and citations in Auditing: A Journal of Practice and Theory. Auditing: A Joumal of Practice and Theory, 8(1), 108117.

Smith, G., and Krogstad, J.L. (1991). Sources and uses of Auditing: A Joumal of Practice and Theory's literature: The first decade. Auditing: A Journal of Practice and Theory, 10(2), 84-97.

Solomon, I., and Shields, M.D. (1995). Judgment and Decision-making Research in Auditing. In R.H. Ashton and A:H. Ashton (Eds.), Judgment and Decision-making Research in Accounting and Auditing (pp.137-175). New York, New York, US: Cambridge University Press.

Srivastava, R.P. (Ed.). (1994). Audit Sympositm XII: Proceedings of the 1994 Deloitte \& Touche/Kansas Symposium on Auditing Problems, Lawrence, Kansas, US: University of Kansas Press.

Stein, M.T., Simunic, D.A., and O'Keefe, T.B. (1994). Industry differences in the production of audit services. Auditing: A Journal of Practice and Theory, 13(Supplement), 128-142.

Stice, J.D. (1991). Using financial and market information to identify pre-engagement factors associated with lawsuits against auditors. The Accounting Review, 66(3), 516-533.

St.Pierre, K., and Anderson, J. (1984). An analysis of the factors associated with lawsuits against public accountants. The Accounting Review, 59(2), 242-262.

Subramanyam, K.R. (1996). The pricing of discretionary accruals. Journal of Accounting and Economics, 22(1-3), 249-281.

Sweeney, A.P. (1994). Debt-covenant violations and managers' accounting responses. Journal of Accounting and Economics, 17(3), 281-308. 
Symposium on Auditing Research (Ed.). (1982). Symposium on Auditing Research IV: Papers Presented by an Audit Group at the University of Illinois at Urbana-Champaign. Urbana-Champaign, Illinois, US: Department of Accountancy, University of Mllinois at Urbana-Champaign.

$\mathbf{T}$

Taylor, M., and Baker, R. (1981). An analysis of the external audit fee. Accounting and Business Research, 9(1), 55-60.

Thiry, B., and Tulkens, H. (1989). Productivity, efficiency and technical progress. Concepts and measurement. Annals of Public and Cooperatioe Economics 60(1), 942.

Thomas, J., and Zhang, X. (2000). Identifying unexpected accruals: A comparison of current approaches. Journal of Accounting and Public Policy, 19(4-5), 347-376.

Tomczyck, S., and Read, W.J. (1989). Direct measurement of supplier concentration in the market for audit services. Auditing: A Journal of Practice and Theory, 9(1), 98106.

Tonge, S.D., and Wootton, C.W. (1991). Auditor concentration and competition among large public accounting firms: Post-merger status and future implications. Journal of Accounting and Public Policy, 10(2), 157-172.

Turpen, R. (1990). Differential pricing on auditors' initial engagements: Further evidence: Auditing: A Journal of Practice and Theory, 9(2), 60-76.

W

Wagstaff, A. (1989). Estimating efficiency in the hospital sector: A comparison of three statistical cost frontier models. Applied Economics, 21(5), 659-672.

Waldman, D.M. (1982). A stationary point for the stochastic frontier likelihood. Journtil of Econometrics, $18(2), 275-279$.

Ward, D.D., Elder, R.J, and Kattelus, S.C. (1994). Further evidence on the determinants of municipal fees. The Accounting Review, 69(2), 399-411.

Warfield, T.D., Wild, J.J., and Wild, K.L. (1995). Managerial ownership, accounting choices, and informativeness of earnings. Journal of Accounting and Economics, 20(1), 61-91.

Watts, R.L., and Zimmerman, J.L. (1986). Positive Accounting Theory. Englewood Cliffs, New Jersey, US: Prentice-Hall, Inc.

Watts, R.L. and Zimmerman, J.L. (1990). Positive accounting theory: A ten-year perspective. The Accounting Review, 65(1), 131-156.

Weets, $V_{x p}$ and Jegers, M. (1997). Are the "Big Six" "big" in Belgium? The European Accounting Review, 6(4), 773-789.

Weiss, L. (1971). Quantitative Studies of Industrial Organization. In M.D. Intriligator (Ed.). Frontiers of Quantitative Economics (pp.362-408). Amsterdam, The Netherlands: North-Holland Publishing Company. 
Wootton, C.W., Tonge, S.D., and Wolk, M. (1994). Pre and post Big 8 mergers: Comparison of auditor concentration. Accounting Horizons, 8(3), 58-74.

\section{$\mathbf{Y}$}

Yardley, J.A., Kauffman, N.L., Cairney, T.D., and Albrecht, W.D. (1992). Supplier behavior in the U.S. audit market. Journal of Accounting Literature, 11, 151-184.

\section{$\mathbf{Z}$}

Zind, R.G., and Zéghal, D. (1989). Some characteristics of the Canadian audit industry. Contemporary Accounting Research, 6(1), 26-47. 


\title{
SUMMARY IN DUTCH (NEDERLANDSE SAMENVATTING)
}

\author{
The pricing and production of audit services \\ (De prijsbepaling en productie van accountantscontroles)
}

Dit proefschrift bestudeert de prijsbepaling en productie van wettelijk verplichte controles op de markt voor accountantscontrole. Meer specifiek onderzoekt dit proefschrift (1) de mate van efficiëntie bij het uitvoeren van accountantscontroles; (2) het effect van mogelijke winststuring door de cliënt op de prijsbepaling en productie van controles door de accountant; en (3) de winstgevendheid van controleopdrachten. Deze drie onderwerpen worden vanuit een (micro-)economisch perspectief en met behulp van empirische analyses bestudeerd.

Hoewel er in het verleden uitvoerig onderzoek is gedaan naar de prijsbepaling en productie van accountantscontroles, bestaat er nog maar weinig eerder onderzoek naar de specifieke bovengenoemde drie onderwerpen. De oorzaak hiervan dient met name te worden gezocht in de beperkte beschikbaarheid van de data die nodig zijn om dit soort onderzoek te kunnen uitvoeren. Doordat in dit proefschrift gebruik kan worden gemaakt van een unieke dataset met gedetailleerde gegevens over individuele controleopdrachten, bestaat de mogelijkheid om eerder onderzoek aan te vullen en een bijdrage te leveren aan belangrijke, maar tot op heden weinig onderzochte onderwerpen op het terrein van de prijsbepaling en de productie van accountantscontroles.

Zoals aangegeven zijn de drie onderwerpen bestudeerd aan de hand van empirische analyses. Hiertoe is een dataset verzameld aan de hand van vragenlijsten die zijn ingevuld door partners van één van de (toen nog) grote zes accountantskantoren in Nederland. De partners werd gevraagd voor een aantal cliënten gegevens omtrent de meest recent uitgevoerde jaarrekeningcontrole te verstrekken. Deze gegevens hadden zowel betrekking op de cliënt als op de controleopdracht. Cliëntgegevens waren onder meer de grootte, complexiteit, balanssamenstelling, risico en kwaliteit van de administratieve organisatie van de 
client. Opdrachtgegevens betroffen de duur van de relatie tussen client en accountant, de prijs die de cliënt voor de controle had betaald aan de accountant, de hoeveelheid uren die door de accountant aan de controle was besteed en de mate watin de accountant naast de accountantscontrole ook nog andere diensten aan de cliënt had verleend. In totaal zijn 157 reacties ontvangen, waarvan er 114 zijn gebruikt in de drie empirische studies. Deze studies worden hieronder besproken.

In de eerste empirische studie wordt de mate van efficiëntie bij het uitvoeren van accountantscontroles bestudeerd. Onderzoek op dit terrein kan belangrijk zijn voor accountantskantoren om effectief te kunnen concurreren op de markt voor accountantscontrole. Als een accountantskantoor diensten wil aaribieden tegen concurrerende prijzen heeft het informatie nodig omtrent de kosten die worden gemaakt ten behoeve van het uitvoeren van controles. In het bijzonder heeft het kantoor gegevens nodig over de minimale kosten die moeten worden gemaakt om een controle te kunnen witwoeren. Aangezien voor dienstverlenende organisaties het merendeel van de kosten samenhangt met de arbeidsuren die door hun medewerkers zijn besteed, heeft het accountantskantoor derhalve ook informatie nodig omtrent het minimum aantal arbeidsuren dat aan een controleopdracht moet worden gespendeerd.

Gebaseerd op eerder onderzoek naar de prijsbepaling en productie van accountantscontroles zijn empirische modellen van controlearbeid en controlekosten samengesteld, waarin zowel cliënt- als opdrachtgerelateerde factoren zijn opgenomen. Aan de hand van deze modellen is vervolgens de arbeids- en kostenefficièntie bepaald met behulp van de zogenoemde 'stochastic frontier' techniek. Eerdere studies omtrent de productie van accountantscontroles hebben altijd impliciet verondersteld dat accountants hun controles op een efficiënte manier uitvoeren omdat deze onderzoeken alle gebruik maken van lineaire regressietechnieken. Daar lineaire regressie een lijn berekent die door het midden van een puntenwolk loopt, kan deze techniek wel de gemiddelde maar niet de minimale hoeveelheid arbeid en/of kosten berekenen die nodig is om een controle uit te voeren. De frontier technieken kunnen dat echter wel. De resultaten laten zien dat voor do steekproef die hier is gebruikt, controleopdrachten kosten- en arbeidsefficiënt lijken te worden uitgevoerd. Met andere woorden: deze opdrachten hadden niet met minder arbeidsuren en/of voor minder kosten kunnen worden uitgevoerd zonder de effectiviteit en de kwaliteit van de controle in gevaar te brengen. Aangezien de uitgevoerde analyses zijn gebaseerd op gegevens van slechts eén accountantskantoor en betrekking hebben op slechts éen jaar, is het moeilijk om te generaliseren en conclusies te trekken aangaande de gehele markt voor accountantscontrole. Men zou echter wellicht kumen stellen dat een efficiente uitvoering van controleopdrachten past bij een concurrerende markt.

Het tweede empirische stuk onderzoekt het effect van mogelijke winststuring op de prijsbepaling en productie van accountantscontroles. Recente gebeurtenissen 
waarbij bedrijven als Enron, WorldCom en Ahold zijn betrokken onderstrepen het belang van dit onderwerp. Immers, niet alleen de bedrijven die beschuldigd worden van winststuring worden bekritiseerd maar ook hun accountants die deze praktijken hadden moeten voorkomen, danwel opsporen en corrigeren. De recente ondergang van Andersen in het kielzog van Enron is hier wel het meest extreme voorbeeld van.

Er zijn vijf manieren waarop accountants met het risico van mogelijke winststuring kunnen omgaan (Francis en Krishnan 1999, 159): (1) conservatievere verklaringen verstrekken aan cliënten die een hoger risico vormen; (2) diënten in hogere risicogroepen buiten de cliëntportefeuille houden; (3) meer werk verrichten tijdens de accountantscontrolle van deze cliënten; (4) aan deze cliënten een premie doorberekenen in de prijs voor de accountantscontrole; en (5) met deze cliënten onderhandelen over aanpassingen in de jaarrekening. In deze studie worden de derde en vierde mogelijkheid onderzocht, alsmede de wisselwerking tussen deze twee mogelijkheden. Als winststuring bijvoorbeeld leidt tot een hogere prijs voor de accountantscontrole is het mogelijk te bepalen of deze hogere prijs wordt veroorzaakt door het besteden van meer tijd aan deze controle, het doorberekenen van een premie, of beide.

Wederom is op basis van eerder onderzoek naar de prijsbepaling en productie van accountantscontroles een aantal empirische modellen samengesteld, ditmaal voor de controleprijs en controlearbeid. Naast de eerder genoemde cliënt- en opdrachtgerelateerde factoren is hier ook een maatstaf voor mogelijke winststuring aan toegevoegd. Twee typen maatstaven zijn bekeken: totale 'accruals' en korte termijn 'accruals' (accruals bestaan uit transitorische posten en anticipatie-posten), beide zowel tegen de absolute als de werkelijke (positieve of negatieve) waarde. Alleen de korte termijn accruals tegen de werkelijke waarde vertoonden significante effecten. In overeenstemming met de argumentatie van Francis en Krishnan (1999, 144) blijkt hieruit dat korte termijn accruals voor accountants voor meer onzekerheid staan dan totale accruals. Bovendien blijkt dat niet alleen de grootte, maar ook de richting van de winststuring voor accountants van belang is, alangezien alleen de werkelijke maar niet de absolute waarde van de korte termijn accruals significant was.

De resultaten laten zien dat de maatstaf voor winststuring de hoeveelheid controlearbeid significant doet stijgen, maar geen effect heeft op de prijs van de accountantscontrole. Deze bevindingen zouden erop kunnen wijzen dat een hoger risico van winststuring accountants ertoe aanzet meer tijd te besteden aan de controle, maar dat dit effect niet via de prijs wordt doorberekend aan de cliènt. Dit resultaat wordt bevestigd door het significante negatieve effect van de maatstaf voor winststuring op de zogenoemde 'realization rate'. Deze realization rate is gedefinieerd als de verhouding tussen de prijs die door de cliënt is betaald voor de controle en de hoeveelheid controlearbeid. Aan de hand van de realization rate kan het effect van winststuring op de wisselwerking tussen controleprijzen en 
controlearbeid worden bepaald. Het significante negatieve teken voor winststuring duidt erop dat het risico van winststuring meer invloed heeft op controlearbeid dan op de prijs van de controle.

In de laatste empirische studie wordt ingegaan op de winstgevendheid van controleopdrachten. Net als het onderwerp van de eerste studie, de efficiëntie van accountantscontroles, kan onderzoek naar de winstgevendheid van controleopdrachten van belang zijn voor beleidsvorming binnen accountantskantoren. Als een kantoor bijvoorbeeld weet dat bepaalde cliënten winstgevender zijn dan anderen, kan daar rekening mee worden gehouden bij het aannemen van nieuwe cliënten of het doen van een offerte voor een controleopdracht.

Vanuit een meer wetenschappelijk oogpunt is de studie over de winstgevendheid van controleopdrachten ingegeven door de bezorgdheid die vaak wordt geuit omtrent het gebrek aan concurrentie op de markt voor accountantscontrole. De redenering is hier dat een hogere concentratie op de markt collusie en monopolistisch gedrag in de hand werkt, waardoor bedrijven hun prijzen boven de kosten uit kunnen tillen. Deze studie onderwerpt deze redenering aan een directe test door te onderzoeken hoe de structuur op de markt voor accountantscontrole (alsmede enkele andere factoren) van invloed is op de verhouding tussen prijzen en kosten (dat wil zeggen, winstgevendheid).

Op basis van eerder onderzoek naar de prijsbepaling en productie van accountantscontroles, literatuur op het gebied van industriële organisatie en studies over lokale markten (gescheiden deelmarkten binnen één grotere markt) is een model samengesteld om de winstgevendheid van controleopdrachten te verklaren. Winstgevendheid is gedefinieerd als de verhouding tussen de prijs die door de cliënt voor de controle is betaald en de kosten die door het kantoor zijn gemaakt tijdens het uitvoeren van die controle. De maatstaven voor marktstructuur die zijn getest betreffen concentratiemaatstaven en marktaandelen, waarbij deze maatstaven zijn berekend op basis van het aantal accountants dat werkzaam is per accountantskantoor. Voorts zijn er drie verschillende definities van lokale markten getest: (1) de zogenoemde COROP-definitie (COROP staat voor Coördinatie Commissie Regionaal Onderzoeksprogramma), die Nederland in 40 gebieden verdeelt, (2) de zogenoemde RBA-definitie (RBA staat voor Regionale Besturen voor de Arbeidsvoorziening), die Nederland in 18 gebieden verdeelt. Beide definities worden vaak gehanteerd door het Centraal Bureau voor de Statistiek bij het publiceren van statistieken; en (3) een definitie die onderscheid maakt tussen de Randstad en de rest van Nederland. Deze laatste definitie is ingegeven door het feit dat de Randstad sterkt verschilt van de rest van het land wanneer er wordt gekeken naar het type economische activiteit, de werkgelegenheid en de bijdrage aan het nationaal product. Dit verschil zou van invloed kunnen zijn op de lokale 
marktstructuur en het effect van deze structuur op de winstgevendheid van de controleopdrachten.

De resultaten laten zien dat de individuele controleopdrachten doorgaans een verlies betekenen voor het accountantskantoor, aangezien gemiddeld genomen per opdracht slechts $95 \%$ van de kosten wordt goedgemaakt. Voorts blijken variabelen die in belangrijke mate de variatie in de controleprijs, de controlearbeid en de controlekosten kunnen verklaren óok belangrijke verklarende variabelen te zijin voor de winstgevendheid van controleopdrachten. Het gaat hier dan om factoren als het risico van de cliënt, de lengte van de relatie tussen de cliënt en de accountant en complexiteit van de cliënt. Het effect van lokale marktstructuur op winstgevendheid lijkt aff te hangen van de gehanteerde lokale marktdefinitie. Wanneer de COROPdefinitie of RBA-definitie wordt gebruikt, lijkt lokale marktstructuur geen significant effect op de winstgevendheid per opdracht te hebben. Wanneer echter het onderscheid tussen de Randstad en het gebied daarbuiten wordt gebruikt om lokale markten te definiëren, dan lijkt het erop dat het hogere marktaandeel van het accountantskantoor in de Randstad ten opzichte van de rest van Nederland een significant positief effect op de winstgevendheid heeft: in de Randstad is de winstgevendheid per opdracht gemiddeld $6 \%$ hoger dan in de rest van het land. Hoewel voor deze bevindingen een aantal verklaringen kan worden geopperd, kan op basis van de data die in dit proefschrift zijn gebruikt niet worden aangegeven welke verklaring de meest waarschijnlijke is. Daarvoor is verder onderzoek noodzakelijk. 



\section{CURRICULUM VITAE}

Caren (Carmen Charlotte Maria) Schelleman was born on July $11^{\text {th }}, 1974$ in Tilburg, the Netherlands. She attended grammar school at Stella Maris College in Meerssen, where she obtained her diploma (with distinction) in June 1992. From 1992 to 1997 she studied business economics (specializing in Accounting and Auditing) at the Faculty of Economics and Business Administration at Universiteit Maastricht, where she graduated with distinction in August 1997. Following graduation, she started working on her dissertation at the Department of Accounting and Information Management at Universiteit Maastricht. As part of her research training she visited the Fisher School of Accounting at the University of Florida in Gainesville, Florida from January to April 1999. Since September 2001 she is an assistant professor at the Department of Accounting and Information Management. Her research interests include auditing, assurance services, and internal control and accounting information systems, both from an economic and a behavioral point of view.

Caren (Carmen Charlotte Maria) Schelleman werd op 11 juli 1974 geboren in Tilburg. Zij doorliep het gymnasium aan het Stella Maris College in Meerssen, waar zij in juni 1992 cum laude haar diploma behaalde. Van 1992 tot 1997 studeerde zij bedrijfseconomie (met een specialisatie in Accounting en Auditing) aan de Faculteit der Economische Wetenschappen en Bedrijfskunde van de Universiteit Maastricht, waar zij in augustus 1997 cum laude afstudeerde. Na haar afstuderen trad zij in dienst bij het Departement Accounting and Information Management van de Universiteit Maastricht om aan haar promotieonderzoek te werken. In het kader van dit onderzoek verbleef zij van januari tot april 1999 aan de Fisher School of Accounting van de University of Florida in Gainesville, Florida. Sinds september 2001 is zij als universitair docent werkzaam bij het Departement Accounting and Information Management. Haar onderzoeksinteresses liggen op het terrein van auditing, assurance services, en internal control en accounting information systems, vanuit zowel economisch als gedragsmatig perspectief. 